\title{
Multi-problem challenges for a renewable future
}

Citation for published version (APA):

Bartekova, E. (2016). Multi-problem challenges for a renewable future: empirical studies on competitive disadvantages from electricity price differentials and mineral supply risk in an open economy world [Doctoral Thesis, Maastricht University]. Datawyse / Universitaire Pers Maastricht. https://doi.org/10.26481/dis.20160627eb

Document status and date:

Published: 01/01/2016

DOI:

10.26481/dis.20160627eb

Document Version:

Publisher's PDF, also known as Version of record

\section{Please check the document version of this publication:}

- A submitted manuscript is the version of the article upon submission and before peer-review. There can be important differences between the submitted version and the official published version of record.

People interested in the research are advised to contact the author for the final version of the publication, or visit the DOI to the publisher's website.

- The final author version and the galley proof are versions of the publication after peer review.

- The final published version features the final layout of the paper including the volume, issue and page numbers.

Link to publication

\footnotetext{
General rights rights.

- You may freely distribute the URL identifying the publication in the public portal. please follow below link for the End User Agreement:

www.umlib.nl/taverne-license

Take down policy

If you believe that this document breaches copyright please contact us at:

repository@maastrichtuniversity.nl

providing details and we will investigate your claim.
}

Copyright and moral rights for the publications made accessible in the public portal are retained by the authors and/or other copyright owners and it is a condition of accessing publications that users recognise and abide by the legal requirements associated with these

- Users may download and print one copy of any publication from the public portal for the purpose of private study or research.

- You may not further distribute the material or use it for any profit-making activity or commercial gain

If the publication is distributed under the terms of Article $25 \mathrm{fa}$ of the Dutch Copyright Act, indicated by the "Taverne" license above, 


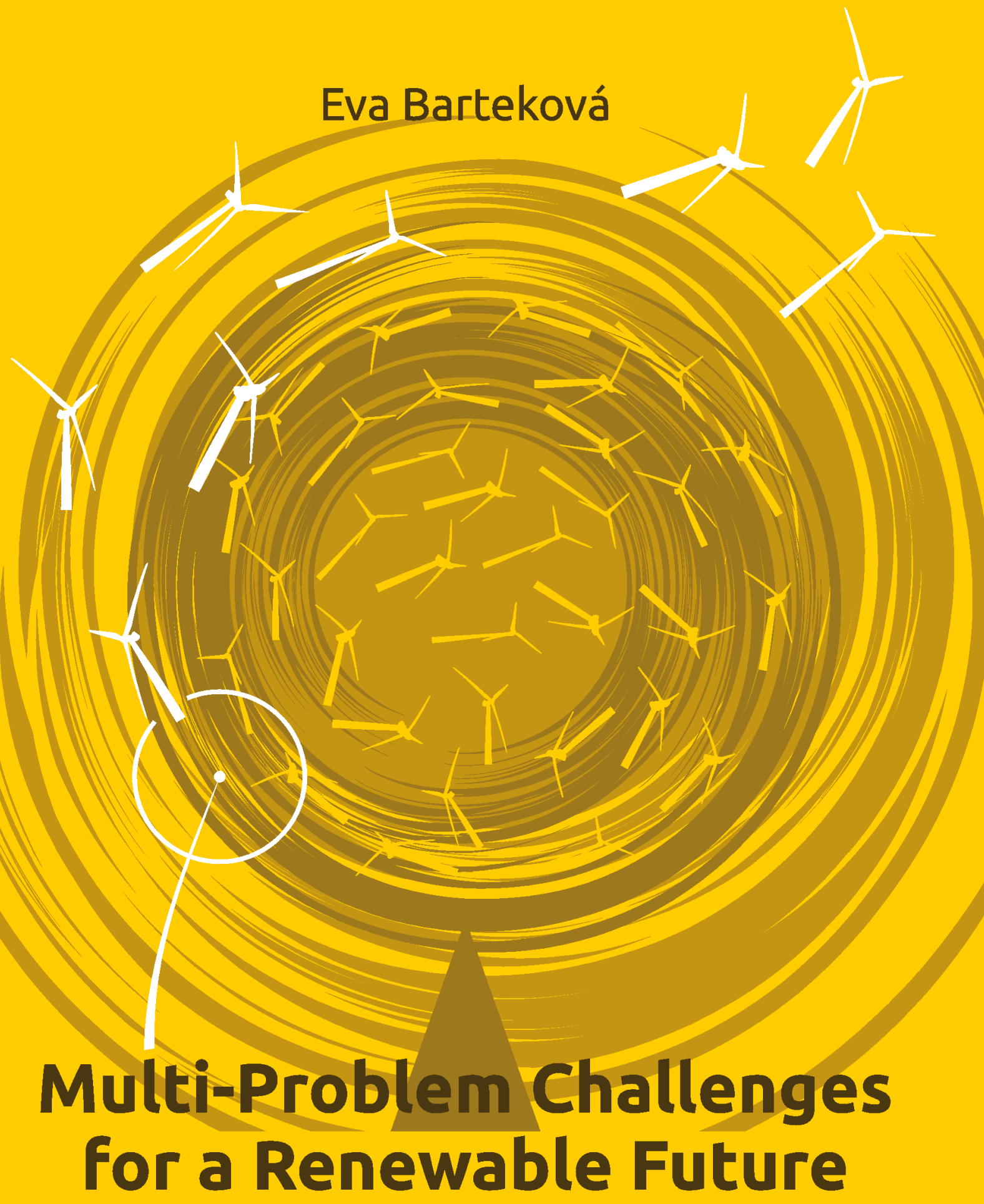

Empirical Studies on Competitive Disadvantages from Electricity Price Differentials and Mineral Supply Risk in an Open Economy World 
C)copyright Eva Barteková, Maastricht 2016

Printing: Datawyse | Universitaire Pers Maastricht

Cover Design: Viktor Petkov, dokmokvok@yahoo.com

ISBN 9789461595812

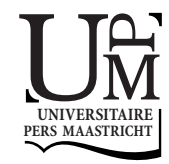




\title{
Multi-Problem Challenges for a Renewable Future
}

\author{
Empirical Studies on Competitive Disadvantages \\ from Electricity Price Differentials and Mineral \\ Supply Risk in an Open Economy World
}

\section{Dissertation}

to obtain the degree of Doctor at Maastricht University,

on the authority of the Rector Magnificus, Prof. dr. L. L. G. Soete,

in accordance with the decision of the Board of Deans,

to be defended in public

on Monday 27 June 2016, at 16.00 hours

by

\section{Eva Barteková}




\section{Supervisor:}

Prof. Dr. René Kemp

\section{Co-supervisor:}

Dr. Thomas Ziesemer

\section{Assessment Committee:}

Prof. Dr. Pierre Mohnen (Chair)

Prof. Dr. Raimund Bleischwitz (University College London)

Dr. Marc Dijk

Dr. Michiko Iizuka (United Nations University - MERIT)

This doctoral dissertation was partly made possible thanks to the financial support from projects I have been involved in and which I am grateful for: GlobEn and SINCERE projects, and DEIP training programme. 
anci, ocimu, Rózke

\& für Bruno 



\section{Acknowledgements}

This PhD has been a long and winding journey to self-knowledge and self-realisation, a journey that opened up for me a whole new universe of the unknown knowns, allowed me to explore new dimensions of the known knowns, and to discover new pathways to pursue towards the known unknowns. I would like to take the opportunity herewith to thank the travel companions who have offered their friendship and direction throughout this journey.

First and foremost, I would like to express my deepest gratitude to my supervisory team. I have had the honour of writing my doctoral dissertation under the supervision of two great scholars, René Kemp and Thomas Ziesemer, to whom I am indebted for their continued support, patient guidance, constructive criticism, exciting discussions and intellectual freedom. Additionally, I am thankful to Thomas for passing on to me the sense for econometric rigour and to René for having inspired my thinking by his evolutionary institutionalist perspectives. During the course of my $\mathrm{PhD}$, I have also had the opportunity to get involved in project work under their supervision, what has been an invaluable experience shaping both this doctoral dissertation and my professional development.

Next, I would like to thank Pierre Mohnen, Raimund Bleischwitz, Marc Dijk and Michiko Iizuka for having accepted to serve as assessment committee members and for their insightful comments. I also have benefited from valuable feedback during the earlier stages of my work. I would like to acknowledge particularly Matt Zolnowski, Ismar Borges de Lima, Walter Leal Filho, Richard Green, Erin Mansur, Felix Höffler, Van Anh Vuong, Raimund Bleischwitz and Patrice Christmann. Furthermore, I am grateful for the intellectual exchanges with the UNUMERIT academic staff, especially with Can Huang, Michiko Iizuka, Robin Cowan, Bart Verspagen, Jojo Jacob, Fred Gault and Gerald Silverberg, as well as with the participants of the First European Rare Earth Resources Conference (Greece), the Future Perspectives on Innovation and Governance in Development conference (the Netherlands), the Second International Conference on Energy and Environment (Portugal) and the UNU-MERIT research tutorial on Macro and Micro Perspectives on Sustainable Development (the Netherlands). Finally, a special thank you goes to a friend and intellectual sparring partner on the last mile, for the numerous interactions, sharing books, ideas and much more, which have altogether significantly shaped my thinking about the coordination debate, as well as my general worldviews. 
I also wish to extend my appreciation to those who have made my life within the Institute easier and more enriching: the PhD Board - Eveline, Mindel, Tatiana and especially Robin who encouraged me to pursue the topic of my dissertation; the UNU-MERIT staff members for their kind support (far beyond administrative duties), in particular Ad, Eric, Eveline, Herman, Howard, Marc, Mourik Jan and Wilma; Lutz for the teaching opportunity; and the DEIP team - it has been a tremendous pleasure to work with you Michiko, Eveline, Alison and Elisa. As for you Eveline, you deserve a special mention for your care and friendship, and for having been always around for a spontaneous smile or an encouraging hug, which have smoothed the highs and lows of my PhD journey and which I am endlessly thankful for! I have also been very fortunate to have met a lot of fantastic people who have made my time in Maastricht unforgettable in one way or another: all the PhD fellows from the amazing 2012 cohort (it's been 18 of us so forgive me if I won't list you guys by name (-)), as well as Iulia, Elisa, Alison, Mueid, Ibrahima, Elvis, Hugo, Francesca R., Serdar, Iman, Daniel, George, Sachin, Francesca G., Vera D., Nadine B., Marco L., Roland V. and many more. Last but not least, I am indebted to my wonderful paranymphs, Iulia and Juan, for making the day of my $\mathrm{PhD}$ defence special.

This final section is dedicated to my loved ones, who have been patiently and lovingly accompanying me on my journey since longer time and to whom I am infinitely grateful for helping me to become the person I have always wanted to be. Achieving all this would have not been possible without the unconditional love and support from my dear parents, Zuzana and Štefan, and my loving sister Katarína. Ever since my childhood, they have instilled in me the sense for hard work and discipline, drive for continuous improvement and the importance of love.

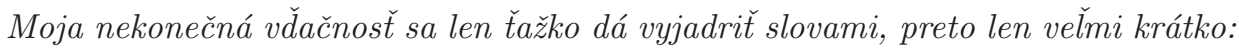

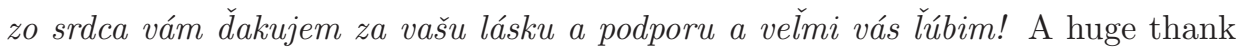
you goes to my extended family in Switzerland: Es riesigs Dankeschön gaht an Eu Roli und Vreni, wo mich während dene Jahre unterstützt händ und mir gmeinsam en schöni Ziit erläbt händ. And to my little darlings who bring sunshine into my everyday life: Cleo, Matti, Zuzanka and Carlito $\bullet$. I can only hardly find the right words to thank the most wonderful of all - the one without whom all this (and a lot more!) would have never felt like a walk in a rose garden. Thank you, Bruno, for having been there for me during all these years, for your encouragement when things were getting tough, for being my partner in crime and sharing the moments of joy, and for the many sacrifices you have made for me. "Sisch das Gfüeu wo du mir gisch, Öpis wome fasch nid cha beschribe, Eifach zwüsse das du da bisch, o we schüsch niemer meh würd blibe..." 
Last but not least, my life's been largely influenced by the legacy of Carlo Abarth - the most genius of automotive pioneers who, thanks to his revolutionary vision, winning spirit and love for impossible missions, not only democratised race cars but with his philosophy continues to inspire generations to come, because...

...Performance Is a State of Mind. 



\section{Summary}

The economic textbook solution to climate change mitigation is to use environmental policies towards all greenhouse gas point sources and to direct support for innovation in low-carbon technologies. Yet, in the absence of a single global carbon price, climate policy relies on unilateral efforts by national governments and on low-carbon technology innovation strategies by individual businesses. In this spirit, the new climate change mitigation framework adopted in Paris in 2015, aims at assuring that the efforts to address the problem of climate change take place on a global scale. The latter is set to be achieved through a combined topdown and bottom-up architecture, which foresees a globally binding treaty under international law, governing the commitments by individual countries to decrease their carbon emissions through nationally determined pledges. Though assuring wide participation by both developed and developing countries, such decentralised approach leaves it to the responsibility of participating countries to design climate change policies in line with their respective country contexts. However, in a world of nation states which are competing with each other economically and which have developed heterogeneous policy approaches reflecting their national priorities, ideologies, interests and legal and cultural traditions, an uncoordinated transition to low-carbon energy systems might not only inhibit reaching the global pledge to limit the temperature increase to well below $2^{\circ} \mathrm{C}$, it might also bring about new problems in terms of increasing the economic burden of emission reduction in countries with more stringent environmental policies.

In this respect, the aim of this dissertation is to shed light on how the coordination of bottom-up processes within the broader context of climate change should be managed, in order to assure a sustainable and equitable transition to a renewable future. In particular, this dissertation analyses the challenges for a transition to low-carbon energy systems, whereby climate change mitigation is interpreted within a wider socio-economic, technological and geopolitical context, as opposed to the narrow view of emission reduction targets. Such approach allows to examine the interconnections between climate change mitigation, energy and mineral resources, and to ultimately draw conclusions on the coordination challenges in a world with interconnected systems, heterogeneous national policies and priorities, and distorted markets. The analytical framework has been informed by theories of public goods and collective action, as well as by the nexus approach to resource governance and by the national system of innovation considerations. The 
dissertation is a collection of three empirical studies, each of which sheds light on the coordination challenges from a different perspective. The latter are analysed using various methodologies, ranging from quantitative analysis of dynamic panel data model, through market analysis and technological landscape assessment, to a comparative political economy analysis of policies and policy styles. Such mixed method approach enables examining the problem of coordination from a more holistic perspective. At the same time, the scope of the dissertation being multidisciplinary, each chapter also makes a scholarly contribution to its respective field.

Chapter 2 examines the economic costs of uncoordinated implementation of environmental policies across countries. In particular, it investigates on to what extent electricity prices for industrial consumers lead to a loss of international competitiveness on country level in terms of attracting foreign direct investment (FDI). The results of the quantitative analysis for the European Union (EU) confirm that besides tax rates, unit labour costs and competitive disadvantage in secondary education, also electricity prices contribute to eroding net FDI inflows of the EU countries. While this is true for both sub-regions, south-western countries tend to be more adversely affected than north-eastern both in the short and the long run. These results have implications on a larger scale too. Should electricity price differentials continue to persist internationally, they might lead to alteration of the global pattern of investment, production and trade.

Chapter 3 analyses the implications of inadequate coordination of policies beyond sectoral stovepipes on global supply chains. This is done by investigating the interconnections between low-carbon technologies and mineral resources. In particular, the chapter investigates the far reaching consequences of rare earth demand-supply imbalances on the deployment and innovation of offshore wind turbines and advanced technology vehicles. On the supply side, the chapter confirms the existence of rare earth supply risk which arises from institutional inefficiency within the market. On the demand side, the results disprove the widespread allegation that supply risk of rare earths impedes the deployment of offshore wind turbines per se. In contrast, the automotive industry and its electrification have been found substantially dependent on the undistorted access to rare earths. The potential supply shortage of the latter would thus largely disrupt the further development of the market altogether. Ultimately, evidence shows that the uncertainty about volatile prices and the threat of supply shortages induce manufacturers to optimise the designs of their products by innovating in less rare earth-intensive topologies, which are however often inferior in terms of their performance.

Chapter 4 investigates on the importance of coordinating collective actions 
at multiple scales within countries, in order to accommodate national interests and domestic circumstances in face of global market distortions. In particular, it examines within a comparative political economy framework how national interest considerations, resource endowment circumstances, countries' historical experience in tackling supply risk and their respective policy styles influenced the development of policy choices regarding rare earths. The overall findings show that despite their similar objectives, the foci of strategies differ across regions. While Europe's efforts target policy dialogue with resource-rich countries, Japan and the United States have a more hands-on approach in research and development initiatives. Australia's and China's policies instead, focus on development of domestic mining activities and on resource protection.

Taken together, the results of the three chapters convey the message that uncoordinated transition to new energy systems might create bottlenecks to socioeconomic, technological and geopolitical systems globally. The dissertation therefore argues for a three-dimensional coordination within a bottom-up climate change policy architecture: within national policies, across national policies and beyond sectoral policies. In fact, in order for climate change policies to be beneficial at country level both environmentally and economically, coordination across countries is required to prevent leakage from countries with more stringent to those with less stringent policies. On top of this, each country should also develop its own multilevel and possibly polycentric system of governance by involving stakeholders at all levels, in order to accommodate the particular domestic contexts and national interests. Finally, besides coordination within sectoral policies, this also needs to occur beyond the sector in order to reflect the interconnections between climate change mitigation, energy and minerals, and potentially other resources. Therefore, from the policy perspective the main contribution of this dissertation is to provide evidence of the need for devising sustainable and equitable climate change mitigation policies, by taking into consideration the distinct and often competing sub-national, national and sectoral collective action mechanisms. 


\section{Contents}

Acknowledgements $\quad$ v

Summary $\quad$ ix

1 Introduction $\quad 1$

1.1 Framework for transition to a renewable future . . . . . . . . . 1

1.2 The coordination conundrum ............... . . 3

1.3 Potential solutions to the coordination challenges . . . . . . . . 7

2 The impact of electricity prices on foreign direct investment: Evidence from the European Union 13

2.1 Introduction . . . . . . . . . . . . . . . . . . 14

2.2 Electricity prices as determinants of foreign direct investment . . . 15

2.3 Data . . . . . . . . . . . . . . . . . . 18

2.4 Methods . . . . . . . . . . . . . . . . . 25

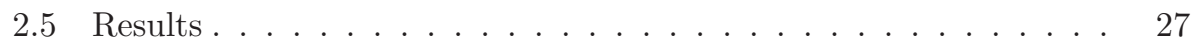

2.6 Conclusions . . . . . . . . . . . . . . . . . . . 34

Appendix A ....................... 41

3 Which low-carbon technologies are subject to supply risks? An inquiry into the economics of rare earths and its implications for innovation

3.1 Introduction . . . . . . . . . . . . . . . . . . . . 44

3.2 Rare earths . . . . . . . . . . . . . . . 46

3.2.1 From discovery to processing . . . . . . . . . . . . . 46

3.2.2 Their industrial uses . . . . . . . . . . . . . 50

3.2.3 The criticality of "not so rare" metals . . . . . . . . . 53

3.3 Supply risk . . . . . . . . . . . . . . . . . . . 54

3.3.1 Geopolitical security and resource dependence . . . . . . 55

3.3.2 Quantity risk .................. 57 
3.4 Demand push . . . . . . . . . . . . . . . . . . 70

3.4 .1 Offshore wind turbines . . . . . . . . . . . . . 73

3.4 .2 Advanced technology vehicles . . . . . . . . . . . . . 82

3.5 Curbing the rare earth dependence . . . . . . . . . . . 89

3.5.1 Material substitutes . . . . . . . . . . . . . . . . 89

3.5.2 Technology substitutes . . . . . . . . . . . . . . . . . . 93

3.5 .3 Secondary market . . . . . . . . . . . . . . . . . 95

3.5 .4 Stockpiling . . . . . . . . . . . . . . . 97

3.6 Factors influencing prices of rare earths $\ldots \ldots \ldots \ldots$

3.6.1 Rare earth price trends . . . . . . . . . . . . . . 100

3.6.2 Impact on low-carbon technologies' producers . . . . . . . 105

3.7 Social costs of rare earths . . . . . . . . . . . . . . 107

3.7.1 The "dirty" clean energy _. . . . . . . . . . . . . . . 107

3.7 .2 Health issues . . . . . . . . . . . . . . . . . 110

3.8 Conclusions: Separating myth from reality . . . . . . . . . . . 111

Appendix B . . . . . . . . . . . . . . . . . 136

4 National strategies for securing a stable supply of rare earths $\begin{array}{ll}\text { in different world regions } & 139\end{array}$

4.1 Introduction . . . . . . . . . . . . . . . . . . . . . 140

4.2 Critical minerals . . . . . . . . . . . . . . . . . . 141

4.3 Theoretical framework and methods . . . . . . . . . . . . . . 144

4.4 Strategies for mitigating rare earth criticality . . . . . . . . . . . 149

4.4 .1 China . . . . . . . . . . . . . . . . . . . . . . . . 149

4.4 .2 The United States . . . . . . . . . . . . . . . 155

4.4 .3 Europe . . . . . . . . . . . . . . . . . . . . . 162

$4.4 .4 \quad J a p a n \ldots \ldots \ldots 170$

4.4 .5 Australia . . . . . . . . . . . . . . . 176

4.4 .6 Summary . . . . . . . . . . . . . . . . . . . . . . . . 182

4.5 Discussion . . . . . . . . . . . . . . . . . . . . 186

4.6 Conclusions . . . . . . . . . . . . . . . . . . . . . . 191

5 Concluding remarks 211

5.1 Main findings . . . . . . . . . . . . . . . . . 211

5.2 Findings and recommendations for the coordination challenges . . 216

$\begin{array}{ll}\text { Valorisation addendum } & 221\end{array}$

$\begin{array}{ll}\text { About the author } & 225\end{array}$ 


\section{List of Tables}

2.1 Summary statistics . . . . . . . . . . . . . . . . 20

2.2 Definition of variables . . . . . . . . . . . . . . . 24

2.3 Comparison of estimates of FDI determinants across estimation

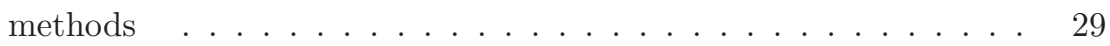

2.4 Policy variables as FDI determinants $\ldots \ldots \ldots \ldots . \ldots . \ldots 33$

A.1 Classification of countries into sub-regions . . . . . . . . . . 41

A.2 Correlation matrix . . . . . . . . . . . . . . . 42

3.1 Abundance of rare earths in continental crust . . . . . . . . . 48

3.2 Main rare earth applications . . . . . . . . . . . . . . . 52

3.3 Generator types in wind turbine technologies and their respective permanent magnet and rare earth contents . . . . . . . . 76

3.4 Vehicle technologies classified by hybridisation and their respective rare earth contents . . . . . . . . . . . . . . . 83

3.5 Current projects on material substitution of rare earths . . . . . 91

3.6 Price comparison of selected rare earth oxides across FOB China and China domestic basis . . . . . . . . . . . . . . 103

3.7 Annualised quarterly volatilities for selected rare earth oxides. . . . 105

B.1 Data on Chinese rare earth production and exports, and respective quotas in 2003-2013 . . . . . . . . . . . . . . 136

B.2 Advanced rare earth projects outside China . . . . . . . . . . 137

4.1 Summary table on rare earth industrial supply chains and strategies in different world regions . . . . . . . . . . . . . . . . 184 


\section{List of Figures}

2.1 Coefficients of variation for electricity prices in EU27 and its southwestern and north-eastern sub-samples . . . . . . . . . . . 21

3.1 Comparison of Chinese export destinations across 1992 and 2012 . 59

3.2 World rare earth export by country in 2000-2012 . . . . . . . . . . 59

3.3 Comparison of world rare earth reserves by country across 1996 and

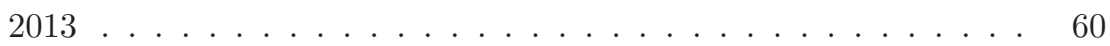

3.4 World mine production by country in 1988-2013 . . . . . . . . 61

3.5 Comparison of world mine production by country across 2009 and

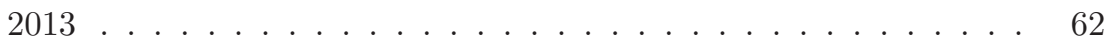

3.6 Chinese rare earth production and exports, and respective quotas in 2000-2013 . . . . . . . . . . . . . . . 6 63

3.7 Estimated global rare earth consumption by country and sector in

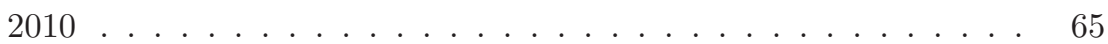

3.8 Chinese rare earth consumption in 2001 and 2011 . . . . . . . . 66

3.9 Global demand forecast for individual rare earths for 2016 . . . . . 71

3.10 Generators in commissioned global offshore wind projects . . . . . 77

3.11 Generators in commissioned global offshore wind projects and in projects under construction . . . . . . . . . . . . 78

3.12 Average power ranges of generators . . . . . . . . . . . . . 79

3.13 Battery technologies deployed in advanced technology vehicles . . . 87

3.14 Global demand and supply forecast for individual rare earths for 201699

3.15 Nominal rare earth prices . . . . . . . . . . . . . . . . . . 101

3.16 Historical prices for selected rare earth oxides . . . . . . . . . . . . 104

4.1 Assessment of rare earth industrial supply chains and strategies in different world regions . . . . . . . . . . . . 185 



\section{Introduction}

"If we lavishly and boldly push forward in the creation of our riches, both material and intellectual, it is hard to over-estimate the pitch of beneficial influence to which we may attain in the present. But the maintenance of such a position is physically impossible. We have to make the momentous choice between brief but true greatness and longer continued mediocrity."

$-($ Jevons, 1906)

\subsection{Framework for transition to a renewable future}

During the first two weeks of December 2015 representatives from 195 countries gathered in Paris to negotiate the text of the new international agreement on climate change (Paris Agreement, or Agreement). Acknowledging that anthropogenic greenhouse gases (GHG) have been the dominant cause of the observed global warming, the aim of the 21st Conference of the Parties to the United Nations Framework Convention on Climate Change was to reach a global accord on limiting the atmospheric concentrations of emissions (Sustainable Innovation Forum, 2015). In particular, energy production, industrial processes, transport and agriculture had been determined as the main drivers behind the growing atmospheric concentration of carbon dioxide, methane and nitrous oxide. Reaching highest levels since 800'000 years, this increase led to rising combined land and ocean surface temperature from the pre-industrial era by 0.85 degrees Celsius (Pachauri et al., 2014). Global warming in turn, has been adversely impacting both natural systems (acidification and ocean warming, melting of ice sheets in Arctic, sea level rise, more frequent occurrence extreme weather conditions, decreasing biodiversity and ecosystem shifts) and human systems (food security, landslides, air pollution, water scarcity and health problems). Strategic consensus view points to the fact that in order to escape the devastating and irreversible consequences of further warming, temperature increases need to be kept below 2 degrees Celsius above the pre-industrial temperatures. In particular, sidestepping the current trajectory for a rise of 4.5 degrees Celsius is estimated to require a reduction in 
anthropogenic emissions by $40 \%$ to $70 \%$ by 2050 , and reaching zero net emissions by 2100 (Pachauri et al., 2014).

To mitigate the hazards of global warming, the Paris Agreement targets to limit the temperature increase to "well below $2^{\circ} \mathrm{C}$ above pre-industrial levels pursuing efforts to limit the temperature increase to $1.5^{\circ} \mathrm{C}$ above pre-industrial levels" and to reach net zero emissions by the second half of the century (The Economist, 2015). In order to reach these objectives, it combines a top-down approach, which foresees a globally binding treaty under international law, with a bottom-up approach, whereby countries commit their shares through nationally determined pledges (Waughray, 2015). Such architecture for an international climate change regime has been earlier put forward by the Harvard Project on Climate Agreements (2015) and long advocated by proponents of a decentralised mechanism (Aldy and Stavins, 2008). In fact, the new regime departs from the previously unsuccessful attempt by Kyoto Protocol (1997) to impose legally binding short term quantitative targets for emission reductions. This top-down scheme advocated market-based approaches to emissions abatement, such as the cap-andtrade program. Yet, because of distributional equity considerations, it failed to include the largest GHG emitters. In representing merely $14 \%$ of global emissions and $0 \%$ of global emissions growth, the expected gains from emission trading could not materialise (Aldy and Stavins, 2008; Stavins, 2015). In contrast, the current architecture of the Paris Agreement led 186 countries, representing more than 96\% of global GHG emissions, to submit Intended Nationally Determined Contributions (INDC). This near-universal agreement including both developed and developing countries has been achieved by the decentralised "pledge-and-review approach" which leaves it to the responsibility of participating participating countries to design climate change policies in line with their respective country contexts (Aldy and Stavins, 2008). On the downside, the INDC targets as self-determined, the level of their stringency reflects countries' domestic circumstances, economic interests and political will of ruling governments rather than the global pledge of 2 degrees Celsius. To bypass this weakness, the Agreement foresees for each country to establish a respective national climate action plan, as well as a mechanism to ratchet up national targets every five years through a stocktaking exercise (Waughray, 2015). The Paris Agreement thus establishes a new global framework for a continuous future effort to address the problem of climate change on a global scale.

This new framework is governed by the mutual consent that mitigating climate change necessitates improved energy efficiency, reduced uses of fossil fuels and their displacement by low- and zero-carbon power generated from renewable 
energy sources (Pachauri et al., 2014; Ribera et al., 2015; Wuester et al., 2015). Accordingly, most of the INDCs target the increased deployment of renewable energy sources within their energy mixes. Nonetheless, substantial differences exist in the level of ambition of countries' national targets. For example, while China's GHG emissions are to peak in 2030 with non-fossil fuel share in energy mix of $20 \%$ by the same year, Uruguay intends to cut $88 \%$ in carbon emissions by 2017 while the share of renewables in its energy mix has reached $55 \%$ already now (Plumer, 2015; Watts, 2015). In general, targets by large countries tend to lag significantly behind targets by smaller countries in absolute terms. Also in relative terms the former are deemed to remain the largest polluters. The more so, since the growth of global emissions during the past decade has been driven by large developing countries, such as China, India, Brazil and Mexico. Additionally, some of the least developed countries, which also tend to be the most vulnerable to impacts of climate change, lack financial resources, technology, as well as economic incentives and strong governance institutions to implement stringent environmental policies. The bottom line is that a decentralised approach to a global low-carbon energy system transition might provide few incentives for individual countries to set their national targets to levels which are politically costly yet technically feasible. In the long term, this might ultimately lead to failure to reach the global pledge of 2 degrees Celsius on the one hand, and to increase the economic burden of emission reduction in countries with more stringent environmental policies on the other. Consequently, in order to assure a sustainable and equitable climate change mitigation, besides a top-down guidance and monitoring there is also a clear need for coordination of the bottom-up processes. The question arises as to how such coordination should be managed. This coordination conundrum is the overarching theme of the dissertation.

\subsection{The coordination conundrum}

The need for coordination of climate change mitigation is inherent to the fact that stabilisation of GHG concentrations in the atmosphere at levels which would avoid anthropogenic interference with the climate system (UNFCCC, 2006) is a global public good and a collective action problem. For public goods, government intervention is required to overcome market failures in achieving efficiency and equity in their allocation and distribution (Kaul et al., 1999). Accordingly, governments attempt to assure for provision of public goods and to correct for externalities through policies on regional or national levels. Yet, the issue of emission reduction, which has previously been considered a matter of national governance, is 
now extending well beyond geographic and political borders. This causes a mismatch between the scope of the problem and the authority of the decision making body and its respective accountability (Ellis, 2015), causing national policies to be ineffective in addressing global externalities. Besides this, failing to tackle environmental costs equitable on a broad base might have adverse economic consequences for single countries, incurring large national costs but small benefits. What is worse, when countries behave as "independent, rational, free-enterprises" and strive to maximise respective gains while bearing only a fraction of the costs of polluting relative to the cost of purifying wastes, this might lead to tragedy of commons by depleting the common resource in the long term - in this case the environment (Hardin, 1968). Indeed, when national targets remain voluntary and largely uncoordinated, countries will tend to protect their respective economic self-interests at the cost of global welfare.

The conventional theory of collective action has been challenged by Ostrom (2010), who argues that common resources can be well-managed when "individuals are well informed about the problem they face and about who else is involved, and can build settings where trust and reciprocity can emerge, grow, and be sustained over time". As such, her thinking opens up a more bottom-up oriented perspective, with strong participation from actors on the ground, towards a polycentric system for collective action at diverse levels, in order to "gain benefits at multiple scales as well as to encourage experimentation and learning from diverse policies adopted at multiple scales". In the particular context of climate change mitigation this translates into a need for better coordinated policies on multiple levels, in particular on the level of firms, communities, local, regional and national governments. Nonetheless, Ostrom (2010) also acknowledges that in the absence of a global institution to coordinate, multitude of actors operating at multiple scales might result in leakage, inconsistent policies and free riding. In this spirit Harvey (2012), in his discussion on urban commons, challenges the view of polycentrism on a large scale: "How can radical decentralisation - surely a worthwhile objective - work without constituting some higher-order hierarchical authority?" Yet rather than opposing the idea of collective action per se, he critiques the rejection of hierarchical forms of governance altogether.

A similar approach to policy making, yet in a more systemic fashion, is advocated by the nexus scholars who examine the interconnections, tensions and tradeoffs between different resources in the wider context of climate change (The Nexus Network, 2015). Such approach allows for a more integrated view of challenges to governance of common resources. In this light, Andrews-Speed et al. (2015) postulate that the main source of resource governance failure lies within the "stovepipe 
character of organization structure and policy making, in government, science and knowledge-making industries and in international organizations". In fact, within silos or stovepiped governance structures, single resources such as food, water, energy, land or minerals, are managed by separate agencies with missing communication across them. However, keeping in mind that resource flows and systems are interlinked, a more interconnected thinking is required for devising policies. Failure to do so might have adverse implications for governance of other parts of the system and might ultimately result in economic, political and humanitarian threats on global scale. Consequently, for a better management of links between resources, the authors advocate adapting existing or creating new governance institutions in line with multilevel and polycentric considerations. Furthermore, the governing frameworks shall be inclusive, drawing on participation from various stakeholders, as well as combine binding and non-binding agreements in order to both ensure and encourage compliance, respectively.

While offering valuable insights on multilevel and polycentric regional and sectoral approaches to the bottom-up coordination problem, the above governance ideas tend to undermine the importance of government policies at national levels. The latter however, form an important part of the new climate change framework, since they govern the transition to low-carbon energy systems within countries' respective national climate action plans. The coordination challenge thus also arises from the heterogeneity of national priorities. For example, China being a developmental state, its policies of the past decades were adopted with the view to propel rapid economic growth and industrialisation, largely overlooking the environmental consequences. In this sense, the concept of national system of innovation "is the key to explaining the behaviour and the performance of the set of institutions on which long-term economic growth and sustainable development are based" (Niosi, 2002). Hence, coordination across national institutions and national policies is important since the latter "contribute to the development and diffusion of new technologies and [...] provide the framework within which governments form and implement policies to influence the innovation process" (Metcalfe, 1995). In the particular case of climate change, national policies set the frame for energy markets (Boot et al., 2014) and for industrial policy processes (The Donor Committee for Enterprise Development, 2014), among others. Accordingly, besides policies on local and regional levels, the level of ambition and the often conflicting priorities of national policies need also to be considered within the coordination conundrum.

From the above discussion it follows that multilevel, polycentric, bottom-up policies, as compared to top-down architectures which have prevailed in climate change agreements until recently, might be superior for governing climate change 
mitigation, or should at least become their strong complement. Yet, at the same time the question arises as to how such heterogeneous policies shall be coordinated across multiple scales and beyond sectoral stovepipes. A sustainable transition to low-carbon energy systems needs both to be backed by institutional structures and economic opportunities on regional, national and international levels, and to be coordinated across different linkages within the global nexus. Lack of such mechanisms can lead to bottlenecks in socio-economic, technological and geopolitical systems globally.

To provide evidence on the pressing issue of coordination within low-carbon energy transition, one such bottleneck arises from increasing non-market electricity price components and from industrial electricity price differentials across countries and over time (European Commission, 2012, 2014; International Energy Agency, 2014). These are resulting from heterogeneous strategies adopted by governments worldwide, such as the development of shale gas production through hydraulic fracturing in the United States, or maintaining strong absolute growth of coal consumption in India on the one hand, and closing down nuclear power plants and subsidising renewable energy in Germany, as well as the introduction of the EU Emission Trading Scheme on the other (Clark, 2014). The bottom line is that electricity price differentials resulting from the absence of coordinated policies might alter firms locational choices of investment (Steitz and Scheyder, 2014). This might ultimately shift the global pattern of investment, production and trade in favour of countries where environmental policies are less stringent.

Another often disregarded bottleneck in the climate change policy debate relates to the fact that low-carbon energy technologies are heavily dependent on the use of minerals, in particular technology metals (Technology Metals Research, 2010). For example, rare earths have seen a rapid upsurge in their demand driven by the deployment of electric vehicles, offshore wind turbines as well as energy efficient fluorescent light bulbs. While there exists no threat of immediate scarcity, the large increase in their demand combined with the inability of markets to deliver new supply in short time frames are affecting the stability of supply and pricing (Bourzac, 2011). What is more, when mined in environmentally unsound fashion in few developing countries, the reliance on metals often comes with high social costs and geopolitical uncertainties (Bradsher, 2010; Hurst, 2010). The ultimate consequence might be that manufacturers shift to designing less rare earth-intensive technologies which, however, are often inferior in terms of their performance and energy efficiencies (Abraham, 2015; Hykawy, 2015). Such problems arise from lack of coordination of policies beyond sectoral stovepipes, i.e. increasing reliance on low-carbon technologies in energy mix without considering the implications for 
minerals upstream the global supply chain.

\subsection{Potential solutions to the coordination challenges}

Further to the above discussion, the question arises as to how coordination of bottom-up processes should be managed: What type of climate change policy architecture is suited for assuring a sustainable and equitable transition to low-carbon energy systems in a world with interconnected systems, heterogeneous national policies and priorities, and distorted markets? The overarching aim of this dissertation is to answer this question by analysing energy and industrial processes related to climate change, and thereby providing evidence on the need to coordinate national and local actions so as to assure a sustainable global outcome. This is done within three empirical studies, each of which sheds light on the coordination challenges from a different perspective. The latter are analysed using various methodologies, ranging from quantitative analysis of a dynamic panel data model, through market analysis and technological landscape assessment, to a comparative political economy analysis of policies and policy styles. Though analysing different aspects of low-carbon energy transition and using different methodological approaches, taken together the studies demonstrate that an uncoordinated local transition to new energy systems creates bottlenecks to socio-economic, technological and geopolitical systems globally. In this respect, the dissertation makes three propositions.

First, lack of coordination of environmental policies across countries leads to reducing the environmental benefits and to increasing the economic costs of emission mitigation strategies in countries with more stringent environmental policies. This is demonstrated for the case of industrial electricity price differentials across countries which arise due to their heterogeneous environmental policies. Accordingly, the aim of Chapter 2 is to quantify the effects of electricity prices as a locational determinant of foreign direct investment (FDI) on a panel of $27 \mathrm{Eu}-$ ropean Union (EU) countries using the system generalised method of moments (GMM) estimation method. The main scholarly contribution of this chapter is to fill the gap in the literature, confirming that besides other locational determinants such as tax rates, unit labour costs and competitive disadvantage in secondary education, also electricity prices contribute to eroding net FDI inflows of the EU countries. In a more general context, this result supports the argument that if coordination is left to markets alone, relocation of investment flows by producers facing competitive disadvantage takes place, in spite of individual government's 
policy choices to correct for distortions on national levels.

Second, inadequate coordination of policies beyond sectoral stovepipes creates bottlenecks across other parts of global supply chains. This proposition is tested in Chapter 3, which investigates to what extent do potential supply shortages of rare earths pose barriers to low-carbon technologies deployment. Through a multidisciplinary approach, the chapter provides an in-depth analysis of the rare earth market. Besides a detailed overview of market forces which distort the global supply, the novelty of this chapter lies within the assessment of the technological landscape of offshore wind turbines and advanced technology vehicles, and of their dependence on rare earths. While the results disprove the widespread allegation that potential supply shortages impede the deployment of offshore wind altogether, they could lead to the disruption of electrification of the automotive industry. From the point of view of devising climate change policy, this translates into the need to coordinate policies beyond their sectoral reach, considering the linkages between resource flows and systems.

Third, coordination of collective actions at multiple scales is essential within countries, in order to accommodate national interests and domestic circumstances in face of global market distortions. This proposition is evaluated across two chapters. Chapter 3 offers insights into innovation strategies by manufacturers of low-carbon technologies with twofold implications. The uncertainty about volatile prices and the threat of supply shortages induce manufacturers to innovate in less rare earth-intensive topologies, which however tend to be inferior in terms of their performance. Alternatively, it might follow that manufacturers, and thus all their innovation activities, relocate to China with a view to sourcing cheaper inputs at stable supply. Chapter 4 instead, examines the extent to which distinct national interests and country contexts, such as resource endowment circumstances, historical experience in tackling supply risk and respective policy styles, shape policy choices by individual countries with regard to securing stable supply of rare earths. This historical qualitative case study type of analysis is the first endeavour in the literature to describe the development trajectories of mineral strategies across the main stakeholder regions in such detail. From a more general perspective, the conclusions of the two chapters illustrate the wish for countries to develop own multilevel systems of governance involving civil societies, industries and various government departments, in order to assure benefits at various levels.

The conclusions of the individual empirical studies as well as the general insights on the coordination conundrum are presented in Chapter 5 . In short, in order for bottom-up climate change policy architecture to be efficient and equitable, the results of this dissertation illustrate the need for coordination across three 
dimensions: within national policies, across national policies and beyond sectoral stovepipes. In this sense, the dissertation argues for a multilevel and polycentric governance mechanism, advocating an integrated approach to low-carbon energy transition rather than focusing on energy-related GHG emissions in isolation.

In summary, this dissertation is a collection of empirical studies, each of which sheds light on the bottom-up coordination challenge from a different perspective. Their overarching theme is the coordination of national and local actions within energy and industrial processes related to climate change mitigation. Though the dissertation does not study the governance of common resources explicitly, it aims at making a contribution to the broader analytical frame on how coordination of bottom-up climate change processes should be managed, in order to assure a sustainable and equitable transition to a renewable future. In particular, this dissertation analyses the challenges for a transition to low-carbon energy systems, whereby climate change mitigation is interpreted within a wider socio-economic, technological and geopolitical context. Such approach allows to examine the interconnections between climate change mitigation, energy and minerals, and to ultimately draw conclusions on the coordination challenges in a world with interconnected systems, heterogeneous national policies and priorities, and distorted markets. Moreover, the scope of the dissertation being multidisciplinary, each empirical chapter also makes a scholarly contribution to its respective field. In particular, Chapter 2 contributes to energy economics and trade literature by addressing the research question as to what extent electricity prices for industrial consumers lead to a loss of international competitiveness within the EU? Next, the contribution of Chapter 3 is in the field of technological change and innovation, by analysing to what extent potential supply shortages of rare earths pose a barrier to the increased adoption and innovation of low-carbon technologies. Finally, the aim of Chapter 4 is to investigate on why different world regions responded differently to the global problem of securing stable supply of critical materials, in particular of rare earths. The latter thus makes a contribution to resource economics and applied comparative political economy analysis. The theoretical frameworks and methodologies used for the analysis are described within the respective chapters. In essence, each of the three chapters conducts applied analysis of specific challenges related to a sustainable and equitable transition to a renewable future. 


\section{Bibliography}

Abraham, D. S. (2015). How new technology is changing the geopolitical landscape of power. Full interview by Larry Mantle available from http://www.scpr.org/programs/airtalk/2015/ 11/24/45353/how-new-technology-is-changing-the-geopolitical-la/. Accessed: 03-12-2015.

Aldy, J. E. and Stavins, R. N. (2008). Climate policy architectures for the post-Kyoto world. Environment: Science and Policy for Sustainable Development, 50(3):6-17.

Andrews-Speed, P., Bleischwitz, R., Boersma, T., Johnson, C., Kemp, G., and VanDeveer, S. D. (2015). Want, Waste Or War?: The Global Resource Nexus and the Struggle for Land, Energy, Food, Water and Minerals. Routledge.

Boot, P., de Jong, J., and Hoogervorst, N. (2014). Reflections on coordination mechanisms - For accomodating increasing amounts of wind and solar in the power market. Technical report, Clingendael International Energy Programme. Available from http://www.clingendaelenergy. com/inc/upload/files/Ciep_paper_2014-05_web.pdf.

Bourzac, K. (2011). The rare-earth crisis. Technology Review, 114(3):58.

Bradsher, K. (2010). Amid tension, China blocks vital exports to Japan. Available from http: //www.nytimes.com/2010/09/23/business/global/23rare.html?pagewanted=all\&_r=1\&. Accessed: 16-11-2013.

Clark, P. (2014). Energy price gap with the US to hurt Europe for 'at least 20 years'. Available from http://www.ft.com/intl/cms/s/0/80950dfe-8901-11e3-9f4800144feab7de.html\#axzz44stJY7vd. Accessed: 30-03-2016.

Ellis, E. (2015). Democracy as a constraint and possibility for environmental action. In Gabrielson, T., Hall, C., Meyer, J. M., and Schlosberg, D., editors, The Oxford Handbook of Environmental Political Theory, pages 505-519. Oxford University Press.

European Commission (2012). European competitiveness report 2012 - Reaping the benefits of globalization. Commission Staff Working Document SWD(2012) 299 final, European Commission. Available from http://ec.europa.eu/enterprise/policies/industrial-competitiveness/ competitiveness-analysis/european-competitiveness-report/files/ecr2012_full_en.pdf.

European Commission (2014). Energy prices and costs report. Commission Staff Working Document SWD(2014) 20 final/2, European Commission. Available from http://ec.europa.eu/ energy/sites/ener/files/documents/20140122_swd_prices.pdf.

Hardin, G. (1968). The tragedy of the commons. Science, 162(3859):1243-1248.

Harvard Project on Climate Agreements (2015). About. Available from http://belfercenter.ksg. harvard.edu/files/hpca_pamphlet17.pdf. Accessed: 14-12-2015.

Harvey, D. (2012). Rebel Cities: From the Right to the City to the Urban Revolution. Verso Books.

Hurst, C. (2010). China's rare earth elements industry: What can the West learn? Technical report, Institute for the Analysis of Global Security. Available from http://fmso.leavenworth. army.mil/documents/rareearth.pdf. 
Hykawy, J. (2015). Jon Hykawy of Stormcrow Capital talks rare earth prices 2015. Available from http://investingnews.com/daily/resource-investing/critical-metals-investing/rareearth-investing/rare-earth-prices-2015-jon-hykawy-stormcrow-capital/. Accessed: 07-122015 .

International Energy Agency (2014). World energy outlook 2013 - factsheet. Technical report, International Energy Agency. Available from http://www.worldenergyoutlook.org/media/ weowebsite/factsheets/WEO2013_Factsheets.pdf.

Jevons, W. S. (1906). The Coal Question: An Inquiry Concerning the Progress of the Nation, and the Probable Exhaustion of our Coal-mines. Macmillan.

Kaul, I., Grunberg, I., and Stern, M. (1999). Global Public Goods: International Cooperation in the 21st Century. Oxford University Press.

Metcalfe, S. (1995). The economic foundations of technology policy: Equilibrium and evolutionary perspectives. In Stoneman, P., editor, Handbook of the Economics of Innovation and Technological Change. Blackwell Oxford.

Niosi, J. (2002). National systems of innovations are "x-efficient" (and x-effective): Why some are slow learners. Research Policy, 31(2):291-302.

Ostrom, E. (2010). Polycentric systems for coping with collective action and global environmental change. Global Environmental Change, 20(4):550-557.

Pachauri, R. K., Allen, M., Barros, V., Broome, J., Cramer, W., Christ, R., Church, J., Clarke, L., Dahe, Q., Dasgupta, P., et al. (2014). Climate change 2014 synthesis report. Technical report, Intergovernmental Panel on Climate Change. Available from http://www.ipcc.ch/pdf/ assessment-report/ar5/syr/SYR_AR5_FINAL_full.pdf.

Plumer, B. (2015). The paris climate talks won't solve global warming. here's what they'll do instead. Available from http://www.vox.com/2015/11/30/9818582/paris-cop21-climate-talks. Accessed: 03-12-2015.

Ribera, T., Sachs, J., Williams, J., Waisman, H., and Segafredo, L. (2015). Pathways to deep decarbonization. Technical report, Deep Decarbonization Pathways Project. Available from http://deepdecarbonization.org/wp-content/uploads/2015/12/DDPP_2015_REPORT.pdf.

Stavins, R. (2015). Paris agreement - a good foundation for meaningful progress. Available from http://www.robertstavinsblog.org/2015/12/12/paris-agreement-a-good-foundation-formeaningful-progress/. Accessed: 14-12-2015.

Steitz, C. and Scheyder, E. (2014). Special report: How fracking helps America beat German industry. Available from http://www.reuters.com/article/us-usa-germany-power-specialreportidUSKBNOEDOCS20140602. Accessed: 14-12-2015.

Sustainable Innovation Forum (2015). Find out more about COP21. Available from http:// www.cop21paris.org/about/cop21. Accessed: 03-12-2015.

Technology Metals Research (2010). What are technology metals? Available from http://www. techmetalsresearch.com/what-are-technology-metals/. Accessed: 09-11-2013. 
The Donor Committee for Enterprise Development (2014). Private sector development synthesis note - industrial policy. Technical report, The Donor Committee for Enterprise Development. Available from http://www.enterprise-development.org/page/industrial-policy.

The Economist (2015). What to expect after a deal that exceeded expectations. Available from http://www.economist.com/news/international/21684144-what-expect-after-dealexceeded-expectations-green-light? fsrc $=\mathrm{scn} \% 2 \mathrm{Ffb} \% 2 \mathrm{Fte} \% 2 \mathrm{Fpe} \% 2 \mathrm{Fed} \% 2 \mathrm{Fgreenlight} . \quad$ Accessed: 19-12-2015.

The Nexus Network (2015). What is the nexus? Available from http://www.thenexusnetwork. org/about/. Accessed: 14-12-2015.

UNFCCC (2006). United Nations Framework Convention on Climate Change:Handbook. Technical report, UNFCCC. Available from http://unfccc.int/resource/docs/publications/ handbook.pdf.

Watts, J. (2015). Uruguay makes dramatic shift to nearly $95 \%$ electricity from clean energy. Available from http://www.theguardian.com/environment/2015/dec/03/uruguaymakes-dramatic-shift-to-nearly-95-clean-energy. Accessed: 03-12-2015.

Waughray, D. (2015). A historic tipping point for climate action. Available from https: //agenda.weforum.org/2015/12/a-historic-tipping-point-for-climate-action/?utm_content= bufferf2a3f\&utm_medium=social\&utm_source=facebook.com\&utm_campaign=buffer. Accessed: 14-12-2015.

Wuester, H., Ferroukhi, R., El-Katiri, L., Saygin, D., Rinke, T., and Nagpal, D. (2015). Rethinking energy - 2015. Technical report, International Renewable Energy Agency. Available from http://www.irena.org/rethinking/IRENA\%20_REthinking_Energy_2nd_report_2015.pdf. 


\section{The impact of electricity prices on foreign direct investment: Evidence from the European Union*}

\section{Abstract}

We address one aspect of the link between environmental policy and international competitiveness by including electricity prices in the traditional framework of foreign direct investment (FDI) analysis and examine the impact of price variation on net FDI inflows in countries of the European Union (EU). We use a panel of 27 countries for a period of 2003 - 2013 and the system generalised method of moments (GMM) as method of estimation. We show that electricity prices among the $27 \mathrm{EU}$ countries do not converge to one price. The main findings of the paper confirm that besides tax rates, unit labour costs and competitive disadvantage in secondary education, also higher electricity prices reduce countries' ability to attract FDI. Despite the immediate effects being relatively small, they are significant across both sub-regions analysed: a 10\% increase in electricity prices leads to a decrease in net FDI inflows as share of GDP by $0.41 \%$ and $0.33 \%$ for the south-western and the north-eastern region, respectively in the short run, and by $0.60 \%$ and $0.48 \%$, respectively in the long run.

Keywords: foreign direct investment, electricity prices, European Union, generalised method of moments

JEL classification: F21, O52, Q43

* This chapter is based on Barteková, E. and T. Ziesemer, 2015. Impact of Electricity Prices on Foreign Direct Investment: Evidence from the European Union, UNU-MERIT Working Paper 2015-021, United Nations University - MERIT. This chapter has also been submitted for publication to The World Economy. We are grateful for support to the GlobEn Project from FoKoS, University of Siegen, and to UNU-Merit. 


\section{$2.1 \quad$ Introduction}

In the course of recent years, regional energy price differentials sparked a debate on the role of energy costs in maintaining countries' international competitiveness in regard to trade. Electricity prices in particular, along with prices for gas, constitute a factor of great uncertainty. In the specific context of the European countries, industrial consumers in the highest priced countries paid 2.5 - 4 times more than those in the lowest priced countries for both electricity and gas for 2008 - 2012 (European Commission, 2014a). To put this into perspective, the lowest price levels for medium size industrial consumers of electricity in the EU were comparable to those in New Zealand, India and Ukraine. On the other extreme, the highest price levels in the EU were well above the highest retail electricity prices charged globally.

Rising disparities in electricity prices, along with variation in other factor costs, impact total production costs and put producers in some of these countries at a competitive disadvantage. This in turn may adversely affect investment decisions by both domestic and international firms and might ultimately lead to altering the global pattern of investment, production and trade. In fact, the share of global FDI in the EU has been on decline during the past decade, dropping from half of the global inflows at the beginning of 2000s to below one fifth of total investment flows in 2012 and 2013 (Vetter, 2014). A large part of this decline is caused by a decrease in intra-EU flows attributed to slow recovery from economic crisis (European Commission, 2012). However, the uneven distribution of FDI inflows across the EU also points to the loss of international competitiveness by some of the countries.

Foreign direct investment has been acknowledged to induce growth and development through increasing capital stock, employment creation, and perhaps knowledge and technology spillovers. While classical factor cost determinants of FDI, such as labour, capital and natural resource costs, have been widely acknowledged in the literature, the potential impact of electricity prices has been neglected so far. We address this gap in the literature by incorporating electricity prices in the traditional framework of FDI. As opposed to the pollution haven literature and carbon leakage literature, we do not examine the effect of environmental policies on trade, rather we investigate to what extent electricity prices for industrial consumers lead to a loss of international competitiveness on country level in terms of attracting FDI. We do so by examining the impact of electricity price levels on net investment inflows for the sample of EU countries. Due to the short time series available on electricity prices we make use of GMM estimation method for 
a dynamic panel data model, which also allows us to address concerns on endogeneity and autocorrelation. We conclude that both short and long run effects of electricity prices on net FDI inflows are significant and negative. Furthermore, their magnitude varies across the EU, the adverse effect being stronger in the south-western sub-region.

The remainder of this chapter is organised as follows: Section 2.2 discusses the theoretical background for analysing the effect of electricity prices on FDI. Section 2.3 identifies variable proxies and respective data sources. Section 2.4 presents the model and discusses the estimation method used. Results along with robustness checks are reported in Section 2.5. Section 2.6 concludes.

\subsection{Electricity prices as determinants of foreign direct investment}

The basis of the literature on international trade and environment was laid in the 1970s, yet it was not until the 1990s when it gained in importance, motivated by the heated debate on environmental and welfare consequences of increased economic integration and trade liberalisation. One of the pressing concerns of the time was that governments aiming to attract foreign capital would enter into "race to the bottom" in environmental regulation. With the unilateral adoption of the Kyoto Protocol, environmentalists warned that differences in environmental policies across countries might have adverse impact on countries' competitiveness, both in terms of a potential distortion of their production specialisation and within the wider context of international downward competition in environmental policies (Rauscher, 2005). Further to this, the effect of environmental regulation on capital flight has been termed "carbon leakage" and is defined as the change in emissions in the rest of the world in response to a unit reduction of emissions by a region which implemented climate policy (Branger and Quirion, 2014). Burniaux and Oliveira Martins (2000) describe two main mechanisms underlying the carbon leakage. The first channel operates through energy markets and relates to carbon abatement across a large group of countries, leading to a reduction of global demand for carbon-intensive fossil fuels and of their prices. Depending on the integration of international energy markets and on supply response of fossil fuel producers, this in turn might induce increased demand and carbon emissions by non-participating countries. The second channel operates through non-energy markets, where carbon abatement raises production costs and affects competitiveness of energy intensive industries. These in turn lose market shares to industries 
located in countries which do not have carbon abatement policies in place, what might ultimately lead to energy intensive goods production being relocated to the latter. The relocation of polluting industries from developed countries with more stringent environmental policies to developing countries with more lax policies has been termed "pollution haven hypothesis" (Levinson, 2008). An extensive body of literature examines the existence of carbon leakage and pollution haven. Sturm (2003) reviews the literature on optimal environmental policy with transboundary pollution and concludes that tighter environmental policy reduces domestic comparative advantage in pollution intensive goods and encourages their foreign production. Rauscher (2005) concludes in his survey that the impact of trade liberalisation and increased factor mobility on environment is weaker than expected, mainly due to the small cost of compliance relative to cost of labour, capital and intermediate inputs. However, Levinson and Taylor (2008) re-examine the link between abatement costs and trade flows and dismiss the claim that the effects of pollution abatement costs are negligible. On the contrary, they find that sectors affected with highest abatement costs have experienced largest relative increases in net imports. In summary, an analogy seems to exist between the theoretical underpinnings of the pollution haven hypothesis and the potential loss of international competitiveness in terms of attractiveness to FDI as investigated within this chapter. Nonetheless, the two differ in their respective aims. While the former relates to the role of unilateral environmental policies on relocation of production and trade flows, the aim of the present chapter is to investigate the role of industrial electricity prices in allocation of FDI flows.

While the need for competitive and affordable energy as one of the determinants of European countries' and industries' international competitiveness has been acknowledged (European Commission, 2014b,d), the empirical literature on the actual impact of price differentials on competitiveness remains limited. In terms of the relationship between energy prices and trade, a recent report by the European Commission (2014c) analyses the impact of energy costs on the export competitiveness of the EU manufacturing industry. Furthermore, Gerlagh and Mathys (2011) study the effect of energy abundance, as an inverse proxy for energy costs, on trade across 14 OECD countries and 10 sectors, while Sato and Dechezleprêtre (2015) measure the response of bilateral trade flows to energy price differentials across 42 OECD countries and 62 sectors. Taken together, these studies find evidence that energy price differentials are statistically significant in determining countries' and sectors' export competitiveness. They also reveal heterogeneity across sectors, the energy intensive trade-exposed sectors being the most adversely affected. The literature on the relationship between energy prices and FDI instead, appears to 
be even more scarce. Besides the report by the European Commission (2014a) which states that regional differentials in energy prices increase the risk of reduced investment in higher priced countries relative to lower priced countries, at present there exists only one empirical study examining this topic: Bilgili et al. (2012) who investigate the determinants of FDI in Turkey considering structural changes (regime shifts) using Markov Regime Switching models. They conclude that growth of electricity prices, along with growth in average prices of high sulphur fuel oil, cooking coal, steam coal and natural gas, have a significant impact on FDI growth in both regimes. While this study presents results of time series for a single country, to-date there exists no empirical evidence for a panel of countries. Therefore, in the present chapter we examine the impact of electricity prices on a panel of European countries' international competitiveness within the framework of FDI analysis. Besides electricity prices, we also consider other determinants that drive firms' decisions to invest in a particular country. We select additional variables by reviewing the FDI literature.

Factor cost differentials as determinants of foreign direct investment were first formulated within the factor price theory of the Heckscher-Ohlin model (Ohlin, 1967). The extension of the latter framework for environmental regulation and flows of factor inputs across borders have been discussed by Merrifield (1988) and McGuire (1982). They pointed out that environmental regulation, through its effects on unit costs, may induce capital movements to countries with less strict regulations. Yet the first comprehensive framework for explaining the existence of multinational enterprises (MNE) was the eclectic paradigm of international production by Dunning (1988). In his theoretical framework, commonly known as the OLI framework, he explained international production integrating ownershipspecific advantages $(\mathrm{O})$, such as technical knowledge, managerial experience, innovation capacity, economies of scope and specialisation; with location-specific advantages $(\mathrm{L})$ in terms of access to new markets, input prices and trade barriers, investment incentives and government policies; and internalisation-incentive advantages (I), such as search and negotiating costs, costs of enforcing property rights, buyer uncertainty, maintaining control over quality of products and avoiding or exploiting government interventions. The OLI framework has later been combined with industry and country characteristics to form the new trade theory. Herein, Helpman $(1983,1984,1985)$ and Ethier and Horn (1990) lay the basis for factor-proportions hypothesis explaining the location of vertically integrated MNEs. According to this, geographically fragmented production by stages across different countries increases with increasing differences in factor intensities and relative factor endowments of countries, as well as with low trade costs and 
interface effects. Contrary to this, proximity-concentration hypothesis predicts that horizontal FDI, by MNEs which produce same goods and services in multiple countries in order to exploit the proximity to customers, occurs in countries with similar factor proportions, large markets and substantial firm specific and export costs (Brainard, 1993; Horstmann and Markusen, 1987, 1992; Markusen, 1984). These two hypotheses were later combined within the knowledge-capital model by Carr et al. (1998), Markusen (1997) and Markusen et al. (1996). According to this model, when countries are of similar size and trade costs are high, this increases production of horizontal MNEs in the host country. At the same time, production of vertical MNEs increases when the host country is small, trading costs are low and there is abundance of skilled labour.

Behaviour of diversified MNEs has been explained by the risk diversification hypothesis, which postulates that firms are risk averse and aim at decreasing the variance of their earnings by geographical diversification of their production (Rugman, 1975, 1976). Several empirical studies establish that macroeconomic shocks, changes in interest and exchange rates as well as in political risk, are the main risk factors which tend to alter FDI behaviour of firms (Aizenman, 1992, 1994; Goldberg and Kolstad, 1995; Spiegel, 1994). Yet, it was only later that literature started to distinguish the effect of uncertainty on different modes of FDI and on types of their financing (Aizenman and Marion, 2004; Russ, 2007; Sayek, 2009). These studies assert that MNEs are able to minimise negative effects of exchange and inflation rate increases by shifting the location of production between home and host countries. Yet, the extent of this investment smoothing strategy depends on the mode of FDI. Finally, government policies, such as fiscal and financial incentives, as well as other incentives relating to building up infrastructure were shown to affect investment decisions. An overview of early research on policy determinants of FDI can be retrieved from Faeth (2009).

To summarise, despite the fact that energy cost differentials as determinants of foreign direct investment were suggested in the literature already in late 1980s, the link between the two has not been investigated empirically. We address this gap in the literature by incorporating electricity prices in the traditional framework of FDI. We do so by examining a panel of EU countries for a period of 2003 - 2013. The choice of data and methodology are discussed in the subsequent sections.

\subsection{Data}

Our analysis is carried out on the sample of EU member states for the period 2003 - 2013. The dependent variable is proxied by net FDI inflow (FDI). We construct 
this based on the Balance of payments - Financial account - Direct investment position reported within the bop_fdi_main dataset (Eurostat, 2014b), whereby we subtract outward investment flows by resident entities from inward flows by foreign enterprises, and scale this to GDP at market prices. We decided to make use of this dataset, which is consistent with BPM5 methodology by IMF Balance of Payments Manual, since the recently launched dataset based on the BPM6 methodology (European Central Bank, 2014a,b; Eurostat, 2014a) is currently still very limited in the coverage of these positions. Another advantage in using this dataset is that investments made or received by special purpose entities (SPE) are excluded for most of the countries. The latter are predominantly used by transnational corporations which channel investments indirectly through these countries, which however are not necessarily the ultimate beneficiaries (Zhan et al., 2014). Consequently, such investment flows are neither in line with the general purpose of FDI (i.e. cross-border investment with the objective of establishing a lasting interest which is evidenced with an ownership of at least $10 \%$ of the voting power of the direct investment enterprise (OECD, 2009)), nor do they contribute to employment creation and local value added. Therefore, including such investments in FDI statistics leads not only to double counting but also to misinterpretation of the actual origin/destination of FDI flows. While Eurostat acknowledges that 85-90\% of FDI in- and outflows for Luxembourg are due to the presence of SPEs, it does not provide for a time series which would be adjusted accordingly. Therefore we decided to exclude Luxembourg from our sample.

We also use the lagged level of the FDI $\left(F D I_{\mathrm{i}, \mathrm{t}-1}\right)$ as explanatory variable since we expect to find agglomeration or saturation effects. In line with this, a positive coefficient of the lagged dependent variable would reflect that investment in previous period attracts current investment inflows, while a negative coefficient would reflect negative externalities generated by saturation.

Bi-annual electricity price (EP) data is available from Eurostat, which classifies industrial consumers by annual consumption bands (Eurostat, 2014b). We use data reported for medium size industrial consumers. This choice is motivated by data availability considerations, but also by the fact that large industrial consumers often source electricity directly from the wholesale market and are subject to long term contracts. Therefore, differentials in retail electricity prices might not have a substantial impact on their investment choices and large industrial consumers are excluded from this analysis. However, there is a break in the electricity price series in the second semester 2007, when reporting was changed: we use the consumption band IC after 2007 (annual consumption between 500 and $2000 \mathrm{MWh}$ ) and standard consumers IE until 2007 (annual consumption of 2000 
MWh). Also, according to the old methodology prices valid on the first day of each semester were reported, while based on the new methodology average prices for each semester are reported. Accordingly, we use data as of 1st of January before 2007 and first semester averages after 2007, in Euro per kWh excluding VAT and other recoverable taxes and levies. The availability of data before 2003 is insufficient, especially for eastern European accession countries. By taking 2003 as the initial year for estimation, we minimise the number of missing data points for electricity prices. Additionally, in order to reflect the heterogeneity of prices across countries, we split our sample into two sub-samples: north-east ( $E P \_N E$ ) and south-west ( $\left.E P_{-} S W\right)$. We classify countries (see Table A.1 in the Appendix) based on the variation of respective electricity prices overtime. The two sub-samples are characterised by different mean values - see descriptive statistics in Table 2.1.

Table 2.1: Summary statistics

\begin{tabular}{lccccc}
\hline Variable & Mean & Std. Dev. & Min. & Max. & N \\
\hline FDI & 1.396 & 5.364 & -22.71 & 28.75 & 293 \\
GDP_G & 1.838 & 3.973 & -17.7 & 11 & 297 \\
EP & 0.09 & 0.030 & 0.041 & 0.224 & 289 \\
EP_NE & 0.083 & 0.030 & 0.041 & 0.224 & 160 \\
EP_SW & 0.099 & 0.029 & 0.049 & 0.186 & 129 \\
ULC & 0.599 & 0.079 & 0.38 & 0.86 & 296 \\
EDU_SEC & 47.765 & 13.529 & 13.4 & 72.2 & 296 \\
GFCF & 3.152 & 1.153 & 0.700 & 6.8 & 297 \\
DEFL & 2.545 & 4.143 & -15.81 & 25.47 & 297 \\
DEFL_LO & 1.377 & 2.301 & -11.41 & 8.23 & 121 \\
DEFL_HI & 3.348 & 4.880 & -15.81 & 25.47 & 176 \\
EATR & 21.971 & 7.274 & 0 & 36.97 & 297 \\
TRANSP & 81.306 & 8.177 & 46.23 & 93.53 & 207 \\
EU & 0.906 & 0.293 & 0 & 1 & 297 \\
PROP_R & 30.606 & 19.83 & 5 & 70 & 297 \\
CORR_F & 38.212 & 19.302 & 1 & 74 & 297 \\
LAB_F & 38.486 & 14.094 & 0 & 69 & 243 \\
\hline
\end{tabular}

One can conclude that electricity prices in south-western countries tend to be higher than in north-eastern countries. For illustration, the three countries with the highest average electricity prices for the period examined are Italy, Cyprus and Malta, while the lowest average electricity prices are charged in Finland, Estonia and Bulgaria. In addition, the coefficients of variation (standard deviation divided by average) for retail electricity prices across the whole sample and the two sub-samples are illustrated in Figure 2.1. The latter illustrates that, despite the ongoing integration of the electricity market in Europe, electricity price dif- 
ferentials for medium size industrial consumers have been increasing over time. Our plot shows in the beginning convergence of retail prices until 2004 for southwest and north-east separately, similar to what was found for wholesale prices by Armstrong and Galli (2005); but the process does not continue, rather we see divergence until 2007 as found earlier by Zachmann (2008); and only partial or temporary convergence thereafter (see also de Menezes and Houllier (2016)). This ultimately highlights the importance of examining the impact of price variation on countries' international competitiveness in terms of attracting FDI. The variable used in our model is thus constructed by interacting the log of electricity prices with regional dummies. In line with the locational advantages as described within the OLI framework, we expect the sign of the coefficients for both regions to be negative.

Figure 2.1: Coefficients of variation for electricity prices in EU27 and its south-western and north-eastern sub-samples.

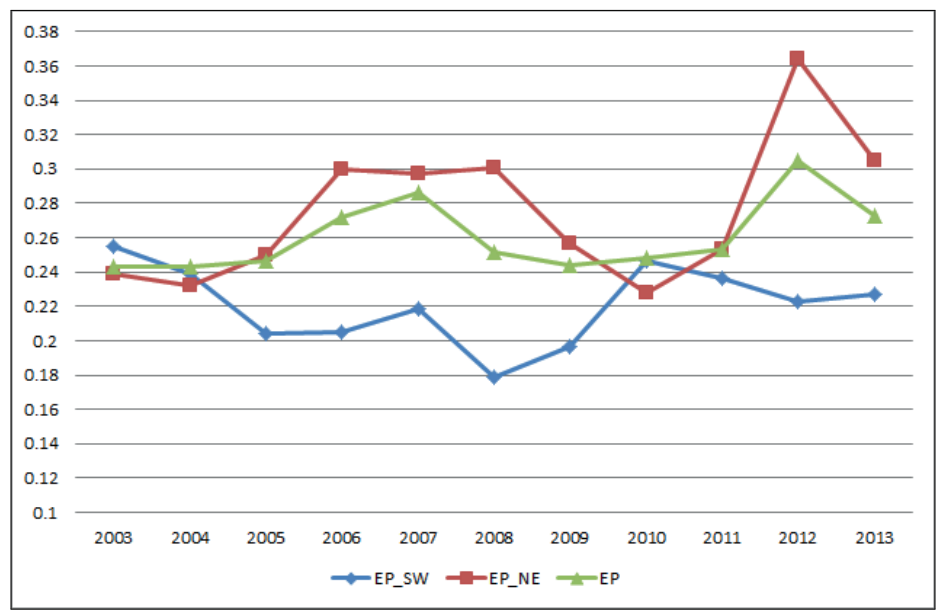

Source: Own calculations based on data collected from Eurostat (2014b).

We select the rest of determinants based on the theories of FDI reviewed in the previous section. Definitions of variables and sources are reported Table 2.2 below. From locational advantages we use real GDP growth $\left(G D P_{-} G\right)$ to proxy the growth of the market size and assume that this is to have a positive impact on investment inflow. Furthermore, we proxy countries' competitiveness by log of unit labour cost $(U L C)$, which we calculate as ratio of remuneration of employees to their labour productivity. We expect high unit labour costs to cause cost disadvantage to firms. Also, according to knowledge capital theory, differences in labour endowment are attractive for vertical FDI. Therefore, we use secondary 
education attainment (EDU_SEC) to proxy labour force skills. We expect these to affect FDI inflows with one period lag. A positive sign of the coefficient would mean that secondary education attracts investment which is intensive in this skill set, while a negative sign would point to the relative comparative disadvantage of the European labour force with secondary education.

In line with risk diversification literature, we consider a proxy of market risk. We do not include exchange rates since the fluctuation of currencies within the EU is rather small, due to the fact that most of the countries adopted the common currency. Instead, we include change in the index of GDP deflator (DEFL) in order to reflect the risk of inflation growth from the perspective of a producer. Again, there is a significant variation of inflation rates across countries and overtime. Since we foresee the impact of inflation in high and low inflation countries on FDI inflows to differ, we split the EU region into two sub-regions: countries with inflation growth rates of above $2 \%$ on average and over time are included in high inflation region ( $\left.D E F L_{-} H I\right)$, while those below this threshold are in low inflation region (DEFL_LO). Differences in standard deviations reported in Table 2.1 point to differences in inflation growth variation across the two sub-regions. The classification is reported in Table A.1. Keeping inflation growth levels low, countries send signals of credibility to investors. Therefore, stable inflation rates are expected to have positive impact on investment decisions. Yet, as discussed in Sayek (2009), while the effects of inflation rates are straightforward in case of horizontal FDI, in case of vertical FDI these depend on degree of substitutability between factors of production.

Finally, in terms of policy variables, we use gross fixed capital formation by general government $(G F C F)$ to proxy public investment in infrastructure and expect this to have a distributed effect over time. We assume a polynomial distributed lag of second order with lag length of four periods ( $t-1$ to $t-4)$. We expect the investment inflow to be increasing in the level of government expenditure. Furthermore, according to previous empirical studies, fiscal incentives prove important determinants of investment inflows. Lacking a reliable and widely available proxy for corporate taxes, we decided to use effective average tax rate (EATR) as collected by Taxation and Customs Union and Eurostat (2014). We expect that increasing tax rates deteriorate the investment climate.

In an extended analysis, we examine the influence of additional policy variables. The EU accession dummy (EU), which we use as proxy for trade barriers, reflects the changing composition of the EU based on countries' year of accession. We also include transport costs (TRANSP) which we proxy with the trading across borders indicator as collected within the Doing Business project (World 
Bank, 2014). The latter measures time and cost associated with exporting and importing a 20-foot container filled with goods. We are aware that this indicator is not perfect, due to some of the assumptions based on which it is constructed. Also, data is only available from 2006 onwards. The sign of both trade cost coefficients will depend on whether FDI inflows are vertical or horizontal. According to the proximity-concentration and factor-proportions hypothesis, high trade costs increase market-seeking FDI across similar economies, while low trade costs across countries with substantial differences in factor endowments induce efficiency-seeking FDI. We also make use of property rights, freedom from corruption and labour freedom indicators as constructed by Index of Economic Freedom (The Heritage Foundation, 2014). We assume that the degree to which countries' laws protect private property rights and to which their governments enforce those laws, along with corruption perception, and labour market flexibility, significantly influence FDI inflows. We expect all three of them to have a small yet positive impact on MNEs decision to enter the market. 
Table 2.2: Definition of variables

\begin{tabular}{|c|c|c|}
\hline Symbol & Description & Source \\
\hline \multicolumn{3}{|c|}{ Dependent Variable } \\
\hline FDI & $\begin{array}{l}\text { Net direct investment } \\
\text { inflow }\end{array}$ & $\begin{array}{l}\text { Net of FDI flows to EU from all countries of the world } \\
\text { adjusted by GDP at market prices: own calculations } \\
\text { based on dataset bop_fdi_main (Eurostat, 2014b) }\end{array}$ \\
\hline \multicolumn{3}{|c|}{ Independent Variables } \\
\hline GDP_G & Real GDP growth rate & $\begin{array}{l}\text { Percentage change on previous year in volumes (Eu- } \\
\text { rostat, 2014b) }\end{array}$ \\
\hline $\mathrm{EP}$ & Electricity prices & $\begin{array}{l}\text { In EUR per kWh excluding VAT and other recover- } \\
\text { able taxes and levies for medium sized enterprises - } \\
\text { bands IE and IC (Eurostat, 2014b) }\end{array}$ \\
\hline ULC & Unit labour cost & $\begin{array}{l}\text { Own calculations based on compensation of employ- } \\
\text { ees, employees domestic concept, GDP at market } \\
\text { prices in volumes, and total employment domestic } \\
\text { concept (Eurostat, 2014b) }\end{array}$ \\
\hline EDU_SEC & $\begin{array}{l}\text { Upper secondary } \\
\text { education attainment }\end{array}$ & $\begin{array}{l}\text { Upper secondary and post-secondary non-tertiary } \\
\text { education in } \% \text { of total population between } 15 \text { to } \\
64 \text { years (Eurostat, 2014b) }\end{array}$ \\
\hline GFCF & $\begin{array}{l}\text { Gross fixed capital } \\
\text { formation }\end{array}$ & For general government (Eurostat, 2014b) \\
\hline DEFL & Deflator growth rate & $\begin{array}{l}\text { Own calculations based on GDP at market prices in } \\
\text { EUR, price index, } 2005=100 \text { (Eurostat, 2014b) }\end{array}$ \\
\hline EATR & Effective average tax rates & $\begin{array}{l}\text { In } \% \text { for non-financial sector from Taxation and Cus- } \\
\text { toms Union and Eurostat }(2014)\end{array}$ \\
\hline TRANSP & Trading across borders & $\begin{array}{l}\text { Measured as distance to frontier (World Bank, 2014) } \\
\text { - values ranging from } 0 \text { to } 100\end{array}$ \\
\hline $\mathrm{EU}$ & EU accession dummy & $\begin{array}{l}\text { Dummy variable reflecting changing composition of } \\
\text { the EU }\end{array}$ \\
\hline PROP_R & Property rights & $\begin{array}{l}\text { Index of Economics Freedom (The Heritage Founda- } \\
\text { tion, 2014) - values ranging from } 0 \text { to 100: Ability to } \\
\text { accumulate private property }\end{array}$ \\
\hline CORR_F & Freedom from corruption & $\begin{array}{l}\text { Index of Economics Freedom (The Heritage Founda- } \\
\text { tion, 2014) - values ranging from } 0 \text { to } 100 \text { : Corrup- } \\
\text { tion perception index }\end{array}$ \\
\hline LAB_F & Labor freedom & $\begin{array}{l}\text { Index of Economics Freedom (The Heritage Foun- } \\
\text { dation, 2014) - values ranging from } 0 \text { to 100: Legal } \\
\text { framework of labour market }\end{array}$ \\
\hline \multicolumn{3}{|c|}{ Control Variables } \\
\hline $\begin{array}{l}\text { EP } \\
\text { Dummies }\end{array}$ & $\begin{array}{l}\text { South-west (SW) and north- } \\
\text { east (NE) }\end{array}$ & Regional classification based on variation in EP \\
\hline $\begin{array}{l}\text { DEFL } \\
\text { Dummies }\end{array}$ & $\begin{array}{l}\text { High inflation (HI) and Low } \\
\text { inflation (LO) }\end{array}$ & Regional classification based on variation in DEFL \\
\hline $\begin{array}{l}\text { Time } \\
\text { Dummies }\end{array}$ & $2003-2013$ & Year dummies \\
\hline
\end{tabular}




\subsection{Methods}

We use the one-step system GMM method to estimate our model. This method is particularly useful to deal with endogeneity and autocorrelation and allows obtaining consistent parameter estimates even with short time series. We estimate the following linear-log model:

$$
\begin{aligned}
F D I_{\mathrm{i}, \mathrm{t}} & =\alpha+\beta_{1} F D I_{\mathrm{i}, \mathrm{t}-1}+\beta_{2} X_{\mathrm{i}, \mathrm{t}-\mathrm{j}}+u_{\mathrm{i}, \mathrm{t}} \\
u_{\mathrm{i}, \mathrm{t}} & =\eta_{\mathrm{i}}+\lambda_{\mathrm{t}}+v_{\mathrm{i}, \mathrm{t}}
\end{aligned}
$$

where subscript $i$ denotes $i$ th country $(i=1, \ldots, N)$ and subscript $t$ denotes $t$ th year $(t=1, \ldots, T) . F D I_{\mathrm{i}, \mathrm{t}-1}$ is the dependent variable with one year lag and $X_{\mathrm{i}, \mathrm{t}-\mathrm{j}}$ is the vector $1 \times \mathrm{x}$ of current and lagged values of additional explanatory variables. The error term $u_{\mathrm{i}, \mathrm{t}}$ is made up of three components: the unobserved country specific effect $\eta_{\mathrm{i}}$, the year specific effect $\lambda_{\mathrm{t}}$, and the disturbance term $v_{\mathrm{i}, \mathrm{t}}$ assumed independent across countries. $\beta_{1}$ and $\beta_{2}$ are the parameters of interest.

Static panel estimation methods such as ordinary least squares (OLS) and fixed effects (FELS) are in general not suitable for estimation of models like ours since they do not allow understanding the autoregressive dynamics of the model. In fact, presence of the lagged dependent variable $F D I_{\mathrm{i}, \mathrm{t}-1}$ among explanatory variables causes autocorrelation of this regressor with the error term $u_{\mathrm{i}, \mathrm{t}}$ due to the presence of individual effects. The estimator $\beta_{1}$ is thus inconsistent and biased upwards when estimated by OLS, which pools all cross-sections together. When fixed effects are introduced, the inconsistency is eliminated by the demeaning process. While individual heterogeneity is wiped out, the estimator remains biased downwards since the transformation causes correlation between transformed lagged dependent variable and transformed error term (Baltagi, 2013). Nickell (1981) shows that this bias is of order $O(1 / T)$ as $N \rightarrow \infty$. Thus even with a small $T$ of 11 periods, this bias represents roughly $9 \%$. Additionally, if explanatory variables are correlated with lagged dependent variable, their coefficients tend to be biased as well.

A solution to this problem is to eliminate fixed effects by transformation. Anderson and Hsiao propose two stage least squares (2SLS), whereby they estimate the model by taking the first difference and then by instrumenting the dependent variable with two period lag (Bond, 2002). While this leads to consistent estimators for samples with large $N$ and small $T$, the estimators remain inefficient. Arellano and Bond (1991) develop differenced GMM estimators (GMMDIFF) based on orthogonality conditions between lagged dependent variable and the error term, where fixed effects are eliminated by first-differencing. The use of all available moment conditions allows obtaining asymptotically efficient estimators for samples 
with small $T$. Yet, it has been argued that lagged levels are weak instruments for first differences, especially when series are highly persistent. In line with this, Arellano and Bover (1995) outline additional moment conditions on equations in levels and Blundell and Bond (1998) fully develop an augmented version of difference GMM by adding level equations to get the system GMM estimator (GMMSYS). They show that using lagged differences as instruments for level equations in addition to lagged levels for equations in differences, reduces the finite sample bias and substantially increases the efficiency of system GMM estimators.

For the estimation of our model we use the system GMM method. Also, we identified the one-step GMM procedure to be most suitable due to the small number of countries in our sample. In fact, $N$ is somewhat small with 27 countries when compared to large cross-sections for which GMM method has originally been developed. Yet, in our model $N$ is still larger than $T$ and therefore GMM method is suitable to be applied. In his analysis of the validity of Blundell and Bond (1998) Monte Carlo simulation results with small number of cross-sections, Soto (2009) confirms that small $N$ does not seem to have important effects on properties of the GMM estimator. He also compares the one- and two-step distributions and concludes that there is almost no gain in efficiency from using the two-step estimator. Additionally, he arguments that one-step system GMM is more reliable in terms of power and error type - I. In line with this, we use one-step GMM for estimating our model.

Furthermore, we find in our specification that the only endogenous variable is the lagged dependent $F D I_{\mathrm{i}, \mathrm{t}-1}$. We also find that the log of unit labour cost is correlated with earlier shocks but not with the current error $u_{\mathrm{i}, \mathrm{t}}$. Hence we treat this as a predetermined variable. In fact, labour costs tend to be influenced by past but not by current values of investment flows in a country. We investigate the endogeneity formally with Durbin and Wu-Hausman tests which confirm that none of the remaining variables is endogenous. These variables are thus treated as exogenous to net FDI inflows. Since they are uncorrelated with either past or present errors, they can enter the instrument matrix in the conventional instrumental variables fashion. The endogenous and predetermined variables instead are instrumented with their respective lagged levels and lagged differences: lags $t$ - 2 and earlier are suitable instruments, provided that they are not correlated with the error term.

One of the main weaknesses of this estimation method is the instrument proliferation and the invalidity of instruments. The topic of instrument proliferation has been addressed by Roodman (2009b), who concludes that using too many instruments overfits endogenous variables and weakens the Hansen test of instruments' 
joint validity. He proposes two approaches to instrument containment: either using only certain lags instead of all available lags as a set of instruments, or collapsing instruments into smaller sets, what allows retaining more information since no lags are dropped. Also Okui (2009) is concerned about the number of valid moment conditions, which is of order $T^{2}$ and can become moderately large even with short $T$. He suggests using small number of moment conditions compared to the whole set available. This issue is even more pressing in case of small number of cross-sections, where number of moment conditions can easily exceed $N$ (Soto, 2009). In line with these suggestions, we combine the two approaches proposed, using the collapse option as specified in Stata command xtabond2 (Roodman, 2009a) with only the most relevant instruments. We limit the past realisation of the lagged dependent variable and only use $t$ - 2 to $t-5$ as instruments. Same for the predetermined unit labour cost where $t-1$ to $t-7$ are used as instruments. To check the robustness of the results we apply different lag lengths with and without collapse option and examine the behaviour of estimates, as well as Hansen and difference-in-Hansen test results for joint instrument validity.

The second line of qualifications is that of using weak instruments. This has been discussed in Bun and Windmeijer (2010) who point out that the Monte Carlo studies by Blundell and Bond (1998) were performed under the assumption that the variance of unobserved heterogeneity term is equal to the variance of idiosyncratic shocks. Yet it is often the case with country level panel data that series are persistent and variance of country effects is high relative to variance of transitory shocks. This may ultimately lead to weak instrument problem for system GMM estimator. In order to explore the strength of instruments in our model, we perform this diagnostic test in the next section along with the estimation results.

Finally, in order to rule out potential interdependencies between cross-sections due to presence of common shocks and unobserved components, we use Pesaran's cross-sectional dependence (CD) test which is suitable for panels with small $T$ and small $N$.

\subsection{Results}

We now present the results of estimation followed by robustness checks. Main estimation results are reported in Table 2.3. Extended results for additional policy variables are reported in Table 2.4. We estimate the model using the four standard estimation methods discussed above. Column (1) contains the estimation results from OLS where cross-sections are pooled together. In column (2) we use fixed 
effects to remove the individual heterogeneity. We then run Hausman specification test under the null hypothesis that there is no systematic difference in coefficients between fixed effects and random effects. We reject the null at $10 \%$ and conclude that fixed effects are present in our model. Subsequently, we eliminate these effects by difference and system GMM estimations, the results of which are reported in columns (3) and (4), respectively. Comparing the coefficients of lagged dependent variable across the four estimations, GMM coefficients fall inside the bounds of coefficients from OLS and FELS. The fact that the latter two are biased in opposite directions allows to conclude that GMM estimators are consistent. Furthermore, the system GMM estimator is more precise in estimating parameters than the difference GMM. Comparing standard errors across the two, we obtain a modest improvement in the precision of the parameter estimate by adding additional moment conditions for level equations.

The estimation results indicate that electricity prices have a negative effect on net FDI inflows as expected. While the immediate effect is relatively small, it is significant in both regions. Yet, it proves larger in the south-western region $\left(L O G_{-} E P_{-} S W\right)$ than in the north-eastern region ( $\left.L O G_{-} E P_{-} N E\right)$, with a $10 \%$ increase in electricity prices leading to a decrease in net FDI inflows by $0.41 \%$ and $0.33 \%$ as share of GDP in the short run, respectively. In the long run, the overall response of FDI inflows to electricity prices increases to $0.60 \%$ for south-western and to $0.48 \%$ for north-eastern regions.

As expected, the effect of unit labour costs $\left(L O G_{-} U L C\right)$ is substantially more pronounced than that of electricity prices, a $1 \%$ increase in unit labour cost causing a $0.12 \%$ decrease in net FDI inflows in the short run. We also observe a negative impact of taxes (EATR): one percentage point increase in effective average tax rate causes net investment inflow to decrease by $0.30 \%$. Lagged FDI (L1.FDI) and GDP growth $\left(G D P_{-} G\right)$ have about the same effect. Both investment inflow from the previous period and market growth have a positive effect, with one percentage point of increase in each inducing $0.32 \%$ increase in investment inflow. This result confirms the presence of agglomeration effects and the importance of the growth of the market size. For what concerns government spending ( $G F C F)$, coefficients reported within the Tables are those for polynomial distributed lags of second order. When recalculated, the real $\beta$ coefficients indicate a negative effect of spending of $-1.18 \%$ after one period lag, while FDI is increasing in the level of government spending after two, three and four period lags, with one percentage point increase in spending increasing FDI inflow by $0.93 \%, 1.02 \%$ and $0.09 \%$ respectively. This implies that after an initial negative impact of government spending, investment pays off in subsequent years, but its effect diminishes over time. 
Table 2.3: Comparison of estimates of FDI determinants across estimation methods

\begin{tabular}{|c|c|c|c|c|}
\hline & $\begin{array}{c}(1) \\
\text { OLS }\end{array}$ & $\begin{array}{c}(2) \\
\text { FELS }\end{array}$ & $\begin{array}{c}(3) \\
\text { GMMDIFF }\end{array}$ & $\begin{array}{c}(4) \\
\text { GMMSYS }\end{array}$ \\
\hline L1.FDI & $\begin{array}{l}0.362^{* * *} \\
(0.0881)\end{array}$ & $\begin{array}{c}0.187 \\
(0.143)\end{array}$ & $\begin{array}{c}0.234 \\
(0.178)\end{array}$ & $\begin{array}{c}0.320^{*} \\
(0.184)\end{array}$ \\
\hline GDP_G & $\begin{array}{l}0.281^{* * *} \\
(0.0907)\end{array}$ & $\begin{array}{l}0.263^{* *} \\
(0.115)\end{array}$ & $\begin{array}{c}0.288^{*} \\
(0.158)\end{array}$ & $\begin{array}{l}0.322^{* *} \\
(0.119)\end{array}$ \\
\hline LOG_EP_SW & $\begin{array}{c}-2.910^{* *} \\
(1.196)\end{array}$ & $\begin{array}{c}-0.264 \\
(4.435)\end{array}$ & $\begin{array}{r}-0.134 \\
(8.906)\end{array}$ & $\begin{array}{c}-4.045^{* *} \\
(1.846)\end{array}$ \\
\hline LOG_EP_NE & $\begin{array}{r}-2.247^{*} \\
(1.139)\end{array}$ & $\begin{array}{c}-4.391^{*} \\
(2.386)\end{array}$ & $\begin{array}{r}-6.098 \\
(5.686)\end{array}$ & $\begin{array}{r}-3.294^{*} \\
(1.708)\end{array}$ \\
\hline DEFL_HI & $\begin{array}{c}0.153^{* *} \\
(0.0710)\end{array}$ & $\begin{array}{c}0.151^{*} \\
(0.0847)\end{array}$ & $\begin{array}{c}0.147 \\
(0.100)\end{array}$ & $\begin{array}{c}0.196^{* *} \\
(0.0748)\end{array}$ \\
\hline $\mathrm{LOG}_{-} \mathrm{ULC}$ & $\begin{array}{c}-5.101 \\
(3.671)\end{array}$ & $\begin{array}{r}-16.77^{*} \\
(9.465)\end{array}$ & $\begin{array}{c}-18.74 \\
(15.16)\end{array}$ & $\begin{array}{r}-11.49^{*} \\
(6.060)\end{array}$ \\
\hline L1.EDU_SEC & $\begin{array}{c}-0.0444^{* *} \\
(0.0176)\end{array}$ & $\begin{array}{r}-0.885^{*} \\
(0.449)\end{array}$ & $\begin{array}{c}-0.870^{* *} \\
(0.385)\end{array}$ & $\begin{array}{c}-0.0532^{* *} \\
(0.0217)\end{array}$ \\
\hline EATR & $\begin{array}{c}-0.264^{* * *} \\
(0.0479)\end{array}$ & $\begin{array}{r}-0.121 \\
(0.145)\end{array}$ & $\begin{array}{c}-0.384^{* *} \\
(0.187)\end{array}$ & $\begin{array}{c}-0.296^{* * *} \\
(0.0673)\end{array}$ \\
\hline PDL0_GFCF & $\begin{array}{r}-1.162^{*} \\
(0.602)\end{array}$ & $\begin{array}{r}-1.176 \\
(0.760)\end{array}$ & $\begin{array}{c}-1.110 \\
(0.874)\end{array}$ & $\begin{array}{c}-1.176^{* *} \\
(0.551)\end{array}$ \\
\hline PDL1_GFCF & $\begin{array}{c}2.767^{* *} \\
(1.222)\end{array}$ & $\begin{array}{c}2.523 \\
(1.488)\end{array}$ & $\begin{array}{c}2.434 \\
(1.496)\end{array}$ & $\begin{array}{l}3.112^{* *} \\
(1.314)\end{array}$ \\
\hline PDL2_GFCF & $\begin{array}{c}-0.855^{* *} \\
(0.384)\end{array}$ & $\begin{array}{c}-0.819 \\
(0.507)\end{array}$ & $\begin{array}{c}-0.802 \\
(0.526)\end{array}$ & $\begin{array}{c}-1.006^{* *} \\
(0.449)\end{array}$ \\
\hline Observations & 188 & 188 & 161 & 188 \\
\hline Instruments & & & 27 & 30 \\
\hline R-sq & 0.445 & 0.535 & & \\
\hline $\operatorname{AR}(2)$ & & & 0.581 & 0.352 \\
\hline Hansen Test & & & 0.239 & 0.374 \\
\hline Difference-in-Hansen: & & & & \\
\hline GMM Instruments & & & & 0.476 \\
\hline Exogenous Variables & & & & 0.270 \\
\hline
\end{tabular}

Notes: Electricity prices and unit labour costs are expressed as logarithm, while all other variables are in ratios or percentages. All estimators are robust to heteroscedasticity and autocorrelation. We report one-step GMM estimators. $F D I_{\mathrm{i}, \mathrm{t}-1}$ is treated as endogenous and only its lags $t$-2 to $t-5$ are included in the instrument matrix. $U L C_{\mathrm{i}, \mathrm{t}}$ is predetermined and instrumented with lags $t-1$ to $t-7$. Collapse option is used. Time dummies are included in all regressions. Standard errors in parenthesis. Significance of p-values is reported as follows: ${ }^{*} p<.1{ }^{* *} p<.05$, ${ }^{* * *}$ $p<.01$. Pesaran cross-section independence CD test has $\mathrm{p}=0.44$.

Furthermore, the coefficient of secondary education (L1.EDU_SEC) is significant, yet very small and negative. This indicates a comparative disadvantage for the European labour force. Indeed, looking at the rates of secondary education at- 
tainment, these are very high relative to the rates of tertiary education attainment, especially for eastern European accession countries. This points to the fact that in order to attract more FDI, rather than high rates of low-skilled, high rates of highly skilled labour force might be required. This hypothesis is supported by the fact that during the past years inward and outward FDI was dominated by financial and insurance activities, which tend to be more high-skill intensive (Eurostat, 2015). In line with this, we also tried using tertiary education attainment rate its coefficient was again small, but positive and insignificant, while coefficients of the other variables remained unaffected.

Finally, we observe a positive and significant coefficient for GDP deflator in the high inflation level sub-region (DEFL_HI). This is rather counterintuitive in terms of the risk diversification literature, since higher inflation rates erode purchasing power of earnings and create distortions in net returns of investment. We hypothesise that the positive coefficient for deflator growth could be a business cycle indicator. Indeed, examining the data closely, the deflator turns out procyclical, as is FDI, increasing during expansion and decreasing during the period of financial crisis. The latter remains positive in the high inflation sub-region, while there is mostly negative net inflow within the low inflation sub-region. This in turn explains the negative, yet highly insignificant coefficient of GDP deflator in low inflation EU countries.

As part of robustness checks, we examine the variance inflation factors of coefficients in order to evaluate potential multicollinearity among variables. The inflation factor is much higher than the recommended value of 10 in case of interacted electricity price terms. This indicates that predictors are strongly correlated, what can also be seen in the correlation matrix in Appendix - Table A.2. To correct for this, we tried using the overall log of electricity prices and one regional interacted term only, instead of both. Rerunning the regression and computing the inflation factors anew, these have decreased substantially. Also the standard error of the interacted term has improved. Yet, there were no changes in terms of significances and magnitudes of the other coefficients.

Some of the diagnostic test results are reported in the lower part of the Table 2.3. GMM estimator requires that there is first-order serial correlation but no second-order autocorrelation in errors terms (Arellano and Bond, 1991). Both difference and system GMM pass the test of first- and second-order serial correlation in disturbances. As the number of moment conditions increases, the Hansen test of joint validity of instruments is performed in order to test the over-identification restrictions. We cannot reject the null hypothesis of correct model specification and validity of instruments. Next, we consider the test of validity for subsets of in- 
struments. The p-values of difference-in-Hansen tests for both instrument subsets of GMM and IV instruments do not allow us to reject their validity. Therefore, we conclude that instruments satisfy the orthogonality condition and can be included in our model. Finally, based on the results of Pesaran's CD test we cannot reject the null hypothesis of cross-sectional independence ( $p$-value of 0.44 ).

We verify the strength of instruments by computing the variance ratio as discussed in Bun and Windmeijer (2010). The authors warn against the weak instrument problem when the variance of the individual heterogeneity is larger than the variance of idiosyncratic shocks. In our case the variance ratio is very small at 0.15 . While this is substantially below the Blundell and Bond (1998) assumption of 1 , according to the Monte Carlo results by Bun and Windmeijer (2010) the absolute bias for a variance factor of this magnitude is relatively small, especially for highly persistent series. Considering this result, it is hard to see why our instruments should be weak.

In the next step we extend our analysis by including policy variables. Due to multicollinearity issues we add them one by one. Results based on one-step system GMM are reported in Table 2.4. This exercise serves at the same time as sensitivity analysis. In fact, when introducing additional variables, main regression results from Table 2.3 remain unaltered. We find that coefficients for property rights $\left(P R O P_{-} R\right)$ and freedom from corruption $\left(C O R R_{-} F\right)$ are both significant. In fact, rule of law seems to affect investment inflows positively, a 10 units increase in the ability to accumulate private property increases net FDI inflow by $0.36 \%$ as share of GDP, while the impact of corruption perception index is somewhat stronger at $0.46 \%$ of FDI inflow as share of GDP. Contrary to this, the regulatory framework of a country's labour market $\left(L A B_{-} F\right)$ is insignificant with a p-value of 0.20 , yet positive.

Last but not least, we add the EU accession dummy (EU) which is a proxy of barriers to trade. Its coefficient is negative but not significant with a p-value of 0.11 . We interpret the negative sign of trade liberalisation as follows: prior to countries' accession to the EU, FDI was mainly market-seeking, whereby MNEs preferred to open plants in these countries to avoid trade costs. With the accession to the EU, trade barriers were removed and MNEs might have shut down the plants in these countries. We thus hypothesise that MNEs within the EU might now be more vertically integrated. Furthermore, the coefficient of transport costs is also negative and significant (TRANSP), a 10 units increase in the indicator of transport costs decreases net FDI inflow as share of GDP by $1.20 \%$. Unfortunately, the use of aggregate data does not allow us to conclude on the dominance of either vertical or horizontal FDI across the EU countries. Note also that adding transport 
costs in the model absorbs the distance and causes the agglomeration effect to turn insignificant with a p-value of 0.24 , while the coefficient of unit labour cost increases substantially and all other coefficients remain stable.

Here again, tests of first- and second-order serial correlation yield the expected diagnostics. Both Hansen and difference- in-Hansen tests do not reject the overidentification conditions and confirm the validity on instrument sets and subsets. Similarly, the results of Pesaran's CD test do not reject the presence of crosssectional independence. 
Table 2.4: Policy variables as FDI determinants

\begin{tabular}{|c|c|c|c|c|c|}
\hline & (1) & $(2)$ & (3) & (4) & (5) \\
\hline \multirow[t]{2}{*}{ L1.FDI } & $0.339^{*}$ & $0.336^{*}$ & $0.318^{*}$ & $0.316^{*}$ & 0.242 \\
\hline & $(0.181)$ & $(0.174)$ & $(0.185)$ & $(0.185)$ & $(0.201)$ \\
\hline \multirow[t]{2}{*}{ GDP_G } & $0.319^{* *}$ & $0.318^{* *}$ & $0.331^{* * *}$ & $0.332^{* *}$ & $0.324^{* *}$ \\
\hline & $(0.119)$ & $(0.117)$ & $(0.118)$ & $(0.122)$ & $(0.132)$ \\
\hline \multirow[t]{2}{*}{ LOG_EP_SW } & $-4.061^{* *}$ & $-4.550^{* *}$ & $-3.903^{* *}$ & $-4.002^{* *}$ & $-4.706^{* *}$ \\
\hline & $(1.692)$ & $(1.812)$ & $(1.857)$ & $(1.845)$ & $(2.116)$ \\
\hline \multirow[t]{2}{*}{ LOG_EP_NE } & $-3.366^{* *}$ & $-3.990^{* *}$ & $-3.139^{*}$ & $-3.212^{*}$ & $-3.945^{* *}$ \\
\hline & $(1.537)$ & $(1.669)$ & $(1.702)$ & (1.697) & $(1.899)$ \\
\hline \multirow[t]{2}{*}{ DEFL_HI } & $0.183^{* *}$ & $0.171^{* *}$ & $0.195^{* *}$ & $0.195^{* *}$ & $0.191^{* *}$ \\
\hline & $(0.0708)$ & $(0.0715)$ & $(0.0739)$ & $(0.0748)$ & $(0.0773)$ \\
\hline \multirow[t]{2}{*}{ LOG_ULC } & -11.24 & $-11.68^{*}$ & $-11.22^{*}$ & $-11.47^{*}$ & $-15.08^{*}$ \\
\hline & $(6.847)$ & $(6.781)$ & $(5.974)$ & $(6.084)$ & $(8.274)$ \\
\hline \multirow[t]{2}{*}{ L1.EDU_SEC } & $-0.0646^{* *}$ & $-0.0681^{* *}$ & $-0.0530^{* *}$ & $-0.0560^{* *}$ & $-0.0830^{* *}$ \\
\hline & $(0.0282)$ & $(0.0309)$ & $(0.0228)$ & $(0.0224)$ & $(0.0350)$ \\
\hline \multirow[t]{2}{*}{ EATR } & $-0.273^{* * *}$ & $-0.256^{* * *}$ & $-0.315^{* * *}$ & $-0.299^{* * *}$ & $-0.349^{* * *}$ \\
\hline & $(0.0712)$ & $(0.0624)$ & $(0.0685)$ & $(0.0677)$ & $(0.0962)$ \\
\hline \multirow[t]{2}{*}{ PDL0_GFCF } & $-1.267^{* *}$ & $-1.270^{* *}$ & $-1.217^{* *}$ & $-1.132^{*}$ & $-0.944^{*}$ \\
\hline & $(0.566)$ & $(0.543)$ & $(0.553)$ & $(0.558)$ & $(0.540)$ \\
\hline \multirow[t]{2}{*}{ PDL1_GFCF } & $3.161^{* *}$ & $3.173^{* *}$ & $3.183^{* *}$ & $3.071^{* *}$ & $2.624^{* *}$ \\
\hline & $(1.352)$ & $(1.335)$ & $(1.323)$ & $(1.317)$ & $(1.239)$ \\
\hline \multirow[t]{2}{*}{ PDL2_GFCF } & $-1.017^{* *}$ & $-1.030^{* *}$ & $-1.030^{* *}$ & $-1.001^{* *}$ & $-0.871^{* *}$ \\
\hline & $(0.461)$ & $(0.459)$ & $(0.452)$ & $(0.450)$ & $(0.413)$ \\
\hline \multirow[t]{2}{*}{ PROP_R } & $0.0361^{*}$ & & & & \\
\hline & $(0.0185)$ & & & & \\
\hline \multirow[t]{2}{*}{ CORR_F } & & $0.0460^{*}$ & & & \\
\hline & & $(0.0255)$ & & & \\
\hline \multirow[t]{2}{*}{ LAB_F } & & & 0.0214 & & \\
\hline & & & $(0.0164)$ & & \\
\hline \multirow[t]{2}{*}{$\mathrm{EU}$} & & & & -1.419 & \\
\hline & & & & $(0.850)$ & \\
\hline \multirow[t]{2}{*}{ TRANSP } & & & & & $-0.120^{*}$ \\
\hline & & & & & $(0.0608)$ \\
\hline Observations & 188 & 188 & 188 & 188 & 181 \\
\hline Instruments & 31 & 31 & 31 & 31 & 31 \\
\hline $\operatorname{AR}(2)$ & 0.305 & 0.318 & 0.356 & 0.355 & 0.946 \\
\hline Hansen Test & 0.187 & 0.493 & 0.390 & 0.405 & 0.288 \\
\hline \multicolumn{6}{|l|}{ Difference-in-Hansen: } \\
\hline GMM Instruments & 0.142 & 0.246 & 0.544 & 0.424 & 0.179 \\
\hline Exogenous Variables & 0.156 & 0.409 & 0.355 & 0.258 & 0.253 \\
\hline Pesaran CD Test & 0.446 & 0.448 & 0.444 & 0.440 & $\dagger$ \\
\hline
\end{tabular}

Notes: Electricity prices and unit labour costs are expressed as logarithm, while all other variables are in ratios or percentages. All estimators are robust to heteroscedasticity and autocorrelation. We report one-step GMM estimators. $F D I_{\mathrm{i}, \mathrm{t}-1}$ is treated as endogenous and only its lags $t$-2 to $t-5$ are included in the instrument matrix. $U L C_{\mathrm{i}, \mathrm{t}}$ is predetermined and instrumented with lags $t$ - 1 to $t$ - $\%$. Collapse option is used. Time dummies are included in all regressions. Standard errors in parenthesis. Significance of p-values is reported as follows: ${ }^{*} p<.1$, ${ }^{* *} p<.05$, *** $p<.01$. †Not enough common observations to perform Pesaran's test. 


\subsection{Conclusions}

In this chapter we have examined the effect of electricity prices on net foreign direct investment inflows within a formal framework of FDI analysis after having shown that electricity prices in the EU do not converge. To our knowledge, no other study has attempted to quantify the effects of electricity prices as a locational determinant of FDI for a panel of countries so far. Therefore, our main contribution is to fill this gap in the literature. The main findings of the chapter confirm that besides tax rates, unit labour costs and competitive disadvantage in secondary education, also electricity prices contribute to eroding net FDI inflows of the EU countries. While the immediate effect is relatively small, it is significant in both sub-regions, though it does not seem to be uniform. In fact, south-western countries tend to be more adversely affected than north-eastern, both in the short and long run. Higher electricity prices in the former seem to be driven mainly by increasing network costs and non-recoverable electricity tax rates (European Commission, 2012). This increase in non-market electricity price components reflects additional costs of primary fossil fuels due to emission trading schemes, as well as costs incurred by diversification of energy sources towards low-carbon technologies.

The fear of losing competitiveness due to charging higher consumer prices has already been addressed by national policies granting tax exemptions and reductions at industry levels. However, this burden is ultimately borne by households and policy makers should be cautious about overburdening these. Rather than shifting the price increase on end-consumers, policies should aim at fostering energy efficiency improvements on the one hand, and reducing price differences on European level on the other, in order to mitigate the effect of electricity prices on locational choices for investment. Should electricity price differentials continue to persist, they might lead to alteration of the global pattern of investment, production and trade. To conclude with, we neither suggest to forbid electricity price differentials across countries nor do we advocate that countries should strive for achieving a common price. We acknowledge that competition among countries based on factor cost differentials is healthy. Instead, the aim of this chapter is to demonstrate empirically that the fear for leakages through capital movements in countries with higher industrial electricity prices is justified, and in line with the earlier claims by Merrifield (1988) and McGuire (1982) who noted that environmental regulation, through its effects on unit costs, may induce capital movements to countries with less strict regulations.

Limitations of this study stem from the limitations of the data used. Electricity prices are not perfectly comparable across countries due to various tax 
exemptions at country, industry and large industrial consumers levels which are not reflected in the data (European Commission, 2014a; Eurostat, 2014b). Furthermore, this analysis considered prices for medium size industrial users. The impact of electricity prices for large companies might be smaller in that these often source electricity directly from the wholesale market, are subject to long term contracts, and might be further exempted from certain network charges, taxes and levies. Consequently, the impact of electricity prices on FDI inflows by these are likely to be overestimated.

Further research might extend this analysis to individual economic activities. For example, it might be interesting to isolate the effect of prices on manufacturing as compared to services, where cost of electricity might be less important (OECD, 2001). This however also calls for better data coverage, especially for energyintensive industries for which electricity price data is currently very limited. 


\section{Bibliography}

Aizenman, J. (1992). Exchange rate flexibility, volatility, and the patterns of domestic and foreign direct investment. Working Paper 3953, National Bureau of Economic Research. Available from http://www.nber.org/papers/w3953.

Aizenman, J. (1994). Monetary and real shocks, productive capacity and exchange rate regimes. Economica, pages 407-434.

Aizenman, J. and Marion, N. (2004). The merits of horizontal versus vertical FDI in the presence of uncertainty. Journal of International economics, 62(1):125-148.

Arellano, M. and Bond, S. (1991). Some tests of specification for panel data: Monte Carlo evidence and an application to employment equations. The Review of Economic Studies, 58(2):277-297.

Arellano, M. and Bover, O. (1995). Another look at the instrumental variable estimation of error-components models. Journal of Econometrics, 68(1):29-51.

Armstrong, M. and Galli, A. (2005). Are day-ahead prices for electricity converging in continental Europe? An exploratory data approach. Working Paper 395, Centre d'Economie Industrielle (CERNA).

Baltagi, B. H. (2013). Econometric Analysis of Panel Data. Wiley, Chichester [etc.].

Bilgili, F., Tülüce, N. S. H., and Doğan, İ. (2012). The determinants of FDI in Turkey: A Markov regime-switching approach. Economic Modelling, 29(4):1161-1169.

Blundell, R. and Bond, S. (1998). Initial conditions and moment restrictions in dynamic panel data models. Journal of Econometrics, 87(1):115-143.

Bond, S. R. (2002). Dynamic panel data models: A guide to micro data methods and practice. Portuguese Economic Journal, 1(2):141-162.

Brainard, S. L. (1993). A simple theory of multinational corporations and trade with a trade-off between proximity and concentration. Working Paper 4269, National Bureau of Economic Research. Available from http://www.nber.org/papers/w4269.

Branger, F. and Quirion, P. (2014). Climate policy and the 'carbon haven' effect. Wiley Interdisciplinary Reviews: Climate Change, 5(1):53-71.

Bun, M. J. and Windmeijer, F. (2010). The weak instrument problem of the system GMM estimator in dynamic panel data models. The Econometrics Journal, 13(1):95-126.

Burniaux, J.-M. and Oliveira Martins, J. (2000). Carbon emission leakages: A general equilibrium view. Working Paper 242, OECD Economics Department.

Carr, D. L., Markusen, J. R., and Maskus, K. E. (1998). Estimating the knowledge-capital model of the multinational enterprise. Working Paper 6773, National Bureau of Economic Research. Available from http://www.nber.org/papers/w6773.

de Menezes, L. M. and Houllier, M. A. (2016). Reassessing the integration of European electricity markets: A fractional cointegration analysis. Energy Economics, 53:132-150. 
Dunning, J. H. (1988). Trade, location and economic activity and the multinational enterprise: A search for an eclectic approach. In Dunning, J. H., editor, Explaining International Production, pages 13-40. Unwin Hyman, London.

Ethier, W. J. and Horn, H. (1990). Managerial control of international firms and patterns of direct investment. Journal of international Economics, 28(1):25-45.

European Central Bank (2014a). Frequently asked questions (FAQs) on the introduction of BPM6. Available from https://www.ecb.europa.eu/stats/external/bpm6/html/BPM6-faqECB.pdf?dad2e270978bb6eb8393bbefd94c7dc7. Accessed: 04-11-2014.

European Central Bank (2014b). Implementing the new balance of payments and international investment position manual (BPM6). Available from https://www.ecb.europa.eu/stats/ external/bpm6/html/index.en.html. Accessed: 04-11-2014.

European Commission (2012). European competitiveness report 2012 - Reaping the benefits of globalization. Commission Staff Working Document SWD(2012) 299 final, European Commission. Available from http://ec.europa.eu/enterprise/policies/industrial-competitiveness/ competitiveness-analysis/european-competitiveness-report/files/ecr2012_full_en.pdf.

European Commission (2014a). Energy prices and costs report. Commission Staff Working Document SWD(2014) 20 final/2, European Commission. Available from http://ec.europa. eu/energy/sites/ener/files/documents/20140122_swd_prices.pdf.

European Commission (2014b). For a European industrial renaissance. Communication from the Commission to the European Parliament, the Council, the European Economic and Social Committee and the Committee of the Regions COM 14 final, European Commission. Available from http://eur-lex.europa.eu/legal-content/EN/ALL/?uri=CELEX:52014DC0014.

European Commission (2014c). Helping firms grow: European competitiveness report 2014. Commission Staff Working Document SWD(2014)277 final, European Commission. Available from http://ec.europa.eu/enterprise/policies/industrial-competitiveness/ competitiveness-analysis/european-competitiveness-report/index_en.htm.

European Commission (2014d). A policy framework for climate and energy in the period from 2020 to 2030. Communication from the Commission to the European Parliament, the Council, the European Economic and Social Committee and the Committee of the Regions COM(2014) 15 final, European Commission. Available from http://ec.europa.eu/smartregulation/impact/ia_carried_out/docs/ia_2014/swd_2014_0015_en.pdf.

Eurostat (2014a). Changes in the methodology and classifications of the balance of payments and the international investment position statistics. Available from http://epp.eurostat.ec.europa.eu/portal/page/portal/balance_of_payments/documents/ Changes-introduced-BPM6-methodology.pdf. Accessed: 04-11-2014.

Eurostat (2014b). Eurostat Database. Available from http://epp.eurostat.ec.europa.eu/portal/ page/portal/eurostat/home. Accessed: 23-07-2014.

Eurostat (2015). Foreign direct investment statistics. Available from http://ec.europa.eu/ eurostat/statistics-explained/index.php/Foreign_direct_investment_statistics \#Continued_ dominance_of_financial_services. Accessed: 30-04-2015. 
Faeth, I. (2009). Determinants of foreign direct investment - A tale of nine theoretical models. Journal of Economic Surveys, 23(1):165-196.

Gerlagh, R. and Mathys, N. A. (2011). Energy abundance, trade and industry location. Working Paper 03.2011, Fondazione Eni Enrico Mattei. Available from http://www.etsg.org/ ETSG2010/papers/gerlagh\%20and\%20mathys.pdf.

Goldberg, L. S. and Kolstad, C. D. (1995). Foreign direct investment, exchange rate variability and demand uncertainty. International Economic Review, 36(4):pp. 855-873.

Helpman, E. (1983). The multiproduct firm: Horizontal and vertical integration. Working Paper 335, Massachusetts Institute of Technology (MIT), Department of Economics. Available from https://ia700606.us.archive.org/24/items/multiproductfirm00help/ multiproductfirm00help.pdf.

Helpman, E. (1984). A simple theory of international trade with multinational corporations. The Journal of Political Economy, pages 451-471.

Helpman, E. (1985). Multinational corporations and trade structure. The Review of Economic Studies, 52(3):443-457.

Horstmann, I. J. and Markusen, J. R. (1987). Strategic investments and the development of multinationals. International Economic Review, pages 109-121.

Horstmann, I. J. and Markusen, J. R. (1992). Endogenous market structures in international trade (natura facit saltum). Journal of international Economics, 32(1):109-129.

Levinson, A. (2008). Pollution haven hypothesis. In Blume, L. E. and Durlauf, S. N., editors, New Palgrave Dictionary of Economics. Palgrave Macmillan.

Levinson, A. and Taylor, M. S. (2008). Unmasking the pollution haven effect. International Economic Review, 49(1):223-254.

Markusen, J. R. (1984). Multinationals, multi-plant economies, and the gains from trade. Journal of international economics, 16(3):205-226.

Markusen, J. R. (1997). Trade versus investment liberalization. Working Paper 6231, National Bureau of Economic Research. Available from http://www.nber.org/papers/w6231.

Markusen, J. R., Venables, A. J., Konan, D. E., and Zhang, K. H. (1996). A unified treatment of horizontal direct investment, vertical direct investment, and the pattern of trade in goods and services. Working Paper 5696, National Bureau of Economic Research. Available from http://www.nber.org/papers/w5696.

McGuire, M. C. (1982). Regulation, factor rewards, and international trade. Journal of Public Economics, 17(3):335-354.

Merrifield, J. D. (1988). The impact of selected abatement strategies on transnational pollution, the terms of trade, and factor rewards: A general equilibrium approach. Journal of Environmental Economics and Management, 15(3):259-284.

Nickell, S. (1981). Biases in dynamic models with fixed effects. Econometrica: Journal of the Econometric Society, pages 1417-1426. 
OECD (2001). Sustainable Development: Critical Issues. OECD Publishing.

OECD (2009). OECD Benchmark Definition of Foreign Direct Investment 2008. OECD Publishing.

Ohlin, B. (1967). Interregional and International Trade, volume 39. Harvard University Press, Cambridge, MA.

Okui, R. (2009). The optimal choice of moments in dynamic panel data models. Journal of Econometrics, 151(1):1-16.

Rauscher, M. (2005). International trade, foreign investment, and the environment. In Mäler, K.-G. and Vincent, J. R., editors, Handbook of Environmental Economics, pages 1403-1456. Elsevier North-Holland.

Roodman, D. (2009a). How to do xtabond2: An introduction to difference and system GMM in stata. The Stata Journal, 9(1):86-136.

Roodman, D. (2009b). A note on the theme of too many instruments. Oxford Bulletin of Economics and Statistics, 71(1):135-158.

Rugman, A. M. (1975). Motives for foreign investment: The market imperfections and risk diversification hypotheses. Journal of World Trade, 9(5):567-573.

Rugman, A. M. (1976). Risk reduction by international diversification. Journal of International Business Studies, pages 75-80.

Russ, K. N. (2007). The endogeneity of the exchange rate as a determinant of FDI: A model of entry and multinational firms. Journal of International Economics, 71(2):344-372.

Sato, M. and Dechezleprêtre, A. (2015). Asymmetric industrial energy prices and international trade. Working Paper 178, Grantham Research Institute on Climate Change and the Environment. Available from http://www.lse.ac.uk/GranthamInstitute/wp-content/uploads/2015/ 02/Working-Paper-178-Sato-and-Dechezlepretre.pdf.

Sayek, S. (2009). Foreign direct investment and inflation. Southern Economic Journal, pages 419-443.

Soto, M. (2009). System GMM estimation with a small sample. Working Paper 395, Barcelona Graduate School of Economics. Available from http://research.barcelonagse.eu/tmp/workingpapers/395.pdf.

Spiegel, M. M. (1994). Sovereign risk exposure with potential liquidation: The performance of alternative forms of external finance. Journal of international money and finance, 13(4):400414 .

Sturm, D. M. (2003). Trade and the environment: A survey of the literature. In Marsiliani, L., Rauscher, M., and Withagen, C., editors, Environmental Policy in an International Perspective, pages 119-149. Kluwer Academic Publishers.

Taxation and Customs Union and Eurostat (2014). Taxation trends in the European Union: Data for the EU Member States, Iceland and Norway. Technical report, European Commission. Available from http://ec.europa.eu/taxation_customs/resources/documents/taxation/ gen_info/economic_analysis/tax_structures/2014/report.pdf. 
The Heritage Foundation (2014). Index of Economic Freedom Database. Available from http: //www.heritage.org/index/. Accessed: 23-08-2014.

Vetter, S. (2014). Recent trends in FDI activity in Europe - Regaining lost ground to accelerate growth. Technical report, Deutsche Bank Research. Available from https: //www.dbresearch.com/PROD/DBR_INTERNET_EN-PROD/PROD0000000000340841/ Recent+trends+in+FDI+activity+in+Europe $\% 3 \mathrm{~A}+$ Regaining.pdf.

World Bank (2014). Doing Business - Trading Across Borders Database. Available from http: //www.doingbusiness.org/data/exploretopics/trading-across-borders. Accessed: 23-08-2014.

Zachmann, G. (2008). Electricity wholesale market prices in Europe: Convergence? Energy Economics, 30(4):1659-1671.

Zhan, J., Bolwijn, R., Casella, B., Clements, J., El Kady, H., Endo, K., Fujita, M., Nebra, N. G., van Giffen, T., Giroud, A., Karl, J., Liang, G., and Miller, A. e. a. (2014). World investment report 2014. Technical report, UNCTAD. Available from http://unctad.org/en/ pages/PublicationWebflyer.aspx?publicationid=937. 


\section{Appendix A}

Table A.1: Classification of countries into sub-regions

\begin{tabular}{|c|c|c|c|c|}
\hline Region Country & North-East & South-West & Low Inflation & High Inflation \\
\hline Austria & & $\mathrm{x}$ & $\mathrm{x}$ & \\
\hline Belgium & & $\mathrm{x}$ & & $\mathrm{x}$ \\
\hline Bulgaria & $\mathrm{x}$ & & & $\mathrm{x}$ \\
\hline Croatia & $\mathrm{x}$ & & & $\mathrm{x}$ \\
\hline Cyprus & $\mathrm{x}$ & & & $\mathrm{x}$ \\
\hline Czech Republic & & $\mathrm{x}$ & & $\mathrm{x}$ \\
\hline Denmark & $\mathrm{x}$ & & & $\mathrm{x}$ \\
\hline Estonia & $\mathrm{x}$ & & & $\mathrm{x}$ \\
\hline Finland & $\mathrm{x}$ & & $\mathrm{x}$ & \\
\hline France & & $\mathrm{x}$ & $\mathrm{x}$ & \\
\hline Germany & & $\mathrm{x}$ & $\mathrm{x}$ & \\
\hline Greece & & $\mathrm{x}$ & $\mathrm{x}$ & \\
\hline Hungary & $\mathrm{x}$ & & & $\mathrm{x}$ \\
\hline Ireland & $\mathrm{x}$ & & $\mathrm{x}$ & \\
\hline Italy & & $\mathrm{x}$ & $\mathrm{x}$ & \\
\hline Latvia & $\mathrm{x}$ & & & $\mathrm{x}$ \\
\hline Lithuania & $\mathrm{x}$ & & & $\mathrm{x}$ \\
\hline Malta & & $\mathrm{x}$ & & $\mathrm{x}$ \\
\hline Netherlands & & $\mathrm{x}$ & $\mathrm{x}$ & \\
\hline Poland & $\mathrm{x}$ & & & $\mathrm{x}$ \\
\hline Portugal & & $\mathrm{x}$ & $\mathrm{x}$ & \\
\hline Romania & $\mathrm{x}$ & & & $\mathrm{x}$ \\
\hline Slovakia & $\mathrm{x}$ & & & $\mathrm{x}$ \\
\hline Slovenia & $\mathrm{x}$ & & $\mathrm{x}$ & \\
\hline Spain & & $\mathrm{x}$ & & $\mathrm{x}$ \\
\hline Sweden & $\mathrm{x}$ & & & $\mathrm{x}$ \\
\hline United Kingdom & & $\mathrm{x}$ & $\mathrm{x}$ & \\
\hline Luxembourg & & excludec & from sample & \\
\hline
\end{tabular}




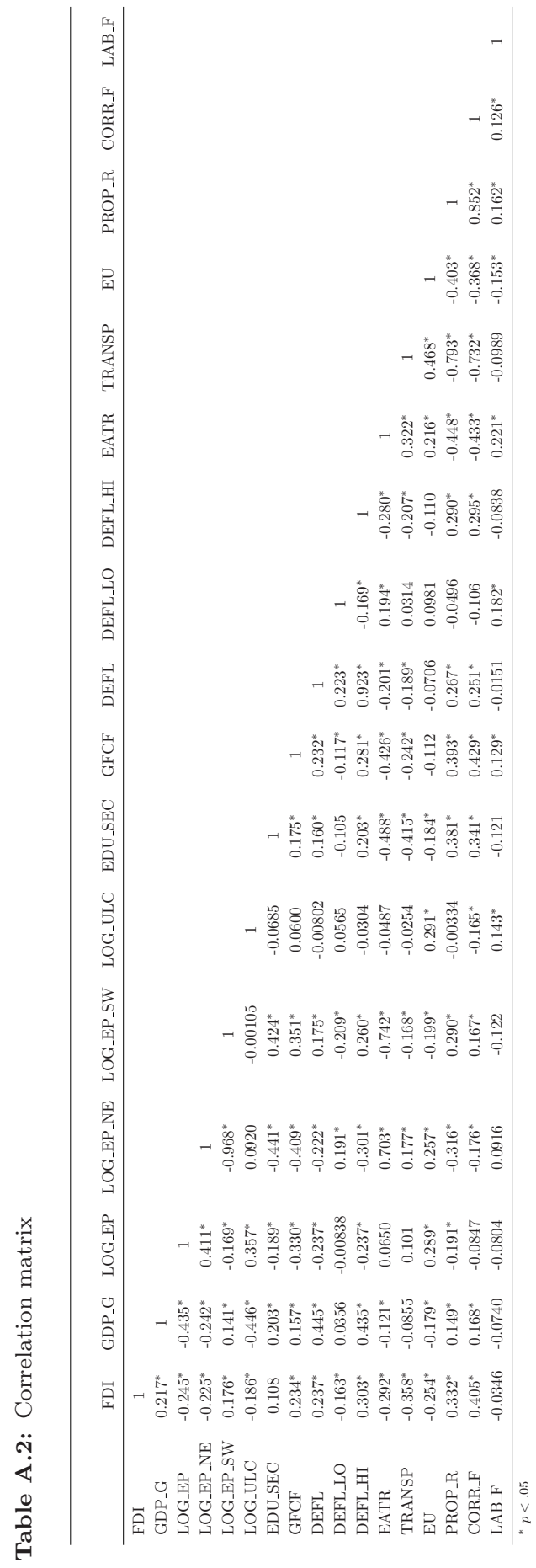




\title{
3 Which low-carbon technologies are subject to supply risks? An inquiry into the economics of rare earths and its implications for innovation*
}

\begin{abstract}
Considering the quest for alternative energy and transportation modes and their importance for low-carbon growth, this chapter examines the supply risk of rare earths and to what extent this poses a barrier to the increased adoption and innovation of low-carbon technologies. Bringing together seemingly disconnected strands of scientific literature, the multidisciplinary approach provides an overarching overview of the economics of rare earths. In terms of supply risk, as opposed to the common belief, it is not China's dominant position per se, but its industrial policies which distort the rare earth market. On the demand side, the results of this chapter disprove the widespread allegation that availability risk impedes deployment of offshore wind altogether. However, a potential supply shortage of rare earths could lead to the disruption of electrification of the automotive industry. Ultimately, uncertainty about volatile prices and threat of supply shortages will induce manufacturers to innovate in less rare earth-intensive topologies, which are however often inferior in terms of their performance and energy efficiencies.
\end{abstract}

Keywords: rare earths, supply risk, wind turbines, advanced technology vehicles, innovation, social costs

JEL classification: L11, L72, O31, Q31, Q34, Q37, Q42, Q53

* This chapter is based on Barteková, E., 2014. An Introduction to the Economics of Rare Earths. UNU-MERIT Working Paper 2014-043, United Nations University - MERIT. Section 3.4 has been published as a book chapter: Barteková, E., 2015. The Role of Rare Earth Supply Risk in Low-Carbon Technology Innovation, in: Borges de Lima, I. and Leal Filho, W. (eds), Rare Earths Industry: Technological, Economic and Environmental Implications (pp. 153-169). Elsevier, Amsterdam, Netherlands. 


\subsection{Introduction}

Within the past couple of years, growing concerns about massively skewed world production and supply of rare earths have emerged in the specific context of lowcarbon technologies. This chapter analyses to what extent the risk of supply disruption constitutes a threat to the deployment of these technologies and how it induces their innovation.

Rare earths constitute a group of 17 chemical elements. As opposed to what the name suggests, they are neither rare nor earths. In fact, they are fairly abundant metals, though they seldom occur in large enough concentrations to make their mining and processing economically viable. According to Humphries (2013), almost $97 \%$ of global rare earth supplies and $50 \%$ of world reserves are owned by China. In line with this, it is often claimed that their geographical concentration poses a potential threat for their future supply. Coupled with this, China's active industrial policies such as export quotas, strategic pricing and consolidation of the industry, exacerbate further the market inefficiencies. As a response to these, projects outside China have been recently taking off: resumption of operations by Molycorp in the United States, establishment of Lynas in Australia, as well as refurbishment of a previously producing mine by Great Western Minerals Group in South Africa, just to mention the major ones. However, long lead times for their development, substantial financial burden and uncertainty, as well as lack of capabilities in terms of technically trained personnel, indicate that these production sites are not expected to become competitors to China any time soon.

On the demand side, rare earths are used as input materials to an ample range of technologies such as mobile devices, computing, magnetic resonance imaging (MRI), compact fluorescent light bulbs and laser technology. More important though, competitive pressures arise from the growing deployment of low-carbon technologies. Increasing power generation capacity along with decarbonising transport driven by the United Nations Framework Convention on Climate Change (UNFCCC, 2015), quicker and more cost-competitive low-carbon energy transition within the European Strategic Energy Technology Plan (SET-Plan) (European Commission, 2015), and eradication of energy poverty and industrialisation by developing countries (Miroux et al., 2011) are all heavily reliant on rare earths. In particular, deployment of wind turbines and electrically powered vehicles, both of which make use of rare earth-based permanent magnets in their generators and electric motors, have often been cited as major drivers of change in rare earth demand. Estimates confirm that demand for dysprosium and neodymium, the two rare earth elements known for their exceptional magnetic properties, is to increase 
by more than $2600 \%$ and $700 \%$ respectively, over the coming 25 years (Alonso et al., 2012a). Consequently, shortages of some of the rare earths were projected to occur already in 2015 (Bourzac, 2011).

The growing imbalance between increased demand and tighter supply suggests that whereas low-carbon technologies are intended to tackle climate changes, their diffusion might be adversely affected by risk of supply disruption. The question thus arises as to what extent potential supply disruption of rare earths poses a barrier to the deployment of low-carbon technologies and how it induces their innovation. A lot of specialised literature exists on different aspects of rare earths, ranging from geology, chemistry and materials science to engineering and life cycle analysis. However, comprehensive analysis in economic literature is missing. In this light, the aim of the current chapter is twofold: to bring these seemingly disconnected strands of literature together, in order to provide an overarching overview of the rare earth economics, and to shed clarity on the far reaching consequences of demand-supply imbalances on the deployment and innovation in low-carbon technologies.

This multidisciplinary approach allows for providing a thorough overview of market forces in place, by investigating on the impact of China's industrial policies on the rare earth market on the one hand, and by assessing the key trends in offshore wind turbines and advanced technology vehicles and their dependence on rare earths on the other. Such analysis enables to draw conclusions on how price and sourcing volatilities influence innovation strategies by manufacturers. For this purpose, data on production, supply and industrial uses of rare earths is collected to determine the existence of supply risk. Next, an overview of existent topologies of generators, electric motors, batteries and other rare earth-intensive parts of offshore wind turbines and advanced technology vehicles and their respective rare earth contents is established by surveying specialised engineering and materials science literature. The results of this exercise constitute an important contribution to the literature in that they point out the coexistence of a variety of offshore wind turbine and advanced technology vehicle topologies, some of which are less rare earth intensive than others. To do so, a unique database is created for offshore wind turbines and advanced technology vehicles, collecting information on technology designs deployed, their respective capacities and global shares. The database permits to generate an overview of the current technology landscapes in unique detail, allows a determination of the cumulative shares of rare earth consumption, helps understanding the supply risk from an economic perspective and determining the implications for innovation and policy. This is yet another important contribution to the literature, since data in such detail are currently 
not available. Finally, the impact of rare earth price volatility on manufacturing these technologies is estimated.

In order to be able to carry out this analysis, it is important to first understand the individual rare earth elements and their respective chemical and physical properties. These, along with the multitude of their uses are reviewed in Section 3.2. Section 3.3 analyses the forces on the supply side of the rare earth market in terms of geopolitical and quantity risks. Herewith, some of the upstream responses to the threat of supply disruption are discussed briefly. A detailed discussion of mitigating strategies in terms of recycling, stockpiling, and materials and technology substitution is provided within Section 3.5. Section 3.4 provides the in-depth analysis of offshore wind turbines and advanced technology vehicles in the context of rare earth supply bottlenecks. Demand and supply are brought together in Section 3.6, where price trends and their impact on innovation strategies by manufacturers are considered. After a brief overview of social costs incurred by mining and processing of rare earths in Section 3.7, the chapter concludes with Section 3.8.

\subsection{Rare earths}

As per the definition of the International Union of Pure and Applied Chemistry (IUPAC), rare earth elements are lanthanoids with atomic numbers 57 to 71, as well as yttrium and scandium which exhibit sufficiently similar properties to be included in this group of transition metals distinguished by their special electron configurations (Connelly, 2005). Classified according to their ionic radii, rare earths constitute two subgroups: light (LREE) and heavy (HREE) rare earths, with scandium not belonging to any of these two (see Table 3.1). An additional group of medium rare earths (MREE) has emerged recently in the language of chemists and metallurgists and denotes samarium, europium and gadolinium (Hatch, 2011b). Other classifications may be considered based on physical, chemical, technological and geochemical attributes, as well as on industrial demand and prices of individual elements.

\subsubsection{From discovery to processing}

The history of rare earths dates back to 1787, when ytterbite ore was accidentally discovered by Lieutenant C. A. Arrhenius at Ytterby, Sweden. However, due to the chemical similarity of rare earths, it took another 7 years until J. Gadolin successfully isolated a previously undescribed "earth" from the ore. In the com- 
ing years, number of mineralogists, geochemists and crystallographers worked on the separation of metallic oxides present in yttria and ceria, both regarded originally as pure oxides themselves. It was not until more than a century later that progress in fractional separation, publication of periodic law of chemical elements and experimental work on the relationship of x-ray spectra to atomic numbers, allowed establishing the final number of "newly discovered elements" within the complex mixture of oxides (Gschneidner and Capellen, 1987; Moeller, 1963; Weeks, 1956). Ultimately, the latter were decomposed into simple oxides of the following rare earth metals: yttria was broken down into yttrium, terbium, erbium, ytterbium, lutetium, holmium, thulium and dysprosium; while ceria was decomposed into cerium, lanthanum, neodymium, praseodymium, samarium, gadolinium, europium and promethium.

The multitude of investigators, who often isolated the same elements independently from each other, resulted in a disjointed plethora of names throughout the history. The final version of universally accepted names were mostly derived from Greek - so is for example the meaning of dysprosium "the difficult to access" while some others were given in honour of scientists who investigated upon them - gadolinium named after Gadolin - or by geographical location - lutetium for the ancient name of Paris, the birthplace of one of the investigators - as well as inspired by astronomy - cerium after planetoid Ceres - and mythology - prometheum (whose spelling was later amended to promethium) from Prometheus - (Gschneidner and Capellen, 1987; Moeller, 1963; Weeks, 1956). The name of the group of elements instead, is considered a historical misnomer which arose from rare earths having been first obtained in form of oxides (what is the modern term for earths) from seemingly rare minerals. Some of the alternative names for this transition group are: lanthanides (derived from lanthanum - the first rare earth element in series), lanthanide elements, lanthanons, or f-type transition elements to denote their ground-state electronic configurations of atoms. It is precisely their electronic configurations, large atomic radii and their position within the periodic table what ranks them among metals rather than earths (Moeller, 1963).

In terms of their rarity, individual elements are found in Earth's crust in different quantities. According to the Oddo-Harkins effect, the even-numbered elements are more abundant than the adjacent odd-numbered elements, resulting from the formers' lower neutron-capture cross sections which prevent them to take up an additional neutron and thus be transformed to a higher element (Cornell, 1993). Furthermore, the lighter elements prove to be more abundant than the heavier ones as a consequence of their different synthesis by atomic fusions in the cores of stars, with heavy elements being made under higher temperatures and pressures 
Table 3.1: Abundance of rare earths in continental crust, ppm (10'000 ppm = 1\%)

\begin{tabular}{|c|c|c|c|c|c|c|}
\hline $\mathrm{Z}^{*}$ & Element & Symbol & (1) & $(2)$ & (3) & $(4)$ \\
\hline \multicolumn{7}{|c|}{ LREE - The Cerium Group } \\
\hline 57 & Lanthanum & La & 30 & 29 & 30 & 35 \\
\hline 58 & Cerium & $\mathrm{Ce}$ & 60 & 70 & 60 & 66 \\
\hline 59 & Praseodymium & $\operatorname{Pr}$ & 8.2 & 9.0 & 6.7 & 9.1 \\
\hline 60 & Neodymium & $\mathrm{Nd}$ & 28 & 37 & 27 & 40 \\
\hline 61 & Promethium $\dagger$ & $\mathrm{Pm}$ & - & - & NA & 0.0 \\
\hline 62 & Samarium & $\mathrm{Sm}$ & 6.0 & 8.0 & 5.3 & 7.0 \\
\hline 63 & Europium & $\mathrm{Eu}$ & 1.2 & 1.3 & 1.3 & 2.1 \\
\hline 64 & Gadolinium & Gd & 5.4 & 8.0 & 4.0 & 6.1 \\
\hline \multicolumn{7}{|c|}{ HREE - The Yttrium Group } \\
\hline 39 & Yttrium & $\mathrm{Y}$ & 33 & 29 & 24 & 31 \\
\hline 65 & Terbium & $\mathrm{Tb}$ & 0.9 & 2.5 & 0.65 & 1.2 \\
\hline 66 & Dysprosium & Dy & 3.0 & 5.0 & 3.8 & 4.5 \\
\hline 67 & Holmium & Ho & 1.2 & 1.7 & 0.8 & 1.3 \\
\hline 68 & Erbium & Er & 2.8 & 3.3 & 2.1 & 3.5 \\
\hline 70 & Ytterbium & $\mathrm{Yb}$ & 3.0 & 0.33 & 2.0 & 3.1 \\
\hline 69 & Thulium & $\mathrm{Tm}$ & 0.48 & 0.27 & 0.3 & 0.5 \\
\hline 71 & Lutetium & $\mathrm{Lu}$ & 0.50 & 0.8 & 0.35 & 0.8 \\
\hline 21 & Scandium & $\mathrm{Sc}$ & 22 & NA & 16 & NA \\
\hline
\end{tabular}

Notes: *Atomic number; †Promethium has no stable isotopes and is not found in nature. Source: Data complied from (1) Taylor (1964), (2) Jackson and Christiansen (1993), (3) Wedepohl (1995), (4) Cotton (2007).

in supernovae only (Cotton, 2007). So do cerium and lanthanum constitute the bulk, while lutetium on the other end of the series has low concentrations within the group. Table 3.1 collects figures from various studies on rare earth elements' continental crust abundance in percentage of parts per million in mass (ppm). Note that these differ in absolute terms in function of the method of estimation used and assumptions made about the genesis of the lower crust. Nevertheless, the order of magnitude is roughly identical across estimations, confirming that rare earths in the upper part of the table are more abundant than those in the lower part, and that those with odd atomic numbers are less common than those with even atomic numbers. Moreover, based on the crustal abundance data for most common chemical elements by Moeller (1963), Taylor (1964) and Wedepohl (1995), rare earths prove to be not less abundant than other common elements. In fact, cerium, which is the most abundant rare earth, is in the same range as nickel and zinc and more common than copper. At the same time, the least abundant lutetium and thulium are more than 100 times more abundant than gold.

While one can conclude on the relative abundance of rare earths when compared to other industrial metals, one needs to keep in mind that rare earths are 
rarely concentrated in minable deposits. They are obtained from lanthanide minerals in form of oxides (REO), which contain a mixture of all rare earth elements (with the exception of promethium). Principal sources of the cerium group are bastnäsite, monazite and cerianite, while the yttrium group is most commonly retrieved from euxenite, xenotime and gadolinite (Cotton, 2007; Moeller, 1963). Despite being contained in as many as 200 minerals (Walters and Lusty, 2011), not all of them can be commercially processed due to the cost, the geographical location as well as the nature of minerals themselves (Moeller, 1963). A selection of those that do, along with their REO contents, is reported by Castor and Hedrick (2006). Similarly, an overview of primary and secondary deposits and their capacities can be found in Walters and Lusty (2011), Castor and Hedrick (2006) and Long et al. (2010). Furthermore, it is important to note how the significance of these minerals has changed over time for the rare earth mining. Monazite which occurs in granitic rocks, used to be the most important source of LREE until it has been abandoned due to its content of radioactive thorium (U.S. Geological Survey, 2013). The same holds for xenotime in placer accumulations of Australia and Malaysia. Contrary to this, bastnäsite mined from carbonatite deposits contains negligible amount of thorium and is currently the most important deposit of rare earths in western hemisphere - in Mountain Pass, California. At the same time, Chinese ionic clays of the iron deposits of Bayan Obo have become the largest source of rare earths in the world. Also important to note is that only a few of the mines are operated for recovery of rare earths themselves. In fact, rare earths are often retrieved as by-products or joint-products of iron ore (China), titanium (Russia), uranium (Canada), zirconium and niobium (some mines in Australia), or thorium (Brazil) (Walters and Lusty, 2011). This implies that their mining decisions are driven primarily by the demand for principal products, rather than by the actual demand for rare earths.

As a consequence of the diversity of rare earth deposits, both extraction techniques and physical and chemical processing techniques depend on the mineralogy and chemical composition of deposits. The extraction techniques vary from more economic and currently most practised surface mining, through underground mining, to in-situ mining suitable for near-surface deposits. The complexity of processing methods also influences the competitive advantage of deposits: the processing of ion adsorption clays is more cost efficient than that of hard-rock deposits, for example. Moreover, HREE are often more complex to process than minerals containing LREE. In general, techniques for processing multiple mineral phases prove to be more complex and costly than processing of many industrial metals concentrated in a single mineral phase. An outline of these can be found in Walters and 
Lusty (2011), Castor and Hedrick (2006), Cotton (2007), Moeller (1963) and Long et al. (2010). The result are high purity compounds, with different purities used for different applications, ranging from mischmetal in alloy metallurgy to rare earth metals with purities of up to $99.9999 \%$ required in magnetic applications (Cotton, 2007; Walters and Lusty, 2011).

\subsubsection{Their industrial uses}

The commercial production of rare earth compounds started after the Second World War, with the availability of improved separation techniques such as ionexchange, partition and liquid-liquid extraction (Gschneidner and Capellen, 1987). These turned the former minor metals into metals of large industrial uses. In line with the developments in their end-uses. rare earths have since then been sold in various forms, ranging from mineral concentrates, mixed chemicals, oxides and metals, to magnets, phosphors and powders (Walters and Lusty, 2011). According to the estimates reported by Henderson (1984), in 1980 more than one third of the production by volume was used in form of mischmetal in metallurgic applications. Catalytic applications for fluid cracking catalysts in petroleum refining and in polyesterification processes constituted another third. By 2010 these have significantly lost on importance, their respective shares dropping to $18 \%$ and $20 \%$ by volume (Kingsnorth, 2011). The usage for glass-polishing compositions and as colouring agents in ceramics remained altogether very similar over time. The recent use of rare earth phosphors seems to be linked to the discovery of their luminescence property, which further allowed for commercialisation in medical applications (laser, X-ray, MRIs), as well as in electronics (cathode ray tube television, energy-efficient fluorescent lamps). Being used in all kinds of visual display devices these days, phosphors account for more than $30 \%$ of consumption by value according to Kingsnorth (2009). Furthermore, with perfectioning of hydrometallurgical processes for extraction of minerals and improved methods for purification of rare earths, increased purities of elements allowed for their wide application in high-tech products, cell phones, hard disk drives (HDD), microphones and digital music players. In terms of their volumes, both phosphors and high-techs constitute only a negligible part of the market at present, though their relative value is high. This can be explained on the example of smartphones, where merely a small fraction of a gram is sufficient to guarantee quality sound, high resolution coloured screen or vibration function, in contrast to several hundred kilograms required for MRIs (Molycorp, 2010; Tasman Metals, 2010). Other uses of rare earths are in defence applications, such as radars and sonars, as well as in nuclear energy applications and fertilisers. Last but not least, despite the fact that the most important 
physical properties of rare earths - ferromagnetism and superconductivity - were discovered back in the 1930s, it was only several decades later that samarium and neodymium-based permanent magnets started to replace conventional aluminiumnickel-cobalt (AlNiCo) magnets. By now, the former constitute more than $20 \%$ of rare earths by volume and almost $40 \%$ by value (Kingsnorth, 2009). Main applications of rare earth magnets are in low-carbon technologies such as electric vehicles and direct drive wind turbines. Similarly, in today's age of miniaturisation of hightech sector, their superior coercivity and higher energy products are essential to keep up effectiveness and efficiency of devices while continuously shrinking their size and weight.

An overview of an unusually wide range of consumer products making use of rare earths is provided in Table 3.2, along with the breakdown of particular elements employed. It becomes obvious that despite their similar chemical properties, rare earths are applied in different combinations, forms and purities within different technologies. The most extensively used ones are those with lower atomic numbers. In contrast, the HREE such as dysprosium, terbium, yttrium are used in minute quantities to enhance the properties of the LREE, such as coercivity and magnetic flux. Holmium, erbium, thulium, ytterbium, lutetium and scandium instead, are considered as minor metals in mass production, this being conditioned by the their relative scarcities (Technology Metals Research, 2010).

To conclude with, rare earths play a key role in enabling digital technology, improving energy efficiency, enhancing environmental protection and are indispensable for health and medical technologies. In all these fields, a growing demand is expected to occur, driven by economic growth from emerging economies on the one hand, and from new technologies under development on the other. Linking the market demand of individual elements from all these technologies back to the proportions in which they can be found in deposits, to the accessibility of their geological locations and to the complexity of their processing, two conclusions stand out: first, the demand for the rare earths is not uniform, what ultimately implies higher prices for the less abundant oxides contained in minerals the processing of which is more complex. Prices are further exacerbated by the fact that rare earths are often mined as by-product and their production rates depend on the production of base metals. Second, in order to keep up the supply of the most commercialised rare earths, such as dysprosium and neodymium, an oversupply of some less utilised oxides, such as samarium and yttrium, which are contained in rare earth ores necessarily occurs. 


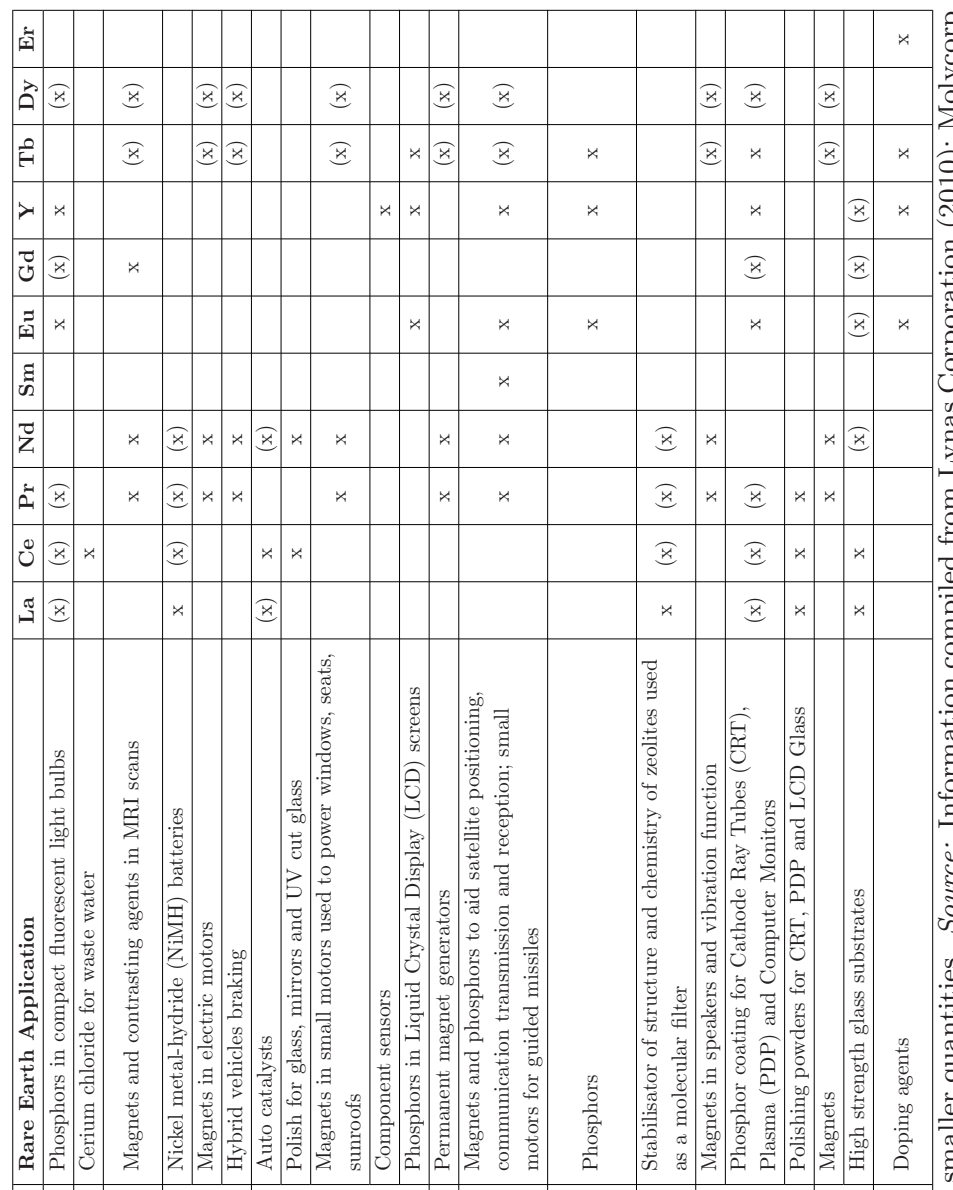

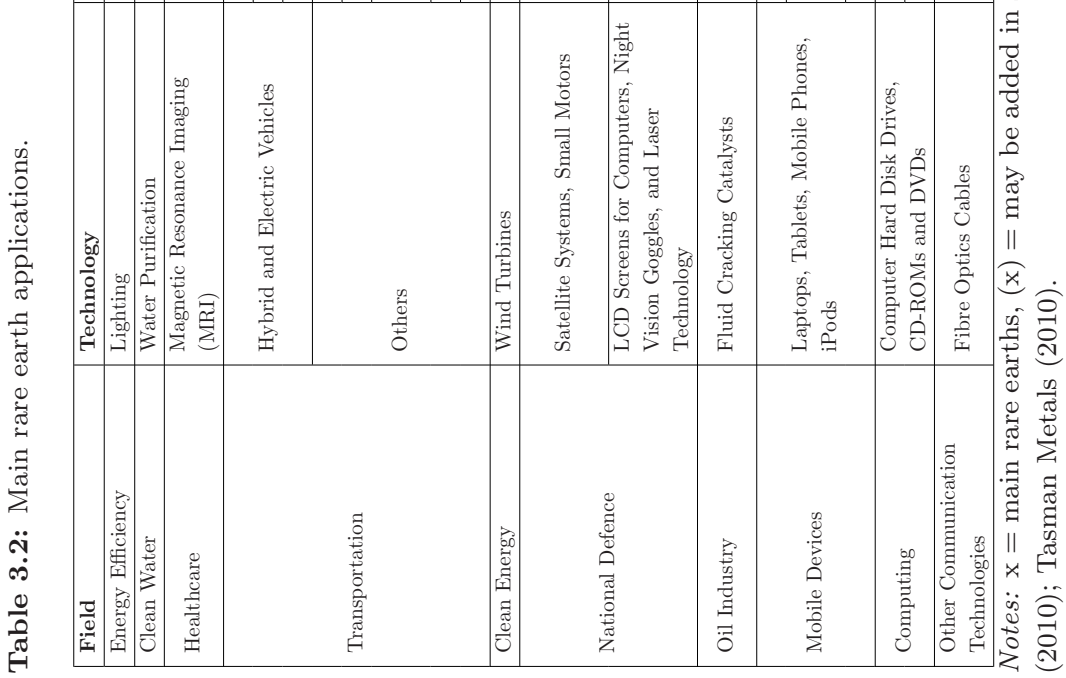




\subsubsection{The criticality of "not so rare" metals}

According to material science literature, the two main mechanisms behind material availability risk are physical constraint and institutional inefficiency. The former is a well researched concept derived from Malthusian and Ricardian considerations of physical constraints on resource availability, in terms of physical exhaustion and quality of supply (Alonso et al., 2007). The concept of institutional inefficiency instead, has not been given sufficient emphasis within the literature, mainly due to its short-term character. The latter arises from local trigger by markets', firms' and governments' failures and may cause supply disruptions globally, resulting in permanent changes to the supply chain or to the materials used therein (Alonso et al., 2007). The most important measure of institutional inefficiency is the concentration within supply chain with regard to the geographic structure of supply and production on the one hand, and the institutional structure based on production and consumption on the other. In the particular case of rare earths, based on the preceding discussion about their abundance and taking into consideration that the static depletion index for REO is 1219 years (as compared to 38 years for copper $)^{1}$, the physical constraint does not seem to be an issue. In turn, looking at the institutional inefficiency, and the geographical concentration of supply in particular, one cannot speak of concentration of rare earth reserves either (see Figure 3.3). In this respect it should be kept in mind though, that not all exploitable deposits are economically viable or located in reliable geopolitical jurisdictions with sound processing in place (Berry, 2013). Instead, the most pressing issue proves to be the geographic and institutional structure of rare earth production, in terms of concentration of their primary production and of control. In fact, China being the single major producer of rare earths exercising control over the global market (see Figure 3.4), might lead to a serious global supply disruption, should a political disturbance on local level occur.

The origins of the concept of supply risk date back to the late 1930s (United States Public Laws, 1939), gained salience in the 1970s when oil and cobalt crisis burst, and have been recently extended to cover non-energy minerals (Erdmann and Graedel, 2011). In fact, a large part of the contemporary literature aims at examining the extent to which mineral supply risk affects national economies, spe-

\footnotetext{
${ }^{1}$ Own calculations based on 2013 estimates of reserves published by U.S. Geological Survey (2014). Note that reserves data fluctuate over time and in function of decreased ore grades and lowered economic extraction feasibility on the one hand, and of newly discovered deposits and their further development on the other. In case of rare earths, the fluctuation in reserves data is further amplified by the numerous ongoing exploration initiatives, many of which have uncertain future (Kingsnorth, 2013a).
} 
cific industries and technologies. In particular, the concept of mineral criticality is predominantly studied within the framework of criticality matrices, whereby minerals are evaluated based on their importance in use (i.e. their chemical and physical properties and their substitutability within technologies) and on their supply risk (i.e. availability and reliability of mineral supply) (National Research Council, 2008). Yet, in terms of empirical literature, the classification of minerals as critical varies from country to country. This is mainly due to different scopes and approaches adopted, but also in line with the level of attention the society pays to certain minerals with regard to technological change and political vision (Erdmann and Graedel, 2011). So is, according to the definition by the US National Research Council (2008), a mineral considered critical if it is subject to supply risk and has high importance in use with little or no substitutes available. The European Commission (2010) instead, follows the approach of relative criticality, i.e. it considers a mineral to be critical when the risk of its supply shortage is higher than that for other minerals. Yet another is the Japanese definition, which adopts a forward looking perspective and defines criticality in terms of mineral's current and future role for increasing the country's competitiveness (Advisory Committee on Energy and Natural Resources, 2009). Despite the conceptual differences, all the three countries conclude on the criticality of rare earths for their economies, due to concentration of production, political risk of the supplier country, short term limitations to expanding the supply and high import dependence (European Commission, 2010; Moss et al., 2011), as well as the expected demand growth from green technologies (Bauer et al., 2010, 2011), and supplier countries' export policies and potential depletion of land-based resources of dysprosium in the coming decades (Kawamoto, 2008).

To summarise, following from the theoretical and empirical studies reviewed, rare earths can be considered highly vulnerable to institutional inefficiencies. The threat of their supply risk arises mainly from political risk and concentration of supply, as opposed to the traditional physical constraint claims. In line with this, Section 3.3 analyses both issues in depth, discussing the geopolitical perspective of rare earth supply risk and the Chinese hegemony in terms of quantity risk.

\subsection{Supply risk}

The major cause of global supply chain disruptions, besides natural catastrophes and factory disasters, is the geopolitical risk when sourcing raw materials from remote regions characterised by lack of political stability (Advisen Ltd, 2013). The latter includes events such as labour disputes (e.g. case of platinum (Chong, 
2013)), civil wars and political upheavals (e.g. Zaire in 1978 (Alonso et al., 2007)), international terrorism (e.g. government's response to 9/11 (Sheffi, 2001)), as well as other dynamics impacting the long term stability of the region. What these events have in common is the local character with global ramifications for the entire supply chain. The 1977 - 1979 "cobalt crunch" is an example of a local event which permanently changed materials, technologies, and sourcing routes within the global cobalt supply chain. Cobalt being a primary input to aerospace and defence industries, was considered strategic to the United States - its major importer. The political unrest in Zaire (now Democratic Republic of Congo), coupled with tight cobalt supplies and increased demand from industrial economies, resulted in a temporary disruption of cobalt supply and a price increase by $330 \%$. These developments triggered both upstream and downstream responses across the supply chain, such as extending production capacities to Zambia, recycling and substitution (Alonso et al., 2007; Shedd, 1999). This lead for example to samarium-cobalt ( $\mathrm{SmCo}$ ) permanent magnets for electrical equipment being substituted by cobaltfree permanent magnets based on neodymium and iron compound. ${ }^{2}$ On the one hand, this substitution resulted in developing a superior magnet technology and thus reducing vulnerability to volatile cobalt prices and to resource dependence on Zaire (Gschneidner and Capellen, 1987). On the other hand though, it indirectly shifted the world dependence from politically unstable Zaire to communist China. In fact, the adoption of neodymium-iron-boron $(\mathrm{NdFeB})$ magnets has been driving the demand for some of the rare earths, the majority supplier of which is China.

\subsubsection{Geopolitical security and resource dependence}

Besides the increased demand for rare earths being an indirect consequence of the cobalt supply chain disruption back in the 1970s, several parallels exist between these two minerals: both are to a large extent by-products, what makes their supply be largely inelastic; the production of cobalt then and of rare earths now has been heavily concentrated, with two thirds of the world cobalt production originating from the Copper Belt, while more than 95\% of rare earths in 2010 were mined in China; similar to the cobalt prices which were set by producers and their sales which were carried out under long term contracts before 1990s, also in the case of rare earths there have been no spot markets with independent traders until recently (Shedd, 1999). Bearing in mind the far reaching consequences of cobalt supply disruptions and the analogies between the two minerals, it proves important to analyse the geopolitics of rare earths.

\footnotetext{
${ }^{2}$ Note that these magnets still contain up to $5 \%$ of cobalt in order to improve the otherwise low Curie temperatures when compared to SmCo magnets (Cobalt Development Institute, 2006).
} 
To start with China, its intention to use rare earths as a tool of foreign policy was implicitly revealed in 1992 when President Deng Xiaoping stated out: "There is oil in the Middle East; there is rare earth in China" (Baotou National Rare Earth Hi-Tech Industrial Development Zone, 2015). The two are not only similar in their respective global reserves of minerals, but also in the fashion in which they could potentially influence the international relations through the control of minerals. Thinking back to the Arab Oil embargo in early 1970s, the oil crisis manifested itself by a shortfall of automotive gasoline and dramatic increases in prices of gasoline and heating fuels. OPEC's control of oil was serving to achieve political and economic goals of oil producing Arab states by exercising pressure on industrialised oil-importing countries. In a similar fashion, though to a lesser extent, China has used its control of rare earths exercising pressure on resourcedependent countries. In the early 2000s, China tightened the supply of rare earths by introducing export quotas and limiting the number of export companies (Ting and Seaman, 2013). Cutting back supply escalated with the 2010 maritime incident between China and Japan, when a Chinese fishing trawler collided with Japanese coast guard vessels in the waters which are since long object of territorial disputes between the two countries. Further to this, China used its position as a diplomatic leverage and imposed an "administrative halt" on rare earth exports to Japan (Bradsher, 2010). Though there has been little doubt that this informal act by Chinese customs related back to the detention of the Chinese captain by Japanese coast guards (Wong, 2010; Reilly, 2012), some claim that there is no clear evidence for or against the embargo (Johnston, 2013). Even if exports resumed within two months time from the incident, China's diplomatic assertiveness has significantly impacted both East Asian and international trade: while Japan's manufacturing is highly dependent on sourcing rare earths from China, the world in turn is dependent on importing manufactures from Japan.

The world's largest economies responded to this threat by financing new rare earth projects outside China, by setting up R\&D initiatives targeting improved extraction, resource efficient use, recycling and substitutes. The EU-US-Japan Trilateral Critical Materials Initiative is an example of a joint initiative to reduce their resource dependence on China (European Commission, 2013; NEDO, 2012; U.S. Department of Energy, 2011). Japan in particular, is now in the process of exploring seabed deposits which also contain rare earth ores (Mori, 2013; Evans-Pritchard, 2013). This is however susceptible to trigger a vicious circle of geopolitical instability in the region since these mineral reserves are found in Japan's Exclusive Economic Zone (EEZ) - another disputed seabed the waters of which are of overlapping claims to both China and Japan (Kawamoto, 2008). 
To summarise, considering the importance of rare earths in low-carbon technologies and in defence appliances, a potential supply disruption might constitute a threat to resource-dependent countries' energy and national security. It is thus possible for rare earth elements to turn into the new elements of geopolitical power - a role previously conferred to oil. Yet, for the moment China's rare earth diplomacy has not exercised strong leverage on import-dependent countries to pursue its own strategic goals to the extent Arab countries had done so during the energy crisis in the 1970s. What is more, China has denied the use of rare earths as a bargaining tool (Huixia, 2010). Nonetheless, geopolitics is not to be underestimated in that it plays a significant role in determining global supply and demand. Also, it is shaped by the balance of power between mineral-rich and mineral-poor countries (de Ridder, 2013). It thus proves important to consider the mineral strategies of exporting countries on the one hand, and policy responses to concerns about supply disruptions by importing countries on the other. In this light, China's rare earth industrial policies are considered next, followed by a short overview of the upstream responses by importing countries. The other mitigation strategies are outlined in Section 3.5.

\subsubsection{Quantity risk}

From the above discussion it becomes clear that concentration alone does not lead to rare earth supply risk. Rather, it is China's abuse of power over resources in terms of its protectionist policies. In fact, rare earths were declared as "protected and strategic materials" more than two decades ago (Tse, 2011). More recently, China has been introducing rare earth industrial policy measures to hold them back for domestic uses. Firstly, resource nationalism in China has seen foreign companies being banned from engaging in any part of the rare earth supply chain, other than forming joint ventures with domestic companies (MOFCOM, 2012a). Secondly, both domestic and joint venture companies became subjected to production quotas (MLR, 2013) and export quotas (MOFCOM, 2012j). Though the latter were abolished further to a ruling by the World Trade Organisation (WTO), they were replaced by resource tax and export licensing in 2015 (MOFCOM, 2014a). Thirdly, the number of companies permitted to export was gradually decreasing from 41 in 2007 to 24 only in $2013 .{ }^{3}$ Furthermore, increased state control on the supply chain was achieved by merging several companies into one "megacompany" (MOFCOM, 2012i), by banning new rare earth mining licenses (MOFCOM, 2012f) and by eliminating smuggling (MOFCOM, 2012g). Additionally, creation of a joint pricing platform (MOFCOM, 2012c) and of a national pricing system (MOFCOM,

\footnotetext{
${ }^{3}$ Considering parent companies.
} 
2012l), accompanied by benevolent production halts (MOFCOM, 2012h) and setting up stockpiles of rare earths (MOFCOM, 2012b), strengthened China's pricing power. Taken together, the protectionist policies demonstrate a clear alignment of China's natural resource policies with its national interests. At the same time, this state interventionism paralysed the market forces in place - supply and demand causing resource-dependent countries to lose grip over rare earth availability, what ultimately lead to increased geopolitical and economic risks. It is important to note however, that not all rare earth metals are affected by supply risk equally. The extent depends on the evolution of future demand, alternative supply as well as the complexity of their processing.

\section{Mined in China}

Global import data of rare earth compounds and metals compiled from UN Statistics Division (2013) shed light into the severity of resource dependence of rare earth-importing countries. In 2012, Japan was the largest importer with 13'829 tonnes, followed by the United States with 10'161 tonnes. France and Estonia imported half as much - 5'520 tonnes and 5'044 tonnes, respectively - tightly followed by Germany with 4'814 tonnes and Malaysia with 4'332 tonnes of rare earth products. Not only are these countries import-dependent, they also tend to source majority of rare earths from China, as illustrated in Figure 3.1. While the three major importers - Japan, the European Union and to some extent the United States - have already been dependent on China back in 1992, by 2012 the relative proportions of Chinese exports to Japan and the EU decreased, while to the US they increased substantially. What is more, by 2012 additional countries started to source rare earths from China, such as Russia, Brazil and Australia, all of them having discontinued domestic production in the 1990s (see Figure 3.4), as well as South Korea and Hong Kong which started manufacturing rare earth-intensive technologies.

Overall, China exported 16'266 tonnes of rare earth products in 2012, $83 \%$ of these as compounds and the rest in form of metals. The other top five global rare earth exporters were Austria, Japan, Russia and the United States. While the latter two were historically primary producers of rare earths, Austria and Japan import rare earths and process these further to produce metal alloys and chemical products for export. Figure 3.2 illustrates the evidence that since 2000 China has been by far the largest supplier of rare earths, though its exports have been decreasing gradually ever since 2003 - from almost 10 times more than the second largest supplier in 2000 to below 2.5 times more in 2012.

Furthermore, to gain a long term perspective, it proves important to examine 
Figure 3.1: Comparison of Chinese export destinations: a) 1992 and b) 2012.

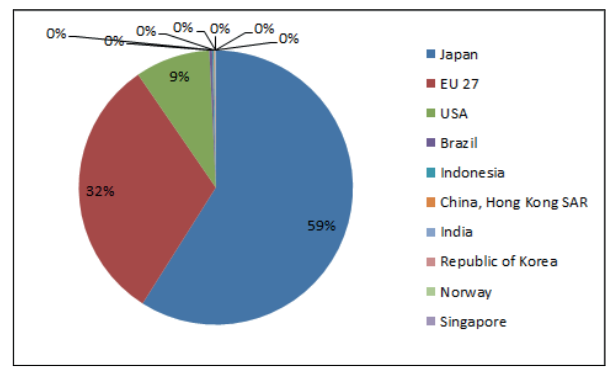

(a) 1992

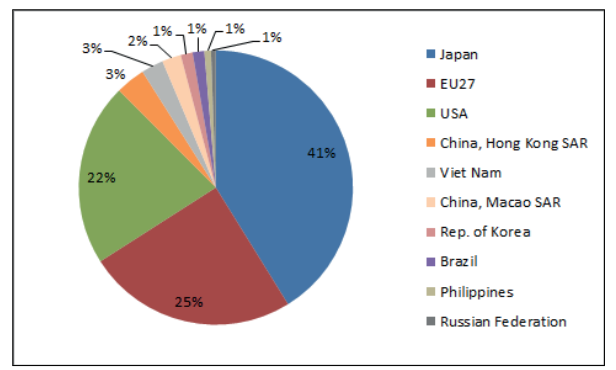

(b) 2012

Notes: The following Harmonized System codes were taken into consideration: HS280530, HS284610, HS284690. Source: Based on data collected from UN Statistics Division (2013).

Figure 3.2: World rare earth export, by country, in tonnes, 2000-2012.

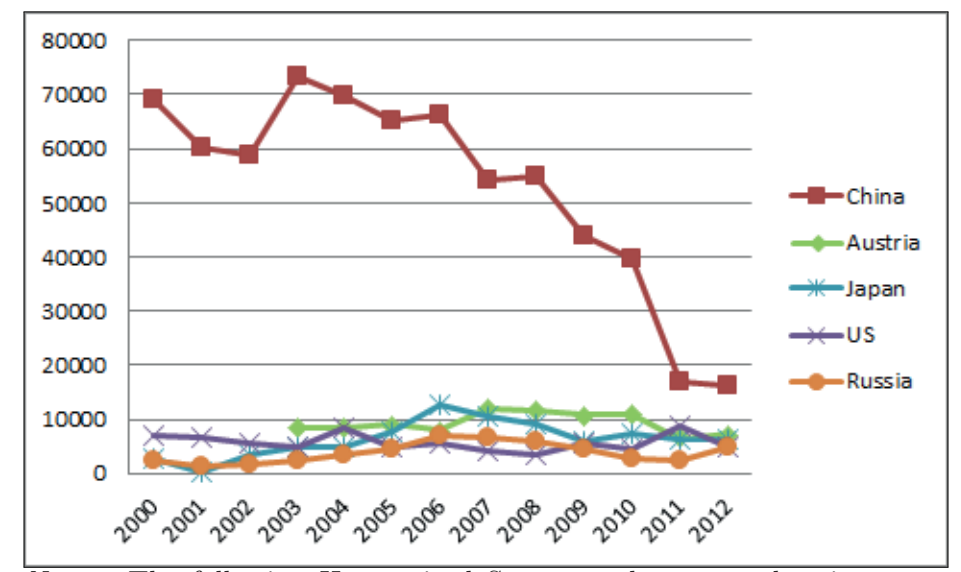

Notes: The following Harmonized System codes were taken into consideration: HS280530, HS284610, HS284690. Source: Based on data collected from UN Statistics Division (2013).

the availability of reserves worldwide. Considering the dynamic nature of reserves, Figure 3.3 shows a snapshot for years 1995 and 2013. China's percentage share of reserves remained constant overtime at approximately $40 \%$. Note that estimates vary from $22 \%$ to $50 \%$ depending on the calculation method used (Humphries, 2013). Though China's reserves in absolute terms increased overtime by $28 \%$, there was a drop of $37 \%$ when considering the sub-period of rapid exploitation in 1995-2002. Other substantial deposits can be found in Brazil (16\%), the Commonwealth of Independent States (CIS) (14\%) and the United States (10\%), with the 
global share of other countries below 5\%. It follows from this, that while China possesses the largest single deposit of rare earths, there exist substantial deposits in other parts of the world too. However, the economic viability of reserves in terms of concentration of ore and ease of processing is not to be neglected. The surficial clay deposits of Jiangxi (China) are much less complex to mine and process than the bulk ore from Strange Lake (Canada) or Xenotime in Lahat (Malaysia) (Long et al., 2010). Another concern is the decreasing quality of mined ores, what requires more costly and energy intensive extraction (Cho, 2012). Also, there are long lead times for new mines development accompanied by higher environmental standards in Western countries, what requires the use of more sustainable mining and processing techniques. Finally, considering the relative distribution of scarcer HREE-rich minerals, $80 \%$ of world's deposits are contained in Chinese ion adsorption clays of South-East Guangdong and Jiangxi Provinces (U.S. Geological Survey, 2013; Walters and Lusty, 2011). LREE instead, can be retrieved in substantial concentrations from Mountain Pass (the United States) and Mount Weld (Australia), besides the Bayan Obo (China) deposit which is the largest of its kind in the world. Taken together, China is expected to remain the rare earth super power beyond the medium term.

Figure 3.3: Comparison of world rare earth reserves, by country: a) 1996 and b) 2013 .

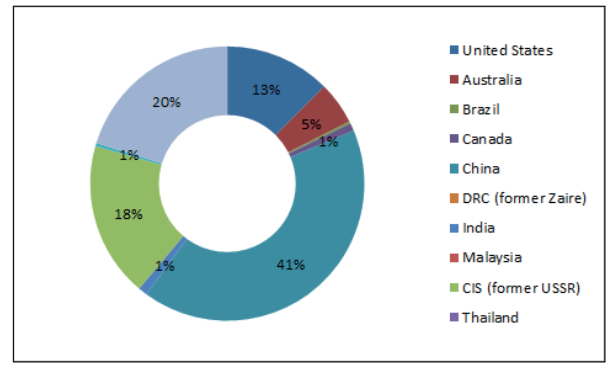

(a) 1995

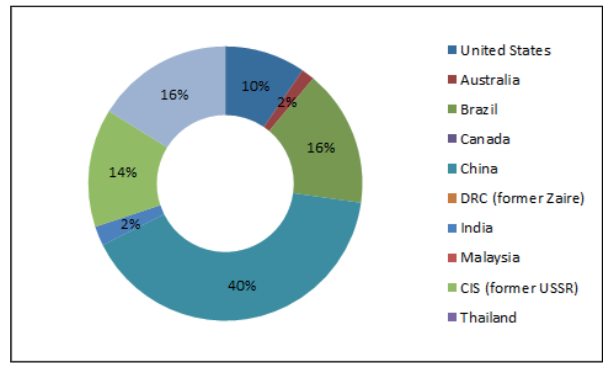

(b) 2013

Source: Based on data collected from U.S. Geological Survey (2014).

In terms of global production trends, various producer countries were leading the rare earth market historically: while in the first half of the 20th century the market was dominated by REO mined from Brazilian, Indian and South African monazite bearing placers, in the second half of the century production shifted to Mountain Pass bastnäsite deposits in the United States. China entered the market in late 1970s and after a transition period in mid-1980s it became the market leader, as a result of its cheap labour force, less stringent environmental 
regulation, but also well trained technical staff in processing and engineering. Lower prices of Chinese REO resulted in squeezing the United States and most of the other producing countries out of the market by early 2000s (U.S. Geological Survey, 2013). Figure 3.4 illustrates China's hegemony in global production of rare earths over the past 20 years. The data is to be interpreted with caution in that it is based on estimates, and might be incomplete with regard to minerals and country coverage. It also does not to account for production from stockpiled material (Walters and Lusty, 2011). During the period examined (1988-2013), China increased its rare earth production by $237 \%$, while the rest of the world decreased production by $66 \%$. Taken together the global production increased by $75 \%$, peaking in 2006 with $136^{\prime} 657$ tonnes. Yet, taking a closer look at Figure 3.5 it becomes obvious that, as opposed to the expectations, China's monopoly has been eroding over time, its share in world production having shrunk from $98 \%$ in 2009 to $89 \%$ in 2013 . While China is still by far the dominant producer, some new players have been entering the global rare earth market. In fact, during the past five years production took off in the American Molycorp, the Australian Lynas, as well as in India Rare Earth Limited and continues in small quantities from Russian stockpiles. With additional increase in their mining capacities and expected development of new projects outside China, a further erosion in China's monopoly is foreseen to occur in medium to long term.

Figure 3.4: World mine production, by country, in tonnes of REO equivalent 1988-2013.

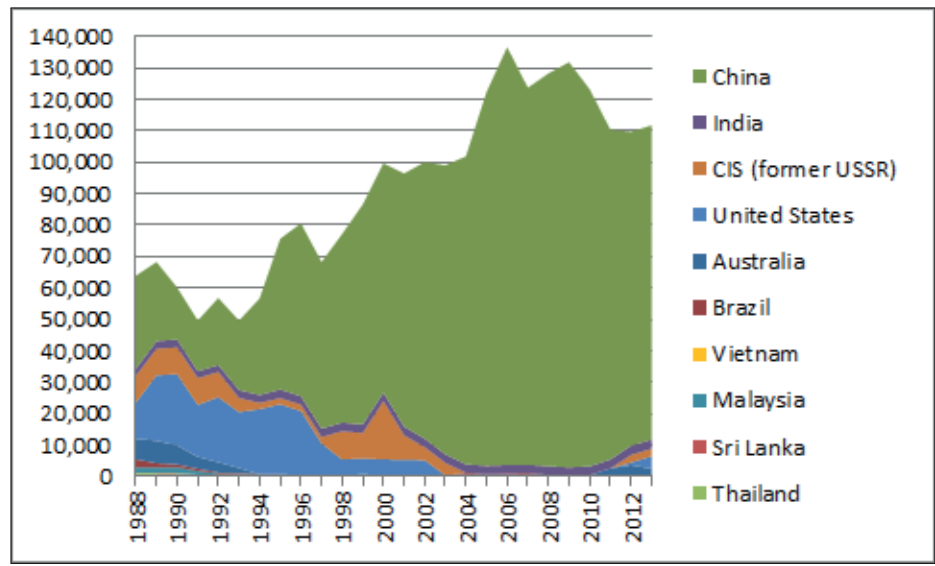

Source: Based on estimates collected from U.S. Geological Survey (2013, 2014). 
Figure 3.5: Comparison of world mine production, by country: a) 2009 and b) 2013 .

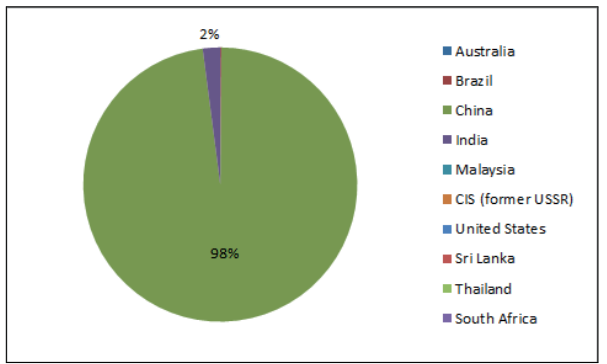

(a) 2009

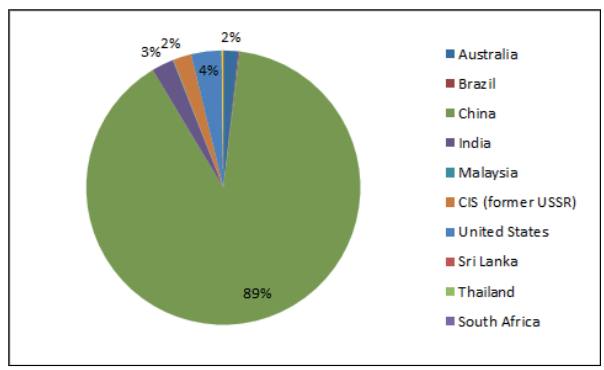

(b) 2013

Source: Based on estimates collected from U.S. Geological Survey (2013, 2014).

Two things need to be noted when discussing Chinese rare earth production. First, the Chinese Government has been setting yearly production quotas, putting forward the environmental damage. To-date these have always been exceeded by production companies. For example, while the quota set by the China Ministry of Land and Resources in 2006 was 86'620, the estimated production was 133 '000 tonnes, exceeding it by 55\%. According to Tse (2011), the discrepancy between sustained high production levels and quotas can be explained by competition among local governments, which derive substantial financial resources from rare earth producers. By 2013, quotas smoothly increased to 93'800 tonnes (MLR, 2013) with a substantially lower production, exceeding the former by a $7 \%$ only (see Table B.1 in Appendix). Quotas limit especially the production of HREE by allocating only $17^{\prime} 900$ tonnes to ionic clays, what is less than $20 \%$ of the overall production allowed. Second, in an attempt to consolidate the industry and to minimise environmental damage, China has been tightening rare earth supply by shutting down illegal mines. During the past years, altogether 110 mines were closed down in the South-Eastern provinces (Information Office of the State Council, 2012; MOFCOM, 2012e). According to estimates, 22'320 tonnes of rare earths were smuggled out of the country in 2011, what represents $130 \%$ of the legally exported quantity (MOFCOM, 2012k). Most of the illicit materials are claimed to have been transported through Taiwan and Hong Kong for further processing in Japan and Vietnam (Want China Times, 2010).

The country has also introduced rare earth export quotas, aiming at satisfying the increasing domestic demand on the one hand and at conserving exhaustible natural resources in line with the 10th Five-Year Plan on the other (Information Office of the State Council, 2012). These became a further source of global market 
distortion and triggered the EU, Japan and the US to log a joint complaint to the WTO (2012). Similarly as in case of Chinese export restraints on bauxite and other industrial materials, the WTO has recently judged the imposition of export duties and quotas on rare earths incompatible with its rules, in that they violate free trade in favour of China's domestic industry. In line with this, China has abolished the export quotas in 2015, yet replaced these with resource tax and export licensing (MOFCOM, 2014a; Shen, 2015). In order to illustrate the extent to which export quotas harmed international trade in reality, Figure 3.6 offers an overview of production, exports and their respective quotas during the past 10 years. The collected data and notes are summarised in Table B.1 within the Appendix. In particular, the export quotas have been decreasing ever since 2005 a reduction by $50 \%$ to 2013 - with the largest annual drop in 2010 by $37 \%$. Since then, only minimal changes in quotas occurred. However, note that from 2011 also alloys with a much less rare earth content are counted towards the quota (MOFCOM, 2011). Though there was no consensus among experts on how the inclusion of ferro-alloys impacted these quotas, in general this seemed to pose no further constraints on satisfying the global demand.

Figure 3.6: Chinese rare earth production and exports, and respective quotas, in tonnes of REO equivalent, 2000-2013.

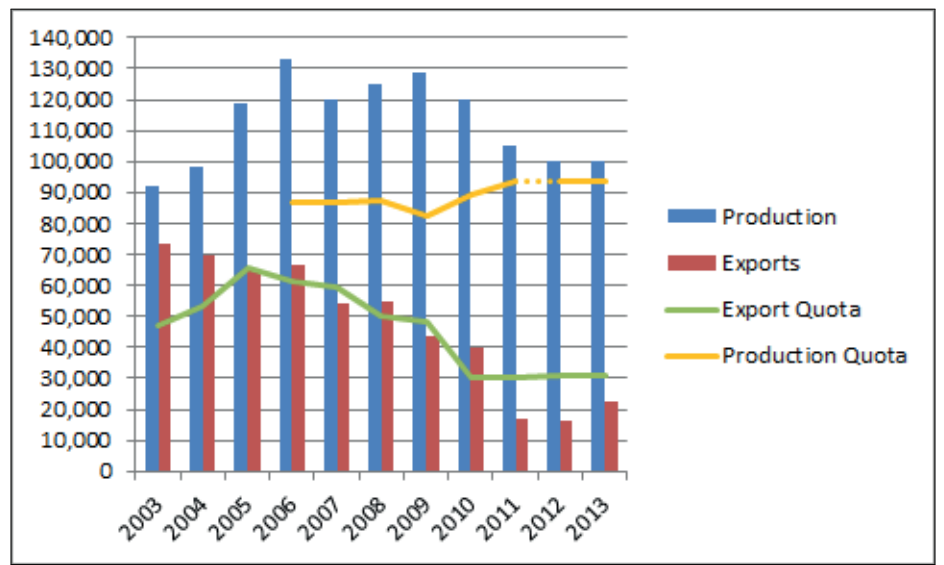

Source: Based on data collected from MOFCOM (2014b); Tse (2011); UN Statistics Division (2013); U.S. Geological Survey (2013, 2014).

Examining the export quotas jointly with the actually exported quantities of rare earths sheds light on how the earlier tight supply turned into a surplus in 
recent years. ${ }^{4}$ In fact, while during the initial years of tightening quotas have limited the actual exports, the majority of quotas remained unfilled in the subsequent years. Chinese exports to the rest of the world shrunk by $70 \%$ between their low in 2012 and the 2008 financial crisis. In fact, due to the weak post-financial crisis global demand, but also due to West running down huge accumulated rare earth stocks during 2010-2011 (Kingsnorth, 2013b), Chinese exports decreased to only a little above the half of the authorised quantities in 2011 and 2012. This trend is expected to reverse with the recovery of major rare earth-importing economies and with the depletion of stockpiled material (Kingsnorth, 2013b; Topf, 2013c). Indeed, the Figure 3.6 indicates a yearly increase in exports by almost 40\% in 2013. Moreover, just like with production quotas, also in case of export quotas there was a split between LREE and HREE. Since 2012, when China started to report the quotas separately for the two groups, the HREE were capped to roughly $12 \%$ of the total. According to China's rare earth development plan, the country intended to maintain tight supply for some of the critical rare earths, namely dysprosium and terbium (Tse, 2011). Along these lines, Lifton (2013) argues that China itself is about to loose self-sufficiency in some of the HREE since "they don't have any more deposits [...] and the other is, they don't want to strain what they've got". Hence, China started to look at global deposits in order to secure its future sources of supply. The Acquisition of a stake in Australian Arafura, as well as the attempted purchase of controlling stakes in both Lynas and Molycorp are examples of China's expansionary attempts to foreign mining territories. Furthermore, there are also signs of China's interest in North Korean rare earths (Schearf, 2014; Wee, 2014).

In conclusion, the present "abundance" of rare earths in terms of unfilled quotas is not to be overestimated, considering the economic recovery of the major importers of Chinese rare earths. While LREE might be back in balance in short term due to new non-Chinese suppliers entering the market, the skewed distribution of HREE-rich deposit reserves in China and the threat of their depletion, along with tight production quotas are expected to cause substantial supply shortages in the near future, especially for the elements labelled critical.

\section{Made in China}

Economically speaking, the industrial policies discussed above benefit domestic producers in that they make more supply available at lower prices. This is in line

\footnotetext{
${ }^{4}$ There seems to be a discrepancy between export quotas as reported by MOFCOM (2014b) and actual exports as collected from UN Statistics Division (2013). Unfortunately, Chinese customs data were not available for comparison.
} 
with China's resource nationalism, whereby export quotas in the past and resource tax and export licensing limitations in force now, are set to satisfy country's own need of rare earths for manufacturing. For industrial upgrading in China speaks also the fact that export quotas were only set for REO and for some metals and alloys, yet not for products higher in the value chain.

Looking at the Figure 3.6, the increasing wedge between the production and the export quotas points to a rising domestic consumption of rare earths. Indeed, while the Chinese consumption was smooth in the 1990s, there was a dramatic increase in the first decade from 19'000 tonnes in 2000 to almost 73'000 tonnes in 2007 - an increase by some $280 \%$ (Zhanheng, 2010). According to estimates by Kingsnorth (2011) adapted in Figure 3.7, China was the major consumer of rare earths with $58 \%$ of estimated global demand, followed by Japan and the North East Asian countries with $22 \%$, the United States with $12 \%$, and $8 \%$ of the global demand spread in the rest of the world.

Figure 3.7: Estimated global rare earth consumption, by country and sector, in tonnes, 2010.

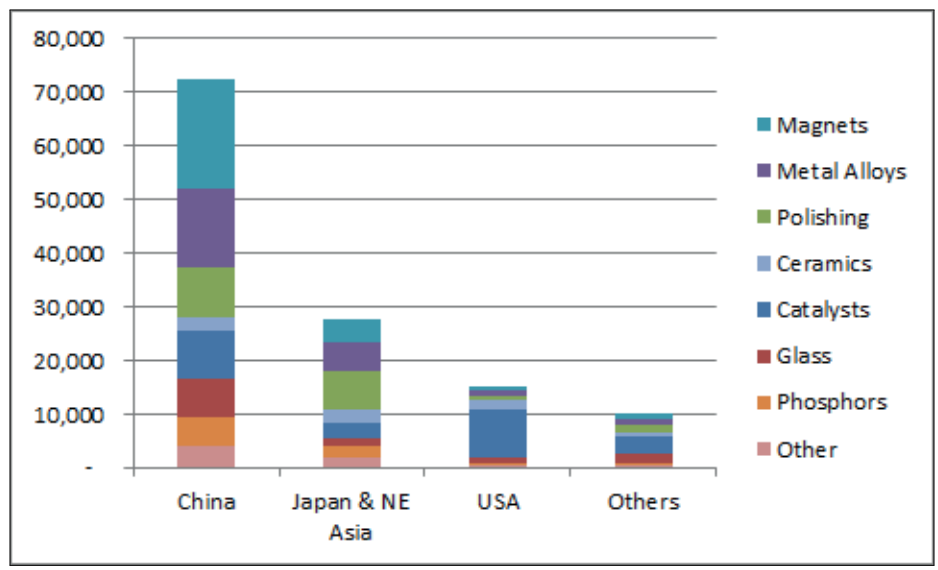

Source: Adapted from Kingsnorth (2011).

Furthermore, as illustrated by Figure 3.8, this increase has been mainly driven by increased production of magnets and phosphors. According to the 2010 data, China manufactured $79 \%$ of all magnets, two thirds of alloys, glass and phosphors, as well as half of the world's phosphor powders. Concerning its dominance in producing magnets in particular, China supplies 80'000 tonnes of NdFeB annually, half of which is used domestically (Kosich, 2013). In spite of this, China currently holds no international patents on neodymium magnets. These are controlled exclusively by the two inventors: Magnequench (previously General Motors, currently owned by Molycorp) which has rights on bonded and hot pressed magnets; and 
Hitachi (previously Sumitomo) with patents on sintered magnets. The latter owns over 615 of them and as of July 2013 licensed some to 2 companies in Japan, 3 in Europe, and 9 in China (Benecki, 2013). Concerning the latter, out of 200 Chinese manufacturers only a quarter holds these licences and can manufacture and sell them worldwide. Those without licenses have filed a complaint against Hitachi extending patent expirations for process patents, what infringes patent rights and ultimately hinders Chinese magnet exports (Kosich, 2013). The legal dispute is not expected to end soon, but should the court rule in favour of Chinese producers, this could lead to concentration of the entire rare-earths-to-permanentmagnets supply chain in Chinese hands. In fact, China already dominates the supply chain from extraction, through processing to production of most finished manufactures. Especially the latter shall contribute to China's economic growth, exporting rare earths in higher value-added forms, which are worth more than in concentrate form.

Figure 3.8: Chinese rare earth consumption, in tonnes, 2001 and 2011.

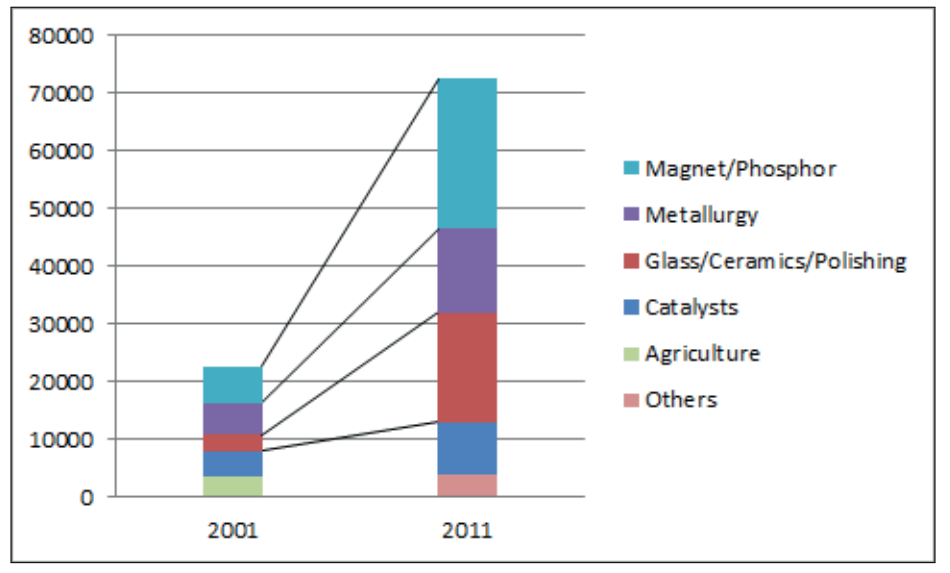

Source: Adapted from Hong (2006); Kingsnorth (2011).

The Chinese efforts to achieve industrial upgrading can be best understood by analysing its science and technology (S\&T) policies. These are drawn up by the Ministry of Science and Technology and target long terms objectives of becoming an innovative nation by 2020 (Mancheri, 2012). The innovation efforts in rare earths started in the 1980s with the approval of the National High Technology Research and Development Program (also labelled as Program 863). This aimed at narrowing the technology gap between China and the developed world by leapfrogging those high-tech fields in which China had relative advantages. Among others, the program focused on rare earths due to their strategic significance and geologi- 
cal abundance (Hurst, 2010). It was followed up on by the National Basic Research Program in the 1990s (Program 973) - a basic research program targeting major strategic needs of the country. Currently, both fundamental and applied research on rare earths is carried out in four major laboratories, focusing mainly on rare earth chemistry, physics and exploration, as well as on environmental protection and on rare earth utilization in both traditional industries and in form of new functional materials. Besides this, the Chinese Society of Rare Earths publishes the only periodic publications focusing on rare earths and organises conferences on rare earth development and application. In terms of research in various fields of rare earth chemistry, paper contributions by Chinese researchers have been increasing ever since 2001 (as opposed to those of Japanese and American researchers) and have made China to become the global center of research for rare earth science and technology (Adachi et al., 2010). These efforts not only made China to become a leader in the global rare earth ore production, they also allowed it to gradually move higher in the value chain. In fact, according to historical export data (UN Statistics Division, 2013), while there has been a gradual decrease in China's exports of rare earths in form of compounds and phosphors since early 2000s, the exports of magnets and motors, and later of high-tech products such as cell phones and electric motors have been picking up in recent years.

In summary, there are two conclusions to be drawn from this discussion. First, China owes its dominant position in the entire rare earth supply chain to its long term S\&T policies. Second, the recent industrial policies not only threaten the availability of supply of rare earth compounds and metals to rest of the world, they also threaten to shift the dominance over the entire supply chain to China.

\section{Can the world compete?}

As previously noted, abundant reserves of rare earth minerals are distributed globally. For example, bastnäsite is mined in Mountain Pass, California - currently the largest non-Chinese deposit of predominantly LREE. Lateritic material in Australia's Mount Weld and Brazilian Araxá is also enriched with deposits with high LREE/HREE ratios. Finally, LREE-dominated Monazite-rich laterite hard-rocks are being examined in under-explored areas of Africa. Instead, peralkaline ingenuous rocks in Russia's Kola Peninsula are a rich deposit of HREE (Walters and Lusty, 2011; Castor and Hedrick, 2006; Long et al., 2010). Additionally, discoveries were made in Greenland, Sweden and Canada, as well as at seabed of Pacific Ocean. Furthermore, it is claimed that the world's largest rare earth deposits are located in North Korea, though no official statistics exist (Els, 2013). Further to these, as of 2011 there were in total 381 projects outside China located across 35 
different countries (Hatch, 2011a). Table B.2 in the Appendix lists a selection of the most advanced non-Chinese projects as identified by Hatch (2014), based on their relative in-situ quantities and on relative physical distributions of specific REO. All these projects contain LREE-rich minerals, in particular lanthanum, cerium and neodymium oxides. But only a few of them are sources of HREE dysprosium, terbium, and yttrium oxides: Bokan, Norra Kär, Kutessay II, Kipawa, Strange Lake and Nechalacho Basal. The top five ranked projects in terms of critical rare earth oxide (CREO) rich deposits are Mount Weld, Steenkampskraal, Bokan, Strange Lake and Norra Kärr. Respective distributions and REO grades can be retrieved from Hatch (2014).

Most of these projects are currently still under development, with stages varying from feasibility studies to initial drilling. Some of the industry experts do not expect the majority of the projects to develop into actual mines, forecasting a success rate of 1-2\%, many of the junior projects already fighting insolvency (Hatch, 2011a; Kingsnorth, 2013a; Schlumpberger, 2013). Moreover, deployment of the few successful ones is not expected to occur before 2017 (Kingsnorth, 2013a). The main barriers to market entry are long lead times due to lengthy mine permitting procedures of up to 10 years (Clagett, 2013), environmental considerations in view of higher ecological standards in developed countries, but also financing ${ }^{5}$, and lack of capabilities in terms of technically trained personnel with expertise and experience in various aspects of rare earth processing and engineering outside of China (Gschneidner Jr, 2010).

Concerning the already producing mines, Mount Weld and Mountain Pass are currently the largest projects with yearly productions capacities of 11'000 tonnes and 15'000 tonnes, respectively - both having the possibility to increase these further depending on the market conditions. However, looking at their annual sales figures at 5'626 tonnes and 13'118 tonnes of REO for 2013 respectively, both fall short of their production quotas (Lynas Corporation, 2014; Molycorp, 2014). While this is caused by currently low demands of cerium - the major product of the two - it is expected that the increased demand for permanent magnets and electric vehicle batteries will push up the demand for lanthanum and neodymium - their other major REO products. Another source of non-Chinese rare earths is a the Indian Rare Earths project which is mining and processing monazite to yield cerium, neodymium, praseodymium and lanthanum in Kerala. Of the CIS countries, Russia and Kyrgyzstan are in possession of rare earth deposits which however are currently not mined, though production occurs from stockpiles. Despite the

\footnotetext{
${ }^{5}$ For illustration, capital costs for the Nechalacho project were estimated at $\$ 1.575$ billion (Avalon, 2014).
} 
low shares of global production of Lynas, Molycorp and Indian Rare Earths - only $2 \%, 4 \%$ and $3 \%$ respectively in 2013 - these were expected to remain the major sources of non-Chinese LREE and their share to increase in the future. However, persisting low rare earth prices and increasing capital needs have recently forced Molycorp and its North American subsidiaries to file for bankruptcy protection (Shah, 2015). In contrast, while CIS currently supplies $2 \%$ of global market, it is expected to expand its operations in 2015 for production of HREE (Prentice et al., 2013). Currently there exist no HREE producers outside China.

Besides ensuring countries' domestic availability of rare earths, additional trends have emerged as a response to Chinese industrial policies. On the level of countries, rare earth importers strive to diversify their sources of supply by strengthening relations with rare earth producers in order to secure foreign resources. Especially Europe and Japan, which do not have access to domestic rare earth resources, have been active in pursuing rare earth diplomacy by setting up cooperation with other countries to jointly explore rare earths. In case of the latter, joint projects with Vietnam (Toyota/Sojitz - Government of Vietnam), India (Toyota - Indian Rare Earths) and Kazakhstan (Sumitomo - Kazatomprom) are expected to come through by 2016 (Fontanella-Khan, 2010; Kingsnorth, 2013a; Sumitomo Corporation, 2012). Regarding the EU, this intends to pursue raw material diplomacy through policy and raw material dialogues, such as the Africa-EU Joint Strategy 2011-2013 (European Commission, 2011).

On the level of companies, two strategies are pursued. Some companies started to relocate their permanent magnet manufacturing facilities to China in order to secure stable and cheaper supply of rare earths (Hayes-Labruto et al., 2013). This links back to the statement by the Vice-chairman of Inner Mongolia Autonomous Region: "imposing controls and reducing exports aim to attract more factories using rare earth metals from home and abroad to Inner Mongolia" (Dingding, 2009). In fact, China's double pricing of rare earths in favour of domestic companies and joint ventures (see Table 3.6) encourages moving production facilities, and with them also technological capabilities to China. The latter thus benefits from foreign technology and knowledge on permanent magnets, what ultimately facilitates its endeavours to climb up the value chain of rare earth products. Other companies responded by creating various linkages across the supply chain. On the upstream side, Lynas assures a yearly supply of 9'000 tonnes to Sojitz, and Molycorp of 10'000 tonnes of rare earths to Mitsubishi (Watanabe and Suzuki, 2012). Similarly, through a strategic alliance with Lynas, Rhodia secures its supply of LREE (Brindal, 2010), while Toyota is to source HREE in the future from Matamec's Kipawa deposit (Miller, 2014). On the downstream side of the supply chain, Moly- 
corp and Hitachi agreed to create a joint venture with the aim of producing rare earth alloys and magnets. This would have assured Molycorp a fully integrated position across the mine-to-magnets supply chain (Stynes, 2010). Furthermore, Avalon Rare Metals entered into an agreement with Solvay under which the latter will process its concentrates into REO (Avalon Rare Metals, 2014).

To sum up, the rest of the world strives to mitigate import dependence of rare earths on China by opening new mines, by tightening relations with countries in possession of rare earth-rich deposits and by closing strategic alliances on company level. While the former is a long term strategy, the latter two are more viable in the short term. In conclusion, from the discussion on industrial uses and on the Chinese hegemony in both production and supply of rare earths, it follows that tighter supply might adversely impact the adoption of technologies which make use of these. In this light, Section 3.4 analyses the demand side as driven by lowcarbon technologies, in an attempt to investigate on the extent to which potential supply shortages pose a barrier to deployment and innovation in these technologies.

\subsection{Demand push}

The increasing demand for rare earths constitutes the other side of the coin within the supply risk debate. Based on the estimates by Kingsnorth (2013c), global demand for rare earths has increased from 85,000 tonnes in 2009 to 125,000 tonnes in 2013, and is forecasted to increase further to 150,000 - 170,000 tonnes in 2016 and to $200,000-240,000$ tonnes in 2020. While this represents an increase by almost 200\% for rare earths as a group, one has to keep in mind that individual rare earths differ in their uses across technologies. This in turn influences their respective demands. According to data in Figure 3.9, the estimated individual demand is highest for cerium, lanthanum and neodymium. Together they constitute some $85 \%$ of the estimated total global demand in 2016. Based on information reported in Table 3.2, demand for these is driven predominantly by hybrid and electric vehicles and by wind turbines, as well as by mobile devices, catalysts, glass and water purification. Indeed, Kingsnorth (2013c) estimates the yearly growth rates of $4-6 \%$ for catalysts and glass and of $8-12 \%$ for permanent magnets, between 2013-2016. The latter may further increase up to $20-25 \%$ annually by 2020 . The large shares of LREE within the demand as a whole are due to the generally larger quantities these are used in within various technologies. On the contrary, shares of HREE in total demand are relatively small. In spite of this, one should not underestimate their functional criticality. For example, dysprosium only constitutes $1 \%$ of the total rare earth demand, yet it is indispensable in permanent magnets due 
to its ability to increase latter's coercive force and magnetic flux density. In fact, Alonso et al. (2012a) forecast an increase of up 724\%, 669\% and 2630\% during the coming 25 years, for neodymium, praseodymium and dysprosium respectively, originating from the production of wind turbines and electric vehicles which make use of permanent magnets. ${ }^{6}$ Additionally, strong demand growth is driven by competitive pressures from other technologies making use of permanent magnets, such as mobile phones and computing.

Figure 3.9: Global demand forecast for individual rare earths, accuracy of data $+/-20 \%$, in tonnes, 2016.

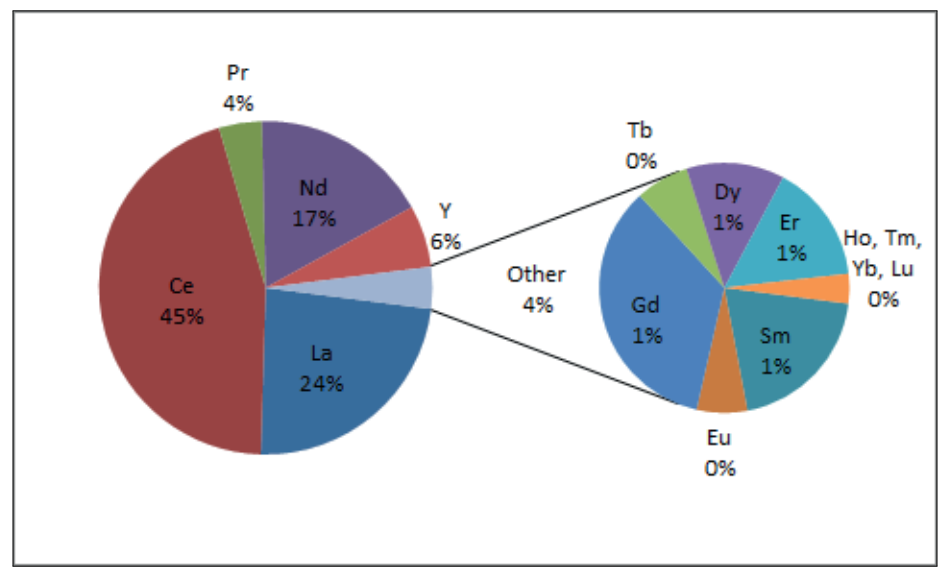

Source: Adapted from Kingsnorth (2013c). Data are a courtesy of Professor Kingsnorth.

It follows from the above, that an increased adoption of low-carbon technologies, driven by institutional settings such as the United Nations Framework Convention on Climate Change and the EU's Strategic Energy Technology Plan on the one hand, and by growth of emerging economies on the other, is to exercise pressure on some rare earths to a larger extent than on others. In this light, the present section examines the specific case of offshore wind turbines and advanced technology vehicles - the two technologies which were identified by scientific literature as the major drivers of change in the rare earth demand, and which are often incorrectly claimed as impossible to be manufactured without rare earth content. As already noted, the criticality of minerals for energy applications, and of rare earths in particular, was put forward by various reports (Bauer et al., 2010, 2011; European Commission, 2010, 2014c; Kawamoto, 2008; Moss et al., 2011). In addi-

\footnotetext{
${ }^{6}$ These are upper bound projections in absence of reuse, recycling and efficiency-in-use improvements, assuming aggressive automotive electrification, all wind using permanent magnets, while other rare earth market demand growing at historical rates.
} 
tion to these, several studies attempted to develop demand scenarios by estimating future deployment of various rare earth-intensive technologies (Alonso et al., 2012a; Elshkaki and Graedel, 2013; Habib and Wenzel, 2014; Hoenderdaal et al., 2013). Although these studies provide a valuable insight into potential medium- to longterm rare earth constraints, their scenario projections rely on strong underlying assumptions about technological inertia. In the case of wind energy, the authors assume solely the most rare earth-intensive direct drive wind turbines to be installed offshore. In reality, however, technological development occurs in the face of changing regulatory frameworks and market conditions. Manufacturers tend to hedge against market volatility by efficiency-in-use improvements, manufacturing alternative designs with reduced rare earth content. Nonetheless, substitution across different wind turbine generator technologies has received little attention in the literature so far. Zepf (2013) was the first to acknowledge the coexistence of various topologies, yet he failed to account for their respective rare earth intensities and thus overestimated their cumulative consumption. In this light, the current section offers an overview of various wind turbine designs and their respective rare earth intensities and market shares. Similarly, in the case of electrically powered vehicles, the section reviews rare earth contents within electric motors and batteries, as well as in small magnets scattered across various parts of vehicles. The latter have been disregarded in scenario development so far, what has led to an underestimation of rare earth demand in automotive markets in general. The main contribution of the section is thus to provide a realistic picture of the dependence of these technologies on rare earths. At the same time, the findings might serve as input for future rare earth demand scenario projections.

The analysis is carried out by first compiling an overview of existent topologies of generators, electric motors, batteries and other rare earth-intensive parts of vehicles and by establishing their respective rare earth contents. For this purpose, specialised engineering and material science literature is reviewed. Results of this literature review constitute an important contribution in that they reveal the coexistence of a variety of topologies, some of which are less rare earth intensive than others. Unfortunately, the scarcity of public information and the lack of consensus do not allow to capture varying compositions of magnets and batteries across different applications and manufacturers within the current analysis. Second, current and future trends in deploying particular technology designs are determined. A database is created collecting information on installed offshore wind turbines as well as on advanced technology vehicle models and battery types. Such analysis generates an overview of the current offshore wind and advanced technology vehicle landscapes in unique detail and ultimately allows the determination of cumulative 
shares of rare earth consumption.

\subsubsection{Offshore wind turbines}

The central priority of the SET-Plan is to create a low-carbon economy and wind power is one of the technologies foreseen to contribute to this transition (Moss et al., 2011). Wind is the fastest growing renewable energy source; it has increased sevenfold over the past 10 years (Global Wind Energy Council, 2014). However, limited space for further development of wind energy onshore, the availability of higher wind speeds, and opportunities to launch industrial wind projects of magnitudes parallel to power stations, led to progressive siting of wind turbines offshore (Hau and Renouard, 2013). In line with this, recent R\&D projects are focusing on challenges primarily in offshore technology, specifically on increasing their capacity, on alternative support structures, on farm layout optimization as well as on their protection (Sun et al., 2012). In terms of drive train innovations, the focus is on improving reliability of gearbox and developing direct drive and hybrid drivetrain technologies. Since these differences are relevant for the rare earth supply risk debate, these technologies are discussed below in more detail.

In the evolution of wind turbine technology, early machines operated at constant speed with gearbox and squirrel cage generator (SCIG) and were later replaced by variable speed machines with doubly-fed induction generators (DFIG) (Kostopoulos et al., 2012). This traditional design with gearbox, connecting the generator with the rotor is also denoted as the conventional Danish concept and is considered as one of the two main standard designs. In this arrangement, gearbox converts mechanical rotational motion of rotor into faster revolutions per minute (rpm) used by the generator, which in turn converts mechanical energy into electrical power by spinning magnets around the coil. Multistage gearboxes prove to be complex machines, their efficiency depending on the number of gear stages and on the power transmitted (Hau and Renouard, 2013). Of designs ranging from a single to three stage systems of planetary and parallel configurations, the most common to be found in larger turbines is one with planetary and two parallel shaft stages. While the main advantage of this traditional wind turbine design lies within the conversion of rotor torque into rpms used by the generator, the main disadvantage is its large number of moving parts such as wheels and bearings. If applied in an offshore setting, faster wind speeds tend to aggravate the problem further (Morris, 2011). In fact, wear of gearboxes renders the technology unreliable, main sources of failure stemming from incorrect dimensioning with respect to load spectra, what makes them most maintenance prone and one of the most expensive parts of a wind turbine (Hau and Renouard, 2013). While gearboxes do 
not suffer from largest failure rates, they have the longest downtime of all turbine parts (Polinder, 2011). In response to this, various efforts were undertaken to eliminate gearbox failures (National Renewable Energy Laboratory, 2007).

After several decades striving to increase the reliability of gearboxes by prolonging their design lives and reducing their servicing schedule, it was proposed to eliminate them completely in order to decrease maintenance costs. This resulted in developing the first gearless generator system by Enercon in 1992 - the direct drive generator with copper windings. In this arrangement, the generator mounted in the nacelle is directly connected with the rotor shaft (Hau and Renouard, 2013). Enercon's electric excitation synchronous generator (EESG-DD) is much larger compared to the high speed generator in the traditional gearbox design. In fact, more electrically excited pole pairs are required in order to generate electricity at low rotational speed, and the larger radius of rotation increases speed of the rotation of magnets around the coil. This however causes the generator to be heavier, what negatively affects weight of tower heads. In addition to this, electromagnets are fed with electricity from the generator itself what causes excitation losses. These issues were partially corrected for with replacement of electromagnets by permanent magnets within the generator's rotor - the so called permanent field excitation generators (PMSG-DD). These do away with excitation losses and greater power density, increase efficiency and grid compatibility of generators and reduce the size of the generator itself and consequently eliminate the heavy nacelle (Hau and Renouard, 2013; Polinder et al., 2006). The design has quickly been adopted by manufacturers and is currently established as the second main standard. Its disadvantage lies within additional cost of a fully rated electronic converter necessary for grid connection (McMillan and Ault, 2010; Arabian-Hoseynabadi et al., 2010), as well as within the cost of rare earth materials used in permanent magnets (Hau and Renouard, 2013). Even though the latter has been decreasing over time, it becomes more relevant with larger dimensions of megawatt (MW) power range wind turbines.

The technology which reduces the use of permanent magnets in wind turbines is a compromise between the two standards. For example, the Multibird wind turbine by Areva contains a drive train machine with a single-stage gearbox combined with a medium speed permanent magnet generator (PMSG - SG). This system combines the advantages of the two standards by decreasing the size, weight and cost and increasing the efficiency of the generator (Hau and Renouard, 2013; Polinder et al., 2006). A more complex design by Aerodyn is made up of Super Compact Drivetrain containing a two-stage gearbox with a permanent magnet generator (PMSG - MG) directly attached to it (Hau and Renouard, 2013). 
Finally, the High Temperature Superconductor (HTS) technology originates from ship propulsion and is currently under development by American Superconductor, General Electric and Suprapower.

Understanding the differences in drivetrain designs is important in the discussion of how rare earths are impacting the deployment of offshore wind turbines. An overview of these technologies can be found in Hau and Renouard (2013) and a discussion on their respective merits and disadvantages in Arabian-Hoseynabadi et al. (2010); Jensen and Abrahamsen (2011); McMillan and Ault (2010); Polinder et al. (2006); Polinder (2011). Table 3.3 summarises generator topologies and is complemented with information on respective magnet and rare earth contents. From information presented in the Table, it follows that by far not all wind turbine technologies use rare earths in their generators. While no permanent magnets are used in either traditional geared and electrically excited gearless drivetrains, reportedly $650 \mathrm{~kg} / \mathrm{MW}$ are used in low speed direct drive machines with permanent magnet excitation. Substantially smaller permanent magnets are used in hybrid drivetrains, with $160 \mathrm{~kg} / \mathrm{MW}$ in medium speed single-stage and $80 \mathrm{~kg} / \mathrm{MW}$ in high speed multi-stage gearbox machines. In terms of rare earth content, PMSG-DD machines with $250 \mathrm{~kg}$ of neodymium, dysprosium, praseodymium and terbium use up 10 times more rare earths per MW of power produced than hybrid designs (Vestas, 2013; Wittrup, 2011). Compared to this, YBCO coated conductors of HTS generators utilise minute quantities of yttrium, barium and copper per MW (Janssen et al., 2012). Figures reported in Table 3.3 are estimates. There is a lack of consensus on permanent magnet content within these generators and publicly available information is scarce. Opinions on permanent magnet content within direct drive generators range from 500-625 kg/MW (Constantinides, Steve, 2010) through 600-800 kg/MW (Jensen et al., 2013), up to $1000 \mathrm{~kg} / \mathrm{MW}$ as reported by various consultants. Magnet and rare earth contents reported in Table 3.3 are based on information by Jensen and Abrahamsen (2011) and Lacal Arántegui et al. (2012). In terms of individual rare earth shares, neodymium is estimated to constitute roughly $30 \%$ of magnet weight, whereas figures for dysprosium vary from $0.8 \%$ (E-magnets UK, 2014) to $11 \%$, depending on the demagnetisation stress (Constantinides, 2012). In fact, doping magnets with dysprosium improves their coercivity and performance at higher temperatures. Neodymium magnets also contain traces of praseodymium and terbium.

Given the coexistence of different drive train technologies, the next step is to examine their penetration within the offshore market. For this purpose, all offshore wind farm projects were screened globally by deployment phase. Data on turbines and their power ranges was collected for fully and partially commissioned projects, 
Table 3.3: Generator types in wind turbine technologies and their respective permanent magnet and rare earth contents.

\begin{tabular}{|l|l|l|l|l|}
\hline \multirow{5}{*}{ Wind Turbine } & Gearbox & Generator & $\begin{array}{l}\text { Permanent } \\
\text { Magnet }\end{array}$ & Rare Earths \\
\hline \multirow{5}{*}{$\begin{array}{l}\text { Geared } \\
\text { Drivetrain }\end{array}$} & Single-Stage & Induction (IG) & - & - \\
\cline { 3 - 5 } & \multirow{5}{*}{ Multi-Stage } & $\begin{array}{l}\text { Wound Rotor Induction } \\
\text { (WRIG) }\end{array}$ & - & - \\
\cline { 3 - 5 } & & Squirrel Cage (SCIG-MG) & - & - \\
\cline { 3 - 5 } & $\begin{array}{l}\text { Doubly Fed Induction } \\
\text { (DFIG-MG) }\end{array}$ & - & - \\
\hline \multirow{5}{*}{ Hybrid } & $\begin{array}{l}\text { Electrical Excited } \\
\text { Synchronous (EESG-DD) }\end{array}$ & - & - \\
\cline { 3 - 5 } & $\begin{array}{l}\text { Permanent Magnet Excited } \\
\text { Synchronous (PMSG-DD) }\end{array}$ & $650 \mathrm{~kg} / \mathrm{MW}$ & $\begin{array}{l}250 \mathrm{~kg} / \mathrm{MW} \\
(\mathrm{Nd}, \mathrm{Dy}, \mathrm{Pr}, \mathrm{Tb})\end{array}$ \\
\cline { 3 - 5 } & $\begin{array}{l}\text { High Temperature } \\
\text { Superconducting (HTS) }\end{array}$ & - & $\begin{array}{l}0.1 \mathrm{~kg} / \mathrm{MW} \\
(\mathrm{Y}, \mathrm{La}, \mathrm{Ce})\end{array}$ \\
\hline \multirow{5}{*}{ Single-Stage } & $\begin{array}{l}\text { Permanent Magnet } \\
\text { Synchronous (PMSG-SG) }\end{array}$ & $160 \mathrm{~kg} / \mathrm{MW}$ & $\begin{array}{l}45 \mathrm{~kg} / \mathrm{MW} \\
(\mathrm{Nd}, \mathrm{Dy}, \mathrm{Pr}, \mathrm{Tb})\end{array}$ \\
\cline { 3 - 5 } & $\begin{array}{l}\text { High Temperature } \\
\text { Superconducting (HTS) }\end{array}$ & - & $\begin{array}{l}0.02 \mathrm{~kg} / \mathrm{MW} \\
(\mathrm{Y}, \mathrm{La}, \mathrm{Ce})\end{array}$ \\
\cline { 3 - 5 } & \multirow{2}{*}{ Multi-Stage } & $\begin{array}{l}\text { Permanent Magnet } \\
\text { Synchronous (PMSG-MG) }\end{array}$ & $\begin{array}{l}25 \mathrm{~kg} / \mathrm{MW} \\
(\mathrm{Nd}, \mathrm{Dy}, \mathrm{Pr}, \mathrm{Tb})\end{array}$ \\
\hline
\end{tabular}

Source: Complied based on information from Buchert (2011); Hau and Renouard (2013); Jensen and Abrahamsen (2011); Lacal Arántegui et al. (2012); Polinder (2011); Zhang et al. (2011).

as well as for those under construction in 2014. Other projects under construction and in stages beyond, for which turbine types were not publicly announced, were omitted. The data was collected from dedicated online databases on global wind farms and news portals with expert coverage on offshore wind (4C Offshore, 2014; Offshore Wind, 2013; Pierrot, 2014; Recharge, 2013; Wind Power Offshore, 2013; Wind Power Monthly, 2013) and enriched with information on generator design specifications from manufacturers' websites. The results are presented in Figure 3.10 , illustrating the shares of various technologies within offshore wind market taking into consideration all projects commissioned by end of April 2014. ${ }^{7}$ In total, 99 offshore wind projects have been operating 2'463 turbines and producing $7.62 \mathrm{GW}$ of offshore wind power globally. Following observations stand out: in terms of capacity generated as illustrated in Figure 3.10a, the most widely spread design is the conventional geared drive train with squirrel cage generator, which together with doubly-fed induction generator make up $96 \%$ of current offshore market. Permanent magnet driven technology lags significantly behind, covering the remaining market share of $4 \%$, with an equal split of $2 \%$ between direct drive and hybrid generator designs. Looking at the distribution of generator types across

\footnotetext{
${ }^{7}$ The analysis is carried out on the level of deployment phase of a farm rather than of wind farms themselves.
} 
projects in Figure 3.10b, 16\% of all commissioned projects make use of permanent market drivetrain technology. This can be explained by the fact that many of these turbines are currently at prototype stage and are being tested in low numbers at various test sites. Finally, the average power range of generator types is illustrated in Figure 3.12a. While conventional geared drive train designs have similar average powers of 2.9 MW for SCIG and of 2.8 MW for DFIG, this is substantially higher for PMSG overall topologies with 3.5 MW. The average of 4.5 MW for EESG-DD is to be interpreted with caution since currently there is only one Enercon turbine deployed offshore worldwide. Having said this, it can be concluded that PMSG drivetrains, though with currently lower market share, tend to be deployed within larger power range turbines. While the UK is the leader in total installed offshore capacity, followed by Denmark and Germany, by far the most permanent magnet driven machines are at present deployed offshore in China. All of these are of direct drive designs and are supplied by Chinese manufacturers Goldwind and XEMX.

Figure 3.10: Generators in commissioned global offshore wind projects.

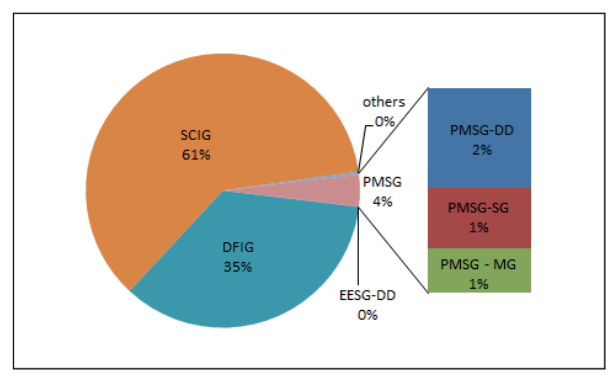

(a) Total capacity (MW)

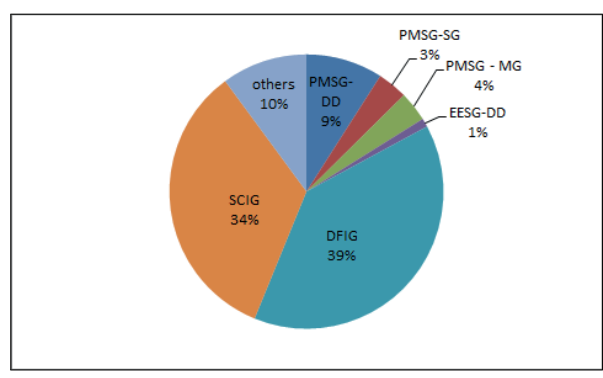

(b) Number of projects

Notes: Based on fully commissioned global offshore wind projects by end of April 2014, test sites included (unless set up onshore). Additionally, partially generating projects with installed capacities announced were included. Some of the projects still operate old wind turbine technology - these were classified as "others". Source: Data collected from websites of respective wind turbine manufacturers, as well as from 4C Offshore (2014); Offshore Wind (2013); Pierrot (2014); Recharge (2013); Wind Power Monthly (2013); Wind Power Offshore (2013).

In order to determine the growth of PMSG technology deployment in offshore wind, data on projects currently under construction was collected as well. Within this dataset, capacity generated increases by more than half to $12.72 \mathrm{GW}$ and number of turbines increases to 3'871. Moreover, looking at Figure 3.11a, the share of PMSG turbines increases to $16 \%$ of total capacity, with shares of hybrid models increasing to $5 \%$ and $6 \%$ for single and multi-stage gearboxes respectively, while the share of direct drive machines increases to $5 \%$. Share of projects rely- 
ing on permanent magnet driven technology increases to $21 \%$ - see Figure $3.11 \mathrm{~b}$. Furthermore, Figure 3.12b indicates that the average power range of permanent magnet excited machines increases slightly to 3.6 MW and the total capacity produced increases by $600 \%$ - from currently $284 \mathrm{MW}$ to 2'000 MW of produced power once these projects turn fully operational. At the same time, increase in geared drivetrains remains below $50 \%$. The market share of electrically excited generator technology remains unchanged. To summarize, there is an acceleration in deploying permanent magnet drivetrains in short term, with the pace of acceleration for hybrid drive trains being three times higher than that of direct drives. This trend is predominantly driven by Germany which is planning to add $600 \mathrm{MW}$ of power produced by PMSG turbines offshore, followed by China and the UK with 464 MW and 436 MW respectively, and Belgium with half as much additional power produced at full commissioning of projects. While Belgium and Germany will be installing only hybrid drives, half of the added MW by PMSG machines in China and the UK will be produced by direct drive generator wind turbines.

Figure 3.11: Generators in commissioned global offshore wind projects and in projects under construction.

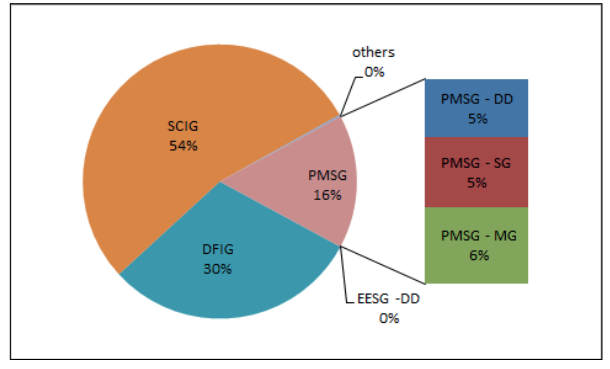

(a) Total capacity (MW)

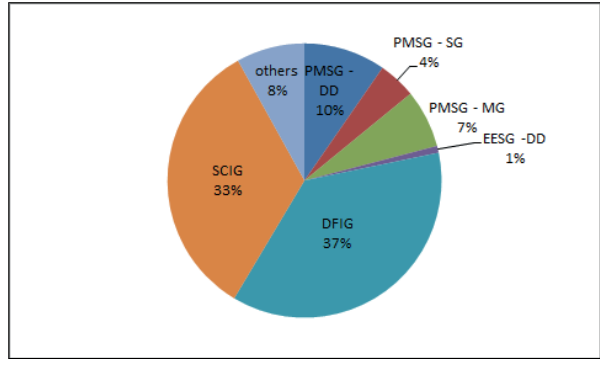

(b) Number of projects

Notes: Based on global offshore wind projects which were fully or partially commissioned or are under construction in 2014, test sites included (unless set up onshore). Projects under construction where turbine types were not publicly announced were omitted. Some of the projects still operate old wind turbine technology - these were classified as "others". Source: Data collected from websites of respective wind turbine manufacturers, as well as from $4 \mathrm{C}$ Offshore (2014); Offshore Wind (2013); Pierrot (2014); Recharge (2013); Wind Power Monthly (2013); Wind Power Offshore (2013).

This trend is further confirmed by an overview of the largest wind turbines with power ranges of up to $10 \mathrm{MW}$ (Power-technology.com, 2014): six use permanent magnet driven synchronous generator (three of them are direct drive and the other three have hybrid drives), one is electrically excited direct drive, one uses HTS and 
Figure 3.12: Average power ranges of generators.

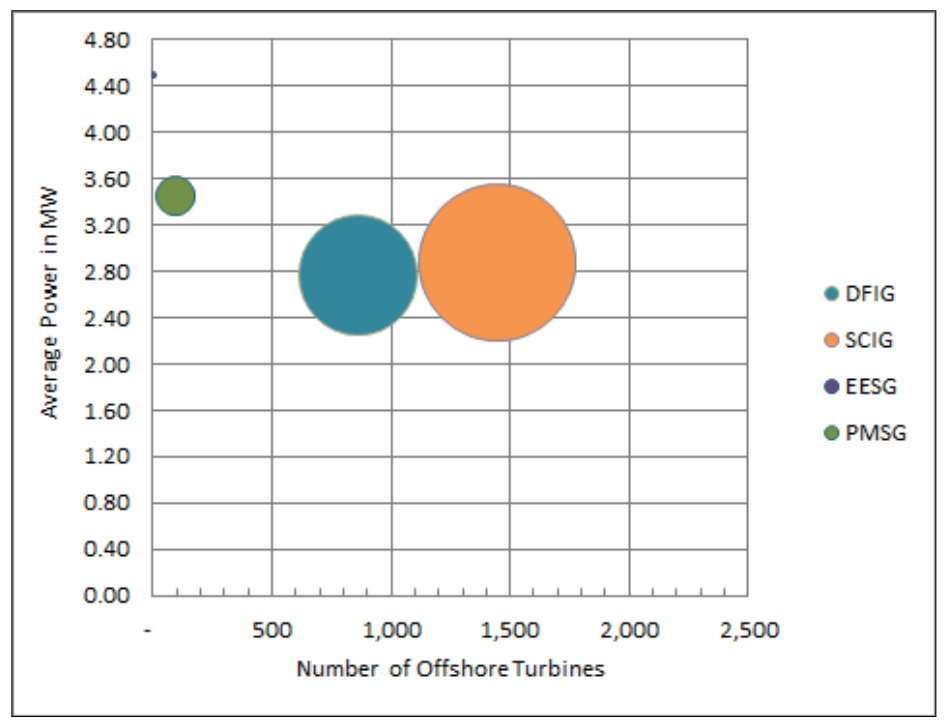

(a) Generators in commissioned global offshore wind projects.

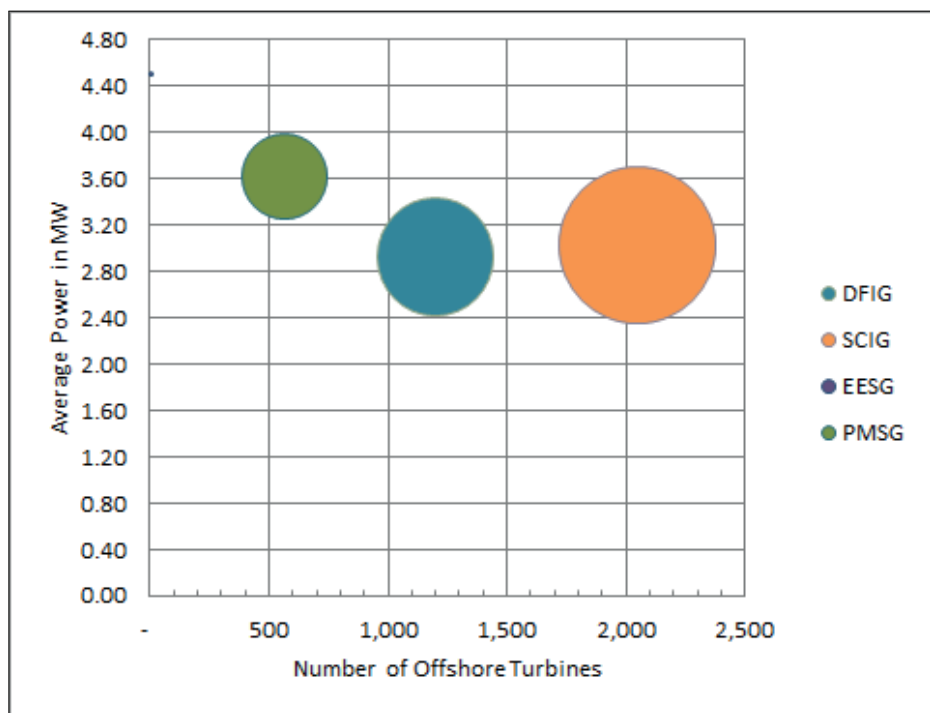

(b) Generators in commissioned global offshore wind projects and in projects under construction.

Source: Data collected from websites of respective wind turbine manufacturers, as well as from 4C Offshore (2014); Offshore Wind (2013); Pierrot (2014); Recharge (2013); Wind Power Monthly (2013); Wind Power Offshore (2013). 
the remaining two utilise conventional gearbox technology. There has also been a tendency to increase the size of wind turbines with the purpose of reducing costs and improving environmental profile of wind energy (Caduff et al., 2012). Looking at the evolution of power ratings, turbine sizes were increasing from $50 \mathrm{~kW}$ with rotor diameter of $15 \mathrm{~m}$ in the 1980s, through $10 \mathrm{MW}$ with rotor diameters of 190 $\mathrm{m}$ and with up to $20 \mathrm{MW}$ turbines currently under development (Chandler, 2004; InnWind, 2013). Having said this, it is important to note that with increasing power ranges, also the amount of rare earths increases. For example, the currently largest PMSG-DD wind turbine of $10 \mathrm{MW}$ would contain 10 times more magnets than turbines with $1 \mathrm{MW}$ power range. Assuming a rare earth content of 250 $\mathrm{kg} / \mathrm{MW}$ as specified in Table 3.3, this implies an increase to approximately 2.5 tonnes in total. Taken together, assuming contents as indicated in Table 3.3 and technology penetration in Figures 3.12a and 3.12b, 108 tonnes of permanent magnets and 40 tonnes of rare earths were used for all currently commissioned offshore wind farm projects as of end of April 2014. Additionally, for all newly installed turbines in projects under construction, manufacturing of generators required 430 tonnes of permanent magnets and slightly more than 150 tonnes of rare earths. On the one hand, this represents an increase in demand for rare earths by approximately $380 \%$; on the other hand, assuming that neodymium constitutes $70 \%$ and dysprosium $5 \%$ of total rare earths used within magnets, as indicated by Du and Graedel (2011), this adds up to less than half a percent of respective neodymium and dysprosium supplies forecasted for 2014. For completeness, note that China, unlike the rest of the world, has been installing PMSG-DD technology onshore as well. This becomes obvious when looking at sales figures of some of the Chinese wind turbine manufacturers. For example, in 2013 Goldwind sold 2'912 MW of direct drive turbine technology, which is by far more than foreseen to be installed in global offshore projects in near term (Goldwind, 2014). ${ }^{8}$ If considered in calculation, permanent magnets used in onshore wind turbines add to the consumption of rare earths, though not substantially.

It would have been interesting to offer a longer term perspective on developments in offshore turbine technology market. Unfortunately, for most of "consent authorised" projects, wind turbine models have not been decided on yet. Same applies for those in "consent application submitted" and in "concept" stages. But considering the total capacities foreseen to be installed within all consented projects, once fully commissioned they will produce between 29 and 31 GW wind power: 22.25 GW in Europe, with Germany, the UK and the Netherlands consti-

\footnotetext{
${ }^{8}$ While sold does not imply installed, this figure is a good indication of importance of direct drive technology onshore.
} 
tuting over $70 \%$, and $8.9 \mathrm{GW}$ in the rest of the world, predominantly in China. In general, future expansion of offshore wind is tied to regulatory stability, as well as to the existence of cable routes and high voltage transmission lines linking offshore wind farms to mainland grid (Hau and Renouard, 2013). Penetration of PMSG topologies in particular, will depend on availability risk and pricing volatility of rare earths on the one hand, and competition from alternative technologies on the other. There exist no estimates on market share of PMSG topologies offshore. For example, while Buchert (2011) expects that share of direct drive drivetrains will increase to $15-40 \%$ by 2020 for the entire wind market, Moss et al. (2011) assume a European penetration of $15 \%$ and $20 \%$ for wind turbines with permanent magnet technology in 2020 and 2030, respectively. At this stage it proves difficult to predict the future technology mix. The share of traditional geared machines, which despite of improvements are most maintenance prone, is expected to diminish overtime. While, it does not seem that either electromagnets or high temperature superconductors would increase their respective market shares in the short to medium term, once testing has been completed, these technologies might become a viable option due to the decreased capital expenditure (capex) and operating expenditure (opex), as well as to the increased efficiency when applied within larger power ranges. As the only commercially available alternative to gearboxes at present, it is probable that PMSG technology is to catch momentum in short run. In fact, considering its technical advantages and the global trend towards wind turbines with larger diameters, and assuming the current tendency in deployment to be further strengthened with operator's need to decrease opex and to increase efficiency, as well as timely commercialisation of such turbine models by new entrants, it can be expected that PMSG technology will gain on market share substantially. However, for this technology to remain cost competitive, it is important that supply of neodymium, dysprosium, and partially praseodymium and terbium remains undistorted both in terms of quantities and price volatilities.

To conclude with, considering the variety of drivetrain designs available on the market, further adoption of offshore wind energy per se is not impeded by potential supply shortage of rare earths. Contrary to this, the deployment of permanent magnet technology in particular, might become prone to supply risk, depending on its total market share and the level of hybridisation adopted. In fact, considering the significant price volatility of rare earths in recent years, even the relatively small quantities used in individual wind turbines might exercise a significant pressure on the final price of a wind turbine. This is further elaborated on in Section 3.6.2. 


\subsubsection{Advanced technology vehicles}

Besides reduction of greenhouse gas emissions, another main line of argumentation in favour of advanced technology vehicles, is the reduction of importer countries' dependence on foreign oil. The question remains though, to what extent does the technology shift from internal combustion engine to advanced technology vehicles expose us to dependence on rare earths.

Electrically powered vehicles were invented in Scotland and in the United States at beginning of the 19th century. The technology boomed in late 19th and early 20th century, these vehicles becoming top sellers in the United States. However, cheap and abundant oil, as well as the invention of electric starter motor, lack of battery technology fulfilling performance requirements and relatively low price of the mass produced Ford-T model prevented electrically powered vehicles from keeping up the competition with conventional internal combustion engine vehicles (Constantinides, 2013; Kirsch, 2000; Ovshinsky et al., 1993; Trigg and Telleen, 2013). Nonetheless, they caught a second breath with oil crises and more stringent environmental regulations of transportation. Based on the level of their hybridisation, modern vehicles can be classified into internal combustion engine vehicles (ICEV), hybrid electric vehicles and all-electric vehicles. Their respective hybridisation factors are provided in Tie and Tan (2013). The group of advanced technology vehicles can be further broken down based on energy sources used into battery, fuel cell and solar energy models. While all the three types have in common the electric motor drives, they differ in configurations. Namely, fuel cell vehicles are powered by hydrogen and oxygen converted by chemical reaction into electricity within fuel cell stacks, while photovoltaic cell vehicles are powered by sunray which is converted into electrical energy within solar cells (Çă̆atay Bayindir et al., 2011; Hannan et al., 2014). These two technologies are still in early stages of development and hence are not part of the current analysis. Regarding the battery technology, this varies based on the extent to which it is used to propel vehicles. Battery electric vehicles (BEV) are propelled entirely by battery packs, while fullhybrid vehicles (HEV) run on fuel alone, and plug-in hybrids (PHEV) use the combination of gasoline and battery. Both HEV and PHEV use battery as power storage units. In case of the former, the discharged battery is recharged by the internal combustion engine or regenerative braking, while it is plugged into charging stations in case of PHEV and BEV (Çă̆atay Bayindir et al., 2011; International Energy Agency - HEV, 2013; Tie and Tan, 2013). Table 3.4 provides an overview of vehicle technologies and identifies the rare earth-intensive parts and quantities used.

From the information presented in Table 3.4, it follows that the electric motor 
Table 3.4: Vehicle technologies classified by hybridisation and their respective rare earth contents.

\begin{tabular}{|c|c|c|c|c|}
\hline Hybridisation & Energy Models & $\begin{array}{l}\text { Propulsion } \\
\text { (Rare Earths) }\end{array}$ & $\begin{array}{l}\text { Battery } \\
\text { (Rare Earths) }\end{array}$ & $\begin{array}{l}\text { Other } \\
\text { (Rare Earths) }\end{array}$ \\
\hline $\begin{array}{l}\text { Internal } \\
\text { Combustion } \\
\text { Engine }\end{array}$ & $\begin{array}{l}\text { Internal } \\
\text { combustion engine } \\
(\mathrm{ICEV})\end{array}$ & $\begin{array}{l}\text { Gasoline or Diesel } \\
\text { Engine } \\
(-)\end{array}$ & $(-)$ & \multirow{6}{*}{$\begin{array}{l}\text { Various parts } \\
(0.22-0.44 \mathrm{~kg}: \\
\mathrm{Nd}, \mathrm{Ce}, \mathrm{Pr}, \mathrm{Dy}, \\
\mathrm{La})\end{array}$} \\
\hline \multirow[t]{2}{*}{ Hybrid Electric* } & $\begin{array}{l}\text { Full-Hybrid } \\
\text { Electric (HEV) }\end{array}$ & \multirow[t]{2}{*}{$\begin{array}{l}\text { Gasoline Engine and } \\
\text { Electric Motor } \\
(0.6 \mathrm{~kg}: \mathrm{Nd}, \mathrm{Dy}, \mathrm{Pr} \\
\mathrm{Tb})\end{array}$} & $\begin{array}{l}\text { NiMH } \\
(3.5 \text { kg: La, Ce, } \\
\text { Nd, Pr); } \\
\text { Li-ion, LiPo, PbA } \\
(-)\end{array}$ & \\
\hline & $\begin{array}{l}\text { Plug-in Hybrid } \\
\text { Electric (PHEV) }\end{array}$ & & $\begin{array}{l}\text { Li-ion, LFP } \\
(-)\end{array}$ & \\
\hline \multirow{3}{*}{ All-electric } & $\begin{array}{l}\text { Battery Electric } \\
(\mathrm{BEV})\end{array}$ & \multirow{3}{*}{$\begin{array}{l}\text { Electric Motor Alone } \\
(0.6 \mathrm{~kg}: \mathrm{Nd}, \mathrm{Dy}, \mathrm{Pr}, \\
\mathrm{Tb})\end{array}$} & $\begin{array}{l}\text { Li-ion, LFP, LiPo, } \\
\text { PbA } \\
(-)\end{array}$ & \\
\hline & Fuel Cell (FCV) & & $(-)$ & \\
\hline & $\begin{array}{l}\text { Photovoltaic Cell } \\
(\mathrm{PCV})\end{array}$ & & $(-)$ & \\
\hline
\end{tabular}

Notes: *There are six types of hybrid electric vehicle drivetrain architectures: mild-HEV and full-HEV, while the latter can be further classified into parallel full-HEV, series full-HEV, seriesparallel full-HEV and complex full-HEV, as well as PHEV. These differ in use of propulsion power and in configurations. Source: Complied based on information published on websites of car manufacturers and from Alonso et al. (2012b); Çağatay Bayindir et al. (2011); China Auto Web (2014); Hannan et al. (2014); Hybrid Autos (2014); Hybrid Cars (2014); International Energy Agency - HEV (2013); Kopera (2004); Plug-In Cars (2014); Tie and Tan (2013); U.S. Department of Energy (2014).

is common for all advanced technology vehicle drivetrains. The most widespread design is the permanent magnet motor with currently more than $80 \%$ of market share, as compared to the induction motor with $11 \%$ penetration of the induction motor (Burwell et al., 2013). This is due to the former's superiority in terms of performance, efficiency and reliability. An overview of main motor design drives, together with their specifications and comparison of performance, can be found in Pellegrino et al. (2012) and Tashakori et al. (2010). Essentially, an electric motor is the reverse of a generator in that it converts electricity into mechanical energy. It has been estimated that an electric traction drive of a representative hybrid vehicle contains approximately $0.6 \mathrm{~kg}$ of rare earths, mainly neodymium and dysprosium (Alonso et al., 2012b). Although there seems to be no consensus on the precise quantities of rare earths, this figure is in range compared with estimates by Campbell (2008) and Zepf (2013). Note that the quantities also depend on the size of the motor, which varies across vehicle models. This has not been accounted for in this section.

The case of batteries is somewhat different in that several battery technologies 
co-exist on the market. An overview of secondary battery systems is reported in Catenacci et al. (2013); Kopera (2004); Råde and Andersson (2001); Rydh and Svärd (2003); Tie and Tan (2013); Van den Bossche et al. (2006). The function of batteries in advanced technology vehicles is to store chemical energy and to convert it into electrical energy used to power vehicles. While in case of HEV, battery stores energy generated from regenerative breaking, BEV and PHEV are charged externally. The extent of power produced depends on the chemical composition of the cell, among others. Battery technologies currently deployed are also summarised within Table 3.4. Two most widespread technologies - nickel metal-hydride (NiMH) and lithium-ion (Li-ion) - are discussed in detail, while the other ones are only touched upon shortly since these are either outdated - nickelcadmium (Ni-Cd) and lead acid (PbA) - or still in stages of development - zinc-air (Zn-air), lithium-sulphur (Li-S) and lithium-iron phosphate (LFP) - or have currently very low market shares due to their unproven viability - Zebra and lithiummetal-polymer (LiPo).

The NiMH battery is made up of a positive nickel hydroxide electrode and a negative electrode of hydrogen absorbed in metal alloy. The most commonly used metal hydride is a multi-element alloy of the type $\mathrm{MN}(\mathrm{Ni}, \mathrm{Co}, \mathrm{Al}, \mathrm{Mn})_{5}$. Such batteries contain up to $10 \%$ mischmetal (MN), made up primarily of lanthanum and to some lesser extent of cerium, neodymium and praseodymium, as well as of metallic impurities (Constantinides, 2013; Kopera, 2004; Lichtenberg et al., 1997; Ovshinsky et al., 1993; Shukla et al., 2001). In terms of rare earth quantities used, Bryce (2010) and SAE International (2010) claim Toyota Prius to be the most rare earth intensive consumer product ever made, with $11 \mathrm{~kg}$ of rare earth content. However, other sources are more moderate with their estimates ranging from $2.17 \mathrm{~kg}$ to $2.45 \mathrm{~kg}$ of rare earths in Prius II batteries alone (Bauer et al., 2011; Schüler et al., 2011), whereas according to Alonso et al. (2012b) a hypothetical mid-size HEV contains $3.5 \mathrm{~kg}$ of rare earths within its battery. Various aspects of NiMH battery technology have been continuously improving over the past 25 years, what contributed to its widespread commercial use, mainly within electrically powered vehicles. Indeed, when compared to $\mathrm{Ni}-\mathrm{Cd}$ and $\mathrm{PbA}$ technologies, the main advantages are its long life, safety, use of non-toxic components and energy density. Nonetheless, major costs of NiMH batteries are tied to commodities such as rare earths and nickel. In fact, their large use of rare earths was one of the reasons why other types of batteries started to catch up. With the development of Li-ion battery the use of rare earths has been eliminated. Its positive electrode involves one of the three families: lithium cobalt, nickel or manganese oxide; and uses graphite in its negative electrode (Broussely et al., 1997; Rydh and Svärd, 
2003). In case of LFP, the cathode consists of $\mathrm{LiFePO}_{4}$ and aluminium foil (Zackrisson et al., 2010), while in case of LiPo, it is made up of polymer materials. Besides the fact that this technology does not contain rare earths, it is also considered superior in terms of twice as high power and energy densities and its lower weight, implying a greater storage in smaller volume when compared to NiMH batteries (Constantinides, 2013; Kopera, 2004). This has however been achieved at the expense of almost twice as high cost and shorter cycle life. In general, battery characteristics translate into vehicle's overall performance (Ovshinsky et al., 1993). For those using Li-ion technology this implies lighter vehicles with better performance, but also smaller range driven without recharging, as well as additional fire safety considerations due to chemical properties of lithium (Baker and Krisher, 2013; The Economist, 2014; Martín, 2013; Wojdyla, 2011). Consequently, further applied research is required to improve on these (Catenacci et al., 2013). For completeness, the availability of lithium production, which is concentrated in South America, also needs to be taken into consideration.

Last but not least, in addition to use in batteries and electric motors, rare earths are used in various other parts of vehicles, such as neodymium and dysprosium contained within small magnets in sunroofs and automatic door locks, and cerium in catalytic converters (Molycorp, 2010). Alonso et al. (2012b) estimated that they constitute $0.44 \mathrm{~kg}$ and are scattered across 700 vehicle parts. Note that this quantity decreases to half when considering rare earth content in basic vehicles in developing countries. Neodymium is estimated to make up two thirds of this quantity, cerium is $18 \%$ and dysprosium and praseodymium are approximately $6 \%$ each. As negligible as these quantities seem per a single vehicle, adding them up across 87.25 million vehicles produced globally in 2013 (OICA, 2014), suggests that altogether 29'700 tonnes of rare earth elements were used in their production in 2013 alone. When converted into REO, using the conversion ratio of 1:0.85 as suggested by Goonan (2011), this quantity constitutes $31 \%$ of global rare earth supply for 2013. In terms of individual rare earths, approximately $70 \%$ of neodymium, $120 \%$ of dysprosium, $20 \%$ of praseodymium, and $8 \%$ of cerium supply forecasted for 2014 were consumed. Considering the tighter supply estimated for 2016 (Kingsnorth, 2013c), consumption of neodymium and dysprosium would increase to approximately $80 \%$ and $210 \%$, respectively. This implies that vulnerability of ICEVs to a potential supply shortage of rare earths is critical and should not be disregarded in future demand projections.

Following the overview of various battery designs, the next step is to examine to what extent car manufacturers adopted the individual designs within their vehicles. For this purpose, global data on advanced technology vehicle models in production 
by end of 2014 was collected. Only passenger cars were taken into account. Buses, heavy duty vehicles, motorcycles and three-wheelers are not within the scope of this analysis. Also, vehicles in prototype or pre-production stages and those not mass produced were excluded, while discontinued models were kept. This dataset was enriched by information on battery usage as indicated by respective manufacturer websites and dedicated online portals. The results are summarised in Figure 3.13a. The most diffused in terms of share of vehicle models is the lithium technology, led by Li-ion with $49 \%$ of total share of vehicle models, followed by LFP and LiPo - both emerging technologies with low shares of $10 \%$ and $5 \%$, respectively. NiMH batteries are employed within nearly a third of currently available advanced technology vehicle models, which ranks them as the second most deployed battery technology. However, when looking at the breakdown of uses across specific vehicle energy models as illustrated in Figure 3.13b, it becomes obvious that the latter are used only within HEV. This is because of the limitations in the former's specific power and energy densities, as well as the lack of scalability with respect to its size. In fact, while HEV are propelled by both ICE and electric motor, in BEV and to some extent in PHEV it is the battery which powers the electric drivetrain, and hence higher performance of the former is required. This makes NiMH batteries unsuitable to be deployed within the latter two energy models (Axsen et al., 2008; Bitsche and Gutmann, 2004). Finally, the share of PbA technology is relatively small at $5 \%$ and is mostly only used within discontinued models.

To determine the cumulative quantities of rare earths used in electrically powered vehicles, it is important to first establish the actual global share of separate energy models as well as share of battery technologies deployed within these. Unfortunately, it turns out difficult to determine the exact quantities, since global stock or sales figures broken down to car maker/model levels are not publicly available. Hence, an estimation was carried out based on information gathered from various sources, such as EV Obsession (2013); evsroll.com (2013); Green Car Congress (2014); Hybrid Cars (2013); Mock (2013); Sehgal (2013); Schreffler (2013); Stoddard (2013); Trigg and Telleen (2013); World Nuclear Association (2014) and Japan Automobile Dealers Association (2013), as well as from car manufacturers' websites. Although several different estimates exist, all point to the general trend of HEV dominating the market with a global share of approximately $86 \%$, while respective shares of PHEV and BEV are approximately $6 \%$ and $8 \%$. For calculations within this section, the following figures for 2013 are used: 93'900 PHEVs, 111'700 BEVs, and about 1'300'000 HEVs. Based on these estimates and on data collected on in Figures 3.13a and 3.13, it was possible to determine the major producers of HEV and their battery usage. Toyota seems to be dominating 
Figure 3.13: Battery technologies deployed in advanced technology vehicles.

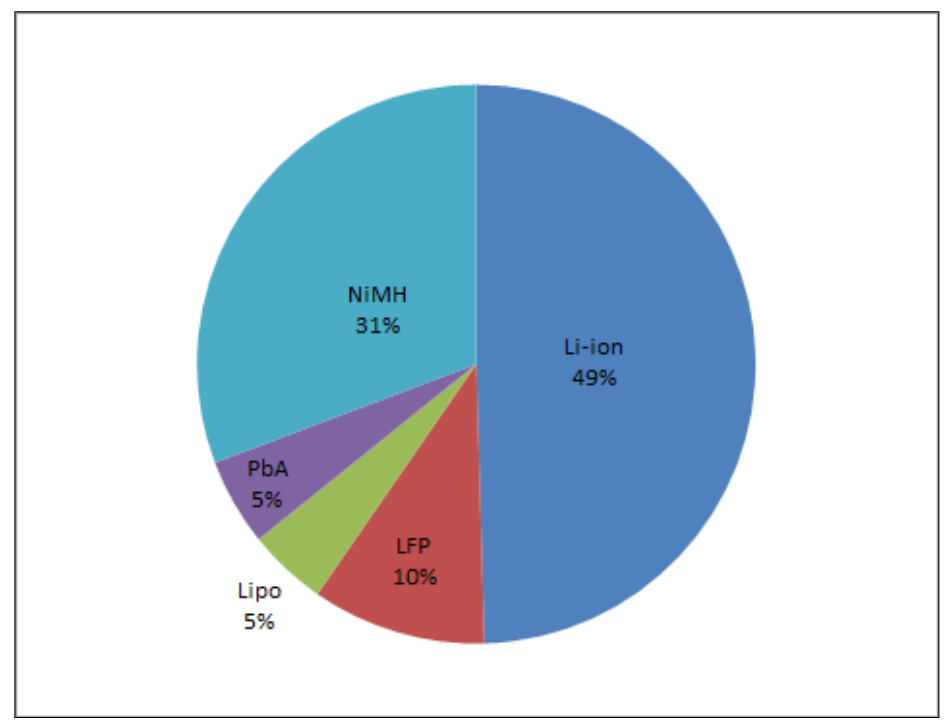

(a) Batteries in advanced technology vehicle models

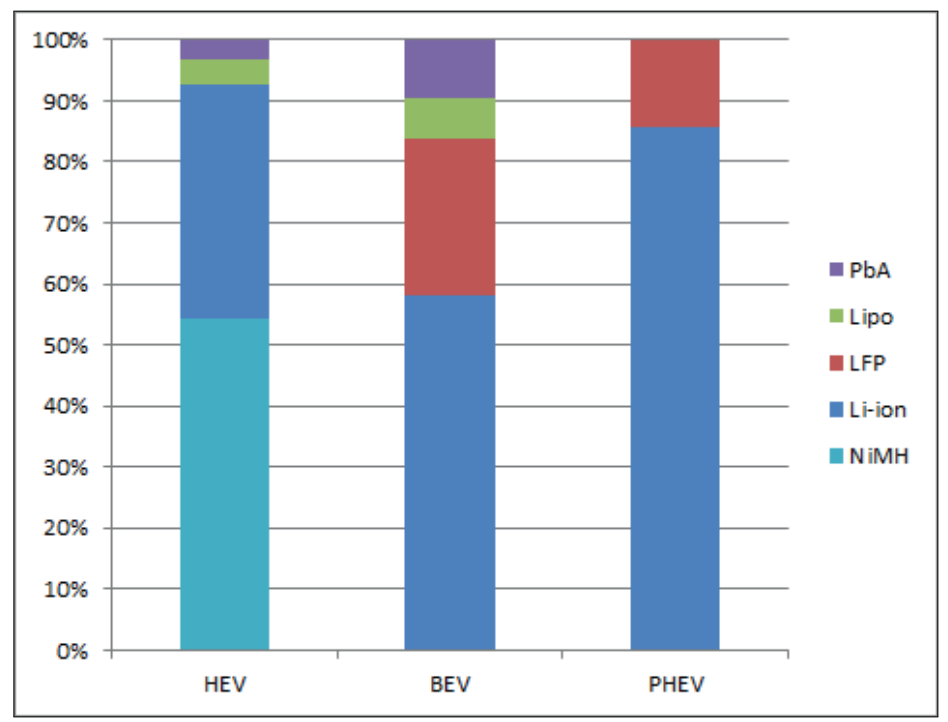

(b) Batteries across vehicle energy models

Notes: Based on mass produced electric passenger cars in production by 2014. Buses, heavy duty vehicles, motorcycles and three-wheelers not considered. Includes also recently discontinued models. Excludes those in concept and pre-production stages. Source: Compiled based on data collected from websites of car manufacturers and from China Auto Web (2014); Hybrid Autos (2014); Hybrid Cars (2014); Plug-In Cars (2014); U.S. Department of Energy (2014). 
hybrid vehicles manufacturing with almost two-thirds of the market share, followed by Honda, Lexus, Nissan and Ford, whose models jointly constitute another quarter of global sales. On the level of batteries deployed, all of the Toyota HEV models (with the exception of Prius V), as well as all the Lexus hybrids and some of the Honda models (Insight, CR-Z and Freed) rely on NiMH batteries. On the contrary, Nissan Serena, Ford Fusion and C-Max, as well as Honda Accord, Civic and Fit use alternative battery technologies. Besides these, Hyundai Sonata, Kia Optima and Chevrolet Malibu have a minor share but none of them uses rare earths in their batteries. It is thus possible to conclude that NiMH batteries currently have an approximate market share of $75 \%$ of all HEVs. In turn, assuming that a NiMH battery and an electric motor contain $3.5 \mathrm{~kg}$ and $0.6 \mathrm{~kg}$ of rare earths respectively, this translates into 723 tons and 3'413 tons respectively, of rare earths used within vehicles sold in 2013 globally. Accounting for the additional $0.44 \mathrm{~kg}$ of rare earths scattered across various parts, electrically powered vehicles consumed $4 \%$ of neodymium, $5 \%$ of lanthanum, and $14 \%$ of dysprosium in total, based on individual supplies forecasted for 2014. In view of tighter supply forecasted for 2016, the share of dysprosium use increases to $24 \%$ (Kingsnorth, 2013c). Finally, considering the growing deployment of advanced technology vehicles projected to reach global annual sales of 6.1 million by 2023 (Schreffler, 2013), these alone would require $18 \%$ of the current annual rare earth production. This is an approximation and holds only when assuming that global production stays the same, as well as the market share of NiMH batteries and rare earth permanent magnet motors remains unchanged, and that no minimisation takes place. In general though, due to the uncertainty in deployment trends of energy models and their charging infrastructures, it is difficult to estimate how much additional demand would be created by electrically powered vehicles in the future. On the one hand, while shares of all three energy models are forecasted to increase, those of PHEV and $\mathrm{BEV}$ are expected to grow faster than that of HEV powertrains. In fact, Navigant Research forecasts a global compound annual growth rate of some $12 \%$ for $\mathrm{HEV}$ and of almost a third for both PHEV and BEV by 2020 (Hurst and John, 2013). This also depends on incentives and regulations by governments, as well as on fuel prices. Finally price decreases envisaged for Li-ion battery packs and potential increasing prices of NiMH batteries due to volatilities in rare earths, might speed up the paradigm shift from NiMH batteries toward the former. Nonetheless, a complete phase-out should not be assumed in the medium term. Several studies suggest that in order to avoid technology lock-in, variety in battery technologies should be supported (Andersson and Råde, 2001; Catenacci et al., 2013; Moss et al., 2011). 
To conclude with, it remains to be seen which of the battery technologies will dominate the advanced technology vehicles market in the future. Likewise, in terms of electric motors possible future development of alternative rare earth-free architectures might replace rare earth permanent magnets. Nonetheless, automotive industry and its electrification are substantially dependent on the availability of rare earths. Therefore a potential supply shortage would disrupt the further development of the market altogether. To what extent this threat is real, depends on availability of material substitutes to be used within permanent magnets, as well as on recycling as an alternative source of rare earths. These are discussed in the upcoming Section 3.5.

\subsection{Curbing the rare earth dependence}

The aim of this section is to discuss mitigation strategies pursued with the view of curbing the dependence on rare earths. According to the material life cycle (Graedel et al., 2011), the choice of product design is important in that it determines the material and product life cycle, which in turn drive the demand for materials used. In this light, the following two subsections investigate the downstream strategies related to alternative designs in wind turbine and electrically powered vehicle technologies, as well as to finding rare earth material substitutes. These are followed by a discussion on the upstream strategies of recycling, as an alternative source to primary materials, and stockpiling, as a short term strategy to supply shortages. Some other upstream strategies have already been noted in Section 3.3.2, such as opening mines outside China, raw materials diplomacy and strategic alliances.

\subsubsection{Material substitutes}

From the quanto-mechanics standpoint, rare earths are unique due to the configuration of their atom shells, what allows them to have unique magnetic interactions with other elements. Consequently, there exist no perfect substitute elements which would achieve same levels of magnetism. Mature magnet technologies are ferrite magnets (based on strontium or barium ferrite) and alloy magnets (AlNiCo and $\mathrm{SmCo}$ ) discussed previously. When compared to NdFeB technology, the former are considered less costly in terms of price volatilities and potential supply disruptions, but are at the same time inferior in terms of their lower magnetization, magnetocrystalline anisotropy and lower coercivity (Skomski and Sellmyer, 2009). It is precisely the high coercivity that makes rare earth high energy density 
magnets essential for direct drive wind turbines and electric traction motors of advanced technology vehicles. In line with this, some of the research streams concentrate on improving the performance of existing non-rare earth-based permanent magnets on the one hand, and the coercivity of permanent magnets with smaller quantities of neodymium and dysprosium on the other. At the same time, minimisation is taking place, which entails development of nanocomposite magnetic material whereby Nd- and Fe-based nanoparticles are mixed together to reach superior magnetic properties. Finally, replacement by cheaper and more abundant materials is being investigated on. A summary of major projects related to permanent magnets is provided in Table 3.5.

In terms of initiatives by countries, the US Department of Energy's Advanced Research Projects Agency-Energy (ARPA-E) provides funding for technologies that eliminate or minimise the use of rare earths, especially through its Rare Earth Alternatives in Critical Technologies (REACT) program. In Japan, related R\&D projects are implemented by the Ministry of Economy, Trade and Industry (METI) and the New Energy and Industrial Technology Development Organisation (NEDO) on the one hand, and the Ministry of Education, Culture, Sports, Science and Technology (MEXT) and the National Institute for Materials Science (NIMS) on the other. The European Union instead, is lacking concentrated capabilities in magnet industry in general and in material knowledge infrastructure in particular (CORDIS, 2012). It currently runs a project which aims at mapping out the European substitution initiatives and proposing roadmaps for critical raw material substitution (CRM_InnoNet, 2015). Besides this, the European Rare Earths Competency Network (ERECON) has been established to explore options for more efficient use and potential substitution of rare earths in major applications (European Commission, 2014a).

In general, most of the research initiatives listed in Table 3.5 are in their initial stages. Since they involve basic research one cannot expect them to result in new technologies. 


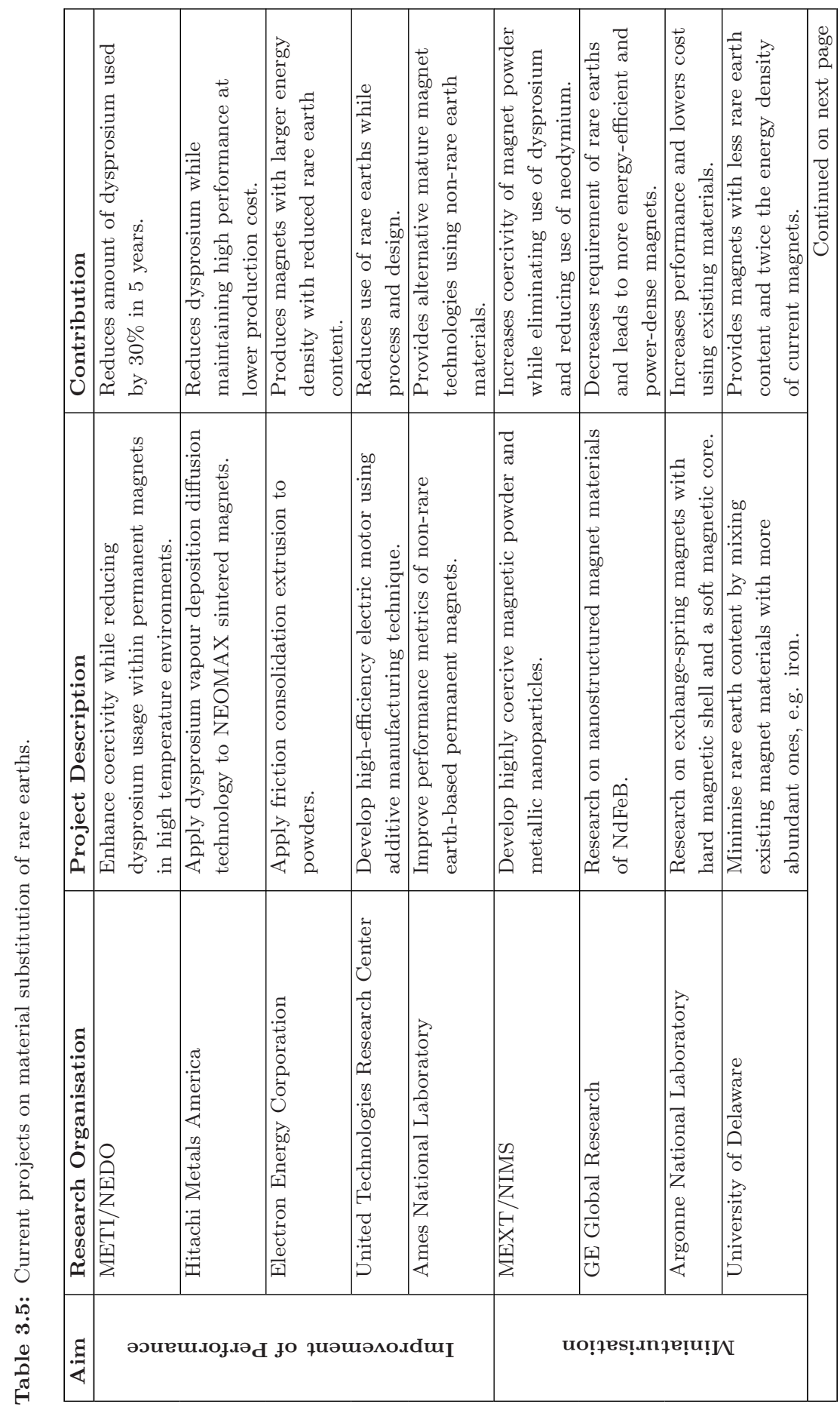




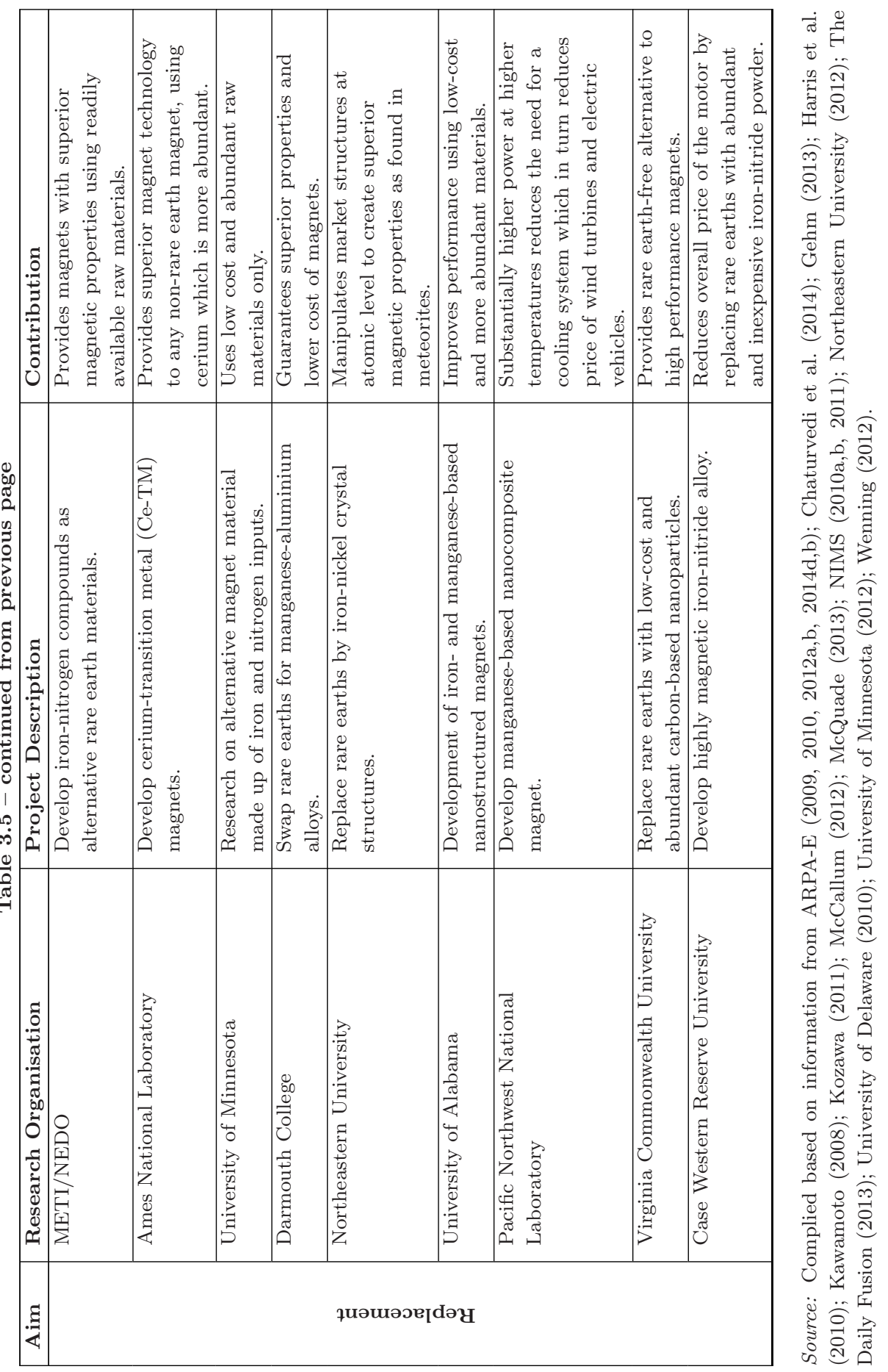




\subsubsection{Technology substitutes}

The increasing price volatilities of rare earths and their tight supply have spurred innovation in new less rare earth-intensive technologies, or which eliminate their use completely. Substitution on the level of technologies is far more progressed than innovation in materials.

\section{Alternative wind turbine designs}

As discussed earlier, the gearbox technology constitutes a viable alternative to permanent magnet drivetrains. Adding a gearbox to the machine not only decreases the size of the generator, it also reduces the quantity of permanent magnets needed, or eventually eliminates them completely. Section 3.4.1 discussed topologies with single or multiple stage gearbox combined with permanent magnet. While it has been pointed out that operational expenses of such designs increase with the large amount of moving parts, recent improvements in gearboxes lead to increased reliability of these drivetrains (National Renewable Energy Laboratory, 2007; Reliawind, 2011).

In terms of larger offshore wind turbines, the electrically induced wind turbines might have been a viable alternative. The downside of this technology is that it uses current from electrical grid. While Enercon, the major producer of this technology, currently only targets onshore wind parks and is not expected to penetrate the offshore market, some of the competitors have been developing this technology further (Dodd, 2013; Patton, 2012). The future trend towards direct drive generators is further underpinned by the EU project on developing a 20 MW wind turbine (INNWIND). While the predecessor of this project (UPWIND) considered conventional direct drivetrain optimisation, the new project is to focus on superconductive and magnetic pseudo direct drive generator (PDD) (InnWind, 2013). This latter concept integrates a low ratio magnetic gear with a permanent magnet generator, thanks to which costly maintenance and reduced efficiency of mechanical gearbox on the one hand, and substantial size and cost of conventional direct drive generators on the other, are eliminated (InnWind, 2014; Magnomatics, 2014).

Furthermore, HTS machines, generating rotor field by superconducting coils, are intended to reduce generator weight and volume, as well as the dependence on rare earths altogether. This however depends on the conductor technology adopted. Currently, the AMSC generators use YBCO conductors (yttrium-bariumcopper oxide), while General Electric makes use of niobium-tin superconductors $(\mathrm{NbSn})$ and Suprapower works with magnesium diboride $\left(\mathrm{MgB}_{2}\right)$ (Magnusson 
et al., 2013). Hence, instead of using neodymium and dysprosium, this design relies on yttrium, lanthanum and cerium - the latter two being the most abundant oxides in terms of supply (Buchert, 2011). In addition, the content of rare earths used is largely reduced as compared to permanent magnets. For illustration, a HTS generator in a $5 \mathrm{MW}$ wind turbine requires up to $3.8 \mathrm{~kg}$ of YBCO superconducting layer, while a PMSG-DD generator in a wind turbine of same dimension makes use of 2.3 tonnes of NdFeB permanent magnet (Henriksen, 2011). Whether HTS machines diffuse to outweigh other offshore technologies remains to be seen. AMSC claims that thanks to its power density advantage, the HTS technology will become the leader at $10 \mathrm{MW}$ and higher power ranges (Cleantech Magazine, 2011). However until the point of their commercial deployment, these designs need to be tested, their reliability proven and their costs reduced (Magnusson et al., 2013).

Overall, it remains to be seen which wind turbine technology will dominate the market going forward. One thing is clear though: in order to make wind energy competitive, producers need to decrease its costs. This can be achieved by increasing reliability and manufacturing larger offshore turbines. Should these be adversely affected by supply risk of some of the components, it is likely that producers will shift away to cheaper and more secure alternatives. To which exactly, will depend on the state of technologies available.

\section{Alternatives to batteries and electric drives in vehicles}

Regarding the automotive industry, alternative technologies for batteries in HEV have already been discussed in Section 3.4.2. Currently, there seems to be a paradigm shift ongoing from NiMH to lithium technology. The rate at which this shift occurs will depend on the extent of supply risk and price volatility of rare earths on the one hand, as well as on price and reliability of the rare earth-free battery alternatives on the other. As an example, Ford has been switching away from NiMH battery in its earlier Escape model to Li-ion battery in its Fusion and C-MAX models. While other technologies are emerging, Li-ion is forecasted to dominate the market in the future, with construction of Tesla's gigafactory expected to further significantly decrease the manufacturing cost of batteries (Forbes, 2014).

In terms of electric motors, potential replacement of permanent magnets used in traction is yet in an elementary phase. Currently only few vehicles rely on induction electric motors where the magnetic field which turns the rotor shaft is created using electrical current (Tesla Motor, 2014). It is the latter which makes the induction motors to be less efficient as compared to the permanent magnet motors, 
which rely on the magnetic fields created around their respective magnets. Besides developing its own technology for induction motor to be used in hybrids, Toyota Motor also currently uses Tesla's induction motor within the RAV4 EV model (Ohnsman, 2011). Similarly, Renault is using an externally excited synchronous motor in some of its models as delivered by Continental (Continental Corporation, 2011; Vignaud and Fennel, 2012). Other car manufacturers are developing electric motors with reduced amounts of dysprosium, such as Nissan within Nissan Leaf and GM within Chevrolet Volt (Renault Nissan, 2012; Redall and Gordon, 2012; Syrett, 2012). Finally, Hitachi has been developing a prototype of a motor using amorphous metal for iron cores and ferrite magnets as rotors (Hitachi Ltd, 2012), while Hybrid Electric Vehicle Technologies has patented a switched reluctance motor which eliminates the use of rare earths by ferromagnetic rotor (Environment News Service, 2012). This technology however is claimed to need more optimisation before being marketed. Also, several other projects are on their way, such as the three financed by ARPA-E: Baldor Electric Company developing rare earthfree traction motor design with improved cooling system (ARPA-E, 2014a); QM Power developing electric motor with use of iron-based magnets and new motor control technique (ARPA-E, 2014c); and University of Texas developing an electric motor with double stator design which is completely rare earth-free (ARPA-E, $2014 \mathrm{e})$.

However, as discussed previously, also regular ICEV contain some quantities of rare earths. Consequently, even if batteries and magnets in advanced technology vehicles could be produced rare earth-free, a substantial level of dependence on rare earths in automotive industry would persist. While this remains a serious issue during the coming years, it is expected that in the long run these can also be replaced by other materials resulting from basic research initiatives as discussed above.

\subsubsection{Secondary market}

In his 2011 analysis of rare earth life cycles, Du and Graedel (2011) note that one of the five points within material flows cycles where losses of rare earths occur is waste management. Hence, improving this stage of life cycle via efficient recycling creates secondary market for rare earths, which in turn decreases dependence of the rare earth-importing countries on Chinese supplies. This would furthermore lower environmental degradation from mining and also address the balance problem (Binnemans et al., 2013). However, while commercial recycling for base metals was developed long ago (lead being the most recycled metal with rate of $80 \%$ ), no large scale recycling of rare earths currently exists. In particular, it has been estimated 
that recycled content ( $\mathrm{RC}$ ) of lanthanum, cerium, praseodymium, neodymium, gadolinium and dysprosium is in the range of $1-10 \%$ and inferior to $1 \%$ for the rest of elements (Graedel et al., 2011). ${ }^{9}$ The global end-of-life recycling rates (EOL-RR) are also less than $1 \%$ for all rare earth elements, due to inefficiencies in collection and processing of discarded products. Instead, no data is available for old scrap ratios (OSR). This can be explained by long in-use lifetimes due to which wind turbines are only available for recycling with a lag of 20 years. In turn, such low levels of recycling imply that substantial quantities that could be reused are lost. This is further confirmed by Goonan (2011) who illustrates the distribution of rare earths from end uses in consumer products to various modes of disposition. Close to no recovery of rare earths occurs for catalysts and metallurgical alloys and to some small extent for coloured glass and ceramics. While technology is available, at present separation of rare earths proves costly. However, considering that stocks of rare earths exceeded annual extraction four-fold in 2007, recycling definitely has a potential to offset part of the primary material mining ( $\mathrm{Du}$ and Graedel, 2011). In this light, several R\&D initiatives have been directed to the area of chemical processing and re-use of material recovered.

For what concerns magnetic materials, as opposed to SmCo magnets, reprocessing $\mathrm{NdFeB}$ magnets is complicated in that corrosion of material requires refining. Also, strong magnetic fields and nickel plating which protects magnets from humid environments make the recycling more complex. Finally, considering the high content of iron which is disposed of as waste (two-thirds as compared to one-third of rare earth content), recycling of $\mathrm{NdFeB}$ magnets is economically not justified (Binnemans et al., 2013; Goodier, 2005). Recycling routes, their respective advantages and disadvantages, as well as current research on recovery of rare earths are described in detail by Binnemans et al. (2013) and Schüler et al. (2011). Preconsumer recycling concerns magnet production scrap and can amount to as much as $30 \%$ of the alloy at the beginning of the manufacturing process. Post-consumer recycling is mostly targeting $\mathrm{NdFeB}$ material present in electronic goods recovered from "urban mines", such as HDD, cell phones and air conditioners, and is becoming an established practice in Japan (Baba et al., 2013; Hitachi Ltd, 2010; Tabuchi, 2010). Re-use of magnets in current form and shape is deemed suitable especially for large magnets in wind turbines and advanced technology vehicles, though it is rarely made use of due to their long service lives. The authors also estimate the global recycling potential for 2020 to lie between 3300 and 6600 tonnes of rare earths for magnets, assuming a global collection rate of 30-60\%, recycling efficiency of $55 \%$ and an average lifetime for magnets in wind turbines of 15 years.

\footnotetext{
${ }^{9} \mathrm{RC}$ is $0 \%$ for yttrium, while no estimates are available for scandium.
} 
In case of $\mathrm{NiMH}$ batteries, these are made up of 8-10\% of rare earth mischmetal, the rest being constituted by nickel, cobalt, manganese and aluminium (Müller and Friedrich, 2006). While until recently rare earths from batteries were lost to the steel industry, nowadays hydrometallurgical and pyrometallurgical methods are employed to recover these, as described by Müller and Friedrich (2006), Binnemans et al. (2013) and Schüler et al. (2011). In case of NiMH batteries, Binnemans et al. (2013) estimate a global recycling potential of 1000 to 1750 tonnes by 2020, assuming the global collection rate to lie between 40 and $70 \%$, with recycling efficiency of $50 \%$, with lifetime for batteries of 10 years. Toyota was the first producer to recover rare earths by recycling NiMH batteries from end-of-life HEV (Toyota Motor Corporation, 2013). In 2013, also Honda announced that it would be reusing raw materials from recycled batteries (and various other used parts) to build new ones (Honda Motor, 2013). In Europe, Umicore claims to be the first to have built a recycling facility to recycle NiMH, Li-ion and Li-polymer battery technologies in 2011 (Umicore, 2014). In the United States, Retriev Technologies is the major recycler of all types of batteries (Retriev Technologies, 2014). Since recycling of vehicle batteries is a developing industry, there is no publicly available data yet.

To conclude with, some of the main constraints to recycling could be solved by appropriate policy responses. For example, in Europe the following legal enforcement of waste collection, recycling of batteries and recovery of vehicles and their components was enacted: Directive 2013/56/EC on Batteries, Directive 2012/19/EU on Waste Electrical \& Electronic Equipment and Directive 2000/53/EC on End of Life Vehicles (European Commission, 2014b). Such policy measures, if efficiently implemented, might help creating a secondary market for rare earths within Europe and thus contribute to its decreased dependence on supply of primary material from China. Besides decreasing private costs, these policies could also decrease social costs to mining by lowering environmental degradation as discussed in Section 3.7.

\subsubsection{Stockpiling}

As opposed to the above strategies, stockpiling is a short term measure which serves as a buffer against interruptions in trade. This is especially true in the period of crisis when storage acts like an alternative source of supply (Nordhaus, 1974). This however only pays out if the price of rare earths and their cost of storing do not exceed the marginal cost of developing reserve capacity.

The European Union has evaluated feasibility of economic stockpiling as a correction measure in the short to medium term (Risk \& Policy Analysis, 2012). 
It also considered the form of stockpiled material, claiming that while stockpiling of concentrates would give end-users the possibility to tailor make their products, the EU itself does not dispose of processing and refining capacity to cope with less processed rare earths at the moment. Finally, due to high costs of up to 940 million Euros required to set up a stockpile on the EU level, it was suggested to keep stockpiling on private level and on voluntary bases. The United States instead, intends to build up national defence stockpile (NDS) of rare earths to support defence production and essential civilian needs in the context of congressionally mandated four year conflict scenario (U.S. Department of Defense, 2013). They however recommend a mix of mitigation strategies, stockpiling being the least of these, due to the relative high cost of federal inventories when compared to other measures.

Several countries have such stockpiles in place already. Japan has established stockpiling in 1983 to cope with short-term supply interruptions of nine rare metals and has recently started to investigate the possibility of a rare earth stockpile (DEFRA, 2012; JOGMEC, 2012; METI, 2011) (Kawamoto, 2008; Maeda, 2010). Besides the national stockpile, companies also keep their private reserves of rare earths (Topf, 2013b). Similarly, South Korea has established a stockpile for strategically important elements, rare earths among others, to cover 60 days of domestic demand, the level of reserves reaching 1'500 tonnes by 2014 (DEFRA, 2012; Japan Metal Bulletin, 2010; Park, 2011). This is to cover both economic and strategic purposes. Also China started to build up strategic reserves in 2011, aiming to purchase 100'000 tonnes of rare earths for national storage. The estimated value of the purchase is almost USD 1 billion, targeting mainly HREE, and is aimed to protect rare earth resources and to establish a secure and stable supply system (Areddy, 2011; Information Office of the State Council, 2012; MOFCOM, 2012b,d; MLR, 2011). Nonetheless, the recent reserve accumulation by China is also foreseen to act as a stabilisation mechanism in times of falling prices (Currie, 2012; Topf, 2013a; Xinhua, 2012).

In conclusion, while stockpiling strategy could significantly mitigate supply shortages and price spikes in periods of disruption, it could by the same token adversely affect prices and quantities of raw materials in periods of acquisition (Risk \& Policy Analysis, 2012). Besides issues with administrative burden and efficiency with public stockpile, as well as speculation and financial risk accompanying private stockpile, this strategy is targeting short term disruptions and hence does not address the potentially long term supply issue. Moreover, should manufacturers substitute away from rare earths, the stockpile might become quickly obsolete (Risk \& Policy Analysis, 2012). Therefore, a combination of strategies discussed 
above should be pursued. This ultimately calls for building up an alternative supply chain outside China.

\subsection{Factors influencing prices of rare earths}

From the above discussion it becomes clear that the major issue of rare earths is the growing imbalance between increased demand and tighter supply. Figure 3.14 depicts demand and supply estimates for 2016. Of the five critical metals, yttrium and terbium appear to be short of supply, while the forecasted demand of neodymium, dysprosium and europium is only slightly inferior to the respective supply figures. However, with a further increase of demand for rare earth magnets from low-carbon technologies, high-tech and medical applications, the former three might also turn out being under-supplied. The more so, if China further tightens the supply of HREE. In this light, Kingsnorth (2013c) forecasts that the nonChinese HREE supply could cover as few as $10 \%$ of the global needs in 2016.

Figure 3.14: Global demand and supply forecast for individual rare earths, $+/-20 \%$, in tonnes of REO, 2016.

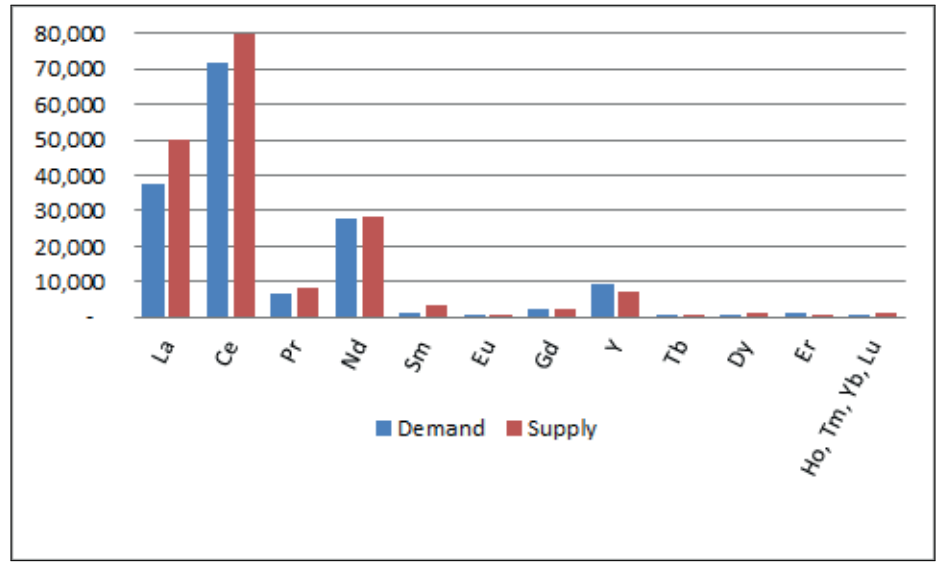

Source: Adapted from Kingsnorth (2013c). Data are a courtesy of Professor Kingsnorth.

This section examines demand and supply, in combination with the Chinese industrial policies, in order to offer a complete picture of the driving forces behind rare earth prices. Both demand and supply tend to be largely inelastic. Since rare earths are often mined as by-products, their mining decisions depend on those of main products. However, with the opening of mines for primary mining of rare earths outside of China, the supply of LREE is expected to become more price 
elastic. Demand in turn is inelastic due to the lack of substitutes for rare earths with similar or superior properties. This ultimately implies that further tightening of the supply by China would drive prices up and trigger higher production costs for technology applications which use rare earths as inputs. While prices alone are not the only factor inducing innovation, they serve as an indicator of scarcity in that they embed developments on the market. Hence, it proves important to understand the historical price development of rare earths.

\subsubsection{Rare earth price trends}

Figures 3.15a and 3.15b report historical price developments for the two groups of rare earth oxides, respectively. Nominal pricing data was collected from various sources and indexed to 100 in 1989 in order to allow for comparison of changes over the period examined (1989-2013). Note that prices vary with quantity and quality of oxides, as well as across producing companies. Due to the fact that rare earths are not exchange traded, no official prices exists. Year-end prices are recorded as reported by various suppliers or users based on long term contracts (Bundesanstalt für Geowissenschaften und Rohstoffe, 2014; U.S. Geological Survey, 2013). Daily time series instead, are calculated mid prices by Thomson Reuters Datastream (2014). Moreover, pricing data is not available historically for uniform purities, what caused some price jumps in historical trends for Samarium, Terbium and Dysprosium between 1999 and 2000. Specific oxide purities taken into consideration are declared below the Figures. Scandium oxide was excluded due to the lack of sufficient historical pricing data available. Promethium was excluded due to its minor use. For comparison, indexed prices for gold and copper as well as the Producer Price Index for Crude Materials for Further Processing (PPI Crude Raw Materials) as constructed by the increased in early 1990s Federal Reserve Bank of St. Louis (2014) are plotted.

It follows from Figure 3.15 that rare earth oxide prices were mixed but fairly stable throughout the 1990s and the first five years of the 21st century. Though majority have higher price changes than those of copper and gold, they remain below the PPI Crude Raw Materials. Overall, prices for HREE tended to be smoother in terms of spikes and also more correlated. In general, they were also substantially higher than those of the LREE. Prices of lanthanum and cerium increased in the early 1990s due to the demand from automotive industry for NiMH batteries and petroleum fluid cracking catalysts, as well as catalytic converters and ultraviolet absorbing glass, respectively (U.S. Geological Survey, 2013). Prices for samarium were on decrease due to the industry substituting away from SmCo to NdFeB permanent magnets. Permanent magnets constituted the largest in- 
Figure 3.15: Nominal rare earth prices, year-end quoted in USD/kg, index $1989=100$.

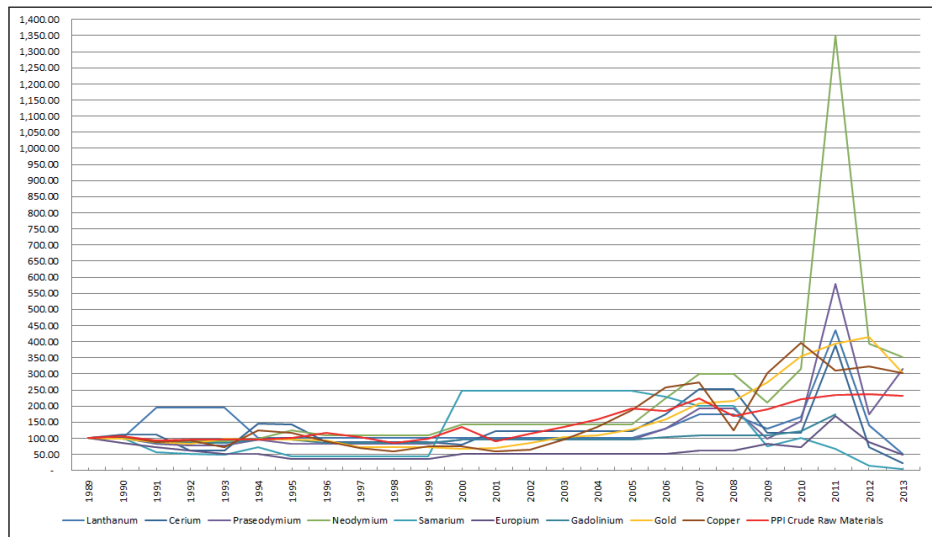

(a) Light rare earth prices, index $1989=100$.

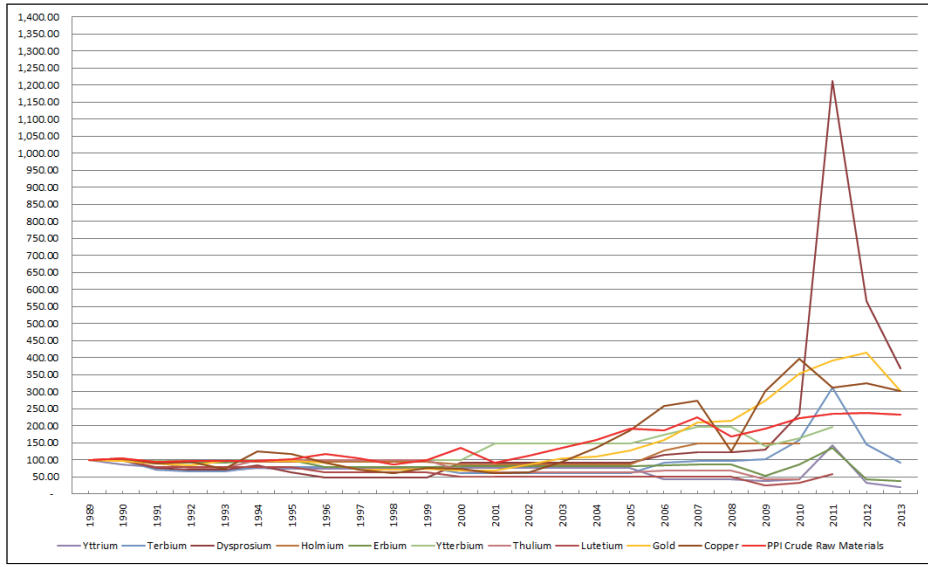

(b) Heavy rare earth prices, index $1989=100$.

Notes: Year-end prices for respective oxides reported in different purities historically: 1989-1999: Dy, Nd 95\%; Pr, Er, Sm 96\%; Yb 99\%, Ce 99.5\%; Ho, Tb, Tm 99.9\%; Eu, Gd, La, Lu, Y 99.99\%; 2000-2009: Dy $99 \%, \mathrm{Sm}, \mathrm{Tb} 99.99 \%$, the rest remains same; in 2010 and 2011 changes with respect to preceding year: Dy $96 \%$ and Sm $99.9 \%$, and Dy $99.5 \%$, respectively; 2012-2013: La, Y $99.999 \%$ and the rest $99.9 \%$. Source: Own calculations based on data compiled from Bundesanstalt für Geowissenschaften und Rohstoffe (2014); Federal Reserve Bank of St. Louis (2014); Thomson Reuters Datastream (2014); U.S. Geological Survey (2013). 
crease over all alloys and metal uses. In line with this, price for neodymium was increasing throughout the entire period (U.S. Geological Survey, 2013). Dysprosium, terbium and praseodymium, also used in production of these magnets, were slightly decreasing due to the growing supply from China. Besides pushing down prices, competitive pricing from Chinese producers also triggered a continuous decrease in the rest of the world's production of rare earths from 1991 onwards. With the shut down of Molycorp and the Russian mining operations in 2002 and 2003, China gained a monopoly and by 2005 it produced some $95 \%$ of global rare earths. Furthermore, in 2005 the export VAT rebate was abolished by the Chinese Government. After 2005, prices and their variations were on increase for both HREE and LREE. This trend was driven by increasing demand from permanent magnets and rechargeable batteries within automotive and electronics industries, as well as from fibre optics and medical applications (U.S. Geological Survey, 2013). This started to increase substantially from 2006 onwards, with $20 \%$ increase within a single year only, a significant part of it coming from China. Besides this, China also introduced production and export quotas to cap the quantities produced and exported. As illustrated by Figure 3.6, the latter have been decreasing until they reached the lowest levels in 2011. In 2007 China adopted export tariffs to further limit the export of rare earths (Tse, 2011). These were ranging from $15 \%$ to $25 \%$ (Metal Pages, 2009) and lead to price discrimination by pricing domestic and foreign firms differently. Table 3.6 provides a comparison between domestic Chinese prices and Chinese prices FOB for the critical REO. Indeed the wedge between them was increasing from 2007 onwards, with FOB prices being at times twice as high as domestic prices, even before transport and storage costs were included. Nevertheless, with the recent abolishment of export tariffs, the Chinese domestic and export prices started to converge. In 2008 prices remained stable, hampered by economic downturn and a stagnant market for most of rare earth oxides and for permanent magnets. The latter decreased further in 2009 from 66'000 tonnes in the previous year to 58'000 tonnes (U.S. Geological Survey, 2013). On the supply side, some of the Chinese producers started to halt their production. The latter was further tightened by the decision to limit new mining permits, and further centralised by establishing the Inner Mongolia Baotou Steel Rare Earth Trading Company (U.S. Geological Survey, 2013). Finally, in 2011 China started to crack down illegal mines and increased the resource tax imposed on bastnäsite and monazite minerals ten-fold (Yuan, 2011). The same year it started the stockpiling program which was to exercise further pressure on demand of rare earths.

All these measures, combined with an increasing demand for rare earths, adversely affected the rare earth prices which were increasing exponentially through 
Table 3.6: Price comparison of selected rare earth oxides (purities in \%), average yearly prices quoted in USD/kg, on FOB China and China domestic basis.

\begin{tabular}{|c|c|c|c|c|c|c|c|c|c|c|}
\hline & \multicolumn{2}{|c|}{ Y Oxide $99.999 \%$} & \multicolumn{2}{|c|}{ Tb Oxide $99.9 \%$} & \multicolumn{2}{|c|}{ Nd Oxide $99 \%$} & \multicolumn{2}{|c|}{ Eu Oxide $99 \%$} & \multicolumn{2}{|c|}{ Dy Oxide $99 \%$} \\
\hline & FOB* & Domestic $\dagger$ & FOB & Domestic & FOB & Domestic & FOB & Domestic & FOB & Domestic \\
\hline 2005 & N/A & 5.28 & 311.19 & 300.99 & 7.34 & 7.38 & 278.08 & 267.55 & 41.38 & 41.43 \\
\hline 2007 & $\mathrm{~N} / \mathrm{A}$ & 6.39 & 582.57 & 517.61 & 29.85 & 26.25 & 314.54 & 279.45 & 88.20 & 78.24 \\
\hline 2008 & N/A & 9.41 & 663.65 & 508.54 & 26.28 & 21.02 & 471.98 & 370.20 & 112.92 & 88.20 \\
\hline 2009 & N/A & 6.28 & 361.09 & 253.82 & 14.83 & 12.29 & 475.06 & 362.99 & 107.55 & 85.25 \\
\hline 2012 & 118.44 & 26.98 & 2037.78 & 964.69 & 124.23 & 77.03 & 2613.35 & 1240.29 & 1205.57 & 660.22 \\
\hline 2013 & 25.74 & 12.34 & 925.86 & 602.10 & 72.09 & 51.80 & 1105.96 & 747.26 & 556.67 & 313.24 \\
\hline Q1/2014 & 20.96 & 10.07 & 788.73 & 554.18 & 69.81 & 51.07 & 925.91 & 727.72 & 465.36 & 294.02 \\
\hline
\end{tabular}

Notes: *FOB China (Freight on Board), †China Domestic. Source: Own calculations based on data compiled from Thomson Reuters Datastream (2014).

2010 and peaked in summer 2011. By far the largest increase since 1989 occurred for neodymium (1250\%) and dysprosium (1112\%), followed by praseodymium, lanthanum, cerium and terbium with respective increases of approximately $480 \%$, $330 \%, 290 \%$ and $210 \%$. Hence, all four oxides used as inputs to permanent magnets, as well as lanthanum used for production of NiMH batteries, have experienced exponential price increases. Contrary to this, the price of samarium used for, in the mean time niche product of SmCo permanent magnets, experienced a decrease by $30 \%$ since 1989 . Similarly, the price of lutetium used in small quantities in x-ray phosphors decreased by roughly $40 \%$. For the rest of the rare earths examined, price increases were below $100 \%$ since 1989 . Overall, following the definition of Nordhaus (1974) one can conclude that due to the sharp increases in prices and to quantitative restrictions which held back substantial supply from the market, rare earth market was in crisis. For comparison, within the same period gold and copper prices were increasing by roughly $290 \%$ and $210 \%$ respectively, while the PPI Crude Raw Materials increased by 140\% between 1989 and 2011.

For a better overview of price developments, daily historical prices are reported in Figure 3.16. Note that the data represents daily averages calculated by Thomson Reuters Datastream (2014) which are rebased to 100 in 2003. It follows from here, that price hikes started in July-August 2010 and reached their peaks in JuneJuly 2011 when the speculative bubble burst. The variation in prices measured as quarterly annualised volatilities is reported within Table 3.7. There was a substantial volatility in Q3/2011 for each of the examined REO, which was further increasing in the first half of 2012 for the five critical REO. The uncertainty about China tightening the supply even more lead to speculation. Companies hoarding rare earths in view of higher profits and then disposing of them triggered further price fluctuations. Prices were on decrease till the end of the first half of 2013. 
On the one hand, this can be attributed to the increased non-Chinese supply of primarily LREE coming from Lynas, which started mining in 2007 and processing in its Malaysia plant by end of 2011, and from Molycorp which resumed mining late 2010 and processing operations a year later. Coupled with this, export quotas have increased by some 3\% from 2011 to 2012 and remained unchanged in 2013. On the other hand, the global demand for rare earths decreased due to the economic downturn. This can be derived from Figure 3.6 which illustrates that export quotas remained unfilled for 2011 and 2012. Also, compared to 1989, prices in 2013 increased by $267 \%$ for dysprosium, $252 \%$ for neodymium and $215 \%$ for praseodymium. These increases outperformed price developments of both gold and copper as well as of the PPI Crude Raw Materials with respective growths of $201 \%, 203 \%$ and $133 \%$. However, most of the other rare earth prices have decreased compared to the 1989 levels, for example lanthanum by $48 \%$ and cerium by $78 \%$. In general it is expected that prices of LREE would decrease further, due to additional supply from Lynas and Molycorp, but at the same time prices for the critical REO would remain strong in the short to medium term, due to recovery of demand from major importing countries and the increased demand from new technologies.

Figure 3.16: Historical prices for selected rare earth oxides, daily, index 12/12/2003 = 100, average quoted in USD $/ \mathrm{kg}$, on FOB China basis.

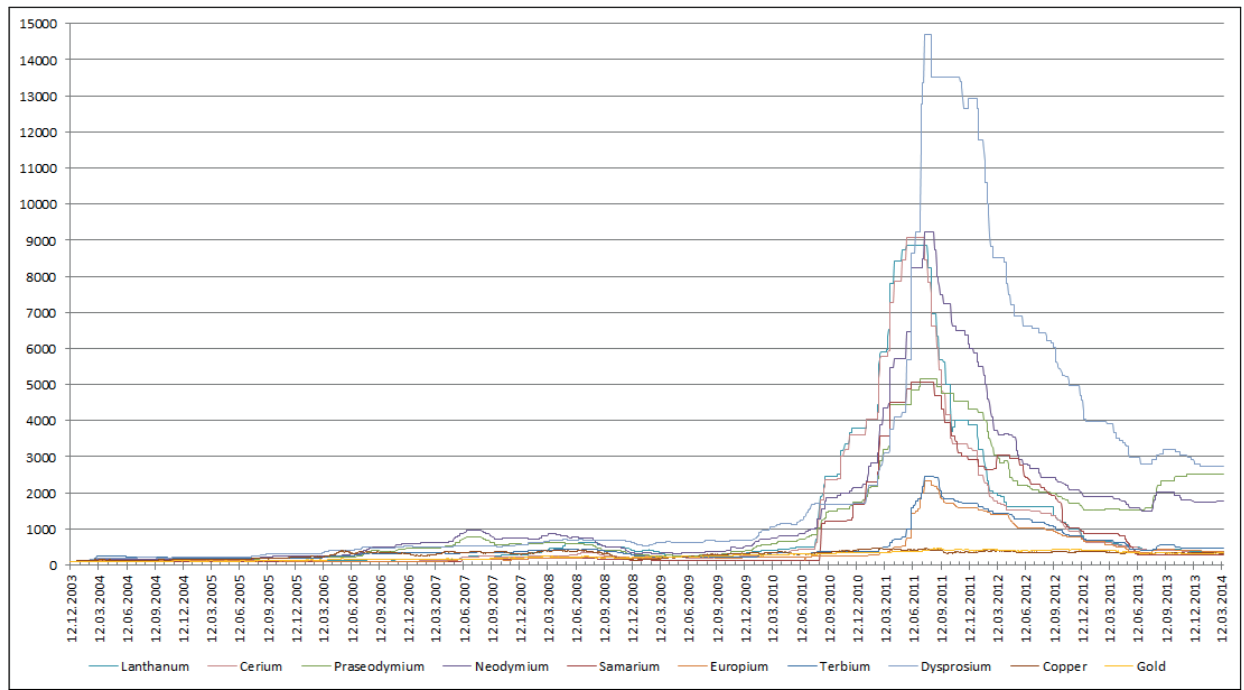

Source: Own calculations based on compiled data from Thomson Reuters Datastream (2014). 
Table 3.7: Annualised quarterly volatilities for selected rare earth oxides, quarterly prices quoted in USD/kg, on FOB China basis.

\begin{tabular}{|c|c|c|c|c|c|c|c|c|}
\hline & Q3 2010 & Q4 2010 & Q1 2011 & Q2 2011 & Q3 2011 & Q4 2011 & Q1 2012 & Q2 2012 \\
\hline Lanthanum & $16.37 \%$ & $374.47 \%$ & $366.10 \%$ & $343.28 \%$ & $348.71 \%$ & $143.07 \%$ & $140.42 \%$ & $59.82 \%$ \\
\hline Cerium & $20.36 \%$ & $439.84 \%$ & $425.33 \%$ & $410.26 \%$ & $412.68 \%$ & $139.05 \%$ & $135.20 \%$ & $65.63 \%$ \\
\hline Praseodymium & $46.15 \%$ & $61.51 \%$ & $59.72 \%$ & $88.99 \%$ & $94.00 \%$ & $108.49 \%$ & $120.27 \%$ & $43.22 \%$ \\
\hline Samarium & $1.47 \%$ & $865.67 \%$ & $840.27 \%$ & $808.42 \%$ & $803.10 \%$ & $122.45 \%$ & $117.11 \%$ & $45.00 \%$ \\
\hline Europium & $7.62 \%$ & $5.85 \%$ & $3.60 \%$ & $77.71 \%$ & $285.42 \%$ & $296.18 \%$ & $303.59 \%$ & $322.21 \%$ \\
\hline Terbium & $48.30 \%$ & $44.48 \%$ & $45.35 \%$ & $84.52 \%$ & $191.66 \%$ & $204.88 \%$ & $211.99 \%$ & $222.02 \%$ \\
\hline
\end{tabular}

Source: Own calculations based on data compiled from Thomson Reuters Datastream (2014).

To conclude with, while price increases in the period of 2002-2008 were driven by the increased demand from countries' economic growth, from 2005 onwards additional non-market forces in form of Chinese industrial policies were distorting the rare earth market. Most significantly, it was the decreased production and export quotas which were feeding expectations of further supply shortages. Speculation has driven up prices in excess of fundamentals, especially in the period of crisis. While increased volatilities indicate risk, at the same time they also signal opportunity to make profits. These were triggered by lack of transparency due to missing spot and forward markets. In the past, trades used to be carried out based on long term contracts and prices set by producers. Once prices started to become volatile, these were fixed to shorter periods. Nowadays, China has set up a trading platform and national pricing system to exercise larger control over prices. The Baotou Rare Earth Products Exchange started trading end of March 2014 (Bloomberg News, 2014) and should bring in more transparency into pricing by regulating supply and demand and setting volatility under control. The question remains though, what are the implications of such volatilities on producers of wind turbine and electrically powered vehicle technologies.

\subsubsection{Impact on low-carbon technologies' producers}

Though China has been dominating the rare earth market since mid-1990s and export and production quotas were in place already in the early 2000s, the rare earth problem has become a prominent topic only in recent years. This is mainly because of the small quantities of rare earths used in single technologies, as well as their largely inelastic demand. Moreover, because rare earth cost is low relative to the total cost of the final products, changes in prices have not had a substantial impact on producer costs. However, price hikes like those in 2010-2011 brought significant uncertainty, which ultimately put pressure on manufacturers and called innovation of rare earth-intensive technologies in question. 
In this light, several experts confirm that further development of direct drives, even though they are the superior technology on open sea, is threatened by pricing and sourcing volatility of raw materials used during manufacturing (Bills and Sison, 2013; Böhmeke, 2013; Sörensen, 2013). In fact, manufacturing costs of a wind turbine are influenced primarily by the wind turbine itself, by the production environment where it is manufactured, by its production status achieved, as well as by the cost of raw material used (Hau and Renouard, 2013). While steel has the largest share of up to $85 \%$ of turbine's total weight, the importance of rare earths used for permanent magnets should not be neglected either. As an illustration, assuming a PMSG-DD with rated power of $2 \mathrm{MW}$, rotor diameter $82 \mathrm{~m}$ and hub height $80 \mathrm{~m}$, and following the components cost breakdown as specified by Hau and Renouard (2013), 80 USD/kg of required quantity of permanent magnet constitutes $23 \%$ of generator costs and $6 \%$ of total component costs. Assuming a variation of prices of permanent magnet up to $420 \mathrm{USD} / \mathrm{kg}$ during the rare earth crisis in 2011 (Polinder, 2011), their share increases to almost two-thirds of the cost of generator and a quarter of cost of all components. This in turn increases the cost per $\mathrm{kW}$ of electricity production by $50 \%$ relative to the competing DFIG gearbox technology with same parameters (as compared to only $7 \%$ when calculated with $80 \mathrm{USD} / \mathrm{kg}$ ). Certainly, lower costs for maintenance and repair in case of PMSGDD design contribute to better economics in the long run and balance higher production costs to some extent. However, uncertainty about high and volatile prices and threat of supply disruption of rare earths is inducing producers to adjust the designs of their drivetrains. In fact, high investment costs might turn rare earth-intensive machines very expensive and counterproductive in pushing down the cost of energy. Offshore wind energy must become cheaper to compete with onshore wind and with other renewable energies.

Concerning raw material costs in advanced technology vehicles, according to the component cost comparison by Burwell et al. (2013), the cost of a $50 \mathrm{~kW}$ permanent magnet electric motor is by $30 \%-200 \%$ higher than that of a copper rotor induction motor of the same size, depending on the pricing of rare earth magnets. From manufacturer's viewpoint, switching to the latter technology would decrease total vehicle costs (even when considering the need for increased battery size) and eliminate the dependence on rare earths. In terms of batteries, these constitute the most expensive part of electric vehicles, ranging from a third to over a half of HEV's component cost. Of the battery costs, almost $60 \%$ are material costs related to cell packs (Bitsche and Gutmann, 2004). For comparison, Li-ion batteries, despite their higher production costs than NiMH batteries, are cheaper in terms of materials used (Toyota, 2010). The cost of rare earths used within a 
NiMH battery, when converted into rare earth mischmetal composed of 63.0 wt.\% La, 17.4 wt.\% Ce, 10.7 wt.\% Pr, 2.2 wt.\% Nd and $6.7 \%$ others according (Lee et al., 2000), and using the daily prices for rare earth metals Freight on Board China as provided by Thomson Reuters Datastream (2014), increased by $500 \%$ from 2005 year end to March 2014 and by 3300\% by end of June 2011, when rare earth crisis peaked. ${ }^{10}$ However, during the time of higher prices manufacturers presumably use up their private stocks to mitigate temporary price hikes.

To conclude with, besides the uncertainty of availability of supply, increasing prices of rare earths are also critical to their use in both wind turbines and advanced technology vehicles. In fact, such price volatility causes the attention of manufacturers to shift away from designing superior rare earth-intensive technologies. In face of increasing demand for these, it might follow that manufacturers, and thus all their innovation activities, relocate to China with view of sourcing cheaper inputs at stable supply.

\subsection{Social costs of rare earths}

Besides private costs of rare earths there is also a social cost to mining minerals containing radioactive thorium and uranium. This manifests itself in form of externalities to environment and health. In fact, while China has been supplying almost the entire world with rare earths during the past 20 years, the costs to environmental degradation and health of local communities have been born entirely domestically. In his famous quote, Wen Jiabao acknowledges that rare earths were under-priced: "In the beginning of the 1980s, we sold rare earths at the price of salt. But they deserve the price of gold. We are just starting to protect our natural interests" (Hayes-Labruto et al., 2013). Having said this, it would seem justifiable for resource-poor countries to pay a surplus on their imports in order to compensate for negative externalities caused by pollution. This section discusses the social costs to the extensive use of primary production of rare earths.

\subsubsection{The "dirty" clean energy}

According to the Chinese Society of Rare Earths and Materials Department of the Ministry of Industry and Information Technology (as cited in Hurst, 2010), up to

\footnotetext{
${ }^{10}$ Note that the cost or rare earths within NiMH changes in function of the composition of mischmetal. For example, Shukla et al. (2001) assumes a cerium-rich mischmetal with the following composition: 25 wt.\% La, 50 wt.\% Ce, 7 wt.\% Pr, 18 wt.\% Nd. Based on this the total cost of rare earths would amount to 159 USD and 918 USD for 30/12/2005 and 30/06/2011, respectively.
} 
$12^{\prime} 000$ cubic meters of waste gas, 75 cubic meters of acidic waste water, as well as one tonne of radioactive waste residue and 2'000 tonnes of mine tailings containing thorium are emitted for each tonne of rare earths produced. With 2013 Chinese production levels, these amount to 100'000 tonnes of radioactive waste and 200 million tonnes of tailing per year. Discharged into rivers without any treatment, these poison the water used for irrigation of farm lands and have catastrophic effects on lives of both local residents, fauna and flora. The severity of the Baotou production facility dumping waste to the Yellow river was documented by several independent Chinese information sources as well as by foreign newspapers (Bradsher, 2013; Guardian, 2012; Hui-juan, 2011; NTDTV, 2013b,a,c). China itself has acknowledged that rare earth mining deteriorates its environment through processing of rare earths (Information Office of the State Council, 2012). In line with this, the Government has been enacting laws since the 1980s on environmental protection, water pollution, land reclamation, pollutant discharge standards, as well as laws on prevention and control of radioactive pollution (National People's Congress, 2011; Information Office of the State Council, 2012). The National 12th Five-Year Plan for Environmental Protection also aims at reducing the discharge of major pollutants by $40 \%$ (MEP, 2012). Moreover, since China in its mineral policy conception committed to building a "well-off society" and implementing the strategy of sustainable development, through a more balanced mineral resources exploitation and environmental protection (Information Office of the State Council, 2003). However, while environmental policies are picking up, these are not expected to reach the stringency of policies implemented by developed countries. In the particular case of rare earths, examining the criteria which rare earth producers must fulfil in order to have production quotas allocated to them (MOFCOM, 2012j), hints to China's genuine concern over environmental pollution. Unfortunately, these measures seem to provide an incentive rather than an imperative to adhere to environmental standards (Liu and Maughan, 2012).

Other examples of precautionary action taken in light of environmental degradation caused by extraction and processing of minerals containing radioactive elements exist in developed countries. France, in its la Rochelle rare earth processing plant, decided to switch the feed materials to a thorium-free rare earth chloride due to concerns about radioactive thorium as a by-product of monazite (Hedrick, 1994). The Mountain Pass mine in the United States was shut down in 2002, after a series of waste water leakages containing heavy metals and radioactive material (Nystrom, 2003). The Australian Lynas outsources the processing of rare earth concentrates to its Lynas Advanced Materials Plant (LAMP) in Kuatan, Malaysia. Here, wastes from the process are also disposed of, supposedly due to 
Malaysia's lower environmental standards. An analogous case of pollution export by developed countries relocating industrial production to a developing country is the case of Asia Rare Earth (ARE), the main shareholder of which (Mitsubishi Chemicals) despite of its established know-how in handling radioactive materials, has relocated the rare earth processing from Japan to Bukit Merah in Malaysia. While products were shipped back to Japan, the radioactive waste remained in Malaysia. Also, it was decided by the Government that thorium was to be stored as a potential nuclear fuel for the future, though the factory itself was operating without a proper waste disposal system and without a permanent dump site in early years (Consumers Association of Penang, 1993).

Despite the evidence, the rest of the world tends to downplay China's environmental motivations to set up export and production quotas. Certainly, China's intention to promote industrial upgrading by using rare earths to manufacture technologically advanced products is undeniable. Nonetheless, there is no reason to question the justifiability of its environmental claims. Keeping in mind the environmental implications of mining and processing of rare earths, there is quite some irony in using 'dirty' rare earths in 'clean' technologies. The use of minerals gained through environmentally dirty processes for the manufacturing of low-carbon technologies translates thus into nexus repercussions, which emerge from the interconnections between low-carbon technologies and mineral resources. Therefore, unless a model of more sustainable extraction and processing, which would reflect efficient and environmentally friendly approach to mining is introduced, rare earths do not live up to their denomination of "green elements". Even if switching to extraction of deposits at seabed of the Pacific Ocean would turn to reality, concerns prevail that rare earth mining might destroy the underwater ecosystem (Arte, 2013). Finally, the race for new mining sites to start operate in shortest delays might come at the expense of upholding environmental standards, especially in developing countries ${ }^{11}$. Taken together, the ultimate implication of the status quo is that consumer countries will either have to accept compensating China for its environmental damages (by tolerating China's various industrial policies - at least those which do not violate the WTO rules) and therefore to accept higher costs of rare earth-intensive low-carbon technologies, or they will have to shift to manufacturing alternative technologies which are less rare earth-intensive

\footnotetext{
${ }^{11}$ It is important to note though, that at the moment prices for most of rare earths are experiencing a downward trend. This has also implications for establishing supply outside China, making the opening of new mines economically non-viable. China strives to fight further price decreases by consolidating the industry and closing down illegal mines, what ultimately also contributes to preserving the environment but at then same time brings about serious distributional conflict.
} 
but might at the same time be inferior in terms of their performance and energy efficiencies. A solution which could satisfy both the need for a stable access to rare earths and the environmental soundness of their production, would be to develop sustainable mining and processing techniques. These might not only solve the problem of externalities to environment and people's health in countries with less stringent environmental policies, they might also enable establishing supply in countries with more stringent environmental policies, and thus ultimately tackle the issue of volatile prices and of import dependence on China.

\subsubsection{Health issues}

The documentation on rare earth mining-caused illnesses is rather scarce globally. At present, there exists only one account of the Malaysian Bukit Merah documented by the Consumers Association of Penang (1993). This book collects testimonies of inhabitants on both children and adults falling sick, on death cases due to leukaemia and brain cancer, as well as on cases of newborns with congenital defects and on mothers suffering from higher miscarriage rate. The health situation has also been documented scientifically by Bertell (1993), who compared the monocyte depression across populations of children exposed to bone-seeking radionuclides. Children from Bukit Merah constituted one of the samples exposed to thorium hydroxide and lead sulphate waste from ARE, and were compared a sample of children from Carey Island - exposed to palm oil, pesticides and herbicides effluences, but no radioactive gases. From the two testing periods in 1987 and 1988, the study concluded on the shift towards lower monocyte counts for children with longer exposure, with more than half of the children tested in the second period having counts of below the normal range. Children from Carey Island instead, though having a similar socio-economic and lower nutritional status, demonstrated superior health. This study confirmed that the increased levels of lead in Bukit Merah children's blood was to be attributed to ARE plant. Furthermore, taking into consideration the Malaysian statistics on leukaemia in 1986, with three cases diagnosed in six months time, the Bukit Meran incidence was some 180 times higher than the Malaysia wide incidence.

For what concerns China, in its report on rare earth industry the Government acknowledges damage to peoples' safety and health (Information Office of the State Council, 2012). Unfortunately, there are no official health statistics from Baotou, the world capital of rare earth production, accessible to underline the extent of this damage. However, according to the Chinese Cancer Map revealed by the journalist Deng Fei and translated in O'Donnell (2013), Baotou is one of the "cancer villages" with a cancer death ratio of more than $70 \%$ of all deaths in 2006 . This high 
cancer rate is claimed to be caused by bad water quality due to the presence of heavy metals and radioactive materials. The contamination of the soil in the vicinity of treatment, storage and disposal areas, as well as the doses of airborne radionuclides on workers exposed to mining and beneficiation facilities in this region are summarised in International Atomic Energy Agency (2011). Another six out of eight provinces with rare earth processing appear on this map as well: Shandong, Sichuan, Jiangxi, Guangdong, Hunan and Yunnan. Ultimately, the Chinese Government has acknowledged the existence of cancer villages, the long term harm to environment and human health, arising from poisonous chemical products emitted, among others, by non-ferrous metal smelting and processing, including rare earths (China Briefing, 2013).

\subsection{Conclusions: Separating myth from reality}

The aim of this chapter was to shed clarity on the far reaching consequences of rare earth demand-supply imbalances on innovation of low-carbon technologies. It provided a detailed overview of market forces in place, investigating the main drivers of demand and supply, as well as the industrial policies distorting the rare earth market. Furthermore, the chapter discussed private and social costs to using rare earths in low-carbon technologies and reviewed mitigation strategies which could help reducing rare earth dependence for the future.

On the supply side, the existence of a supply risk was confirmed. Rather than from physical scarcity, this has been shown to arise from institutional inefficiency within the market. China is currently the largest global producer with a market share of $89 \%$ and also possesses single largest reserves of rare earths. However, as opposed to the common belief, concentration per se is not the main driver of supply disruption. Instead, it is China's abuse of market power as a means of political instrument to achieve its economic targets. In fact, China has been holding a monopoly on rare earths during the past 20 years, but only recently it started to significantly tighten their supply. In line with its resource nationalism, China introduced several industrial policies to satisfy own needs of rare earths for manufacturing higher valued added products. Restrictions such as introduction of production and export quotas, as well as banning of foreign companies from engaging in the supply chain within China, are holding back rare earth supply from the global market. While both export and production quotas have been continuously decreasing, the former remained largely unfilled in 2011 - 2013. Though the situation is expected to reverse with the recovery of major rare earth-importing economies, it is the decrease in production quotas which ultimately tightens both 
international and Chinese supply. Rather than the cumulative quotas, it is the limitation these impose on the production and export of more scarce HREE which poses the main threat to disruption. Coupled with other measures of intentional supply disruptions, such as the national pricing system and double pricing practices, these protectionist policies favour China's national interests of industrial upgrading and substantially distort the market.

The rest of the world responded to these threats by diversification of supply. From long term perspective, opening new mines outside China shall assure a more diversified supply of rare earths. However, due to various political, economic, financial and environmental obstacles, most of the mines are expected to start producing with a delay of up to 10 years, if at all. What is more, while the overall reserves of rare earths seem to be distributed evenly across the globe, $80 \%$ of continental HREE deposits are concentrated in ionic clays of China. This implies that even if non-Chinese rare earth projects brought LREE supply back to balance, HREE will remain critical going forward. In this respect, mining from the Pacific Ocean seabed might become an alternative in the long term, yet at the same time it might lead to geopolitical tensions in East Asia. Short term strategies for diversifying supply are raw materials diplomacy on country level and strategic alliances along the supply chain on company level. Though these might solve potential short term supply disruptions of LREE, no immediate alternatives to mitigate HREE shortages exist outside of China. In such cases, stockpiling might serve as a backup resource in times of crisis. Yet, besides the issues with administrative burden and efficiency with public stockpiles, and speculation and financial risk accompanying private stockpiles, this strategy is suitable as a short term solution only. A more sustainable option to address the supply shortages of primary materials is to establish recycling as a secondary source of rare earths.

The demand for rare earths is driven primarily by permanent magnets used in low-carbon technologies, in consumer electronics as well as in medical applications. This chapter has examined the role of rare earths in the specific context of offshore wind turbines and advanced technology vehicles. The results disprove the widespread allegation that availability risk of rare earths impedes deployment of offshore wind per se. However, the deployment of permanent magnet technology in particular, might become prone to supply risk depending on its future market share and the level of hybridisation adopted. This topology is characterised by high rare earth intensity. However, while its share of total capacity produced is currently growing at a rate of $600 \%$, the share of annual global supply of neodymium and dysprosium remains negligible. Despite the superiority of this technology on the open sea, manufacturers have been developing alternative technologies. Innova- 
tion in technology substitutes is mainly market-based, arising from individual wind turbine manufacturers and driven by the need to keep the offshore wind energy competitive. It was the recent pricing and sourcing volatilities of rare earths which have led manufacturers to optimise the design of their wind turbines by innovating in less rare earth-intensive topologies. For example, hybrids combine low ratio magnetic gears with smaller permanent magnets, while HTS machines use conductors relying on minute quantities of the most abundant rare earths. Innovation in turbine designs has also been driven by the fact that currently there exist no substitutes for rare earths within permanent magnets. While various innovation initiatives have emerged in the direction of minimisation through nanocomposite magnets, and of replacement by cheaper and more abundant materials, the results of this basic research are not expected to yield commercially deployable technologies any time soon. In particular, in the United States and Japan, the innovation in raw material substitutes is mainly science-based, carried out within public-private partnerships and financed through government programs. In this respect, Europe lags significantly behind, mainly due to the lack of general materials knowledge infrastructure. In all three countries, material substitution is also governed by their respective critical material strategies.

The automotive industry and its electrification instead, are substantially dependent on undistorted access to rare earths. A typical electrically powered vehicle requires around $0.6 \mathrm{~kg}$ of rare earths for its electric traction drive, and in function of the energy model, additional $3.5 \mathrm{~kg}$ for the battery. Besides these, every energy model, including the conventional ICEV, contains up to $0.44 \mathrm{~kg}$ of rare earths scattered across various parts. Despite the seemingly small quantities, the latter alone would require approximately $70 \%$ and $120 \%$ of neodymium and dysprosium supply forecasted for 2014, while respective shares would increase to $80 \%$ and $210 \%$ considering tighter supply estimates for 2016. The current share of electrically powered vehicles in total rare earth demand is substantially smaller, yet this is expected to increase in the future with their growing deployment. Therefore a potential supply shortage would disrupt the further development of the market altogether. Further to this, the innovation strategies by manufacturers are focusing on finding replacements for permanent magnets within electric traction drives. These include induction electric motors, motors with reduced amounts of critical rare earths, and the use of ferrite magnets, most of which however tend to be inferior in terms of their performance and energy efficiencies as compared to the permanent magnet electric motors. Additionally, some of the innovation initiatives in rare earth-free traction drives are financed by the US Department of Energy through its REACT program and by the Japanese Ministry of Economy, 
Trade and Industry. Here again, Europe lags behind in terms of policy driven innovation. Regarding batteries, while there is a substantial uncertainty in the deployment trends of energy models and of their charging infrastructures, price decreases envisaged for Li-ion battery packs and potential future price volatilities and availability risk of rare earths, might speed up the paradigm shift from NiMH toward Li-ion batteries. Yet, even if the dependence of electric motors and batteries on rare earths could be significantly reduced through research and innovation activities, this is expected to remain substantial within the automotive industry due to the indispensability of rare earths in various other vehicle parts.

In summary, uncertainty about volatile prices and threat of supply shortages induce manufacturers to innovate in less rare earth-intensive topologies, which are often inferior in terms of their performance and energy efficiencies. Alternatively, in the face of increasing demand for these, it might follow that manufacturers, and thus all their innovation activities, relocate to China with view of sourcing cheaper inputs at stable supply. Keeping in mind the slow pace of increase of supply outside China, as well as the low efficiency of recycling, it becomes imperative for policy makers to design policies in order to avoid getting the world 'trapped' in the rare earth dependence. In this light, more concerted action in research should be directed towards $\mathrm{R} \& \mathrm{D}$ on material substitution, on increasing efficiency in use of critical raw materials, on setting up recycling and on developing sustainable mining and processing techniques - especially for handling toxic wastes safely. The latter also proves important with regards to high social costs of mining in form of externalities to environment and people's health, and might ultimately enable establishing supply in countries with more stringent environmental policies, for example in Scandinavia and Greenland. This could ultimately have positive implications on lowering the supply risk and pricing volatility of rare earths. Finally, technical skills and manufacturing capabilities in rare earth processing need to be re-built in order to close the gap between China and the Western countries and to put the latter back on the map of global players. 


\section{Bibliography}

4C Offshore (2014). 4C Offshore Wind Farm Database. Available from http://www.4coffshore. com/windfarms/. Accessed: 20-01-2014.

Adachi, G.-y., Imanaka, N., and Tamura, S. (2010). Research trends in rare earths: A preliminary analysis. Journal of Rare Earths, 28(6):843-846.

Advisen Ltd (2013). Chemical companies: Minimizing the risks of supply chain disruptions. Available from http://corner.advisen.com/pdf_files/2013_AIG_ChemicalIndustryReport.pdf. Accessed: 13-11-2013.

Advisory Committee on Energy and Natural Resources (2009). Strategy to secure rare metals (Draft). Technical report, Ministry of Economy, Trade and Industry. Available in Japanese only from http://www.meti.go.jp/committee/materials2/downloadfiles/g90603a07j.pdf.

Alonso, E., Gregory, J., Field, F., and Kirchain, R. (2007). Material availability and the supply chain: Risks, effects, and responses. Environmental Science E Technology, 41(19):6649-6656.

Alonso, E., Sherman, A., Wallington, T., Everson, M., Field, F., Roth, R., and Kirchain, R. (2012a). Evaluating rare earth element availability: A case with revolutionary demand from clean technologies. Environmental Science \& Technology, 46(6):3406-3414.

Alonso, E., Wallington, T., Sherman, A., Everson, M., Field, F., Roth, R., and Kirchain, R. (2012b). An assessment of the rare earth element content of conventional and electric vehicles. SAE International Journal of Materials \& Manufacturing, 5(2):473-477.

Andersson, B. A. and Råde, I. (2001). Metal resource constraints for electric-vehicle batteries. Transportation Research Part D, 6(5):297-324.

Arabian-Hoseynabadi, H., Tavner, P., and Oraee, H. (2010). Reliability comparison of directdrive and geared-drive wind turbine concepts. Wind Energy, 13(1):62-73.

Areddy, J. T. (2011). China moves to strengthen grip over supply of rare-earth metals. Available from http://online.wsj.com/news/articles/SB10001424052748704124504576117511251161274. Accessed: 06-03-2014.

ARPA-E (2009). University of Delaware: High energy permanent magnets for hybrid vehicles and alternative energy. Available from http://arpa-e.energy.gov/?q=arpa-e-projects/high-energycomposite-permanent-magnets. Accessed: 25-02-2014.

ARPA-E (2010). Secretary Chu awards \$9.6 million for transformational energy research projects. Available from http://arpa-e.energy.gov/?q=arpa-e-news-item/secretarychu-awards-96-million-transformational-energy-research-projects. Accessed: 25-02-2014.

ARPA-E (2012a). Argonne National Laboratory: Nanocomposite exchange-spring magnets for motor and generator applications. Available from http://arpa-e.energy.gov/?q=arpa-eprojects/exchange-spring-magnets. Accessed: 25-02-2014.

ARPA-E (2012b). University of Alabama: Rare-earth-free permanent magnets for electric vehicle motors and wind turbine generators: Hexagonal symmetry based materials systems Mn-Bi and M-type Hexaferrite. Available from http://arpa-e.energy.gov/?q=arpa-e-projects/rare-earthfree-nanostructure-magnets. Accessed: 25-02-2014. 
ARPA-E (2014a). Baldor Electric Company: Rare-earth-free traction motor for electric vehicle applications. Available from http://arpa-e.energy.gov/?q=arpa-e-projects/rare-earthfree-traction-motor. Accessed: 13-03-2014.

ARPA-E (2014b). Electron Energy Corporation: Solid state processing of fully dense anisotropic nanocomposite magnets. Available from http://arpa-e.energy.gov/?q=arpa-e-projects/newprocessing-technology-permanent-magnets. Accessed: 13-03-2014.

ARPA-E (2014c). QM Power: Advanced electric vehicle motors with low or no rare earth content. Available from http://arpa-e.energy.gov/?q=arpa-e-projects/efficient-high-torqueelectric-vehicle-motor. Accessed: 13-03-2014.

ARPA-E (2014d). United Technologies Research Center: Additive manufacturing of optimized ultra-high efficiency electric machines. Available from http://arpa-e.energy.gov/?q=arpa-eprojects/additive-manufacturing-electric-vehicle-motors. Accessed: 13-03-2014.

ARPA-E (2014e). University of Texas at Dallas: Double-stator switched reluctance motor technology. Available from http://arpa-e.energy.gov/?q=arpa-e-projects/double-stator-motordesign. Accessed: 13-03-2014.

Arte (2013). Seltene Erden: Die Dunkle Seite der Hightech-Metalle. Available from http://www. youtube.com/watch?v=TGLC59rCCDc. Accessed: 01-03-2014.

Avalon (2014). Projects - Nechalacho: Location and ownership. Available from http:// avalonraremetals.com/projects/rare/thor_lake/. Accessed: 22-03-2014.

Avalon Rare Metals (2014). Avalon enters into rare earth refining agreement and strategic partnership. Available from http://www.marketwired.com/press-release/avalon-enters-intorare-earth-refining-agreement-and-strategic-partnership-tsx-avl-1884848.htm. Accessed: 2803-2014.

Axsen, J., Burke, A., and Kurani, K. S. (2008). Batteries for plug-in hybrid electric vehicles (PHEVs): Goals and the state of technology circa 2008. Technical report, Institute of Transportation Studies, University of California. Available from http://www.its.ucdavis.edu/ research/publications/publication-detail/?pub_id=1169.

Baba, K., Hiroshige, Y., and Takeshi, N. (2013). Rare-earth magnet recycling. Hitachi Review, 62:452-455.

Baker, M. and Krisher, T. (2013). Tesla says car fire began in battery after crash. Available from http://seattletimes.com/html/businesstechnology/2021950569_apusteslafire.html. Accessed: 02-02-2014.

Baotou National Rare Earth Hi-Tech Industrial Development Zone (2015). Rare earth: An introduction. Available from http://www.rev.cn/en/int.htm. Accessed: 05-07-2015.

Bauer, D., Diamond, D., Li, J., McKittrick, M., Sandalow, D., Telleen, P., and Wanner, B. (2011). US Department of Energy Critical Materials Strategy. Technical report, U.S. Department of Energy. Available from http://energy.gov/sites/prod/files/DOE_CMS2011_FINAL_Full.pdf.

Bauer, D., Diamond, D., Li, J., Sandalow, D., Telleen, P., and Wanner, B. (2010). US Department of Energy Critical Materials Strategy. Technical report, U.S. Department of Energy. Available from http://energy.gov/sites/prod/files/edg/news/documents/criticalmaterialsstrategy.pdf. 
Benecki, W. T. (2013). Hitachi Metals, Ltd. - The magnet industry newsmaker. Available from http://www.waltbenecki.com/uploads/hitachi_in_the_news.pdf. Accessed: 28-03-2014.

Berry, C. (2013). Rare earth stocks show signs of life, but will the uptrend stick? Available from http://www.theaureport.com/pub/na/chris-berry-rare-earth-stocks-show-signs-oflife-but-will-the-uptrend-stick. Accessed: 05-12-2013.

Bertell, R. (1993). Internal bone seeking radionuclides and monocyte counts. Internatinal Perspectives in Public Health, 9:21-27.

Bills, K. A. and Sison, A. F. (2013). Gamesa Wind: Medium speed drivetrains offer best compromise. Available from http://www.wind-drivetrain.com/MediaCenter.aspx. Accessed: 26-01-2014.

Binnemans, K., Jones, P. T., Blanpain, B., Van Gerven, T., Yang, Y., Walton, A., and Buchert, M. (2013). Recycling of rare earths: A critical review. Journal of Cleaner Production, 51:1-22.

Bitsche, O. and Gutmann, G. (2004). Systems for hybrid cars. Journal of Power Sources, $127(1): 8-15$

Bloomberg News (2014). Chinese exchange starts rare earths trading amid WTO dispute. Available from http://www.resourceinvestor.com/2014/03/28/chinese-exchange-starts-rareearths-trading-amid-w. Accessed: 31-04-2014.

Böhmeke, G. (2013). Samsung Heavy Industries: Gearbox vs direct drive. Available from http://www.wind-drivetrain.com/MediaCenter.aspx. Accessed: 26-01-2014.

Bourzac, K. (2011). The rare-earth crisis. Technology Review, 114(3):58.

Bradsher, K. (2010). Amid tension, China blocks vital exports to Japan. Available from http: //www.nytimes.com/2010/09/23/business/global/23rare.html?pagewanted=all\&_r=1\&. Accessed: 16-11-2013.

Bradsher, K. (2013). China tries to clean up toxic legacy of its rare earth riches. Available from http://www.nytimes.com/2013/10/23/business/international/china-tries-to-cleanup-toxic-legacy-of-its-rare-earth-riches.html?_r=0. Accessed: 01-03-2014.

Brindal, R. (2010). Lynas rare earths contract extended to 10 years. Available from http://www.theaustralian.com.au/business/lynas-rare-earths-contract-extended-to-10years/story-e6frg8zx-1225821818140. Accessed: 28-03-2014.

Broussely, M., Planchat, J. P., Rigobert, G., Virey, D., and Sarre, G. (1997). Lithium-ion batteries for electric vehicles: Performances of 100 Ah cells. Journal of Power Sources, 68(1):812 .

Bryce, R. (2010). Rare earth metals and their use in advanced batteries. Presented during 2010 Sustainable Mobility Seminar, California, the USA. Available from http://www. winddrivetrain.com/MediaCenter.aspx.

Buchert, M. (2011). Rare earths - a bottleneck for future wind turbine technologies? Available from http://www.oeko.de/oekodoc/1296/2011-421-en.pdf. Accessed: 18-01-2014. 
Bundesanstalt für Geowissenschaften und Rohstoffe (2014). Rohstoffpreismonitor. Available from http://www.bgr.bund.de/DE/Themen/Min_rohstoffe/Produkte/produkte_node. html\#rohstoffpreise. Accessed: 22-03-2014.

Burwell, M., Goss, J., and Popescu, M. (2013). Performance/cost comparison of induction-motor \& permanent-magnet-motor in a hybrid electric car. Available from http://www.coppermotor.com/wp-content/uploads/2013/08/Techno-Frontier-2013MBurwell-ICA-EV-Traction-Motor-Comparison-v1.8-Eng1.pdf. Accessed: 19-02-2014.

Caduff, M., Huijbregts, M. A., Althaus, H.-J., Koehler, A., and Hellweg, S. (2012). Wind power electricity: The bigger the turbine, the greener the electricity? Environmental Science E Technology, 46(9):4725-4733.

Çă̆atay Bayindir, K., Gözüküçük, M. A., and Teke, A. (2011). A comprehensive overview of hybrid electric vehicle: Powertrain configurations, powertrain control techniques and electronic control units. Energy Conversion and Management, 52(2):1305-1313.

Campbell, P. (2008). System cost analysis for an interior permanent magnet motor. Technical report, Ames Laboratory - U.S. Department of Energy. Available from http://www2.metcer.ameslab.gov/Ames\%20Laboratory\%20Report\%20IS-5191\% 20IPM\%20Cost\%20Analysis\%20by\%20P.\%20Campbell.pdf.

Castor, S. B. and Hedrick, J. B. (2006). Rare earth elements. Industrial Minerals volume, 7th edition: Society for Mining, Metallurgy, and Exploration, Littleton, Colorado, pages 769-792.

Catenacci, M., Verdolini, E., Bosetti, V., and Fiorese, G. (2013). Going electric: Expert survey on the future of battery technologies for electric vehicles. Energy Policy, 61:403-413.

Chandler, H. (2004). Wind Energy: The Facts: An Analysis of Wind Energy in the EU-25. European Wind Energy Association.

Chaturvedi, A., Yaqub, R., and Baker, I. (2014). Microstructure and magnetic properties of bulk nanocrystalline MnAl. Metals, 4(1):20-27.

China Auto Web (2014). Available from http://chinaautoweb.com/chinese-brands/. Accessed: 11-02-2014.

China Briefing (2013). China releases first plan to protect environment from toxic chemicals. Available from http://www.china-briefing.com/news/2013/02/26/china-admitsto-cancer-villages-releases-first-plan-to-protect-environment-from-toxic-chemicals.html. Accessed: 01-03-2014.

Cho, R. (2012). Rare earth metals: Will we have enough? Available from http://blogs.ei. columbia.edu/2012/09/19/rare-earth-metals-will-we-have-enough/. Accessed: 24-11-2013.

Chong, U. (2013). The worldwide ramifications of South Africa's labor disputes. Available from http://www.slate.com/articles/technology/future_tense/2013/06/south_africa_s_ labor_disputes_and_shortages_of_platinum_palladium_for_catalysts.html. Accessed: 05-122013.

Clagett, N. (2013). A rare opportunity: Streamlining permitting for rare earth materials within the United States. Geo. Wash. J. Energy ES Envtl. L., 4:123. 
Cleantech Magazine (2011). The giant wind gamble. Available from http://www. cleantechinvestor.com/portal/wind-energy/9552-the-giant-wind-gamble.html. Accessed: 1303-2014.

Cobalt Development Institute (2006). Cobalt facts - Magnetic alloys. Available from http://www. thecdi.com/cdi/images/documents/facts/COBALT_FACTS-Magnetic_Alloys.pdf. Accessed: 13-11-2013.

Connelly, N. G. (2005). Nomenclature of Inorganic Chemistry: IUPAC Recommendations 2005. Royal Society of Chemistry.

Constantinides, S. (2012). The important role of dysprosium in modern permanent magnets. Available from http://www.arnoldmagnetics.com/WorkArea/DownloadAsset.aspx?id=5701. Accessed: 06-11-2014.

Constantinides, S. (2013). Rare earth elements in transportation. Presented during Materials Science \& Technology 2013 Conference, Montreal, Canada. Available from http: //www.arnoldmagnetics.com/WorkArea/DownloadAsset.aspx?id=6091.

Constantinides, Steve (2010). The magnetic material challenge. Presented during ARPA-E Workshop on Rare Earth and Critical Materials, Arlington, Virginia. Available from http://www.power-eng.com/articles/print/volume-115/issue-3/ features/direct-drive-vs-gearbox-progress-on-both-fronts.html.

Consumers Association of Penang (1993). Wasted Lives: Radioactive Poisoning in Bukit Merah. Consumers' Association of Penang.

Continental Corporation (2011). Renault electric vehicles equipped with Continental electric motor. Available from http://www.continental-corporation.com/www/ pressportal_com_en/themes/press_releases/3_automotive_group/powertrain/press_releases / pr_20110913_elektromotor_en.html. Accessed: 13-03-2014.

CORDIS (2012). SC5-13f-2015 - Strategic international dialogues and cooperation with raw materials producing countries and industry. Available from http://cordis.europa.eu/programme/ rcn/664724_en.html. Accessed: 07-07-2015.

Cornell, D. H. e. a. (1993). Rare earths from supernova to superconductor. Pure and Applied Chemistry, 65(12):2453-2464.

Cotton, S. (2007). Lanthanide and Actinide Chemistry, volume 27. John Wiley \& Sons.

CRM_InnoNet (2015). CRM_InnoNet - Substitution of critical raw materials. Available from http://www.criticalrawmaterials.eu/project-summary/. Accessed: 30-07-2015.

Currie, A. (2012). Rare earth investors could benefit from Chinese stockpiling. Available from http://rareearthinvestingnews.com/7478-rare-earth-investors-could-benefit-fromchinese-stockpiling.html. Accessed: 06-03-2014.

de Ridder, M. (2013). The geopolitics of mineral resources for renewable energy technologies. Technical report, The Hague Centre for Strategic Studies. Available from http://www.hcss. $\mathrm{nl} /$ reports/the-geopolitics-of-mineral-resources-for-renewable-energy-technologies/127/. 
DEFRA (2012). A review of national resource strategies and research. Technical report, United Kingdom Government. Available from https://www.gov.uk/government/uploads/system/ uploads/attachment_data/file/69526/pb13722-national-resource-strategies-review.pdf.

Dingding, X. (2009). Rare earth, common problem. Available from http://www.chinadaily.com. cn/bizchina/2009-09/03/content_8649171.htm. Accessed: 21-05-2014.

Dodd, J. (2013). Enercon looks at new E-126 7.5MW prototype. Available from http://www. windpowermonthly.com/article/1194352/enercon-looks-new-e-126-75mw-prototype. Accessed: 13-03-2014.

Du, X. and Graedel, T. E. (2011). Global in-use stocks of the rare earth elements: A first estimate. Environmental science \& technology, 45(9):4096-4101.

E-magnets UK (2014). How neodymium magnets are made. Available from http://www.ndfebinfo.com/neodymium_magnets_made.aspx. Accessed: 06-11-2014.

Els, F. (2013). Largest known rare earth deposit discovered in North Korea. Available from http: //www.mining.com/largest-known-rare-earth-deposit-discovered-in-north-korea-86139/. Accessed: $21-05-2014$.

Elshkaki, A. and Graedel, T. (2013). Dynamic analysis of the global metals flows and stocks in electricity generation technologies. Journal of Cleaner Production, 59:260-273.

Environment News Service (2012). No rare earths in next generation electric vehicles. Available from http://ens-newswire.com/2012/11/23/no-rare-earths-in-next-generation-electricvehicles/. Accessed: 13-03-2014.

Erdmann, L. and Graedel, T. E. (2011). Criticality of non-fuel minerals: A review of major approaches and analyses. Environmental Science 85 Technology, 45(18):7620-7630.

European Commission (2010). Critical raw materials for the EU. Report of the Ad-hoc Working Group on Defining Critical Raw Materials, European Commission. Available from http://ec. europa.eu/enterprise/policies/raw-materials/files/docs/report-b_en.pdf.

European Commission (2011). Tackling the challenges in commodity markets and on raw materials. Communication from the Commission to the European Parliament, the Council, the European Economic and Social Committee and the Committee of the Regions COM(2011) 25 final, European Commission. Available from http://eur-lex.europa.eu/LexUriServ/LexUriServ. do?uri=COM:2011:0025:FIN:en:PDF.

European Commission (2013). Third EU-Japan-U.S. Trilateral Conference on Critical Materials - Towards new models in efficient management of critical materials. Available from http: //ec.europa.eu/research/industrial_technologies/event-13_en.html. Accessed: 12-11-2013.

European Commission (2014a). European Rare Earths Competency Network. Available from http://ec.europa.eu/enterprise/policies/raw-materials/erecon/index_en.htm. Accessed: 1303-2014.

European Commission (2014b). Policies - Waste. Available from http://ec.europa.eu/ environment/waste/index.htm. Accessed: 04-03-2014. 
European Commission (2014c). Report on critical raw materials for the EU. Report of the Adhoc Working Group on Defining Critical Raw Materials, European Commission. Available from http://www.amg-nv.com/files/Report-on-Critical-Raw-Materials-for-the-EU-2014.pdf.

European Commission (2015). Strategic energy technology plan. Available from https://ec.europa.eu/energy/en/topics/technology-and-innovation/strategic-energytechnology-plan. Accessed: 20-12-2015.

EV Obsession (2013). World electrified vehicle sales (2013 report). Available from http:// evobsession.com/world-electrified-vehicle-sales-2013/. Accessed: 21-05-2014.

Evans-Pritchard, A. (2013). Japan breaks China's stranglehold on rare metals with sea-mud bonanza. Available from http://www.telegraph.co.uk/finance/comment/ ambroseevans_pritchard/9951299/Japan-breaks-Chinas-stranglehold-on-rare-metals- withsea-mud-bonanza.html. Accessed: 27-03-2014.

evsroll.com (2013). Hybrid car statistics. Available from http://www.evsroll.com/Hybrid_Car_ Statistics.html. Accessed: 19-02-2014.

Federal Reserve Bank of St. Louis (2014). Federal Reserve economic data - Producer Price Index: Crude materials for further processing. Available from http://research.stlouisfed.org/fred2/ series/PPICRM. Accessed: 22-03-2014.

Fontanella-Khan, J. (2010). Toyota Tsusho in deal for India Rare Earths. Available from http: //www.ft.com/intl/cms/s/0/fde2d544-02f8-11e0-bb1e-00144feabdc0.html\#axzz2xL2uXk2G. Accessed: 22-03-2014.

Forbes (2014). Gigafactory will cost Tesla $\$ 5$ billion but offers significant cost reductions. Available from http://www.forbes.com/sites/greatspeculations/2014/03/11/gigafactory-will-costtesla-5-billion-but-offers-significant-cost-reductions/. Accessed: 13-03-2014.

Gehm, R. (2013). Hitachi Metals reduces rare-earth dysprosium in electric-motor magnets. Available from http://articles.sae.org/11988/. Accessed: 13-03-2014.

Global Wind Energy Council (2014). Global cumulative installed capacity 1996-2013. Available from http://www.gwec.net/wp-content/uploads/2012/06/02_glob-cum-inst-wcap-96-13. jpg. Accessed: 31-04-2014.

Goldwind (2014). Goldwind - Annual Report 2013. Available from http://www.goldwindglobal. com/upload/files/201404/201404221722971.pdf. Accessed: 21-05-2014.

Goodier, E. (2005). The recycling and future selection of permanent magnets and powder cores. Available from http://www.arnoldmagnetics.com/WorkArea/DownloadAsset.aspx?ID=4474. Accessed: 30-01-2014.

Goonan, T. G. (2011). Rare earth elements - End use and recyclability. Scientific Investigations Report 2011-5094, U.S. Department of Interior - U.S. Geological Survey. Available from http://pubs.usgs.gov/sir/2011/5094/pdf/sir2011-5094.pdf.

Graedel, T., Allwood, J., Birat, J.-P., Buchert, M., Hagelüken, C., Reck, B. K., Sibley, S. F., and Sonnemann, G. (2011). Recycling Rates of Metals: A Status Report. United Nations Environment Programme. 
Green Car Congress (2014). Navigant Research forecasts new EV global sales of >346'000 units in 2014; 10 predictions for the year. Available from http://www.greencarcongress.com/2014/ 01/20140108-navigantev.html. Accessed: 21-05-2014.

Gschneidner, K. A. and Capellen, J. (1987). Two hundred years of rare earths, 1787-1987. Technical report, Rare-earth Information Center, Iowa State University, Ames. Available from https://www.ameslab.gov/files/TwoHundredYearsRE.pdf.

Gschneidner Jr, K. (2010). The rare earth crisis - The lack of an intellectual infrastructure. Available from https://www.ameslab.gov/files/RE_Crisis_Intell_Infrastruc_12.9.10.pdf. Accessed: 22-03-2014.

Guardian, T. (2012). Rare-earth mining in China comes at a heavy cost for local villages. Available from http://www.theguardian.com/environment/2012/aug/07/china-rare-earth-villagepollution. Accessed: 01-03-2014.

Habib, K. and Wenzel, H. (2014). Exploring rare earths supply constraints for the emerging clean energy technologies and the role of recycling. Journal of Cleaner Production, 84:348-359.

Hannan, M. A., Azidin, F. A., and Mohamed, A. (2014). Hybrid electric vehicles and their challenges: A review. Renewable and Sustainable Energy Reviews, 29:135-150.

Harris, V., Chen, Y., Yang, A., Yoon, S., Chen, Z., Geiler, A., Gao, J., Chinnasamy, C., Lewis, L., Vittoria, C., et al. (2010). High coercivity cobalt carbide nanoparticles processed via polyol reaction: A new permanent magnet material. Journal of Physics D: Applied Physics, 43(16):165003.

Hatch, G. (2011a). Critical rare earths - global supply \& demand projections and the leading contenders for new sources of supply. Available from http://www.criticalrareearthsreport. com/. Accessed: 22-03-2014.

Hatch, G. (2011b). Rare-earth terminology - A quick refresher on the basics. Available from http://www.techmetalsresearch.com/2012/12/rare-earth-terminology-a-quick-refresher-onthe-basics/. Accessed: 24-09-2013.

Hatch, G. (2014). TMR Advanced Rare-Earth Projects Index. Available from http://www. techmetalsresearch.com/metrics-indices/tmr-advanced-rare-earth-projects-index/. Accessed: 22-03-2014.

Hau, E. and Renouard, H. V. (2013). Wind turbines: Fundamentals, Technologies, Application, Economics. Springer.

Hayes-Labruto, L., Schillebeeckx, S. J., Workman, M., and Shah, N. (2013). Contrasting perspectives on China's rare earths policies: Reframing the debate through a stakeholder lens. Energy Policy, 63:55.

Hedrick, J. B. (1994). Thorium. Available from http://minerals.usgs.gov/minerals/pubs/ commodity/thorium/690494.pdf. Accessed: 01-03-2014.

Henderson, P. (1984). Rare Earth Element Geochemistry, volume 510. Elsevier Amsterdam.

Henriksen, M. (2011). Feasibility study of induction generators in direct-drive wind turbines. Master's thesis, Technical University of Denmark. Accessed: 13-03-2014. 
Hitachi Ltd (2010). Hitachi develops recycling technologies for rare earth metals. Available from http://www.hitachi.com/New/cnews/101206.html. Accessed: 01-03-2014.

Hitachi Ltd (2012). Highly efficient industrial 11kW permanent magnet synchronous motor without rare-earth metals. Available from http://www.hitachi.com/New/cnews/120411.html. Accessed: 13-03-2014.

Hoenderdaal, S., Espinoza, L. T., Marscheider-Weidemann, F., and Graus, W. (2013). Can a dysprosium shortage threaten green energy technologies? Energy, 49:344-355.

Honda Motor (2013). Honda established world's first process to reuse rare earth metals extracted from nickel-metal hydride batteries for hybrid vehicles. Available from http://www. hondanews.info/news/en/corporate/c130303eng. Accessed: 04-03-2014.

Hong, F. (2006). Rare earth: Production, trade and demand. Journal of Iron and Steel Research, International, 13:33-38.

Hui-juan, L. (2011). The heavy cost of rare earth shouldered by residents of Inner Mongolia. Available from http://www.wantchinatimes.com/news-subclass-cnt.aspx?id= 20110206000006\&cid=1505. Accessed: 01-03-2014.

Huixia, S. (2010). Wen says rare earths not a bargaining tool. Available from http://english. caixin.com/2010-10-07/100186501.html. Accessed: 16-11-2013.

Humphries, M. (2013). Rare earth elements: The global supply chain. Technical report, Congressional Research Service. Available from https://fas.org/sgp/crs/natsec/R41347.pdf.

Hurst, C. (2010). China's rare earth elements industry: What can the West learn? Technical report, Institute for the Analysis of Global Security. Available from http://fmso.leavenworth. army.mil/documents/rareearth.pdf.

Hurst, D. and John, G. (2013). Electric vehicle market forecasts: Executive summary. Technical report, Navigant Research. Available from http://www.navigantresearch.com/research/ electric-vehicle-market-forecasts.

Hybrid Autos (2014). Available from http://www.hybrid-autos.info/. Accessed: 11-02-2014.

Hybrid Cars (2013). Top 10 best-selling hybrids. Available from http://www.hybridcars.com/ best-selling-hybrids. Accessed: 19-02-2014.

Hybrid Cars (2014). Available from http://www.hybridcars.com/. Accessed: 11-02-2014.

Information Office of the State Council (2003). China's policy on mineral resources. Available from http://news.xinhuanet.com/zhengfu/2003-12/23/content_1244900.htm. Accessed: 3003-2016.

Information Office of the State Council (2012). Situation and policies of China's rare earth industry. Available from http://english.gov.cn/archive/white_paper/2014/08/23/content_ 281474983043156.htm. Accessed: 25-11-2013.

InnWind (2013). Innovative wind conversion systems: 10 - $20 \mathrm{MW}$ for offshore applications. Available from http://www.innwind.eu/Publications. Accessed: 13-03-2014. 
InnWind (2014). WP3 - Electromechanical conversion. Available from http://www.innwind.eu/ Work-Packages/WP3-Electromechanical-Conversion. Accessed: 13-03-2014.

International Atomic Energy Agency (2011). Radiation protection and NORM residue management in the production of rare earths from thorium containing minerals. Technical report, International Atomic Energy Agency. Available from http://www-pub.iaea.org/MTCD/ Publications/PDF/Pub1512_web.pdf.

International Energy Agency - HEV (2013). Clean vehicle options. Available from http://www. ieahev.org/about-the-technologies/. Accessed: 30-01-2014.

Jackson, W. D. and Christiansen, G. (1993). International strategic minerals inventory summary report - rare-earth oxides. U.S. Geological Survey Circular 930-N, U.S. Department of Interior - U.S. Geological Survey. Available from http://pubs.usgs.gov/circ/1993/0930n/report.pdf.

Janssen, L., Lacal Arántegui, R., Brøndsted, P., Gimondo, P., Klimpel, A., Johansen, B., and Thibaux, P. (2012). Scientific assessment in support of the materials roadmap enabling low carbon energy technologies: Wind energy. JRC-Scientific and Strategic Reports EUR 25197 EN - 2012, European Commission Joint Research Centre Institute for Energy and Transport. Available from http://publications.jrc.ec.europa.eu/repository/bitstream/111111111/ 26289/1/reqno_jrc68191_set-plan\%20materials\%20pdf.pdf.

Japan Automobile Dealers Association (2013). 2014 new passenger car sales monthly rankings. Available from http://www.jada.or.jp/contents/data/ranking.html. Accessed: 19-02-2014.

Japan Metal Bulletin (2010). South Korea to increase rare earth and rare metal stockpile. Available from http://www.japanmetalbulletin.com/?p=4341. Accessed: 09-03-2014.

Jensen, B. B. and Abrahamsen, A. B. (2011). High temperature superconducting (HTS) technology for generators. Presented during 2nd International Conference on Drivetrain Concepts for Wind Turbines, Bremen, Germany. Available from http://orbit.dtu.dk/fedora/objects/orbit: 107410/datastreams/file_10145277/content.

Jensen, B. B., Mijatovic, N., and Abrahamsen, A. B. (2013). Development of superconducting wind turbine generators. Journal of Renewable and Sustainable Energy, 5(2):023137.

JOGMEC (2012). China moves to strengthen grip over supply of rare-earth metals. Available from https://www.jogmec.go.jp/content/300059711.pdf. Accessed: 06-03-2014.

Johnston, A. I. (2013). How new and assertive is China's new assertiveness? International Security, 37(4):7-48.

Kawamoto, H. (2008). Japan's policies to be adopted on rare metal resources. Quarterly Review, $27: 57-76$

Kingsnorth, D. J. (2009). The rare earth market: Can supply meet demand in 2014? Presented during PDAC 2009, Toronto, Canada.

Kingsnorth, D. J. (2011). Meeting the challenges of supply this decade. Available from http: //files.eesi.org/kingsnorth_031111.pdf. 
Kingsnorth, D. J. (2013a). Kingsnorth believes rare earth element demand and prices to increase. Available from http://investorintel.com/rare-earth-intel/dudley-kingsnorth-believesthat-ree-demand-and-prices-will-double-by-2015/. Accessed: 22-03-2014.

Kingsnorth, D. J. (2013b). Professor Dudley Kingsnorth's bullish position on REE markets. Available from http://www.youtube.com/watch?v=yUlUH5BNvDU. Accessed: 01-03-2014.

Kingsnorth, D. J. (2013c). The rare earths industry: Undergoing rejuvenation. Presented during Rare Earths 2013 Conference, Shanghai, China.

Kirsch, D. A. (2000). The Electric Vehicle and the Burden of History. Rutgers University Press, New Brunswick, NJ [etc.].

Kopera, J. J. (2004). Inside the nickel metal hydride battery. Cobasys, MI.

Kosich, D. (2013). Patent fight could impact half of global rare earth metal supply. Available from http://www.mineweb.com/mineweb/content/en/mineweb-industrial-metalsminerals-old?oid=200793\&sn=Detail. Accessed: 28-03-2014.

Kostopoulos, D., Polinder, H., and van den Brink, A. (2012). High temperature superconducting generators for direct drive wind turbines: A review. In EWEA 2012 Online Conference Proceedings. Available from http://proceedings.ewea.org/annual2012/allfiles2/ 1559_EWEA2012presentation.pdf.

Kozawa, S. (2011). Trends and problems in research of permanent magnets for motors - Addressing scarcity problem of rare earth elements. Science and Technology Trends, Quarterly Review, 38:40-54.

Lacal Arántegui, R., Suomalainen, K., and Corsatea, T. (2012). 2012 JRC wind status report: Technology, market and economic aspects of wind energy in Europe. JRC-Scientific and Policy Reports EUR 25647 EN, European Commission Joint Research Centre Institute for Energy and Transport. Available from http://publications.jrc.ec.europa.eu/repository/ bitstream/111111111/27437/1/2012_jrc_wind_status_report_final_online.pdf.

Lee, J., Jang, K., Jung, J., Kim, D., Yu, J., Lee, S., Park, J., and Lee, H. (2000). Mm-Ni type hydrogen storage alloy for Ni/MH secondary cell. Washington, DC: U.S. Patent and Trademark Office. US Patent 6,106,768.

Lichtenberg, F., Köhler, U., Fölzer, A., Adkins, N. J. E., and Züttel, A. (1997). Development of AB 5 type hydrogen storage alloys with low Co content for rechargeable Ni-MH batteries with respect to electric vehicle applications. Journal of Alloys and Compounds, 253:570-573.

Lifton, J. (2013). Jack Lifton from the China Rare Earth Summit on the 'Extreme shortage of terbium and yttrium'. Available from http://www.youtube.com/watch?v=3A6o00_TL3E. Accessed: 26-11-2013.

Liu, H.-W. and Maughan, J. (2012). China's rare earths export quotas: Out of the China-raw materials gate, but past the WTO's finish line? Journal of International Economic Law, 15(4):971-1005.

Long, K. R., Van Gosen, B. S., Foley, N. K., and Cordier, D. (2010). The principal rare earth elements deposits of the United States - A summary of domestic deposits and a global perspective. Scientific Investigations Report 2010-5220, U.S. Department of Interior - U.S. Geological Survey. Available from http://pubs.usgs.gov/sir/2010/5220/. 
Lynas Corporation (2010). What are rare earths? Available from http://www.lynascorp.com/ Pages/What-Are-Rare-Earths.aspx. Accessed: 06-11-2013.

Lynas Corporation (2014). Annual report 2013. Available from http://www.lynascorp.com/ Annual\%20Reports/Lynas_Annual\%20Report_2013\%20FINAL\%201272078.pdf. Accessed: 28-03-2014.

Maeda, R. (2010). Japan considering rare earth stockpile. Available from http://www.mineweb. net/mineweb/content/en/mineweb-political-economy?oid=112183\&sn=Detail. Accessed: 0603-2014.

Magnomatics (2014). Electrical machine with fully integrated magnetic gear offering unrivalled torque density. Available from http://www.magnomatics.com/Technology/pseudodirect-drive.aspx. Accessed: 13-03-2014.

Magnusson, N., Jensen, B. B., Abrahamsen, A. B., and Nysveen, A. (2013). Superconducting generator technology for large offshore wind turbines. Presented during 10th Deep Sea Offshore Wind R\&D Conference, Trondheim, Norway. Available from https://www.sintef.no/project/DeepWind\%202013/Deepwind\%20presentations\% 202013/A2/Magnusson,\%20N_SINTEF.pdf.

Mancheri, N. A. (2012). Science and technology policy of China and moving up in the supply chain: The case of rare earth industry. Available from http://www.punjabiuniversity.ac.in/cdeiswebsite/papers/33\%20Nabeel\%20Mancheri\% 20Science\%20and\%20Technology\%20Policy\%20of\%20China_.pdf. Accessed: 26-11-2013.

Martín, H. (2013). FAA steps up investigation of Boeing 787 Dreamliner. Available from http: //articles.latimes.com/2013/jan/22/business/la-fi-dreamliner-investigation-20130122. Accessed: 02-02-2014.

McCallum, R. W. (2012). Replacing critical rare earth materials in high energy density magnets. Bulletin of the American Physical Society, 57.

McMillan, D. and Ault, G. W. (2010). Techno-economic comparison of operational aspects for direct drive and gearbox-driven wind turbines. Energy Conversion, IEEE Transactions on, 25(1):191-198.

McQuade, M. (2013). Energy efficiency: Materials and manufacturing processes. Available from http://iee.ucsb.edu/files/McQuade.UCSB_.EE\%20Materials\%20and\%20Manufacturing\%

20Process.May-2103.pdf. Accessed: 13-03-2014.

MEP (2012). MEP explains the national 12th Five-Year Plan for Environmental Protection. Available from http://english.mep.gov.cn/News_service/infocus/201202/t20120207_ 223194.htm. Accessed: 01-03-2014.

Metal Pages (2009). Duties \& taxes - Chinese export tariffs. Available from http://www.metalpages.com/resources/chinese-export-tariffs/. Accessed: 14-11-2013.

METI (2011). Challenges and actions in economic/industrial policies. Available from http:// www.meti.go.jp/english/aboutmeti/policy/fy2012/fy2012policies.pdf. Accessed: 06-03-2014. 
Miller, E. (2014). Matamec Explorations Inc. - Director of IR Edward Miller talks rare earths in Quebec. Available from http://rareearthinvestingnews.com/19596-matamec-explorationsinc-tsxv-mat.html. Accessed: 28-03-2014.

Miroux, A., Hamdi, M., Sampath, P. G., Lim, M., and Razo, C. (2011). Technology and innovation report 2011: Powering development with renewable energy technologies. Technical report, UNCTAD. Available from http://unctad.org/en/Docs/tir2011_en.pdf.

MLR (2011). The national research of the rare earth reserve will be completed, and the domestic pricing power will be strengthened. Available from http://www.mlr.gov.cn/kczygl/xsfx/ 201106/t20110630_891443.htm. Accessed: 06-03-2014.

MLR (2013). Land and Resources issued the notice on the 2013 annual total rare earth tungsten ore, antimony ore mining control targets. Available from http://www.mlr.gov.cn/zwgk/zytz/ 201309/t20130906_1267679.htm. Accessed: 24-11-2013.

Mock, P. (2013). European vehicle market statistics - Pocketbook 2013. Technical report, International Council on Clean Transportation. Available from http://www.theicct.org/sites/ default/files/publications/EU_vehiclemarket_pocketbook_2013_Web.pdf.

Moeller, T. (1963). The Chemistry of the Lanthanides. Reinhold New York.

MOFCOM (2011). Regular press conference of the Ministry of Commerce on July 15, 2011. Available from http://english.mofcom.gov.cn/article/newsrelease/press/201107/20110707672428. shtml. Accessed: 26-11-2013.

MOFCOM (2012a). Catalogue for the guidance of foreign investment industries (amended in 2011). Available from http://english.mofcom.gov.cn/article/policyrelease/domesticpolicy/ 201203/20120308027837.shtml. Accessed: 24-11-2013.

MOFCOM (2012b). China "building up rare earth reserves". Available from http://english. mofcom.gov.cn/article/counselorsreport/asiareport/201207/20120708233202.shtml. Accessed: 24-11-2013.

MOFCOM (2012c). China launches rare earth trading platform. Available from http://english. mofcom.gov.cn/article/counselorsreport/asiareport/201208/20120808275052.shtml. Accessed: 24-11-2013.

MOFCOM (2012d). China may start building rare earths stockpile in Sept. Available from http: //english.mofcom.gov.cn/article/newsrelease/counselorsoffice/westernasiaandafricareport/ 201208/20120808301520.shtml. Accessed: 06-03-2014.

MOFCOM (2012e). China shuts down illicit rare rarth mines. Available from http://english. mofcom.gov.cn/article/counselorsreport/asiareport/201207/20120708249353.shtml. Accessed: 26-11-2013.

MOFCOM (2012f). China to continue rare earth protection: Official. Available from http://english.mofcom.gov.cn/article/counselorsreport/europereport/201207/ 20120708251407.shtml. Accessed: 24-11-2013.

MOFCOM (2012g). China to tighten standard for rare-earth mining, cut number of license. Available from http://english.mofcom.gov.cn/article/counselorsreport/asiareport/ 201207/20120708235128.shtml. Accessed: 24-11-2013. 
MOFCOM (2012h). China's rare earths giant continues production halt. Available from http: //english.mofcom.gov.cn/article/newsrelease/counselorsoffice/westernasiaandafricareport/ 201212/20121208505487.shtml. Accessed: 24-11-2013.

MOFCOM (2012i). Chinese rare earth firm to form megacompany. Available from http: //english.mofcom.gov.cn/article/newsrelease/counselorsoffice/westernasiaandafricareport/ 201212/20121208508083.shtml. Accessed: 24-11-2013.

MOFCOM (2012j). Ministry of Commerce notice no. 86 of 2012 on the 2013 rare earth export quota reporting conditions and reporting procedures of the announcement. Available from http://wms.mofcom.gov.cn/article/zt_gypck/ysjsh/201211/20121108458854.shtml. Accessed: 23-11-2013.

MOFCOM (2012k). Plight of China's rare earths industry persists. Available from http: //english.mofcom.gov.cn/article/newsrelease/counselorsoffice/westernasiaandafricareport/ 201211/20121108453379.shtml. Accessed: 26-11-2013.

MOFCOM (2012l). System to price rare earths. Available from http://english.mofcom.gov. cn/article/newsrelease/counselorsoffice/westernasiaandafricareport/201208/20120808277446. shtml. Accessed: 24-11-2013.

MOFCOM (2014a). Announcement no. 97 of 2014 announced the "2015 classification of goods export license management certification directory". Available from http://www.mofcom.gov. cn/article/b/e/201412/20141200854927.shtml. Accessed: 11-01-2015.

MOFCOM (2014b). Industrial exports - Non-ferrous metals (copper, lead, zinc, tungsten, antimony, tin, rare earth, silver, etc.). Available from http://wms.mofcom.gov.cn/article/ zt_gypck/ysjsh/? Accessed: 20-11-2013.

Molycorp (2010). Rare element technologies. Available from http://www.molycorp.com/ technology/green-element-technologies/. Accessed: 06-11-2013.

Molycorp (2014). Molycorp reports fourth quarter \& full year 2013 financial results. Available from http://www.molycorp.com/investors. Accessed: 28-03-2014.

Mori, H. (2013). Rare earths treasure trove found in seabed near Minami-Torishima. Available from https://ajw.asahi.com/article/behind_news/social_affairs/AJ201303220057. Accessed: 27-03-2014.

Morris, L. (2011). Direct drive vs. gearbox: Progress on both fronts. Available from http://www.power-eng.com/articles/print/volume-115/issue-3/features/direct-drive-vsgearbox-progress-on-both-fronts.html. Accessed: 26-01-2014.

Moss, R., Tzimas, E., Kara, H., Willis, P., and Kooroshy, J. (2011). Critical metals in strategic energy technologies. JRC-Scientific and Strategic Reports EUR 24884 EN - 2011, European Commission Joint Research Centre Institute for Energy and Transport. Available from http://setis.ec.europa.eu/publications/jrc-setis-reports/critical-metals-strategic-energytechnologies.

Müller, T. and Friedrich, B. (2006). Development of a recycling process for nickel-metal hydride batteries. Journal of power sources, 158(2):1498-1509. 
National People's Congress (2011). Law of the People's Republic of China on prevention and control of radioactive pollution. Available from http://www.china.org.cn/china/ LegislationsForm2001-2010/2011-02/14/content_21915263.htm. Accessed: 01-03-2014.

National Renewable Energy Laboratory (2007). Gearbox reliability collaborative. Available from http://www.nrel.gov/wind/grc/. Accessed: 18-01-2014.

National Research Council (2008). Minerals, Critical Minerals, and the US Economy. National Academies Press.

NEDO (2012). The Second Trilateral EU-Japan-U.S. Conference on Critical Materials - Seminar on the strategic implications of global shortages in critical materials. Available from http: //www.nedo.go.jp/content/100483482.pdf. Accessed: 12-11-2013.

NIMS (2010a). High coercivity neodymium magnet without using heavy rare earth element dysprosium. Available from http://www.nims.go.jp/eng/news/press/2010/08/p201008301.html. Accessed: 13-03-2014.

NIMS (2010b). Rare earths the potential of NIMS. Available from http://www.nims.go.jp/ eng/publicity/nimsnow/2010/hdfqf10000007ynd-att/NIMS_NOW1010E.pdf. Accessed: 1303-2014.

NIMS (2011). Research trends on rare earth and critical elements in Japan. Available from http://energy.gov/sites/prod/files/Session_A7_Hono_NIMS.pdf. Accessed: 13-03-2014.

Nordhaus, W. D. (1974). The 1974 report of the President's Council of Economic Advisers: Energy in the economic report. The American Economic Review, 64(4):558-565.

Northeastern University (2012). Sustainable technology: Super magnets without rare earth metals. Available from http://www.northeastern.edu/research/wp-content/uploads/2012/09/ 5Spring2012_Vol2_No3.pdf. Accessed: 25-02-2014.

NTDTV (2013a). Chinese regime appease Inner Mongolia. Available from http://www.youtube. com/watch?v=nOWBUJ6FDmI. Accessed: 01-03-2014.

NTDTV (2013b). Rare earth experts embarrassed in Malaysia. Available from http://www. youtube.com/watch?v=9HtRFzxZidc. Accessed: 01-03-2014.

NTDTV (2013c). Rare earth minerals turn villages to ruins. Available from http://www.youtube. com/watch?v=TGLC59rCCDc. Accessed: 01-03-2014.

Nystrom, E. C. (2003). From neglected space to protected place: An administrative history of Mojave National Preserve. Available from http://www.nps.gov/history/history/online_books/ moja/adhi/adhi8a.htm. Accessed: 01-03-2014.

O'Donnell, M. A. (2013). Cancer Village Map. Available from http://shenzhennoted.com/2013/ 02/25/cancer-villages/. Accessed: 01-03-2014.

Offshore Wind (2013). Available from http://www.offshorewind.biz/. Accessed: 20-01-2014.

Ohnsman, A. (2011). Toyota readying motors that don't use rare earths. Available from http://www.bloomberg.com/news/2011-01-14/toyota-readying-electric-motorsthat-don-t-use-rare-earths.html. Accessed: 13-03-2014. 
OICA (2014). World motor vehicle production statistics - 2013. Available from http://www. oica.net/category/production-statistics/2012-statistics/. Accessed: 30-03-2014.

Ovshinsky, S., Fetcenko, M., and J., R. (1993). A nickel metal hydride battery for electric vehicles. Science, 260(5105):176-181.

Park, S. (2011). S. Korea boosts rare-earth stockpile target as prices gain. Available from http://www.bloomberg.com/news/2011-08-12/s-korea-to-boost-rare-earthstockpiles-explore-local-deposits.html. Accessed: 06-03-2014.

Patton, D. (2012). China maps a wind turbine future without rare-earth magnets. Available from http://www.rechargenews.com/wind/article1294209.ece. Accessed: 21-05-2014.

Pellegrino, G., Vagati, A., Boazzo, B., and Guglielmi, P. (2012). Comparison of induction and PM synchronous motor drives for EV application including design examples. Industry Applications, IEEE Transactions on, 48(6):2322-2332.

Pierrot, M. (2014). The Wind Power - Wind turbines and wind farms database. Available from http://www.thewindpower.net/. Accessed: 20-01-2014.

Plug-In Cars (2014). Available from http://www.plugincars.com/. Accessed: 11-02-2014.

Polinder, H. (2011). Overview of and trends in wind turbine generator systems. Presented during XEMC-Darwind Symposium, Eindhoven, The Netherlands. Available from https://afdelingen.kiviniria.net/media-afdelingen/DOM100000223/Verslagen_ presentaties/2011/20111107_XEMC-Darwind_symposium/HenkP-Wind_Polinder_kivi11.pdf.

Polinder, H., Van der Pijl, F. F., De Vilder, G.-J., and Tavner, P. J. (2006). Comparison of directdrive and geared generator concepts for wind turbines. Energy conversion, IEEE transactions on, 21(3):725-733.

Power-technology.com (2014). The world's 10 biggest wind turbines. Available from http://www. power-technology.com/features/featurethe-worlds-biggest-wind-turbines-4154395/. Accessed: 20-01-2014.

Prentice, A., Devitt, P., Busvine, D., and Neely, J. (2013). Russia to invest $\$ 1$ bln in rare earths to cut dependence on china. Available from http://www.reuters.com/article/2013/09/10/russiarareearth-china-idUSL5N0H51K920130910. Accessed: 28-03-2014.

Råde, I. and Andersson, B. A. (2001). Requirement for metals of electric vehicle batteries. Journal of Power Sources, 93(1):55-71.

Recharge (2013). Available from http://www.rechargenews.com/news/. Accessed: 20-01-2014.

Redall, B. and Gordon, J. (2012). Analysis: Search for rare earth substitutes gathers pace. Available from http://www.reuters.com/article/2012/06/22/us-rareearths-alternativesidUSBRE85L0YB20120622. Accessed: 13-03-2014.

Reilly, J. (2012). China's unilateral sanctions. The Washington Quarterly, 35(4):121-133.

Reliawind (2011). Available from http://www.reliawind.eu/. Accessed: 26-01-2014. 
Renault Nissan (2012). When less is more: Nissan cuts rare earth element usage in electric motors by 40 per cent. Available from http://blog.alliance-renault-nissan.com/blog/when-less-morenissan-cuts-rare-earth-element-usage-electric-motors-40-cent. Accessed: 13-03-2014.

Retriev Technologies (2014). Recycling technology - NiCad \& NiMH. Available from http: //www.retrievtech.com/recycling/nicad-and-nimh. Accessed: 04-03-2014.

Risk \& Policy Analysis (2012). Stockpiling of non-energy raw materials. Technical report, European Commission. Available from http://ec.europa.eu/enterprise/policies/raw-materials/ files/docs/stockpiling-report_en.pdf.

Rydh, C. J. and Svärd, B. (2003). Impact on global metal flows arising from the use of portable rechargeable batteries. The Science of the total environment, 302(1-3):167-184.

SAE International (2010). Hybrids, EVs face new challenge: The possible rarity of rare earths. Available from http://articles.sae.org/8544/. Accessed: 19-02-2014.

Schearf, D. (2014). North Korea's rare earths could be game changer. Available from http:// www.voanews.com/content/north-korea-rare-earths-game-changer/1832018.html. Accessed: 21-05-2014.

Schlumpberger, C. (2013). Krise am Markt für Seltene Erden. Available from http://www.marktundmittelstand.de/nachrichten/produktion-technologie/krise-am-marktfuer-seltene-erden/. Accessed: 22-03-2014.

Schreffler, R. (2013). Analysts downsize global PHEV, EV sales forecasts. Available from http:// wardsauto.com/sales-amp-marketing/analysts-downsize-global-phev-ev-sales-forecasts. Accessed: 21-05-2014.

Schüler, D., Buchert, M., Liu, R., Dittrich, S., and Merz, C. (2011). Study on rare earths and their recycling. Technical report, Öko-Institut eV Darmstadt. Available from http://www. oeko.de/oekodoc/1112/2011-003-en.pdf.

Sehgal, V. (2013). White paper on global electric cars market. Technical report, RNCOS Business Consultancy Services. Available from http://www.slideshare.net/shushmul/global-electriccars-market-oct13.

Shah, R. (2015). Molycorp, Inc. signs restructuring support agreement with key creditors; agreement covers more than $70 \%$ of $10 \%$ secured noteholders. Available from http://investorintel.com/technology-metals-news/molycorp-inc-signs-restructuring-supportagreement-with-key-creditors-agreement-covers-more-than-70-of-10-secured-noteholders/. Accessed: 30-07-2015.

Shedd, K. B. (1999). Metals prices in the United States through 1998 - Cobalt. In Plunkert, P. A. and Jones, T. S., editors, Metals Prices in the United States through 1998. U.S. Department of Interior - U.S. Geological Survey.

Sheffi, Y. (2001). Supply chain management under the threat of international terrorism. International Journal of Logistics Management, The, 12(2):1-11.

Shen, H. (2015). China to levy new resource tax on rare earths May 1st. Available from http://investorintel.com/technology-metals-intel/china-to-levy-new-resource-taxon-rare-earths-on-may-1st/. Accessed: 31-07-2015. 
Shukla, A. K., Venugopalan, S., and Hariprakash, B. (2001). Nickel-based rechargeable batteries. Journal of Power Sources, 100(1):125-148.

Skomski, R. and Sellmyer, D. J. (2009). Anisotropy of rare-earth magnets. Journal of Rare Earths, 27(4):675-679.

Sörensen, H. (2013). Vattenfall Denmark: Balancing Capex and Opex. Available from http: //www.wind-drivetrain.com/MediaCenter.aspx. Accessed: 26-01-2014.

Stoddard, H. (2013). Global hybrid, EV volume to see incremental growth by 2016. Available from http://wardsauto.com/plants-amp-production/global-hybrid-ev-volume-seeincremental-growth-2016. Accessed: 21-05-2014.

Stynes, T. (2010). Molycorp, Hitachi Metals reach rare-earth deal. http://online.wsj.com/news/ articles/SB10001424052748703581204576033382079826492. Accessed: 28-03-2014.

Sumitomo Corporation (2012). Starting rare earth production in Kazakhstan. Available from http://www.sumitomocorp.co.jp/english/news/detail/id=25526. Accessed: 22-03-2014.

Sun, X., Huang, D., and Wu, G. (2012). The current state of offshore wind energy technology development. Energy, 41(1):298.

Syrett, L. (2012). Rare earths to become rarer in electric vehicles. Available from http://www.indmin.com/Article/3133551/Rare-earths-to-become-rarer-in-electricvehicles.html. Accessed: 13-03-2014.

Tabuchi, H. (2010). Japan recycles minerals from used electronics. Available from http: //www.nytimes.com/2010/10/05/business/global/05recycle.html?pagewanted=all\&_r=0. Accessed: 01-03-2014.

Tashakori, A., Ektesabi, M., and Hosseinzadeh, N. (2010). Characteristics of suitable drive train for electric vehicle. Presented during the 3rd International Conference on Power Electronic and Intelligent Transportation System (PEITS), Shenzhen, China. Available from https: //www.academia.edu/1513960/Characteristics_of_suitable_drive_train_for_electric_vehicle.

Tasman Metals (2010). Principal uses of rare elements. Available from http://www. tasmanmetals.com/s/PrincipalUses.asp. Accessed: 06-11-2013.

Taylor, S. R. (1964). Abundance of chemical elements in the continental crust: A new table. Geochimica et Cosmochimica Acta, 28(8):1273-1285.

Technology Metals Research (2010). What are technology metals? Available from http://www. techmetalsresearch.com/what-are-technology-metals/. Accessed: 09-11-2013.

Tesla Motor (2014). About the size of a watermelon, with a lot more juice. Available from http://www.teslamotors.com/roadster/technology/motor. Accessed: 13-03-2014.

The Daily Fusion (2013). Iron-nitride magnets will make electricity generation cheaper and greener. Available from http://dailyfusion.net/2013/10/iron-nitride-magnets-will-makeelectricity-generation-cheaper-and-greener-22428/. Accessed: 25-02-2014.

The Economist (2014). Why lithium batteries keep catching fire. Available from http://www.economist.com/blogs/economist-explains/2014/01/economist-explains-19?fsrc= $\mathrm{scn} / \mathrm{fb} / \mathrm{wl} / \mathrm{bl} / \mathrm{ee} /$ whylithiumbatterieskeepcatchingfire. Accessed: 02-02-2014. 
Thomson Reuters Datastream (2014). Rare earth oxides and metals pricing data 2005-2014. Accessed: 22-03-2014.

Tie, S. F. and Tan, C. W. (2013). A review of energy sources and energy management system in electric vehicles. Renewable and Sustainable Energy Reviews, 20:82-102.

Ting, M. H. and Seaman, J. (2013). Rare earths: Future elements of conflict in Asia? Asian Studies Review, 37(2):234-252.

Topf, A. (2013a). Chinese stockpiling around the corner. Available from http: //rareearthinvestingnews.com/15348-chinese-stockpiling-around-the-corner.html. Accessed: 06-03-2014.

Topf, A. (2013b). Japan on buying spree as Chinese REE exports soar. Available from http://rareearthinvestingnews.com/10306-japan-on-buying-spree-as-chinese-reeexports-soar.html. Accessed: 06-03-2014.

Topf, A. (2013c). Prices, quotas and smugglers: Making sense of rare earths in China. Available from http://rareearthinvestingnews.com/15702-prices-quotas-andsmugglers-making-sense-of-rare-earths-in-china.html. Accessed: 22-11-2013.

Toyota (2010). Lithium-ion battery. Available from http://www.toyota.com/esq/vehicles/ batteries/lithium-ion-battery.html. Accessed: 11-02-2014.

Toyota Motor Corporation (2013). Toyota honored for reducing, reusing, and recycling. Available from http://www2.toyota.co.jp/en/news/13/10/1029.html. Accessed: 04-03-2014.

Trigg, T. and Telleen, P. (2013). Global EV outlook: Understanding the electric vehicle landscape to 2020. Technical report, International Energy Agency. Available from http://www.iea.org/ publications/globalevoutlook_2013.pdf.

Tse, P.-K. (2011). China's rare-earth industry. Open-File Report 2011-1042, U.S. Department of Interior - U.S. Geological Survey. Available from http://pubs.usgs.gov/of/2011/1042/of20111042.pdf.

Umicore (2014). Umicore battery recycling. Available from http://www.batteryrecycling. umicore.com/UBR/. Accessed: 04-03-2014.

UN Statistics Division (2013). UN Comtrade Database. Available from http://comtrade.un.org/ db/. Accessed: 18-11-2013.

UNFCCC (2015). What is COP21? Available from http://www.cop21.gouv.fr/en/learn/whatis-cop21/. Accessed: 03-12-2015.

United States Public Laws (1939). Strategic and Critical Materials Stock Piling Act. Chapter 190, enacted june 7, 1939. Text from https://legcounsel.house.gov/Comps/Strategic\%20And\% 20Critical\%20Materials\%20Stock\%20Piling\%20Act.pdf. Accessed: 30-06-2015.

University of Delaware (2010). University of Delaware: High energy permanent magnets for hybrid vehicles and alternative energy. Available from http://energydeals.wordpress.com/ 2010/08/24/university-of-delaware-high-energy-permanent-magnets-for-hybrid-vehiclesand-alternative-energy/. Accessed: 25-02-2014. 
University of Minnesota (2012). Iron nitride permanent magnet, alternative to rare earth and neodymium magnets. Available from http://license.umn.edu/technologies/20120016_ironnitride-permanent-magnet-alternative-to-rare-earth-and-neodymium-magnets. Accessed: 2502-2014.

U.S. Department of Defense (2013). Strategic and critical materials 2013 report on stockpile requirements. Technical report, U.S. Department of Defense - Office of the Under Secretary of Defense for Acquisition, Technology and Logistics. Available from http://mineralsmakelife.org/assets/images/content/resources/Strategic_and_ Critical_Materials_2013_Report_on_Stockpile_Requirements.pdf.

U.S. Department of Energy (2011). Trilateral EU-Japan-U.S. Conference on Critical Materials for a Clean Energy Future. Available from http://energy.gov/sites/prod/files/2013/05/f0/ TRILATERAL_CRITICAL_MATERIALS_WORKSHOP_SummaryReportfinal\%2020111129. pdf. Accessed: 12-11-2013.

U.S. Department of Energy (2014). Fueleconomy.gov. Available from http://www.fueleconomy. gov/. Accessed: 11-02-2014.

U.S. Geological Survey (2013). Minerals Yearbooks - Rare earths: 1962-2011. Available from http: //minerals.usgs.gov/minerals/pubs/commodity/rare_earths/\#pubs. Accessed: 23-11-2013.

U.S. Geological Survey (2014). Mineral Commodity Summaries - Rare earths: 1988-2014. Available from http://minerals.usgs.gov/minerals/pubs/commodity/rare_earths/\#pubs. Accessed: 23-11-2013.

Van den Bossche, P., Vergels, F., Van Mierlo, J., Matheys, J., and Van Autenboer, W. (2006). SUBAT: An assessment of sustainable battery technology. Journal of Power Sources, 162(2):913-919.

Vestas (2013). Rare earth elements from a life cycle assessments perspective. Available from http://www.vestas.com/en/about/sustainability\#!material-use. Accessed: 18-01-2014.

Vignaud, A. and Fennel, H. (2012). Efficient electric powertrain with externally excited synchronous machine without rare earths magnets using the example of the Renault system solution. Presented during Vienna Motor Symposium 2012, Austria. Available from http://myrenaultzoe.com/Docs/2012_wien_vortrag_uv.pdf.

Walters, A. and Lusty, P. (2011). Rare earth elements. Technical report, British Geological Survey. Available from http://www.bgs.ac.uk/downloads/start.cfm?id=1638.

Want China Times (2010). Rare earth smuggling from China exceeds official exports. Available from http://www.wantchinatimes.com/news-subclass-cnt.aspx?id= 20120810000079\&cid=1102. Accessed: 26-11-2013.

Watanabe, C. and Suzuki, I. (2012). Japan signs deal with India on rare earth production, supply. Available from http://www.bloomberg.com/news/2012-11-16/japan-signs-deal-withindia-on-rare-earth-production-supply.html. Accessed: 28-03-2014.

Wedepohl, H. K. (1995). The composition of the continental crust. Geochimica et Cosmochimica Acta, 59(7):1217-1232. 
Wee, H. (2014). Why China wants North Korea's rare earth minerals. Available from http: //www.cnbc.com/id/101418459. Accessed: 21-05-2014.

Weeks, M. E. (1956). Discovery of the Elements. Journal of Chemical Education, 6th edition.

Wenning, S. (2012). Innovation spotlight: Manganese based permanent magnet. Available from http://www.ct-si.org/news/item.html?id=142v. Accessed: 25-02-2014.

Wind Power Monthly (2013). Available from http://www.windpowermonthly.com/. Accessed: 20-01-2014.

Wind Power Offshore (2013). Available from http://www.windpoweroffshore.com/. Accessed: 20-01-2014.

Wittrup, S. (2011). Permanente magneter volder vestas problemer i produktionen. Available from http://ing.dk/artikel/permanente-magneter-volder-vestas-problemer-iproduktionen-123609. Accessed: 18-01-2014.

Wojdyla, B. (2011). The straight story on the Chevy Volt battery fire. Available from http://www.popularmechanics.com/cars/alternative-fuel/hybrids/the-straight-story-on-thechevy-volt-battery-fire-6601217. Accessed: 02-02-2014.

Wong, G. (2010). China halts ministerial-level contacts with Japan. Available from http://www. chinapost.com.tw/china/national-news/2010/09/20/273193/China-halts.htm. Accessed: 1611-2013.

World Nuclear Association (2014). Electricity and cars. Available from http://www.worldnuclear.org/info/Non-Power-Nuclear-Applications/Transport/Electricity-and-Cars/. Accessed: 21-05-2014.

WTO (2012). Dispute settlement: Dispute DS432: China - Measures related to the exportation of rare earths, tungsten and molybdenum. Available from http://www.wto.org/english/tratop_e/ dispu_e/cases_e/ds432_e.htm. Accessed: 25-11-2013.

Xinhua (2012). China mulls rare earth purchase-reserve mechanism. Available from http://www. china.org.cn/business/2012-06/01/content_25537152.htm. Accessed: 06-03-2014.

Yuan, G. (2011). China to raise resource tax on rare earth exports. Available from http: //usa.chinadaily.com.cn/china/2011-03/25/content_12230990.htm. Accessed: 22-03-2014.

Zackrisson, M., Avellan, L., and Orlenius, J. (2010). Life cycle assessment of lithium-ion batteries for plug-in hybrid electric vehicles - Critical issues. Journal of Cleaner Production, 18(15):1517-1529.

Zepf, V. (2013). Rare Earth Elements: A New Approach to the Nexus of Supply, Demand and Use: Exemplified Along the Use of Neodymium in Permanent Magnets. Springer Science \& Business Media.

Zhang, Z., Matveev, A., Ovrebo, S., Nilssen, R., and Nysveen, A. (2011). State of the art in generator technology for offshore wind energy conversion systems. Available from http: //www.elkraft.ntnu.no/eno/Papers2011/IEMDC-Ziaoqiang.pdf. Accessed: 20-01-2014.

Zhanheng, C. (2010). Outline on the development and policies of China rare earth industry. Available from http://www.cs-re.org.cn/en/modules.php?name=news\&file=article\&sid=35. Accessed: 26-11-2013. 


\section{Appendix B}

Table B.1: Data on Chinese rare earth production and exports, and respective quotas, in tonnes, 2003-2013.

\begin{tabular}{lllll}
\hline Year & Production & Production Quota & Exports & Exports Quota \\
\hline 2003 & $92^{\prime} 000$ & NA & $73^{\prime} 522$ & $47^{\prime} 059$ \\
2004 & $98^{\prime} 000$ & NA & $69^{\prime} 713$ & $52^{\prime} 941$ \\
2005 & $119^{\prime} 000$ & NA & $65^{\prime} 207$ & $65^{\prime} 580$ \\
2006 & $133^{\prime} 000$ & $86^{\prime} 620$ & $66^{\prime} 410$ & $61^{\prime} 070$ \\
2007 & $120^{\prime} 000$ & $87^{\prime} 020$ & $54^{\prime} 353$ & $59^{\prime} 643$ \\
2008 & $1255^{\prime} 000$ & $87^{\prime} 620$ & $54^{\prime} 986$ & $49^{\prime} 990$ \\
2009 & $129^{\prime} 000$ & $82^{\prime} 320$ & $43^{\prime} 918$ & $48^{\prime} 155$ \\
2010 & $120^{\prime} 000$ & $89^{\prime} 200$ & $39^{\prime}, 13$ & $30^{\prime} 258$ \\
2011 & $105^{\prime} 000$ & $93^{\prime} 800$ & $1^{\prime} 861$ & $30^{\prime} 184$ \\
2012 & $100^{\prime} 000$ & $93^{\prime} 800$ & $16^{\prime} 265$ & $30^{\prime} 996$ \\
2013 & $100^{\prime} 000$ & $93^{\prime} 800$ & $22^{\prime} 493$ & $30^{\prime} 999$
\end{tabular}

Notes: Production quotas for 2003-2005 are unknown. For 2012 there was no production quota announced, therefore assumed unchanged. Data according to MLR (aligned with MIIT from 2010 onwards) reported annually, set for HREE and LREE separately. Exports are estimates and do not contain illegally mined quantities. Export quota figures before 2005 recalculated into REO, since officially published in gross weight. They are summed across semi-annual allocations to both Chinese companies and foreign joint ventures. Since 2012 MOFCOM reports allocations for HREE and LREE separately. Source: Based on data collected from MOFCOM (2014b); Tse (2011); UN Statistics Division (2013); U.S. Geological Survey (2013, 2014). 
Table B.2: Advanced rare earth projects outside China, by company.

\begin{tabular}{|c|c|c|}
\hline Company Name & Project Name & Country \\
\hline Alkane Resources & Dubbo Zirconia Project & Australia \\
\hline Arafura Resources & Nolans & Australia \\
\hline Avalon Rare Metals & Nechalacho Upper & Canada \\
\hline Avalon Rare Metals & Nechalacho Basal & Canada \\
\hline Commerce Resources & Ashram Main & Canada \\
\hline Commerce Resources & Ashram MHREO & Canada \\
\hline Frontier Rare Earths & Zandkopsdrift & South Africa \\
\hline Great Western Minerals Group & Hoidas Lake & Canada \\
\hline Great Western Minerals Group & Steenkampskraal & South Africa \\
\hline Greenland Minerals and Energy & Kvanefjeld & Greenland \\
\hline Greenland Minerals and Energy & Sørensen & Greenland \\
\hline Greenland Minerals and Energy & Zone 3 & Greenland \\
\hline Hudson Resources & Sarfartoq & Greenland \\
\hline Lynas Corporation & Mount Weld CLD & Australia \\
\hline Lynas Corporation & Mount Weld Duncan & Australia \\
\hline Lynas Corporation & Kangankunde & Malawi \\
\hline Matamec Explorations & Kipawa & Canada \\
\hline Molycorp & Mountain Pass & USA \\
\hline Navigator Resources & Cummins Range & Australia \\
\hline Pele Mountain Resources & Eco Ridge & Canada \\
\hline Quest Rare Minerals & Strange Lake Granite & Canada \\
\hline Quest Rare Minerals & Strange Lake Enriched & Canada \\
\hline Rare Element Resources & Bear Lodge & USA \\
\hline Stans Energy & Kutessay II & Kyrgyzstan \\
\hline Tasman Metals & Norra Kärr & Sweden \\
\hline Tasman Metals & Olserum & Sweden \\
\hline Ucore Rare Metals & Bokan & USA \\
\hline
\end{tabular}

Source: Adapted from Hatch (2011a, 2014). 



\section{National strategies for securing a stable supply of rare earths in different world regions*}

\section{Abstract}

The rising imbalance between increased demand for minerals and their tighter supply has resulted in growing concerns about their criticality. This has in turn stimulated both resource-rich and resource-poor countries to take active role in implementing mineral strategies. This chapter explains why different world regions responded differently to the global problem of securing stable supply of critical minerals, in particular of rare earths. It first provides an in-depth overview of development trajectories of rare earth strategies through a historical case study analysis of major stakeholder regions - China, the United States, Europe, Japan and Australia. Next, within a comparative political economy framework it examines the extent to which distinct national policy styles, national interests, resource endowment and historical experience in tackling supply risk shaped the different policy choices. The overall findings show distinctive differences in policy strategies. Whereas Europe opts for a policy dialogue with resource-rich countries, Japan and the United States have a more hands-on approach in research and development initiatives. Australia's and China's policies instead, focus on development of domestic mining activities and on resource protection.

Keywords: mineral criticality, rare earths, critical mineral strategies, comparative political economy

JEL classification: L72, L78, O57, Q34, Q38

* This chapter is based on Barteková, E. and R. Kemp, 2016. Critical Raw Material Strategies in Different World Regions, UNU-MERIT Working Paper 2016-005, United Nations University - MERIT. This chapter is forthcoming in Resources Policy, 49 (Sept 2016), 153-164. doi:10.1016/j.resourpol.2016.05.003. The work has been supported by green.eu and SINCERE projects. We are grateful to Raimund Bleischwitz and the participants of the research tutorial on Macro and Micro Perspectives on Sustainable Development for the helpful comments. 


\subsection{Introduction}

Global population growth, economic growth by developing countries, technological change and government policies have been the main driving forces reshaping the global demand for non-energy minerals in recent years. These trends led to ever increasing consumption, both in terms of total quantity and of variety of minerals used. Particularly affected are technology metals which are used as input materials for mass production of various technologies due to their specific chemical and physical properties (Technology Metals Research, 2010). Yet, these very same properties make technology metals difficult to substitute in their functional uses. What is more, most of them tend to have relatively small and concentrated markets and are often mined and refined in developing regions, exposing importing countries to political and economic risks. In fact, lack of political stability and increased resource protection by producing countries might have adverse effects for the entire supply chain. Additionally, many of these metals are by-products of major minerals, what further exacerbates their supply. Taken together, the imbalance between increased demand and tighter supply has resulted in growing concerns about criticality of these metals and about the impact of their supply shortages on industrialisation and green growth.

A group of metals called rare earths spurred a heated debate over potential implications of such imbalances on countries' competitiveness in general and on deployment of modern technologies in particular. Their special properties of ferromagnetism, superconductivity and luminescence make them key technology components in many electronic applications, such as cell-phones, hard disk drives and computer screens, as well as in various low-carbon technologies, mainly in electric motors and batteries of electric vehicles and in some wind turbine generators (Lynas Corporation, 2010; Tasman Metals, 2010). Their total demand is relatively small compared to other industrial metals, yet it has been rapidly expanding with the increased deployment of these technologies. In particular, demand for dysprosium and neodymium, the two most critical rare earth elements in terms of their functional uses, has been projected to increase by more than $2600 \%$ and $700 \%$ respectively, over the coming 25 years (Alonso et al., 2012). Further tensions on the rare earth market are caused by China's dominance over mining and production with $89 \%$ of global market share (U.S. Geological Survey, 2014), as well as by its industrial policies aimed at satisfying own needs for manufacturing higher value added products. Restrictions such as production and export quotas, as well as banning of foreign companies from engaging within the supply chain, led to tighter global supply and increased prices of rare earths. Price hikes like those 
in 2011, when rare earth crisis burst, brought about significant uncertainty about availability and reliability of supply. These concerns have in turn stimulated the United States, Japan and Europe, which are the main consumer countries and almost entirely import dependent from China, to take an active role in implementing mineral strategies with view of minimising their vulnerability to supply of rare earths (European Commission, 2013).

Despite their similar objectives, the strategies undertaken differ across regions. While Europe's efforts target policy dialogue with resource-rich countries, Japan and the United States have a more hands-on approach in research and development (R\&D) initiatives in substitution, minimisation and improvement of performance of critical material-free functionalities. Australia's and China's policies instead, focus on development of domestic mining activities and on resource protection. In this light, the aim of the present chapter is to map out how the issue of mineral criticality has been taken up within various countries overtime and to explain why countries adopted different approaches in securing stable supply of critical minerals, in particular of rare earths. For this purpose, the chapter carries out a historical case study type of qualitative analysis across the major stakeholder regions - China, the United States, Europe, Japan and Australia - offering a historical perspective on how the trajectories of critical mineral strategies developed over time. In the next step, the chapter applies a comparative political economy framework to examine the extent to which distinct national policy styles, national interests, resource endowment and historical experience in tackling supply risk shaped the different policy responses by countries.

The rest of the chapter is structured as follows: Section 4.2 defines the concept of mineral criticality and discusses its interpretation across various countries. Section 4.3 discusses the theoretical framework and method of analysis. Section 4.4 provides a historical perspective of mineral strategies implemented in different world regions, while Section 4.5 offers a comparative political economy interpretation of the differences in these strategies. Section 4.6 concludes.

\subsection{Critical minerals}

The origins of the literature on supply risk date back to the late 1930s and gained salience in the 1970s when oil and cobalt crisis burst. In recent years, the debate has been revived and extended to non-energy minerals. The contemporary literature aims at developing methods to evaluate criticality of minerals on the one hand, and at examining the extent to which potential bottlenecks affect national economies, specific industries or technologies on the other. In particular, the 
aim is to provide industries and manufacturers with informed decisions in order to anticipate and mitigate the adverse effects the criticality of input materials to their production processes might cause, and to provide directions for policy and industry makers in formulating mineral strategies.

Theoretical studies on supply risk can be classified into three broad categories based on the methodology they use to assess criticality: criticality matrices, criticality indices, and scenario or time series analysis (Erdmann and Graedel, 2011). The most relevant for evaluating mineral criticality in a broader context are criticality matrices. The first to develop a comprehensive conceptual framework was the US National Research Council (2008b). Within their criticality matrix, minerals are evaluated based on their importance in use and on their supply risk, i.e. availability and reliability of mineral supply. The degree of importance is evaluated from the perspective of minerals' chemical and physical properties and their substitutability within technologies. Mineral supply risk is influenced by geologic, technical, environmental and social, as well as political and economic factors in the long term. In the short to medium term instead, supply risk translates into physical unavailability or higher prices, and is caused by increased demand and limitations to expand production in the short period of time. Within this framework, a critical mineral is one which is subject to supply risk and has high importance in use with little or no substitutes available. Authors also note that criticality is a dynamic concept and can change overtime with technology innovation, popularity of using particular technologies, as well as rise of regulatory and environmental issues. This framework was later extended by Graedel et al. (2012) who added environmental implications as a third dimension to it. They thus evaluate criticality of metals within a criticality space rather than within a matrix. They also add a temporal perspective to supply risk - short versus long term - and propose to evaluate vulnerability to supply restriction on three organisational levels: global, national and corporate. Achzet and Helbig (2013) review the most important empirical studies and find out that, while risks can indeed be summarised in three broad categories of supply risk, vulnerability and ecological risk, there is a lack of consensus on appropriate indicators. They conclude that the most often used indicators are quantitative, such as country risk, country concentration, depletion time, by-product dependency, company concentration and demand growth. Contrary to this, qualitative indicators such as substitutability, risk of strategic use and climate change vulnerability are applied by very few studies only. Similarly, studies tend to understate the role of social, ecological and political (other than country risk) determinants of supply risk. In this light, Erdmann and Graedel (2011) state out that classification of materials as critical relates to the level of 
attention society pays to certain materials in terms of technological change and political vision.

In terms of the empirical literature, several countries have assessed the criticality of minerals for their respective economies. The list of critical materials varies from country to country, due to different scopes and approaches adopted. For example the report by the US National Research Council (2008b) considers a mineral to be critical "if it performs an essential function for which few or no satisfactory substitutes exist" and "if an assessment also indicates a high probability that its supply may become restricted, leading either to physical unavailability or to significantly higher prices for that mineral in key applications". At the same time, the report by the European Commission (2010b) follows a relative concept of criticality, whereby a mineral is labelled critical "when the risks of supply shortage and their impact on the economy are higher than for most of the other raw materials". While both studies use criticality matrices for a short term assessment, the first sets out more of a qualitative assessment of supply risk while the second uses mostly quantitative indicators. Despite the conceptual differences, both studies agree on the criticality of rare earths, due to their high import dependence, distorted supply, low recycling rates and lack of substitutability. The updated version of the European study examines separately two sub-groups of rare earths (heavy and light) as well as scandium (European Commission, 2014). While the level of economic importance is very similar for the two, the supply risk is substantially higher for heavy rare earths due to their higher demand growth projections and to the entire global supply originating from China (dysprosium is part of this sub-group). Likewise, Japan has labelled rare earths as critical since these are essential for maintaining and increasing country's industrial competitiveness and their potential supply disruption would negatively impact Japan's economy. Japan defines "rare metals" as those which are either scarce or economically or technologically difficult to extract in pure form and for which a substantial industrial demand exists both now and in future due to technological innovation (Advisory Committee on Energy and Natural Resources, 2009). In this sense, Japan adopts a more forward looking perspective to mineral criticality than the United States and Europe. As opposed to the import dependent countries, Australia is the major exporter of minerals globally, yet it is a relatively a small consumer of both major and minor minerals. Due to this, its downstream sectors are not exposed to the issue of mineral criticality. Consequently, Australia considers mineral criticality as its own "resource potential" to tap into the global demand for these minerals, among others for rare earths (Skirrow et al., 2013). Last but not least China, which is the leading global producer but at the same time it also consumes most 
of its domestic production, is very protective about its minerals. In fact, China has declared rare earths as "protected and strategic materials", what allows it to take advantage of its domestic resources for own industrial upgrading (Information Office of the State Council, 2012).

One of the commonalities across the above cited studies is that they all define mineral criticality in terms of supply risk and their importance for the economy. The other one concerns the fact that critical minerals seem to be more relevant from an economic and a geopolitical perspective than from a physical constraint perspective. In fact, reserves for several critical minerals are abundant and their size can be further increased by mineral exploration and technology development. In the particular case of dysprosium and neodymium, limitations to increasing their production outside China exist in the short term and are further exacerbated by potential shortages due to their rapid demand growth. Nonetheless, the major concern relates to political factors, such as the concentration of supply and the political risk associated with supplier countries' resource nationalism. The latter becomes even more pressing considering the high import dependence by consumer countries which strive to establish an undistorted access to these minerals. This rising relevance of economic and political dimensions of criticality has translated into a policy trend, whereby critical minerals are considered a strategic matter. In line with this, developments on the mineral market are influenced by active government intervention in both resource-rich and resource-poor countries. Governments' mineral strategies however do not occur in a vacuum. They are shaped by national interests, resource endowment and countries' historical experience in tackling supply risk, as well as by national institutional context. Therefore, in order to understand the development of policy choices over time, one needs to analyse the entire system in which these mineral strategies developed.

\subsection{Theoretical framework and methods}

The present chapter attempts to explain why different world regions responded differently to the global problem of securing stable supply of critical minerals, in particular of rare earths. In fact, despite their similar objectives, strategies undertaken by various world regions tend to differ in their foci. This chapter argues that policy responses are a result of path dependent processes embedded in countries' national interests, resource endowment and their historical experience in tackling supply risk. Viewing political development as path dependent, i.e. a process that unfolds over time, allows explaining how earlier processes embedded in an environment with change-resistant institutions and collective action problems 
influence current social outcomes (Pierson, 2000). The development trajectories of current mineral strategies are thus shaped by individual countries' historical courses of action, in terms of their strategic perception of rare earths, their efforts to develop rare earth supply chains, as well as their strategies to handle earlier events of mineral supply risk. Additionally, institutional variables matter greatly for understanding the cross-national differences in policy making. They include the legal system, the openness of the administrative system and political system, the role of consultation and interest mediation. The institutional factors are captured through the notion of "policy style", which holds that countries have developed distinctive ways for achieving similar goals and standards through legal traditions, political structures, industrial organisation and cultural attitudes (Kagan, 2000).

The nature of policy styles has been studied by a large body of empirical literature which developed in the second half of the 20th century. The most prominent of these is the comparative political analysis by Richardson et al. (1982) who coined the concept of policy style. They define policy making and implementation style as "the interaction between a) the government's approach to problem-solving and b) the relationship between government and other actors in the policy process". In an attempt to identify the main characteristics of the ways in which societies formulate and implement policies, they devise a matrix of national policy styles based on the government's approach to problem solving, which can be taking either anticipatory (active) or reactive stance, and on the government's relationship to other actors, which can be characterised either as consensus or as imposition. This allows the authors to classify Western European countries across four policy styles. Furthermore, Feick (1992) examines to what extent nations matter with respect to public policy choices, by integrating the findings of comparative studies of social, economic, environmental and occupational health and safety policies of Great Britain, Sweden and United States. In particular, he considers how countryspecific variables, such as institutional and organisational structure, cultural orientation and policy style influence policy profiles. According to his definition, policy style "should capture the characteristics of policymaking and implementation process involving the interaction of actors constrained by institutional prerequisites as well as cognitive and normative orientations, procedural preferences and substantive interests". He summarizes the main characteristics of policy style from the literature as pertaining to: 1) conflict resolution (competition/conflict, cooperation/consensus, formality, drama); 2) problem solving (scope, direction, speed, time frame); 3) participation and interaction (openness, participation, atmosphere). Finally, Van Waarden (1995) defines policy style as "the routine choice behaviour or 'standard operating procedures' which policymakers tend to develop in 
the policy process" and affirms that policy styles are strongly rooted in legal, political and administrative institutions and cultures specific to every nation. Given this embeddedness, policy styles tend to be resistant to changes due to economic and political internationalisation. After ascertaining the most salient characteristics of policy styles of Great Britain, France, Germany, the Netherlands and the United States, he distinguishes between six types of policy styles, some of which overlap with the characteristics discussed by Richardson et al. (1982) and by Feick (1992): 1) liberal-pluralist versus tatist versus corporatist; 2) active versus reactive; 3) comprehensive versus fragmented or incremental; 4) adversarial versus consensual versus paternalistic; 5) legalistic versus pragmatic styles; 6) formal versus informal network relations.

Earlier institutional work has acknowledged the role of policy styles in environmental regulation. The most prominent is the book by Vogel (1986) on environmental regulatory styles in the United States and the United Kingdom in the 1970s and 1980s, about which he concludes that despite the similarities in their legal systems, there are important differences in policy styles across the two. In particular, the American approach is rigid and rule oriented, making use of environmental standards, allowing no self-regulation by industry and prosecuting companies. Contrary to this, the British approach is flexible and informal, with almost no emission standards in place, with an important role for industry self-regulation and few cases of prosecution. The author concludes that the effectiveness of the British environmental regulation through voluntary compliance has achieved similar results as the adversarial approach adopted by the US which produced greater resistance from business. On a similar note, Kagan (2000) discusses the contrasting styles of environmental regulation, regulation of employment and of financial institutions in the United States and Japan. His review reinforces the views that the American regulation is adversarial and legalistic, and describes the Japanese regulation as being more informal and less legalistic. In fact, in Japan the policies are formulated through informal interaction between government and industry associations and are implemented through informal administrative guidance and voluntary plans by companies. Also, regulatory officials believe that consultative and educational style results in better compliance and are thus less inclined for punitive action. Löfstedt et al. (2001) re-examine the environmental regulation in European and American contexts and acknowledge the changing nature of their policy styles over time. While the American style can still be largely characterised as adversarial and the European style as consensual, in Europe the environmental regulation has become stricter whereas in the United States it has turned less contentious but not comparatively stricter. The authors conclude that one of the main 
drivers for this fundamental change lies within trust. In fact, American regulators appear to be more trusted than ever, while public distrust toward regulators is on increase in the EU. Similarly, Hung Lo et al. (2000) derive China's policy style from an analysis of Shanghai's environmental impact assessment system in terms of policy ideology, policy content, regulatory process, public participation and policy consequences. The authors describe China's policy style as active, highly legalistic and adhering to procedural formalities, but at the same time shaped by informal political activity, especially from municipality leaders and bureaucratic agencies in charge of economic and urban development. Also, the policy style is discretionary and agency-dominated with complete lack of institutional channels to open consultation and public participation. Especially in terms of the latter, Chinese policy style in environmental regulation differs substantially from that of the industrialised countries examined in this chapter. Finally, O'Neill (2000) analyses regulatory styles of Britain, Germany, France, Australia and Japan in the context of hazardous waste trading as part of a broader system of environmental regulation. In terms of access to policy process and mode of policy implementation, the author finds strong similarities between Australia and Germany. Despite the differences in their federal structures, both are characterised by high levels of government control. Yet, Australia is also known for its open system of regulation, accommodating the involvement by electorate and environmental groups on the level of Commonwealth Government. Indeed, the latter have been seen to have fundamentally altered policy outcomes. The Commonwealth Government follows a neo-corporatist approach and has balanced government-industry-society relations.

In summary, critical mineral strategies can be understood as an outcome of temporal processes. We therefore propose to analyse their formulation within the framework of countries' institutional contexts, their national interests, resource endowment and respective historical experiences in tackling supply risk. In line with this, we conduct a qualitative analysis of historical developments in order to map out how the issue of mineral criticality, in particular that of rare earths, has been taken up overtime across a variety of countries. In particular, we identify the major processes, institutions and actors who played a role in the formulation of respective countries' mineral strategies. The interpretation of policy styles is informed by the empirical literature on environmental regulatory styles, since literature on regulatory styles to mineral policies is not available. The policy styles in this paper are used as a sense making device, rather than as the object of analysis. The object of analysis is the history of policy action around critical minerals in the major rare earth producing and consuming countries and regions: China, the 
United States, Europe, Japan and Australia.

The rare earth industrial supply chain development is evaluated within the generic supply chain framework across four main processes: 1) extraction of oxides from the earth's crust; 2) processing through separation and refining into metals, alloys and powders; 3) manufacturing of component parts such as magnets, motors and generators; and 4) assembling these into end use low-carbon technologies such as wind turbines and advanced technology vehicles (Bauer et al., 2010). The rare earth mineral strategies instead, are evaluated across seven elements which were identified as common across the countries analysed, and which largely correspond with categories considered by other studies (Bauer et al., 2010): 1) domestic diversification of supply (mining regulation, data and information gathering, exploration, permitting, workforce training, research and development $(\mathrm{R} \& \mathrm{D})$ ); 2) foreign diversification of supply (financing of projects abroad); 3) resource diplomacy (policy dialogue, i.e. oversight of free trade issues, development aid, international collaboration); 4) stockpiling (private and public); 5) recycling (established recycling processes, waste management policies, training programmes); 6) R\&D (substitution, minimisation, improvement of performance, industry-university-government linkages, training programmes); and 7) resource protection (export and production restrictions, consolidation of industry, investment restrictions). For this purpose, besides mineral policies, the analysis also covers industrial and innovation policies. Furthermore, in order to illustrate better the different policy directions taken by individual stakeholders in response to the common problem of security of rare earth supply, the results of the qualitative analysis are translated into scores. These have been assigned based on the respective elements of rare earth-to-low-carbon technology supply chains and national mineral strategies listed above. The scale of assigning the scores is explained in the Section 4.4.6, which also gathers the results within Table 4.1 and illustrates these graphically within Figure 4.1. The results are subsequently interpreted within the proposed comparative political economy framework in Section 4.5.

To our knowledge, to-date there exist only two studies which endeavour to discuss the country strategies for minerals (Hilpert and Mildner, 2013; International Raw Materials Observatory, 2016). Yet none of them explains the development of critical mineral strategies as an outcome of temporal processes within a framework of comparative political economy analysis. Therefore the main contribution of this chapter is within both political economy analysis of regulation and resource economics fields. 


\subsection{Strategies for mitigating rare earth criticality}

This section is not intended to provide a complete account of historical developments; rather it describes the major events which played a role in the formulation of countries' mineral strategies. For this purpose, a variety of countries affected in distinct ways by rare earth criticality has been selected. The analysis begins with resource-rich China which is currently the dominant producer but at the same time also the largest consumer of rare earths globally. Next, the United States and Australia, which represent the competitive fringe, are examined. Both countries possess economic deposits of rare earths, yet as opposed to the US, Australia's consumption is rather negligible. Finally, Japan and the European Union are both completely import dependent, however while the former uses them as intermediate goods, the latter sources rare earths mainly in form of finished products. Besides these countries, there exist other smaller players on the market, such as India and Russia which produce small quantities of rare earths, and numerous junior rare earth projects in various other countries which are currently under development. Yet it will take some years until these might actually start mining and production. On the demand side, South Korean manufacturing industry also relies on rare earth imports, yet the exposure to criticality seems much lower than in the case of Japan.

\subsubsection{China}

China was one of the first countries to have started developing its mineral resources in a systematic fashion since the 1950s. Strengthening of geological work, strategic prospecting for minerals, as well as early enactment of laws and regulations on mineral resources, such as the Mineral Resources Law which dates back to 1982, were at the heart of its early formulated mineral policy (Information Office of the State Council, 2003). Though the strategic principle of "the development of the mining industry" has ever since remained the basis of China's policy, as reflected within all of it's Five-Year plans, the scope has been significantly broadened: from targeting domestic public and private investment in the past, to nowadays aiming to attract foreign technology and capital for exploration and development of domestic mineral resources, as well as to Chinese companies gaining access to sources of minerals abroad (Information Office of the State Council, 2003). These developments have ultimately led to China becoming the major global player in mineral resource mining and processing. 
In terms of rare earths, China entered the market in the 1950s when Baotou Iron and Steel Company started mining the iron deposits at Bayan Obo in Inner Mongolia, of which rare earths are co-products. Yet, it was not until the early 1970s when $\mathrm{Xu}$ Guangxian, also known as the father of Chinese rare earth chemistry, developed the new extraction method of rare earths and kicked off their large scale extraction in China. Moreover, after the Cultural Revolution the idea that natural resources processing and export might fuel Chinese economic growth was put forward by President Deng Xiaoping. To underlie the strategic importance of rare earths in this context, in 1992 he stated out: "There is oil in the Middle East; there is rare earth in China..." (Baotou National Rare Earth Hi-Tech Industrial Development Zone, 2015). At that time, a special industrial zone was set up in Baotou to attract foreign direct investment in rare earth facilities, with the view of bridging the technology gap between China and the developed world (Mancheri et al., 2013). After a transitory period in the 1980s, China took the lead in the global rare earth production in the early 1990s, and was gradually increasing its monopoly position over the next two decades. With $98 \%$ of market share it reached the absolute monopoly in 2009 , which has been slightly eroding ever since (U.S. Geological Survey, 2015a). This success is often attributed to China's cheap labour force and lower regulatory costs, as well as to its favourable deposits of rare earths in terms of quantity, size and heavy rare earth content (Haxel et al., 2002). Undeniably, lower prices of Chinese rare earth oxide contributed to the rest of the world losing their market shares by early 2000s. Yet, prices alone were not the only engine behind the remarkable success of the Chinese rare earth industry development.

The Chinese rare earth innovation system dates back to the 1960s when the first research institutes were established. The Baotou Research Institute of Rare Earths, which was established in 1963 under the former Ministry of Metallurgy Industry and in 1992 merged into Baotou Iron \& Steel (Group) Company, is now the largest rare earth technological R\&D institution specialized on rare earths in China. It has more than ten subsidiaries and employs altogether more than 700 employees, half of them engineering technicians (BRIRE, 2015). Its research focuses on industrial uses of rare earths such as metallurgy, environmental protection, new materials and application in traditional industry. Similarly, the General Research Institute for Nonferrous Metals established in 1952, has been working on R\&D of non-ferrous metals and facilitating the development of the rare metals industry across China ever since. It was transformed from an R\&D institute into a research company in 2000 and its main research aims are to develop resource-saving, highly efficient, environmentally friendly and internationally competitive technologies and 
to provide materials' solutions for new strategic industry development (GRINM, 2015). In the meantime, Xu Guangxian became the major protagonist of the Chinese rare earth industry. He was chairing the National Natural Science Foundation of China, launched several rare earth research programs in the 1990s and also established other two laboratories carrying out research on rare earths (Hurst, 2010). The State Key Laboratory of Rare Earth Materials Chemistry and Applications is affiliated with the College of Chemistry and Molecular Engineering in Peking University, employs more than 60 faculty members, and deals with basic research on rare earth material chemistry, new rare earth materials and materials designs (RELAB, 2015). The CAS Key Laboratory of Rare Earth on Advanced Materials and Valuable Utilization of Resources is affiliated with ChangChun Institute of Applied Chemistry under the supervision of the Chinese Academy of Sciences, has 32 faculty members, and its main research directions include applied research on rare earth chemistry and physics, chemical biology of rare earths and their separation chemistry (CAS, 2015). Additionally, innovation and diffusion of knowledge take place through the Chinese Society of Rare Earths. This was established in 1979 as the first national society on rare earth science, technology and applications in the world. Its aim is to promote sustainable and sound development of the industry, gathering together more than 100'000 registered experts who engage in various aspects of rare earth $\mathrm{R} \& \mathrm{D}$. The organization also publishes the only two peer-reviewed journals on rare earths in the world: Journal of Rare Earths (both in English and Chinese) and Chinese Rare Earths (in Chinese only), as well as the newsletter Chinese Rare Earth Information. It also maintains a comprehensive database of rare earth research, and hosts meetings and conferences, such as the International Conference on Rare Earth Development and Application (Chinese Society of Rare Earths, 2015).

Ever since Guangxian's invention, China has been doing a lot of R\&D in rare earths to achieve global leadership in the industry. In 1986 the National High Technology Research and Development Program (Program 863) was endorsed by President Deng Xiaoping. The objective of the Program is to boost innovation capacity in the high-tech sectors, as well as to achieve breakthroughs and to leapfrog development in key technical fields in which China enjoys relative advantages or in which it should take strategic positions to fulfil its strategic objectives (MOST, 2015b). The overall investment in the Program during the period 1986-2010 was 96.7 billion RMB (or approximately 14 billion EUR according to 2015 exchange rates) (ERAWATCH, 2015b). Since rare earths are recognized as one of the strategic resources for China and are contained in most of the technology fields covered by the Program, a lot of R\&D initiatives were targeting these. Furthermore, 
the National Basic Research Program (Program 973), which targets China's basic research and promotes collaboration between research institutes, universities and industries, was established in 1997 (MOST, 2015a). The objectives of the Program are to strengthen original innovations and to address scientific issues concerning national, economic and social development so as to improve China's innovation capabilities. The program budget for the period 1998-2010 was 15.7 billion RMB (or approximately 2.3 billion EUR according to 2015 exchange rates) (ERAWATCH, 2015a). Moreover, the National Program for Long and Medium Term Scientific and Technological Development (2006-2020) lists rare earth-intensive technologies as key target of basic and frontier R\&D (Information Office of the State Council, 2012). To conclude with, not only the quantity but also the quality of Chinese research on rare earths has increased over time. For example, paper contributions by Chinese researchers in rare earth chemistry and their quality have been constantly on increase since the early 1990s, the pace of improvement having accelerated sharply after 2001. Increased research funding and the foundation of national rare earth research centres, as well as transfer of foreign R\&D bases to China, have made China to become the global centre of research for rare earth science and technology (Adachi et al., 2010).

In light of the recent changes in international manufacturing structure caused by the sluggish growth in most developed countries, a new ten year action plan Made in China 2025 - has been presented by Premier Li Keqiang, endorsing the blueprint for the next generation of manufacturing in China. Its aim is to: “...seek innovation-driven development, apply smart technologies, strengthen foundations, pursue green development and redouble [our] efforts to upgrade China from a manufacturer of quantity to one of quality." (Hui, 2015). Among the ten sectors covered are also new materials, high energy vehicles and high-end robotics, all of which involve the use of rare earths. Increasing the competitiveness of Chinese manufacturing also entails Chinese firms moving up the value chain in production and innovation. In the particular case of rare earths, this idea has been put forward already in 1999 by President Jiang Zemin who stated: "Improve the development and applications of rare earth, and change the resource advantage into economic superiority." (Baotou National Rare Earth Hi-Tech Industrial Development Zone, 2015). Further to this, China has been pursuing various strategies to achieve its long term goal of manufacturing higher value added forms of rare earths. With regard to innovation, various initiatives allowed China to shift gradually from export of rare earth compounds and metals, towards export of intermediaries such as magnets and phosphors, and high-tech products like mobile phones, computers, batteries and electric motors (Bromby, 2015a). Another strategy was the 
technology transfer through foreign direct investment. An example of a successful technology transfer was the acquisition of Magnequench in the mid- 1990s by two Chinese companies with close ties to the Chinese Government. Magnequench was a subsidiary of General Motors which commercialized the manufacturing of bonded permanent magnets and enjoyed a monopoly in supplying laser-guided smart bombs (Molycorp Inc, 2015b; Robison and Ratnam, 2010). Just a few years after this acquisition, its plant in Indiana was closed down and the operations along with the know-how were transferred to Tianjin in China, and later expanded to Singapore and Thailand. This move helped China to gain access to the neodymium-based permanent magnet technology, which previously was only available in the United States and Japan. Nowadays China manufactures around $80 \%$ of global annual output, yet it does not hold any patents on neodymium-ironboron magnets (Shen, 2015c). The rights on bonded and hot pressed magnets in the US are currently held by the newly refurbished Magnequench owned by Molycorp, while Hitachi in Japan holds patents on sintered magnets. At present, only nine companies in China are licensees of Hitachi. This leaves most of the Chinese manufacturers without the possibility of exporting their magnets globally. China has recently filed a complaint against Hitachi extending patent expirations for which the coverage ended in July 2014 (Hitachi Metals, 2013; Kosich, 2013). Should the legal dispute end in favour of the Chinese manufacturers, this would extend the Chinese monopoly from rare earth extraction and processing to include also manufacturing of finished products.

To protect its own industrial upgrading and to hold back rare earths for its domestic uses, China has declared rare earths as "protected and strategic materials" more than two decades ago (Information Office of the State Council, 2012). In line with this, China prescribed protected exploitation of rare earth minerals and issued the National Plan for Mineral Resources (2008-2015). Further to these, it introduced the following industrial policies: foreign companies are banned from engaging in any part of the supply chain other than forming joint ventures with domestic companies; both domestic and joint venture companies are subjected to production and export quotas; state control is increased by banning new rare earth mining licenses and by eliminating smuggling; it has been proposed to create a joint pricing platform and a national pricing system; to fight the overproduction and strengthen its pricing power, China supports benevolent production halts, continues phasing out some production capacities and accumulating large strategic stockpiles (MOFCOM, 2012a,f,b,c,d,e,g,h; MLR, 2013; Shen, 2014). Taken together, these protectionist policies demonstrate a clear alignment of China's rare earth strategy with its national interests of industrial upgrading and creating 
competitive advantage for its manufacturing. Yet, China's main lines of argumentation behind are environmental and social costs arising from excessive mining and polluting techniques employed to mining and processing of rare earths. In line with these, China has announced its aim to build a "well-off society", to implement the strategy of sustainable development and to increase resource protection and their efficient use during the first two decades of the new century (Information Office of the State Council, 2003, 2012). However in 2014, further to the dispute settlement filed by the US, the EU and Japan against the Chinese trade restrictions, the World Trade Organisation (WTO) ruled that China violated the international trade rules (WTO, 2014). In 2015, China abolished the export tariffs and quotas, but introduced new industrial policy in form of resource tax and export licensing in order to prevent over-consumption and to boost industrial upgrading (MOFCOM, 2014; Shen, 2015b). What is more, following the 12th Five-Year Plan, the Government continues consolidation and restructuring of the upstream side of the supply chain. By merging rare earth producers into six state-owned industrial groups, it intends to regulate production volumes in order to keep the environmental damage under control and to stabilise prices, to minimise potential competition from emerging global players and to achieve full integration of its rare earth industry (Lifton, 2015). This should further help to eliminate smuggling, which occurs under the protective umbrella of local governments and which China has been unsuccessfully combating during the past decade (Shen, 2015a,d).

Finally, China's strategy of manufacturing more high value added goods is expected to put pressure on its domestic resources in the near future. In fact, China plans sourcing more than $40 \%$ and $70 \%$ of manufacturing components domestically by 2020 and 2025, respectively. It thus proves essential that China assures reliable access to minerals, especially to heavy rare earths (Berry, 2015). China's concern about potential future resource bottlenecks has been addressed within its "go global policy", one of the objectives of which is acquisition of strategic resources abroad (Humphries, 2015). In particular, the outbound direct investment in the mining sector is expected to achieve 390 billion USD over the next five years (344.7 billion EUR according to 2015 exchange rates). China also strives to diversify its rare earth supply sources internationally. In 2005, China National Offshore Oil Corp made a bid for the American oil group UNOCAL, however the deal failed due to political opposition by the US Government. Though UNOCAL was primarily an oil and gas producer, it also owned the Mountain Pass mine - America's largest deposit of rare earths and currently one of the only two non-Chinese rare earth projects in operation (Chovanec, 2010). Some years later, Chinese companies successfully acquired a stake in the Australian Arafura, and 
also attempted to purchase a controlling stake in Lynas (The Sydney Morning Herald, 2009). There are also signs of China's interest in North Korean rare earths (Schearf, 2014). Furthermore, the Chinese Sheng Kang Ning Mining Investment, a subsidiary of one of the six major Chinese rare earth producing companies, formed a joint venture with Canadian Pele Mountain Resources which owns the only mine that has previously produced rare earth oxides in Canada (InvestorIntel, 2015). Besides taking equity positions in foreign companies, China also offers grants and loans to countries in exchange for access to their raw materials. Administered by the Department of Aid to Foreign Countries, almost half of China's economic development aid has been disbursed to resource-rich Africa (Hanauer and Morris, 2014). Regarding domestic measures for increasing availability of raw materials, China implemented the concept of circular economy as the new economic model of development. The latter is based on the " $3 R$ " principles, i.e. reduction, reuse and recycling activities conducted in the process of production, circulation and consumption (Standing Committee of the National People's Congress, 2008). While no official information is available on the extent to which the concept of circular economy is implemented in the context of rare earths, the Central Government has been setting targets for more efficient resource use and waste management across various industries, part of which are also non-ferrous metals (State Council, 2013).

\subsubsection{The United States}

The debate on the security of mineral supply has a long tradition in the United States and is strongly related to military and security interests in the US policy making. The term critical material was first introduced in the late 1930s within the Strategic and Critical Materials Stock Piling Act (United States Public Laws, 1939). The National Defense Stockpile, considered as the cornerstone of the US mineral policy, was established some years later (National Research Council, 2008a). This is today administered by the Defense Logistics Agency (DLA) - Strategic Materials and is intended to support military and essential civilian needs at times of national emergency. Economic stockpiles instead, are intended to smooth temporary interruptions of mineral flows, and were first proposed by the National Commission on Supplies and Shortages, which was itself established two years prior by President Ford in 1976 (National Commission of Supplies and Shortages, 1976). In the early 1950s the President's Materials Policy Commission (Paley Commission) was appointed by President Truman, in order to address the concerns of continued adequacy of post-Second World War raw material supplies in the United States (Mason, 1952). Within their report, the Commission made recommendations on increasing supply of raw materials by encouraging exploitation 
on public lands by private enterprises, by improving technology for commercial extraction, recycling, production of substitutes and redesign of equipment, as well as by more responsible stockpile procurement and establishing multilateral contracts, among others. The criticality of imported non-energy materials was further examined within the National Security Study Memorandum by the Nixon Administration (Council on International Economic Policy, 1974). The study also evaluated the US policy options to safeguard against supply and price manipulation and shortages, such as developing self-sufficiency, diversifying foreign sources of supply, developing economic stockpile and consumer-producer cooperation. In the late 1970s, the two oil price shocks and the interruption of Zairian cobalt production caused by political insurrection, increased concerns about the US dependence on foreign minerals. Further to these, the report on strategic and non-energy minerals by the US Congressional Budget Office (1983) analysed the country's vulnerability to supply disruptions of eight major minerals. It concluded that the most important options for the short term were stockpiling and subsidising domestic production. Diversification of sources of supply, encouraging exploitation and production on public lands, intensification of R\&D in the field of metals and materials, and using foreign policy initiatives were directed more towards long term mineral security, instead.

National materials and mineral policies and goals to assure materials availability for national economic well-being, national defence and industrial production have been formulated within the National Materials and Minerals Policy, Research and Development Act of 1980 (United States Public Laws, 1980). These included: basic R\&D for extraction, processing and recycling of materials and improved understanding of their performance and substitution in engineering designs; improved collection and dissemination of scientific material and data; establishing early warning system for supply issues; measures to promote industrial innovation in materials and material technologies; encouraging cooperative materials research across private corporations and federal and state institutions; assessing opportunities to promote multilateral agreements for materials development in foreign nations. The importance of materials research has been further acknowledged by the National Critical Materials Act (United States Public Laws, 1984) which provided for the establishment the National Critical Materials Council. This was responsible for formulating and coordinating national materials policies and priorities of research activities of the entire government, as well as for monitoring needs for critical materials and advising the President on global trends and their implications for national economy and security. Due to its ample responsibilities, the Council was mandated to cooperate with various federal departments and agencies 
which have had instituted materials research programs within their agendas, such as the National Security Council, the Council of Environmental Quality, the Office of Management and Budget and the Committee on Materials within the Office of Science and Technology Policy.

Regarding rare earths in particular, the well-established regulatory environment has contributed to the rare earth industry boom. The United States has been dominating the rare earth market in the second half of the 20th century until the 1980s. Production was located in Mountain Pass California's Mojave Desert. Originally the area was prospected for uranium and later mined for europium oxide which was used for colour TV screens. Over time, other light rare earths and at a later stage also some of the heavy rare earths were mined here, what ultimately led to large scale production between 1965 and 1995. During this period, Molycorp not only supplied rare earths for the US Government's stockpiles, it was also the major supplier of rare earths globally. In 1998, after a series of water leakages containing heavy metals and radioactive material, Molycorp temporarily suspended operations and continued only with extracting ores from stockpiles (Molycorp Inc, 2015c; Nystrom, 2003). Yet in 2002, the company's environmental problems and low prices of rare earths from China forced Molycorp completely out of the market. However, only a few years later Molycorp received a 30 year mining plan permit and in 2007 extraction of neodymium and praseodymium resumed. In 2010 the company managed to secure environmental permits to begin construction of the Phoenix project and restarted active mining on site. At present, Molycorp is producing only a small part of the global demand, especially of light rare earths. In 2012 it completed the acquisition of Neo Material Technologies what allowed it to start producing and developing neodymium-iron-boron magnetic powders used in the production of permanent magnets. To further strengthen its position as a mine-to-magnetics vertically integrated player with global supply chain, Molycorp formed joint ventures with Daido Steel and Mitsubishi Corporation to manufacture sintered neodymium-iron-boron permanent magnets in Japan (Molycorp Inc, 2014). Furthermore, Molycorp in collaboration with Siemens and Shin-Etsu, works on minimising the amount of dysprosium within magnets used for direct drive turbine generators (Molycorp Inc, 2015a). In spite of all these initiatives and of the favourable regulatory environment, Molycorp and its North American subsidiaries were forced to file for bankruptcy protection in 2015, due to increasing capital needs, delays in the Phoenix Project, as well as low rare earth prices caused by the removal of Chinese export tariffs and by the large illegal mining and trade in rare earths (Shah, 2015). While its European and Asian separation facilities continue to operate, the suspension of Mountain Pass might yet again disrupt the 
rare earth industry, at least until the end of the decade when the emerging junior projects are expected to start producing.

Besides producing rare earths, the United States also manufactures various higher value-added products containing rare earths. In terms of permanent magnets, the search for innovative composition of magnets started with the cobalt crunch in the late 1970s. The fact that samarium-cobalt magnets were expensive and supply of cobalt was volatile turned out as an issue for General Motors, which used these in the starter motors of their automobiles. Several research groups started to work on neodymium-iron-boron magnets in the United States, both at industry level and as collaboration between academic, industrial and state laboratories. In the end, two companies succeeded in fully developing and patenting the permanent magnet technology which was nearly cobalt free, contained neodymium and traces of dysprosium and had superior properties compared to any technology commercialized before: General Motors in the United States developed bonded magnets, while the Japanese Sumitomo Special Metals (now Hitachi Metals) developed sintered magnets in 1983 (Robinson, 1987). General Motors subsequently established a new division called Magnequench, which was manufacturing rare earth magnets during two decades. However, when Magnequench was acquired by a consortium of Chinese companies, its factories were closed down and production was outsourced to China (Robison and Ratnam, 2010). Some years later, what was left of Magnequench became part of Neo Material Technologies and was subsequently acquired by Molycorp.

The change in geopolitics in the late 1980s, such as the end of the Cold War and the stabilisation of the situation in supplier countries of South Africa, provoked a loss of strategic perception of non-energy minerals by the United States (Humprheys, 1995). This trend has however been reversed two decades later, when China tightened its rare earth export quotas, Molycorp shut down the production and Magnequench production lines relocated overseas. In fact, it was the disruption in the industry which led to revival of interest of both the Government and public in rare earths. Ultimately, concerns over losing domestic capacity to produce critical minerals and its implications for national security and industrial production led to the development of Critical Materials Strategy. The current Strategy was developed in 2010 by the US Department of Energy (US DOE) and is based on three pillars (Bauer et al., 2010). The first one deals with diversifying supply chains in order to mitigate supply risk by facilitating extraction, refining and manufacturing within the US and by encouraging additional sources of supply globally. The second pillar is targeting R\&D in material and technology substitutes, in order to meet material needs of the clean energy economy. The third 
pillar foresees research into recycling processes coupled with design of policies which would promote recycling, reuse and more efficient use of critical materials.

To start with diversification of supply, the importance of developing domestic rare earth supply has been highlighted in a statement by Senator Murkowski: "rather than sit on our hands while China corners the market on these strategic elements, we can and should pursue timely production of the rare earth supplies that exist within our own borders" (Ucore Rare Metals, 2013). In this respect, improving the permitting process for critical mineral mines, providing financial assistance for domestic production and processing, as well as education, information gathering and stockpiling are viewed as the most important policy directions. Some of these have also been reflected in the recent legislation proposals (Humphries, 2013). For example, the Critical Minerals Policy Act of 2013 aims at facilitating the reestablishment of domestic critical mineral industries by devising policies targeting environmentally responsible production, manufacturing and recycling of critical minerals (Murkowski, 2013). The Act would require establishing a list of critical minerals to the US economy, improve the permitting process, provide for worker training and associated grants to academic institutions related to critical minerals, and require the Secretary of Energy to conduct R\&D program for producing rare earth elements from non-traditional sources. Instead, the National Strategic and Critical Minerals Production Act of 2015 is directed towards the Secretary of the Interior and the Secretary of Agriculture and seeks to define critical and strategic minerals and to streamline the federal permitting process. The latter is to be achieved by establishing a lead agency responsible for issuing mine permits within minimal time limits, maximising domestic mineral resource development and mitigating environmental impacts (Amodei, 2015). The measures proposed within this legislation were supported by the United States Magnetic Materials Association, an organisation lobbying for securing a stable supply of rare earths, as well as by other industry representatives (USMMA, 2012). Additionally, the Association for Rare Earth, an opinion leader for rare earth industry, strongly urged the accession of the United States to the United Nations Convention on the Law of the Sea (RARE, 2012). This should help securing the US sovereign rights to the Exclusive Economic Zones (EEZ) and thus to new sources of rare earths from the seabed floor.

In terms of knowledge and capabilities, with the disruption of the rare earth industry, the US lost not only their primacy in rare earth production and magnet manufacturing, but also the know-how and the expertise in rare earth mining, processing, chemistry and manufacturing, which in turn slowed the R\&D and innovation activities in the field. The lack of trained workforce was highlighted 
by Gschneidner Jr (2010) who claims that today there is more than 15 times less people employed in every aspect of rare earth industry than was before the disruption. He therefore called for establishing training programs in conjunction with a research centre with long tradition in critical materials research and in close collaboration with universities, governmental laboratories and non-profit research organisations. Such centre would, besides providing training, also promote networking and diffusion of knowledge, and coordinate activities with the Rare Earth Industry and Technology Association (REITA). For what concerns information gathering, the US Geological Survey (USGS) provides the most comprehensive domestic and international non-energy historical mineral data, among others mineral yearbooks and commodity summaries which contain data on domestic and international mining and production, consumption, technology uses and other market trends for rare earths (U.S. Geological Survey, 2015b). Besides this, the US DOE also engages with stakeholders through various technical workshops, in order to gain better understanding on current trends in rare earths and other critical minerals. With regards to inter-agency collaboration, the Subcommittee on Critical and Strategic Mineral Supply Chains was established by the White House Office of Science and Technology Policy, the goal of which is to facilitate the effort across federal agencies in identifying and addressing policy implications of strategic mineral supply issues (U.S. Department of Energy, 2015). Finally, several R\&D initiatives, such as such as the Small Business Innovation Research and the Critical Materials Energy Innovation Hub, have been set up to provide funding for development of techniques which improve separation and decrease cost of processing rare earths (Bauer et al., 2011).

Securing foreign supply of rare earths relies mainly on resource diplomacy initiatives. According to the US DOE, cooperation with other resource-poor countries could help "to optimize resources for research and accelerate research and development on key topics" (Bauer et al., 2010). In line with this, the US DOE is involved in international discussion and collaboration through the annual Trilateral US-EU-Japan Conference on Critical Materials for a Clean Energy Future, the US-Australia Joint Commission Steering Committee Meeting on Science and Technology, the US-Japan Roundtable on Rare Earth Elements Research and Development for Clean Energy Technologies, and the Trans-Atlantic Workshop on Rare Earth Elements and Other Critical Materials for a Clean Energy Future (U.S. Department of Energy, 2015). With regards to resource-rich countries which tend to violate free trade agreements, the oversight of a rule-based global trading is the principal strategy of the United States. In this respect, the United Steelworkers, North America's largest industrial union, filed a petition under Section 301 
of the US Trade Laws about the WTO violations by China concerning the green technology sector (United Steelworkers, 2010). In the same spirit, the Rare Earth Caucus, in a letter to President Obama in 2012, pointed to the need to address Chinese restrictions, quotas and embargoes in the rare earth market (U.S. House Rare Earth Caucus, 2012). In the same year, the US filed a complaint at WTO, jointly with Japan and Europe, against China's export restrictions. President Obama argued in his speech: "We want our companies building those [high-tech] products right here in America. But to do that, American manufacturers need to have access to rare earth materials which China supplies. Now, if China would simply let the market work on its own, we'd have no objections." (CNN Wire Staff, 2012). Besides the limited availability of rare earths, the US administration was concerned about their increasing prices for non-Chinese consumers, and ultimately about the latter moving their operations, jobs and technologies to China. Of particular concern are rare earths for military uses, such as missile guidance systems, drones and strike fighters. The dependence of the US military on heavy rare earths from China has been acknowledged by the U.S. Department of Defense (2013). This recommended the US Administration to accumulate 120 million USD (103.9 million EUR according to 2015 exchange rates) worth of heavy rare earths, especially yttrium, dysprosium and erbium, as part of a 320 million USD (277 million EUR according to 2015 exchange rates) program to stockpile 23 critical materials. Despite the warnings by the Strategic Materials Advisory Council (2013) against stockpiling being a risky mitigation strategy, the DLA Strategic Materials received authorisation to acquire six materials to mitigate their supply risk, including dysprosium metal and yttrium oxide (U.S. Department of Defense, 2015).

R\&D plays a central role across all three pillars of the Strategy, though it proves most important in developing substitutes and recycling. In terms of permanent magnets, several initiatives are in place on substitution, minimisation and improvement of performance of rare earth-free magnets. The government-owned Ames Laboratory has the longest history in research in materials science, design and theory. It closely cooperates with the Iowa State University and has 745 employees and associates. Its Materials Preparation Center specialises in purification, preparation and characterisation of metals, alloys and compounds, including rare earths. Also since 2013, Ames Laboratory leads the Critical Materials Institute - a US DOE Innovation Hub gathering researchers from national laboratories, academia and industry, with the aim of developing substitute materials and technologies which are more resource efficient and eliminate the need for using raw materials under potential supply shortages, and transferring these to the mar- 
ket through technology license agreements (Ames Laboratory, 2015). Besides the Ames Laboratory, there are several other national laboratories which, through their basic and applied research initiatives, help reducing criticality of materials. Furthermore, the University of Delaware runs a research program on the next generation of permanent magnets (Bauer et al., 2011). In terms of financing, the Advanced Research Projects Agency (ARPA), established in 2009 by the US DOE, provides funding for early-stage technology innovations which eliminate or minimise the use of rare earths through its Rare Earth Alternative in Critical Technologies (REACT) program. In 2010, ARPA together with the Office of Science and the Office of Energy Efficiency and Renewable Energy provided 50 million USD (44.4 million EUR according to 2015 exchange rates) funding for research on rare earths, materials substitutes in high-energy-density permanent magnets, rare earth-free battery technologies and alternative electric motor and wind turbine generator designs that do not use permanent magnets (Bauer et al., 2010).

Regarding the recycling of rare earths in the United States, some initiatives are already in place. For example, the Center for Resource Recovery and Recycling, established using the National Science Foundation funding, groups together two American and one European universities in material engineering. It aims at advancing technologies that recover, recycle and reuse materials through manufacturing process (CR3, 2015). Moreover, the US DOE's Critical Materials Institute developed recovery and separation technology for neodymium, dysprosium and praseodymium from electronic waste, which has now been licensed to a rare earth exploration junior company (Duchesne, 2015). From an industry perspective, Retriev Technologies is the major recycler in the United States. They recycle rechargeable nickel-metal-hydride (NiMH) batteries containing rare earths, though the process is currently only targeting recovery of cadmium (Retriev Technologies, 2014). Nonetheless, as opposed to Europe and Japan, the United States does not have regulation in place which would enforce recycling standards and encourage private sector to collect and recycle end-of-life products. These are necessary in order to develop economically viable recycling processes in the country.

\subsubsection{Europe}

As opposed to the United States, the European Union output of metallic minerals has been historically low and decreasing over time, representing today only $3 \%$ of the world production (European Commission, 2008). This is mainly caused by exhaustion of favourable domestic deposits, decreased exploration and development of new deposits, reduced access to mineral deposits due to lack of planning policies and restrictive environmental standards, as well as insufficient development of new 
technologies for exploration, production and processing of minerals (Tiess, 2010). These developments ultimately led to increasing import dependence of minerals on foreign imports, some of which currently exceed the rate of $80 \%$, and thus make Europe vulnerable to external developments.

The debate on security of mineral supply in Europe was initiated within The Community's Supplies of Raw Materials report (European Commission, 1975). This pointed out the necessity of maintaining access to sources of supply from developing countries, in order to accommodate manufacturing needs and those for economic development of European countries. It identified the following supply problems: insufficient knowledge on present and future outlooks of minerals; relative and absolute shortages of minerals; insufficient diversification of supply; and political problems due to instability and monopoly position of supplier countries. In order to spread the risk, the report suggested developing European resources, exploitation of raw materials from seabed and diversification of foreign sources of supply. Furthermore, recycling of waste, substitution by other materials and new manufacturing processes, as well as extension of product life were advocated as remedies for mineral shortages. Finally, the report proposed to handle the risk of temporary bottlenecks and price fluctuations by long-term contracts, emergency stocks and international agreements. The latter should have been taken up within multilateral trade negotiations, and entailed observance of international rules relating to notification and consultation procedure of Article XI of the General Agreement on Tariffs and Trade (GATT). The report concluded by reiterating the need for common guidelines within the Community, arguing that the scale of security of supply was too big to be coped with on the individual member state level. It called for coordination of activities at different levels, as well as for launching common initiatives.

Despite the fact that minerals used to play a central role for Europe, as reflected by the European Coal and Steel Community, common political priorities in securing non-energy mineral supply have been missing from the European policy agendas until recently. This stands in a sharp contrast to energy minerals, such as oil and gas, where rising energy costs and high dependence on energy imports have been at the centre of political attention ever since the 1970s. While all Member States were found to have established by now government funded institutions which coordinate geological and geophysical surveys providing data on the location and the nature of mineral reserves, there tend to be substantial differences within countries' Minerals Planning policies. These are mainly related to land use planning legislative structures and policies, as well as to permitting procedures for exploration and mineral extraction, and to the Environmental Impact Assessment 
required within the authorization process (Wagner et al., 2004). Also in terms of securing mineral supplies, European countries have formulated different strategies in line with their respective domestic situations. For example, besides promoting domestic exploration, extraction and reprocessing of minerals and foreign investment in mining projects, the German strategy focuses on R\&D for substitution, resource intensity and recycling, in which it already has an established track record. It also intends to increase education and information diffusion by empowering faculties that deal with topics of geoscience, minerals and mining. As an example of establishing partnerships with resource-rich countries, the German Government has signed an intergovernmental agreement for resources, industry and technology partnership with Mongolia, to secure access to rare earths and coal in exchange for machines to extract resources (DEFRA, 2012). France's Strategic Metals Plan aims at understanding industrial needs with respect to critical metals, identifying the most critical resources and updating the mining inventory. This is in line with the existence of abundant gold and polymetallic nodule deposits located in the French EEZ, as well in former colonies of French Guyana and New Caledonia. Furthermore, France intends to accelerate the implementation of recycling projects and increasing R\&D in substitution. In terms of international cooperation, the French Geological Survey signed an agreement with the Kazakh national uranium miner to help developing Kazakhstan's rare earth metal deposits (DEFRA, 2012). Contrary to these, Finland as a resource-rich country, places focus on its own mineral sector, which is comprised of exploration, mining and processing, as well as of production and supply of machinery, technology and services for these operations. Its strategy is linked to promoting exploration and efficient use of resources, by using tax incentives, reducing permit processing times, enhancing availability and distribution of geoscientific and environmental data on the one hand, and to reducing the environmental impact of the industry and increasing its productivity by establishing research programmes for developing innovative solutions, improving material and energy efficiency of processing technologies and creating incentives for recycling and reuse of waste on the other (Ministry of Employment and the Economy, 2010). Similarly Sweden, which is the leading mining nation within the European Union, has developed a comprehensive mineral strategy. The minerals and mining industry is targeted through eleven action areas, among which are achieving greater resource efficiency through analysis of extraction and recycling potential, establishing a more effective regulatory framework by shortening permitting lead-times, fuelling infrastructure investments, promoting research and innovation to create competitiveness of the mineral industry, increasing skill supply that meets the needs of the industry and promoting investment (Ministry of 
Enterprise Energy and Communications, 2013). Both Finland and Sweden have important economic deposits of rare earths. Yet, while these countries have an established track record in mineral policy making, strategies in others are still in their infancy (EUROMINES, 2016).

The need for an integrated approach was brought back to the political agenda by the request of Council of the European Union (2007) to "develop a coherent political approach with regard to raw materials supplies for industry, including all relevant areas of policy (foreign affairs, trade, environmental, development and research and innovation policy) and to identify appropriate measures for costeffective, reliable and environmentally friendly access to and exploitation of natural resources, secondary raw materials and recyclable waste, especially concerning third-country markets". The European Commission (2007b) has further called for the development of a raw materials policy based, among others, on international multilateral and bilateral agreements, streamlining access to domestic raw materials and improving resource efficiency through better use of resources embedded in waste. Finally, the urgency for a common policy response to ensure that the European industry has sufficient access to raw materials at undistorted prices has been expressed by Gnter Verheugen, the European Commission Vice President: "European industries need predictability in the flow of raw materials and stable prices to remain competitive. We are committed to improve the conditions of access to raw materials, be it within Europe or by creating a level playing field in accessing such materials from abroad." (European Commission, 2007d). The European Union subsequently launched a public consultation on the Commission Raw Materials Initiative (European Commission, 2007c). The Initiative itself was formulated in 2008 and revised in 2011 (European Commission, 2008, 2011). It is currently coordinated by the Directorate General Internal Market, Industry, Entrepreneurship and SMEs, though the Initiative is a collaborative effort of other Directorates, such as Trade, Environment, Research and Innovation, and International Cooperation and Development. It should help the European Union to form a coherent strategy on long term sustainable supply of non-energy raw materials in the context of the EU industrial policy: "Securing reliable and undistorted access to raw materials is increasingly becoming an important factor for the EU's competitiveness and, hence, crucial to the success of the Lisbon Partnership for growth and jobs.". The Raw Materials Initiative is implemented primarily through the European Innovation Partnership (EIP) on Raw Materials. This stakeholder platform was endorsed in 2013 and brings together representatives from industry, public services, academia and NGOs with the aim of providing guidance on challenges related to non-energy non-agricultural raw materials (European Commission, 2015c). Besides contribut- 
ing to the 2020 objectives of the EU Industrial policy, it also plays an important role in meeting the objectives of the Innovation Union, and the Resource Efficient Europe initiatives of the European Commission.

The Raw Material Initiative itself is built on three pillars. The first one represents access to raw materials on world markets at undistorted conditions. This foresees active raw materials diplomacy and involves managing external policies and dialogues with developing resource-rich countries. An example of such a policy dialogue on access to raw materials and natural resources management is the Joint Africa - EU Strategy implemented in 2007 (European Commission, 2007a). This is based on mutual interest from Europe's development policies aimed at strengthening states, promoting sound investment climate and sustainable management of raw materials in developing countries, and its own need for undistorted access to raw materials. This has been first put forward within the report on Community's Supplies of Raw Materials (European Commission, 1975) and implemented a year later when the First Lom Convention was established between the EU and the African-Caribbean-Pacific States (Tiess, 2010). Its aim was securing preferential mineral imports into the European Community in exchange for financial aid and investment in the participating countries. The convention has been abandoned after it was found incompatible with the WTO rules and has now been replaced by the Cotonou Partnership Agreement. The latter is based on development, political, economic and trade cooperation, especially in countries which are committed to implementing reforms that focus on improved transparency and governance in extractive industries (European Commission, 2015a). The EU has supported further initiatives to promote transparency and accountability in the extractive industry in developing countries within the framework of the Extractive Industries Transparency Initiative (2015) and the Kimberly Process Certification Scheme (2015). On the other hand, the European Union also strives to remove measures introduced by resource-rich countries which distort competition and increase global prices of raw materials. With regards to filing the joint WTO complaint against Chinese restrictions on rare earths, the EU Trade Commissioner Karel De Gucht stated out: "These measures hurt our producers and consumers in the EU and across the world, including manufacturers of pioneering hi-tech and 'green' business applications." (European Commission, 2012). Finally, the European Union also manages strategic partnerships with other resource-dependent countries. The Trilateral Critical Materials Initiative is taking form of annual meetings with stakeholders from Japan and the US and with participation of Australia, Canada and South Africa, and aims at identifying common interests and positions in the international context of securing mineral supply by improving extraction, finding 
substitutes, improving efficiency and encouraging recycling (European Commission, 2013; NEDO, 2012; U.S. Department of Energy, 2011).

The second pillar of the Initiative aims at setting framework conditions to foster sustainable supply of raw materials from European sources. Among the most pressing issues are access to land, streamlining the permitting process across Member States and public funding of exploration. In terms of rare earths, currently there exist only two advanced projects in Europe, one in Sweden and the other in Greenland, owned by a Canadian and an Australian company, respectively. Both have a potential to secure the European rare earth supply and are very attractive due to their deposits of heavy rare earth-rich minerals. Yet, the actual start of their production will depend on environmental permitting and finances available for further development (ERECON, 2015). In terms of rare earth processing, Europe also has two separation plants: Silmet in Estonia owned by Molycorp and La Rochelle in France owned by Solvay. Furthermore, Less Common Metals in the UK produces rare earth metals and alloys, while Treibacher produces polishing powders, compounds and some alloys in Germany and Slovenia (ERECON, 2015). For what concerns stockpiling instead, this is not part of the European mineral strategy. Though some countries do have experience with publicly stockpiling critical minerals, none of them currently accumulates inventories of rare earths (Risk \& Policy Analysis, 2012). Contrary to this, establishing the knowledge base on mineral deposits and networking between national geological surveys proves important to determine the domestic sources of mineral supply. In fact, one of the hurdles that hinder the implementation of the Raw Materials Initiative is the lack of EU-wide comprehensive mineral statistics. Separate databases are available on country level, yet these only cover country relevant data. To date only the British Geological Survey produces some of the statistics covering the whole European Union. As a response to this, the Minerals4EU project is currently under development and has the task of putting in place an EU mineral knowledge base and intelligence network (European Commission, 2015e).

Moreover, the EU aims at promoting research projects focusing on extraction and processing of minerals. One such project is the European Technology Platform on Sustainable Mineral Resources (ETP SMR, 2015). This is an international association grouping various stakeholders across the value chain since 2005, and is committed to providing a coordination function for minerals related technological research, development and education activities, in order to enable exploration and inventory of resources, mineral extraction from land and seabed deposits, mineral processing, metallurgy and recycling. Finally, in terms of skills shortage, the European Union is encouraging generation of new high skills in various aspects of 
minerals through its Erasmus Mundus Minerals and Environmental Programme. The latter is coordinated by the Federation of European Mineral Programs (2015) and provides a strong link between industry and participating universities. In the particular context of rare earths, the EURARE (2015) project was established in 2013 to set the basis for development of the European rare earth industry by evaluating resources in Europe, developing technologies for efficient exploitation of resources, establishing critical mass of scientist and engineers, and developing integrated knowledge management system. This project brings together academia, industry and geological surveys. Additionally, the European Union has established a multi-stakeholder European Rare Earths Competency Network (ERECON) to improve the rare earth supply security of Europe (European Commission, 2015d). One of the working groups is mandated to explore options for primary production of rare earths in the EU. The other one explores options for more efficient use, potential substitution and end-of-life recycling of rare earths, and is thus linked to the third pillar of Raw Materials Initiative.

The third pillar of the Raw Materials Initiative aims at reducing primary consumption of raw materials through resource efficiency, recycling, substitution and increased use of renewable raw materials. In terms of improving resource efficiency, the EU has introduced the Ecodesign Directive which sets mandatory ecological requirements for energy-using and energy-related products and also includes provisions for the design of resource-efficient products (European Commission, 2015b). Concerning recycling, this has a long tradition in Europe. In fact, the EU's waste management policy has evolved over the past three decades through various environmental action plans and framework legislations. The Thematic Strategy on the Prevention and Recycling of Waste was adopted in 2005 as part of the 6th Environment Action Plan. The Waste Framework Directive of 2008 is the cornerstone of EU's waste policy and treats the management of waste disposal, hazardous waste and oil waste. It establishes a five step waste hierarchy and its development today takes place within the context of the Raw Materials Initiative, as well as within the 7th Environment Action Programme and the Resource Efficiency Roadmap (European Commission, 2010a). In particular, waste shipments are controlled for by the regulation on shipments of waste, while the End of Life Vehicles Directive restricts the use of hazardous materials used in vehicles and sets reuse, recovery and recycling targets. The Waste Electronic and Electrical Equipment Directive (WEEE) lays down collection, recycling and recovery targets for electric goods, while the Directive Restricting the use of Hazardous Substances (RoHS) restricts the use of hazardous substances in the former. Additionally, the Batteries Directive has been set up to regulate collection, recycling and recovery targets for batter- 
ies (European Commission, 2010c). The latter directives prove especially relevant for the recovery of rare earths, since they make rare earth intensive end-of-life products a fast growing segment for recycling. In Europe, Umicore - a materials technology and recycling group, claims to be the first to have built a facility to recycle various battery technologies, including NiMH batteries from electric vehicles (Umicore, 2014). In terms of recycling magnetic material, Solvay - a chemicals company, announced plans to recover rare earths from light bulbs and permanent magnets (Solvay, 2012). Yet, no large scale permanent magnet recycling has been commercialised in Europe so far. While magnets from wind turbines and electric vehicles are suitable for reuse, they are not available for recycling due to their low penetration and long service lives. Similarly, material recovery from urban mines, such as hard disc drives, cell phones and air conditioners is not a set up practice in Europe yet, mainly due to lack of processes in place for disassembling end-of-lifeproducts. In 2013, the EU set up the European Rare Earth (Magnet) Recycling Network of academia and industry, which should train young chemists and engineers in the recycling of rare earths (EREAN, 2015). Besides this, the Belgian KU Leuven is funding a knowledge platform (RARE3) focusing on advanced recycling and reuse of rare earths and other critical minerals, and participates in the Center for Resource Recovery and Recycling in the US (Katholieke Universiteit Leuven, 2015).

Besides recycling, also improvements in manufacturing processes and substitution can help decreasing import dependence on minerals. The joint scientific research and technological development policy in Europe dates back to the 1960s, when the Working Party on Scientific and Technical Research Policy (PREST) was created. This was later superseded by the Scientific and Technical Research Committee (CREST), which was commissioned to coordinate national policies and to define objectives of interest to the Community in the field of science and technology. Specifically, its subcommittee on raw materials research and development was set up to provide a forum for cooperation in R\&D in mining, in new techniques for processing ores and their recycling, among others (European Commission, 1975). At present, the critical mass for research and innovation on European level is built through public-private partnerships, such as the EIP on Raw Materials. Being a multi-stakeholder group which supports innovation activities along the entire value chain, it helps meeting the objectives of the Europe 2020 Innovation Union initiative for creating an innovation friendly environment. Similarly, the European Institute of Innovation and Technology (EIT) Raw Materials established in 2014 as a knowledge and innovation community (KIC), shall help boosting competitiveness, growth and attractiveness of the European raw materials sector via 
innovation and entrepreneurship (European Institute of Innovation and Technology, 2015). Bringing together education institutions, research labs and industry, it covers activities from mining through processing, recycling and substitution. Furthermore, the Network on Industrial Handling of Raw Materials for European Industries (ERA-MIN) has been established in 2011 within the ERA-NET scheme, in order to promote coordinated research across the entire value chain by networking European stakeholders, road mapping research priorities and implementing joint actions (ERAMIN, 2015). One of its working groups covers issues related to substitution of critical minerals. While a comprehensive policy framework to support substitution of critical minerals in applications is currently being set up, at this stage there exist no research projects financed on the European level for finding rare earth substitutes. This may be due to the fact that historically the downstream side of the rare earth value chain was not developed extensively in Europe (the only exceptions are Vacuumschmelze and Magnetfabrik Schramberg in Germany, both of which produce rare earth permanent magnets and are licensees of the Japanese Hitachi Metals). Nonetheless, there is one project which resulted from the EU 7th Framework Program (FP7) and has the objective of developing high-performing rare earth-free magnetic materials (NANOPYME, 2015). Another initiative funded by FP7 is the Critical Raw Materials Innovation Network which has been established to map out critical raw material substitution initiatives at the EU and Member States levels, to identify opportunities for developments in the field of substitution of critical raw materials, to propose a roadmap for the substitution of critical materials in five key applications (among other rare earths in permanent magnets), and to provide a platform for the stakeholder community (CRM_InnoNet, 2015).

\subsubsection{Japan}

Japan, similarly to Europe, has been historically a resource-poor country dependent on imports of oil, gas and various minerals from overseas. Yet, while Europe's dependence on imports of rare earths is mainly in terms of manufacturing end use technologies such as wind turbines and advanced technology vehicles, Japan's economy is significantly dependent on refining rare earths into metals and alloys, as well as on manufacturing and exporting component parts and high value added products which use rare earths as input materials. In fact, Japan is the largest consumer of dysprosium which is used as doping agent in permanent magnets in high-tech products such as cell phones and hard disk drives, as well as in home appliances, in robotics and in electric motors of hybrid and electric vehicles (Kawamoto, 2008). The stable supply of rare earths is thus detrimental for maintaining the interna- 
tional competitiveness of Japan's automotive and electronics industries, in which Japan is the global leader. In 2008, Japan was 100\% dependent on rare earth imports and sourced $90 \%$ of these from China (Shen, 2015e). Besides the economic dependence, there is also a geopolitical perspective to importing minerals from abroad. While China's assertive actions are not uncommon in the disputed waters (The Economist, 2013), Japan has seen itself involved in a maritime incident when a Chinese fishing trawler collided with Japanese coast guard vessels. The detention of the Chinese captain resulted in a diplomatic dispute between the two countries, the ultimate consequence of which was China halting rare earth exports to Japan for a period of two months (Bradsher, 2010). It was this incident that made both the Government and the private sector aware of the Japanese vulnerability to political risk tied to import dependence from China. As stated out by the Toyota Motor Corp spokesman right after the incident: "There are many risks in depending on one nation." (Hosaka, 2010). Akihiro Ohata, Japan's former Minister of Economy, Trade and Industry went a step further in reaffirming: "the situation reminded us of the need to craft a long-term strategy to procure rare earths" (MarketWatch, 2010). Furthermore, Nippon Keidanren (Japan Business Federation) in its proposal for Japan's Trade Strategy, called for restoring the discipline against restrictive measures affecting exports of rare earths under the WTO agreements (Nippon Keidanren, 2011). As a response to the threat of supply disruption, the Japanese Government allocated additional 101.2 billion Yen (730 million EUR according to 2015 exchange rates) from the Supplementary Budget for 2010 for securing rare earths and other natural resources in the context of promoting green innovation (MOF, 2010).

The Japanese mineral strategy in itself dates back to the economic warfare against Japan during the Second World War. During this time, the majority of Japan's merchant vessels were sunk by the Allies and Japan was forced to withdraw its troops from its strongholds in South-East Asia and Pacific islands. Moreover, the American embargo on pig-iron and oil increased Japan's import dependence on iron ore from China and Korea and forced it to use up its enormous raw material stockpiles. This gradually led to shortages of steel, oil and coal, which were detrimental for manufacturing Japan's armaments, and thus adversely impacted its ability to sustain military operations (Milward, 1977). Further to this incident, the Japanese Government, in view of sustaining its economic security, set the stability of supply of imported resources as the main aim of its energy policy. In 2006 the Japanese Ministry of Economy, Trade and Industry (METI) deliberated over the New National Energy Strategy, one of the aims of which was to strengthen resource diplomacy and energy and environmental cooperation, through strate- 
gic utilization of official development assistance (ODA) and promotion of mutual investment, as well as through overseas resource development and diversification of supply (METI, 2006). The government's role of supporting exploration and development of projects, by assisting negotiation of Japanese exploration companies with foreign state-run companies in resource producing countries as well as by overseeing that resource producing countries are not introducing distorting measures, was laid down within the Guidelines for Securing Natural Resources (METI, 2008). Furthermore, the Strategic Energy Plan of 2007, which was later revised in 2010 and 2014, put forward recycling and stockpiling of rare metals, as well as seabed exploration (METI, 2014). METI also set a goal for improving resource security by increasing self-sufficiency to $80 \%$ for base metals and to $50 \%$ for rare metals by 2030 (Japan Metal Bulletin, 2010). Based on the above, and in the context of green innovation inducing economic growth, METI spelled out its comprehensive strategy to assure stable supply of resources and energy within its 100 Actions to Launch Japan's New Growth Strategy (METI, 2010a).

Over time, Japan developed a truly comprehensive strategy to guide and coordinate policy on securing raw materials supplies. This is best illustrated by Yukio Edano, Japan's former Minister of Economy, Trade and Industry: "We want to further diversify sources of suppliers, secure our interests and support domestic technological development to cut the amount used and promote recycling." (Kaneko, 2012). In particular, the Japanese Strategy for Ensuring Stable Supplies of Rare Metals is coordinated by METI and is built on four pillars, it's main objective being to sustain economic security (Advisory Committee on Energy and Natural Resources, 2009). The first pillar targets diversifying supply sources through strategic resource diplomacy. The Government's main task in this respect is to facilitate technology transfer, infrastructure development and energy cooperation through bilateral and multilateral trade agreements, which would serve the development objectives of resource-rich countries and at the same time assure access to raw materials for Japan. This strategy is closely linked to establishing joint exploration initiatives with resource-rich countries and their financing. In Japan such initiatives take form of public-private partnerships whereby public institutions, such as the Japan Oil, Gas and Metals National Corporation (JOGMEC), carry out overseas field surveys and provide financial assistance to high risk mine development projects. JOGMEC was established in 2004 by merging together the Metal Mining Agency of Japan, which was itself created in 1963 as the Metallic Minerals Exploration Financing Agency of Japan, and the Japan National Oil Corporation which was established in 1967 as Japan Petroleum Development Corporation (JOGMEC, 2015a). Nowadays, JOGMEC's tasks lie within promoting exploration 
and development for oil, natural gas, non-ferrous metals and minerals, by providing loan guarantees and financial assistance, domestic and overseas mining related information and cutting-edge technological tools for exploration, processing and recycling, as well as within national stockpiling and technical assistance for dealing with mine pollution. In particular, JOGMEC in joint cooperation with Sojitz, a general trading company with a track record of 40 years in rare earth trading (Sojitz, 2013), assisted the set-up of long term supply agreements, joint ventures and strategic alliances with producers in various countries, such as Vietnam (Vinacomin, 2012), Kazakhstan (Paxton, 2012), Australia (Sojitz, 2013), India (Shah, 2014) and Mongolia (Tanquintic-Misa, 2015), in exchange for exploration technology, know-how transfer and project financing. The overseas business operations by Japanese companies are furthermore supported by: the Japan Bank for International Cooperation which conducts lending, investment and guarantee operations to the private sector; the Nippon Export and Investment Insurance which conducts trade and investment insurance business operations; and the Japan International Cooperation Agency which coordinates Japan's official development assistance. Overall, the supply diversification strategy contributed to successfully decreasing Japan's dependence on Chinese imports of rare earths down to 60\% in 2014 (Shen, 2015e). Besides the initiatives targeting resource-rich countries, Japan also cooperates with resource-poor countries through the Trilateral Conference on Critical Materials, where common strategy for tackling security of supply or rare earths is discussed. Finally, Japan is also pioneering exploration for heavy rare earths on seabed deposits within Japan's EEZ (Evans-Pritchard, 2013). Though publicprivate partnerships in seabed exploration for mineral resources in Japan date back to the 1980s (Deep Ocean Resources Development, 2015), the basic framework for promotion of ocean-based strategies, such as enhancement of scientific knowledge on oceans, development of ocean industries and strengthening international competitiveness, has only been established in 2007 with the promulgation of the Basic Plan on Ocean Policy (Terashima, 2009).

Recycling of scrap and end-of-life products constitutes the second pillar of the Japanese mineral strategy, which calls for improved utilization of existing recycling processes and promoting R\&D in recycling technology (Advisory Committee on Energy and Natural Resources, 2009). Japan's legislation dates back to the 1970s and systematically covers the topic of waste reduction and recycling promotion by recycling-related laws. In particular, recycling guidelines were first established in 1990 by METI and aim at promoting voluntary initiatives by businesses across various sectors. Several other policies were drafted since then, such as the Law for Promotion of Effective Utilisation of Resources (1991), the Basic 
Law for Promoting the Creation of a Recycling-Oriented Society (2000) and the Home Appliances Recycling Law (2001), all of which contributed to the successful establishment of the recycling-oriented society in Japan. For example, the Home Appliances Recycling Law started to regulate collection and recycling of home appliances and gave thus rise to urban mining in Japan - the systematic collection of end-of-life products for establishing a recycling of raw materials. Collecting these appliances made it in turn possible for companies to develop recycling processes for the recovery of steel, copper, aluminium, and other materials. With the financial assistance of METI, these processes were later extended to recycling of rare earths, mainly dysprosium and neodymium. One such initiative was the development of automatic dismantling equipment to recover rare earths from air conditioners by Mitsubishi Electric in close cooperation with magnet and appliances manufacturers (Mitsubishi Electric, 2012). Similarly, Hitachi has developed recycling technologies to separate and collect rare earth magnets from hard disk drive motors, air conditioners and other compressors (Hitachi Ltd, 2010). In terms of NiMH batteries, both Honda and JOGMEC's Metals Mining Technology Group have developed technologies to recover rare earths and reuse them for production of new batteries (Honda Motor, 2013; JOGMEC, 2015b). Besides initiatives on recycling, METI and other government agencies are promoting the " $3 R$ s policy" (reduce, reuse, recycle) in order to create "a sustainable economic system that pursues environmental protection as well as economic growth" (METI, 2010b). The idea of expanding from single a "R" (i.e. recycling of products and materials) to incorporating reduction of waste generation and reuse of parts and products has been put forward by the Waste Prevention and Recycling Subcommittee of the Industrial Structure Council in 1999. What is more, Japan is currently proposing to extend this policy to a regional level and create a "sustainable Asia based on 3Rs" (METI, 2004).

Besides striving to secure stable access to raw materials, Japan also aims at promoting the use of alternative materials so as to maintain its competitiveness and to develop new industries. In the context of rare earths, the initiatives are mainly targeted towards lowering the usage of rare earths in permanent magnets. Their production dates back to early 1970s when Japan began producing samarium-cobalt magnets. In 1982 Sumitomo Special Metals (now merged with Hitachi Metals) patented the Neomax sintered neodymium permanent magnets, and to-date still holds 615 patents licensed to 14 companies globally (Hitachi, 2015; Hitachi Metals, 2013). Permanent magnets are used within electric motors of electric and hybrid vehicles, in the production of which Japan is the world leader. In this respect, Japan's aim is to strengthen industry-university-government linkages 
as well as collaboration across up- and downstream sides of the supply chain (Advisory Committee on Energy and Natural Resources, 2009). Such efforts are carried out under the auspices of METI and the Ministry of Education, Culture, Sports, Science and Technology (MEXT), and are financed through funding agencies: the New Energy and Industrial Technology Development Organization (NEDO); and the Japan Science and Technology Agency along with the Japan Society for the Promotion of Science, respectively. While METI is promoting applied research through the National Institute of Advanced Industrial Science and Technology as well as industry related projects, MEXT is advocating basic research at universities and strategic research by the National Institute for Materials Science (NIMS) and by the RIKEN research institution (NIMS, 2011). NIMS in particular, is the national research and development agency specializing in materials science. It has a long tradition of research, being established in 2001 by merging the National Research Institute for Metals and the National Institute for Research in Inorganic Materials, which were established under the auspices of the former Science and Technology Agency in 1956 and 1966, respectively. NIMS currently employs over 1500 researchers and its mission is to carry out fundamental and basic research, to share advanced research equipment and to develop and apply cutting-edge nanotechnology (NIMS, 2011). For example, in the context of rare earths in magnets, NIMS set up the Elements Strategy Initiative Center for Magnetic Materials dedicated to $R \& D$ of novel high performance permanent magnets free of critical elements. NIMS also provides training and education through its International Center for Young Scientists, as well as through various joint graduate school and internship programs. Finally, it also maintains external collaboration through centres of excellence (for example with Toyota, Honda and LG) and joint research centres with universities (NIMS, 2015). The most important examples of such industry-university-government collaborative projects are the Rare Metal Substitute Materials Development Project coordinated by METI and the Elements Science and Technology Project by MEXT (NIMS, 2015). The respective rare earth project themes aim at developing a new category of permanent magnets with reduced amounts of dysprosium and neodymium by minimisation (nanotechnology), by substitution for other metals, or by improving performance of rare earth-free magnets, while achieving comparable magnet properties to neodymium-iron-boron permanent magnets. Furthermore, magnet saving motor developments by small motor makers are financed through METI, which in 2012 alone provided a subsidy of 5 billion yen (36.2 million EUR according to 2015 exchange rates) expecting a $30 \%$ decrease in domestic dysprosium consumption within two years (Japan Metal Bulletin, 2012). Examples of such initiatives are the NEDO - Hitachi In- 
dustrial Equipment Systems collaboration and the NEDO - Hokkaido University collaboration, both of which resulted in developing rare earth-free electric motor technologies (Hitachi Ltd, 2012; Japan for Sustainability, 2011).

The last pillar of the Japanese mineral strategy relates to stockpiling of strategic materials.. This shall hedge against short-term supply risk, as a complement to the medium and long term strategies covered by the previous three pillars. The idea of stockpiling dates back to the Second World War, when energy materials such as oil were stockpiled in order to mitigate adverse consequences of import restrictions from abroad. Further to the oil crisis, the national stockpiling scheme for rare metals was established in 1983 (JOGMEC, 2015c). According to the scheme, rare metals are stockpiled in response to Japan's degree of import dependence, to the unavailability of substitutes within Japan's manufacturing industry and to the high geological concentration of their global production. While the exact list of stockpiled metals is confidential, at the end of 2010 Japan had stockpiles of chromium, cobalt, gallium, indium, manganese, molybdenum, nickel tungsten and vanadium (Risk \& Policy Analysis, 2012). At present, the Japanese stockpiles serve both economic and military purposes and are managed by JOGMEC based on market trends. There is no official information on Japan's public stockpile of rare earths, yet their demand and supply situation is continuously monitored by JOGMEC. There is however evidence of private stockpiling activities ongoing due to the current low rare earth prices (Shen, 2015a).

\subsubsection{Australia}

Australia is yet another relevant stakeholder within the discussion on rare earth mineral strategies. However, not from the perspective of a consumer country, but as one of the major exporters globally. Australia's mineral exports account for approximately $60 \%$ of value of goods and services, and $10 \%$ of country's GDP (Skirrow et al., 2013). While the country is known for being a leader in extracting iron ore, nickel, aluminium, gold and coal, rare earth exploration has been historically much less significant. In fact, deposits of rare earths were mainly discovered as a result of uranium and thorium prospecting. Australia has been a historical exporter of monazite since 1950s, which was used for extraction of rare earths and thorium in overseas processing plants. Until the mid-1990s, France was one of the major importers of Australian monazite. Yet when the debate on the toxicity of waste disposal intensified in France, its monazite processing plant was closed down, what lead to complete disruption of the monazite mining industry in Australia (Hoatson et al., 2011). Moreover, since the beginning of the 20th century there were several attempts to establish small scale commercial rare earth 
production in Australia, but the projects were not successful due to lack of capital, environmental concerns, low grades and low tonnage (Geoscience Australia, 2010). However, the increases in metal prices in the early years of the new millennium have revived exploration interests for rare earths. The first major mining project was established in 2007 at the Mount Weld deposit, which is one of the world's richest deposits of rare earths with low thorium contamination, and also one of the only two non-Chinese producers of rare earths globally. The mine is currently managed by Lynas Corporation. The first stage of mining activities was completed in 2008. The ore produced is concentrated in the concentration plant on-site and shipped to the Lynas Advanced Materials Plant (LAMP) in Malaysia for further refining (Lynas Corporation, 2015). LAMP is the world's largest refinery of rare earths and the first one to be constructed outside of China during the past decades. However, the construction of the plant faced opposition from Malaysian community lobby groups and local inhabitants due to concerns that radioactive waste from rare earth production would have adverse environmental and health impacts (Stop Lynas, 2015). Indeed, the locational choice for the processing plant was motivated by strategic reasons of lower capital and operating costs as compared to an Australian location, by a tax exemption granted by the Malaysian Government, and possibly by the country's lax environmental regulations on toxic waste disposal (Bradsher, 2011). The intention to dispose of the radioactive waste in Malaysia sparked controversy against both Lynas and the Australian Government. As a response to this, the latter issued a statement on the Australian laws prohibiting the import of radioactive waste into the country: "National legislation stipulates that Australia will not accept responsibility for any waste product produced from offshore processing of resources purchased in Australia such as iron ore, mineral sands and the rare earth produced by Lynas Corporation" (Sta Maria, 2012). Despite the opposition, the Malaysia's Atomic Energy Licensing Board has initially granted a temporary operating licence, which was in 2014 extended to a two year full operating stage licence.

From the Australian perspective, rare earths have been determined as critical minerals with high resource potential (based on availability and costs of production and estimates of world demand). According to the assessment by Geoscience Australia, rare earths rank within "category 1" of resource potential, based on their level of criticality from the global perspective, on Australia's current resources and potential for new discoveries, as well as on the rare earth market size and growth outlook (Skirrow et al., 2013). Indeed, Australia has large potential for mining of rare earths and other critical minerals. Besides Mount Weld, there are several junior projects in the advanced stage of development, some of which contain high 
percentage of heavy rare earths. In particular, of all global projects outside China, the Dubbo Zirconia deposit is the richest deposit with up to $60 \%$ of heavy rare earth oxide content (Hoatson et al., 2011). Once this project turns operational, it might become a swing producer of heavy rare earths globally. Hence, as opposed to China, Japan, the United States and Europe, Australia sees its resources as a source of future income from exports, rather than as input materials for its weak manufacturing industry (Bromby, 2015b). Consequently, rare earth criticality per se is not an issue for the country, since it is a relatively small consumer of minerals. In line with this, also its policies are directed towards the upstream parts of supply chain, such as mining and production.

From an institutional perspective, mineral and energy policies are concentrated in the hands of the Department of Industry and Science, while previously this function was assumed by the Department of Resources, Energy and Tourism (Department of Industry and Science, 2015e). The overarching aim of the mineral policy is to expand Australia's resource base and to increase the international competitiveness and sustainability of resources sector. Australia, as a mineral producer, is characterized by large commodity endowment, political stability, supportive policy settings, long term stability of mining industry and data availability for prospective mining (Barnicoat, 2013). This gives it a significant advantage in providing secure supply of rare earths, as compared to other prospective producer countries such as Brazil, South Africa, Vietnam and Kazakhstan. Increasing the investor confidence in Australia's resources sector has been achieved through various resource programs. To start with, Australia undertook a domestic pilot to test how applying the Extractive Industries Transparency Initiative (EITI) rules and principles could be suited to country's conditions. The results of the test confirmed the strength of Australia's governance frameworks in extractive industries and recommended the implementation of an adapted EITI model. This shall bring about more transparency and better information management practices, which are important for inducing investment into and development of the extractive sector (Department of Industry and Science, 2015b). In terms of sustainability of mining, the Government launched the Leading Practice Sustainable Development Program for the Mining Industry, which provides information on sustainable mining practices to mine managers, communities and regulators through various workshops and a series of handbooks (Department of Industry and Science, 2015c). Another initiative is the Working in Partnership to promote long term effective partnerships between the stakeholders of the mining industry and communities, with particular focus on building indigenous business capacity (Department of Industry and Science, 2015f). In addition to this, the National Mine Safety Framework initiative 
was developed by a multi-stakeholder steering group with the aim of assuring safety of workers in the mining industry (Department of Industry and Science, 2015d). Finally, besides participating in key international fora, through which it seeks to maximise its export opportunities and to enhance its energy security, Australia also engages in bilateral minerals and energy consultations with its main trading partners to identify and facilitate two-way commercial opportunities within resources sector. For example, during the 34th Meeting of the Australia-Japan High Level Group on Energy and Minerals Consultations, the opportunities for investing in Australian rare earths were discussed, among others (Department of Industry and Science, 2011).

Though exploration constitutes only a minor part of the Australian economy, it proves significant in discovering commercially valuable resources for further extraction. Yet the exploration sector has now reached a ten year low, facing decreased productivity and rising costs, with the quality and the quantity of newly discovered sites decreasing over time. It is for this reason that the Australian Government mandated the Productivity Commission to undertake an inquiry into the nonfinancial barriers to mineral and energy exploration (Productivity Commission, 2013). The latter has in turn issued a list of recommendations on reducing green and red tape from regulatory burdens. In line with this, within the proposed 2015 energy market reforms agenda, the Government prioritizes the improvement of geoscience information in order to attract commercial exploration, eradication of duplicative survey and data collection efforts to reduce cost for businesses and improve public understanding of the sector, the streamlining of regulation for mineral and energy resources development, as well as the establishment of policy framework to support new mineral and energy resources development, especially less common minerals and rare earths (Department of Industry and Science, 2015a). Particular value is laid on implementing the "one-stop shop" for environmental approvals which should decrease the time and cost of the permitting process. Similarly, the provision of pre-competitive geoscientific information, as provided by Australian geological survey organisations, shall encourage exploration activities (Geoscience Australia, 2015). In terms of financial incentives instead, the Government introduced the Exploration Development Incentive which provides economic incentives to invest in small exploration companies. The latter raise capital from private sector investors through exploration credits, paid as a refundable tax offset to Australian resident shareholders (Australian Taxation Office, 2015). Furthermore, the R\&D tax incentive designed to encourage companies to engage in $\mathrm{R} \& \mathrm{D}$ activities applies to mining companies of various sizes and contributes to funding of drilling and exploration activities (Edwards, 2015). 
In addition to the initiatives described above, Australia has also launched the Industry Innovation and Competitiveness Agenda in 2014, as part of Government's Economic Action Strategy. It concerns reforms to boost competitiveness and is centred on four goals: lower cost and business friendly environment; more skilled labour force; better economic infrastructure; and industry policy which fosters innovation and entrepreneurship. One of the key initiatives to achieve the fourth goal is establishing non-profit Industry Growth Centers (Australian Government, 2014). The government intends to invest 188.5 million AUD (or approximately 119 million EUR according to 2015 exchange rates) over a period of 4 years within sectors with high competitive strength. Among those selected are also the mining equipment, technology and services sector, and the oil, gas and energy resources sector. The role of the Centers will be to develop roadmaps of priority actions with view of increasing the competitiveness of respective sectors, to help improving regulatory environment and to facilitate industry-university-government partnerships, with the view of developing innovative products and services. Furthermore, the Agenda intends to place science at the centre of industrial policy, bringing together universities, R\&D corporations, industry initiatives and publicly funded research agencies (Department of Industry and Science, 2014). One such agency is the Commonwealth Scientific and Industrial Research Organisation (CSIRO) - Australia's leading multidisciplinary research organization. It was established in 1926 as the Council for Scientific and Industrial Research with the purpose of carrying out scientific research on topics of Australia's farming, mining and manufacturing industries. These were later expanded across all fields of primary, secondary and tertiary industries. For example, the CSIRO Minerals Down Under Flagship initiative was set up in order to promote industry-university-community linkages and thus to further technology and innovation solutions for more efficient development of country's mineral resources across the entire value chain (CSIRO, 2013). For rare earths in particular, CSIRO is currently developing methods for better and less energy intensive ways to extract these from the ore body (Treadgold, 2015). Similarly, the Australian Nuclear Science and Technology Organisation (ANSTO) Minerals branch has been involved in developing various processing options for rare earths from minerals of different grades for more than two decades (ANSTO, 2015). This international mining consultancy is the world leader in uranium and rare earth processing, radioactivity control and fundamental research applied to industrial problems.

However, Australia also brings resource nationalism perspectives into its mineral strategies. For example, the recent foreign acquisitions of Australian mining companies have sparked concerns among politicians and the public about the possi- 
bility of losing grip over country's resources. As a response to these, the Australian regulators blocked several bids by foreign companies for Australian mineral producers. Such was the case of the unsuccessful attempt of Chinalco to increase its stake in Rio Tinto's iron ore, copper, and aluminium assets, as well as the bid by China Minmetals Corp for OZ Minerals which owns and operates copper-gold mines, and the proposed takeover of a controlling stake in Lynas by China Non-Ferrous Metal Mining Company which were both halted by Australia's Foreign Investment Review Board (Macalister, 2009; Scott, 2009). Analogously, the Australian policy makers strive to ensure that country's natural resources are not only benefiting international mining companies, but also the Australian population. This idea has been reflected within the Review of Australia's Future Tax System (also known as the Henry Tax Review) (Minerals Council of Australia, 2008), which has later become basis for the mining taxation overhaul. The Australian Government developed a package of tax reforms "to harness the super profits of our mining boom and redirect them to the vital task of national economic reform... We will ensure Australia gets a fair share of our resource wealth, directing the proceeds towards sustainable economic growth right across the economy." (Australian Government, 2010). The roots of this decision go back to more than half a century of persistently high current account deficits caused by Australia's narrow export base and large imports of capital goods (The Australian Business Journal, 2010). The Government first announced its intention to introduce a Resource Super Profits Tax (RSPT) in 2010, which would tax mining projects on profits, rather than on production. The introduction of such a tax would have implied levying $40 \%$ rate on excess profits of all extractive industries. While the proposal for this tax received support from several renowned economists (Argy et al., 2010), there was a controversy among the largest explorer companies grouped under the umbrella of the Minerals Council of Australia (The Australian Business Journal, 2010). This has ultimately resulted in an "advertising war" against the new tax measure and lasted until the resignation of the Prime Minister in summer 2010 (Davis, 2011). Subsequently, his successor abolished the RSPT and replaced it by Mineral Resource Rent Tax (MRRT), the design of which was a compromise between the industrial lobby led by BHP Billiton, Xstrata and Rio Tinto, and the Government (Australian Associated Press, 2012). As a second best option, this new tax policy was implemented in 2012 and levied a 30\% tax on excess profits generated from the extraction of coal and iron ore or anything produced by in-situ consumption of coal or iron ore. Yet, its design and implementation were criticized by economists (The Economist, 2012), as well as by some mining lobby groups and the federal opposition who claimed that the policy would not raise the expected revenues 
and would drive investment and jobs outside of Australia instead (Mercer, 2011). After winning the elections the Coalition repealed the tax in 2014, aiming to restore the industry confidence (Australian Taxation Office, 2014; Minerals Council of Australia, 2013).

\subsubsection{Summary}

This final subsection highlights the most important points identified within the preceding historical account. The static interpretation of results is summarised within Table 4.1. The latter translates the results of the qualitative analysis into scores, which have been assigned across the key elements of supply chains and mineral strategies. In particular, rare earth industrial supply chains are evaluated within the generic supply chain framework across four main processes: 1) extraction of oxides from the earth's crust; 2) processing through separation and refining into metals, alloys and powders; 3) manufacturing of component parts such as magnets, motors and generators; and 4) assembling these into end use low-carbon technologies such as wind turbines and advanced technology vehicles (Bauer et al., 2010). Regarding rare earth mineral strategies instead, these are evaluated across seven elements which were identified as common across the countries analysed and largely correspond with categories considered by other studies (Bauer et al., 2010): 1) domestic diversification of supply; 2) foreign diversification of supply; 3) resource diplomacy; 4) stockpiling; 5) recycling; 6) R\&D; and 7) resource protection. The scores have been assigned based on the status quo of the respective rare earth-to-low-carbon technology supply chains (first two columns) and national mineral strategies (rest of the table) as follows: well established supply chains and mineral strategies have been scored ++ , while those which are currently under development or are weakly established have been scored + . The absence of mineral strategies altogether and the non-existent supply chains have been marked with $o$. All elements have been evaluated within the specific context of rare earths, with the exception of the development aid component of resource diplomacy.

In order to illustrate better the different policy directions taken by individual stakeholders, the results of the qualitative analysis are also illustrated graphically within Figure 4.1. The latter is a collection of two-dimensional diagrams of the variables evaluated (same as in Table 4.1). The qualitative elements of supply chains and mineral strategies have been translated into quantitative variables, by assigning scores ranging from 0 to 4 as follows: on the one extreme, the nonexistent supply chains and mineral strategies have been scored a 0 , while on the other the strongly established supply chains and mineral strategies have been 
assigned a 4. In between, scores 1, 2 and 3 have been used to indicate weakly established, partially established or well established but incomplete supply chains and mineral strategies respectively, based on the evidence found in the qualitative analysis. These quantitative variables are represented on the axes of the respective charts, whereby the length of their spokes corresponds to the scores assigned. In particular, Figures 4.1b to 4.1f illustrate national mineral strategies evaluated across seven elements, while Figure 4.1a illustrates the industrial supply chain development across its four sub-processes.

The aim of such assessment is to help understanding the different policy directions taken by individual stakeholders in response to the common problem of security of rare earth supply. The general observation stands out that China appears to be the only country with a fully vertically integrated rare earth supply chain. In fact, while downstream parts of supply chains tend to be well established across all major stakeholders (with the exception of Australia), currently only China disposes of well integrated activities on the upstream side of the supply chain (with Australia outsourcing processing to Malaysia, Japan and Europe lacking domestic supply, and the United States having recently shut down Molycorp). The scores assigned within Figure 4.1 illustrate the diversity of policy directions taken by individual stakeholders, ranging from resource diplomacy by Europe, through a more hands-on approach in $\mathrm{R} \& \mathrm{D}$ in Japan and the United States, to policies targeting diversification of domestic supply and resource protection by Australia and China. These results, along with the analysis of policy styles, form the basis for the comparative political economy discussion in Section 4.5. 


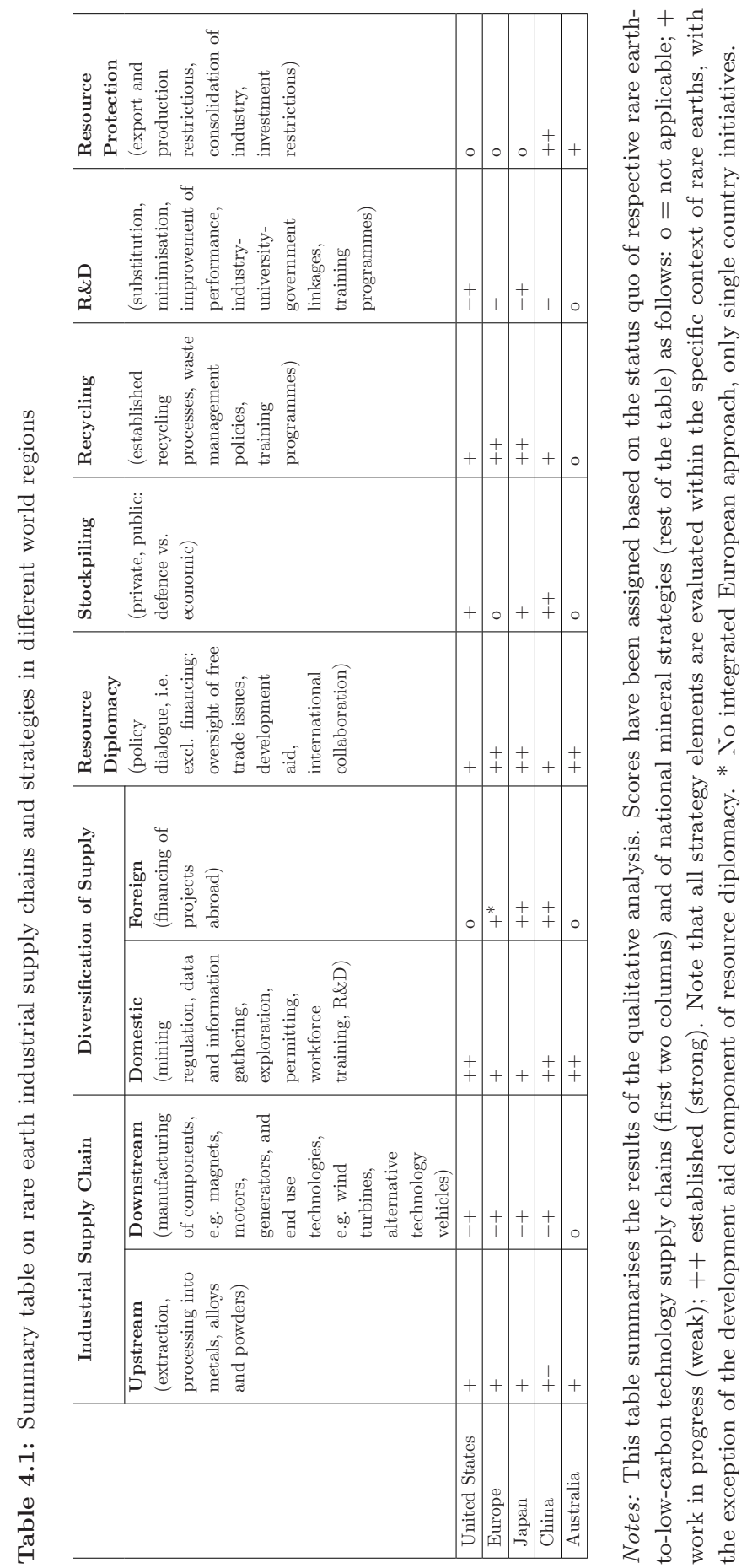




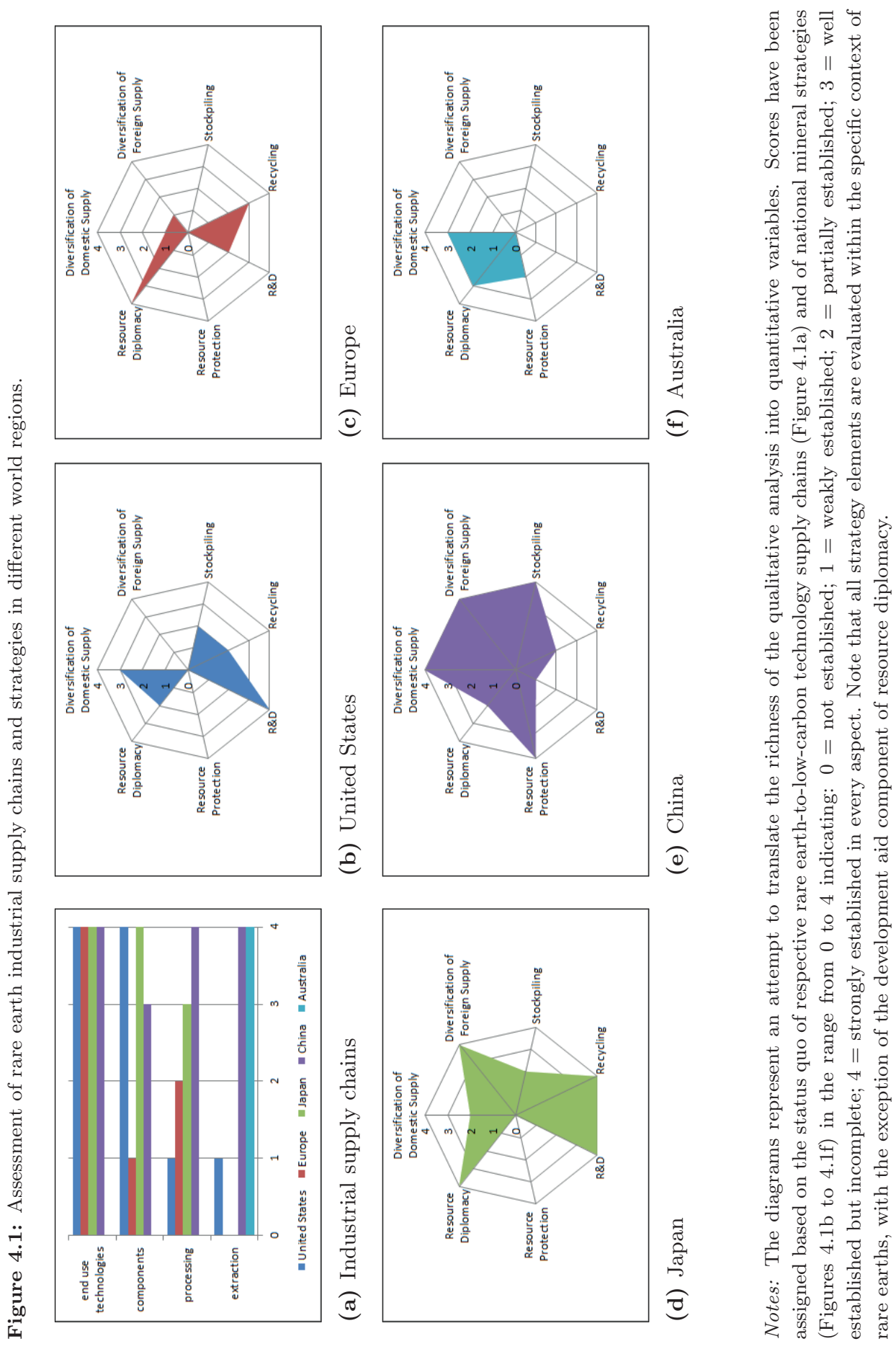




\subsection{Discussion}

The information presented in the previous section serves as basis for explaining why different world regions responded differently to the global problem of securing stable supply of critical materials. This is done within a comparative political economy framework, by examining the influence of national interests, resource endowment, countries' historical experience in tackling supply risk and their respective national policy styles, on the development of policy choices addressing the stable supply of rare earths.

To start with China, its well-established policies targeting the rare earths industry are rooted in China's tatist, activist, comprehensive and legalist policy style. China treating rare earths as "protected and strategic materials" reflects its preference for policy solutions through state regulation. In fact, its industrial policies prescribe protected exploitation of rare earth minerals, and at the same time limit the access of foreigners to the Chinese market, regulate domestic production and stockpiling, and explicitly increase the state control within the industry. The issue of industry influence is complicated. On the one hand, the tight control of production quotas and phasing out domestic production capacities illustrates the lack of institutional channels for industry associations to intervene in the policy making process. On the other hand, the informal authority structure makes the enforcement rather difficult. In fact, the central government has been unsuccessfully fighting over-production and smuggling which occur under the protective umbrella of local governments. This is in line with findings by Hung Lo et al. (2000) who describe China's policy style as active, legalistic and adhering to procedural formalities, but at the same time shaped by informal political activity. However, in addition to its national policy style, Chinese industrial policies have also been shaped by the influence of transnational organisations. In fact, the ruling of the WTO against China violating international trade rules led to abolishing tariffs and quotas and to introducing resource tax and export licensing. Furthermore, the radical and innovative nature of China's policy style is reflected in its early efforts to establish the rare earth innovation system. Policies targeting rare earths are embedded within comprehensive $R \& D$ programmes and within the new action plan for industrial upgrading. Such comprehensive policy making with long term vision is rooted in the stability of the one-party regime and the centralisation of the political power. However, China is a developmental state, what makes it difficult to compare it with the remainder of developed countries analysed in this chapter. In fact, its state policies, focusing on growth and industrialisation, have placed national interests in the forefront and neglected the environmental consequences. 
This has also been reflected in the rare earth industry, where excessive mining and polluting techniques led to large environmental and social costs. What is more, the lack of environmental concerns in policy making has been worsened by the missing public participation. Furthermore, the fact that China is a resource abundant country explains some of its policy priorities. Because of its large domestic supply, China does not have policies in place specifically targeting recycling of rare earths (though the latter might have been indirectly encouraged within its recent circular economy legislation). Likewise, despite the existence of extensive R\&D programs, China does not seem to focus on R\&D in substitution and minimisation of rare earths in applications, neither does it seem to target improvement of performance linked to rare earth-free designs. Yet, China seems to be aware of the pressure on its domestic resources and in line with this orients its resource diplomacy along the "go global policy". This targets acquisition of strategic resources abroad and technology transfer through foreign direct investment and is another example of the rational planning by Chinese policy makers.

In contrast to the Chinese policy style, the American style is liberal-pluralist, less comprehensive, somewhat activist but also adversarial and legalist. This has significantly shaped the critical mineral policy priorities in terms of diversification of domestic supply, R\&D initiatives, partially strategic stockpiling and resource diplomacy. The debate on security of mineral supply is rooted in a historical legalist tradition, whereby the term critical material was first introduced within the Strategic and Critical Materials Stock Piling Act of 1939 and continues to reappear in other legislations ever since. This has laid the basis for a well-established regulatory environment, which in turn facilitated the rare earth industry development in the United States during the second half of the 20th century. Yet, its continuous success was inhibited by the adversarial and fragmented policy by the Government. For example, as Molycorp, the only American rare earth producer, faced criminal investigations due to wastewater breaches, it was forced to suspend and later to completely shut down its operations. The fragmented policy style can clearly be seen from the United States abandoning its strong interest in security of supply in the 1980s. This also interfered with its activist approach in terms of R\&D. In fact, the United States has a long tradition of national laboratories engaging in research on different aspects of metals, which was also the main driving force behind the search for innovative composition of permanent magnets in the 1970s. After a temporary loss of strategic perception of non-energy minerals due to a change in geopolitics, the revival of American attention in rare earths two decades later was driven by the disruption of the domestic industry and by limitations in the international trade. The prominence of $R \& D$ became eventually even 
stronger, reflected in the creation of new laboratories focusing specifically on critical materials research, in the establishment of research programs at universities and of comprehensive financing of projects. Nowadays, R\&D is firmly established across all three pillars of the Critical Materials Strategy and is mainly seen to drive substitution and minimisation of rare earths and improvement of performance of rare earth-free designs. Besides this, the United States also has a strong military tradition, the implications of which can be seen in mineral policy making. In fact, in order to decrease the current dependence of the US military on China, the Department of Defense authorised the National Defense Stockpile to stockpile heavy rare earths. Finally, the American industrial associations also tend to have a significant influence on critical minerals policy making, lobbying for industry interests and addressing their concerns directly to the Congress. An example of such intervention is the initiative by the largest US industrial union which ultimately played a significant role in the US filing a complaint to WTO against China's export restrictions. The participation by interest associations, organisations and unions in the policy making process is one of the main differences between the United States and China, and is clearly facilitated by the liberal-pluralist policy style of the former. Similarly, as opposed to China, the US policy making in the context of critical minerals can be characterised by highly formalised interagency collaboration facilitating the policy making effort across federal agencies.

Concerning Europe, one cannot speak of a single regulatory style since the Europe Union was formally established only in 1993 (though it existed previously as European Community since 1967). The more so, since it is composed of nations which, through their different development trajectories, developed different institutional contexts. The tatist, activist and paternalist policy style of France, contrasts strongly with the policy style of the United Kingdom which is liberalpluralist, pragmatic and reactive, while Germany and Sweden are both corporatist and rank between comprehensive and fragmented, and active and reactive regulatory styles (Van Waarden, 1995). This heterogeneity of policy styles within the European Union makes the discussion of institutional determinants of policy making more complex. Additionally, until recently the non-energy minerals policy has been largely uncoordinated across the EU. In this respect, the differences in countries' Mineral Planning policies may potentially be attributed to their distinct regulatory styles. Yet they might also be a simple reflection of countries' distinct national interests in minerals. Nonetheless, the regulatory style differences explain at least part of the countries' engagement in securing mineral supplies. For example, the more active involvement of the state in France and Germany led to establishing partnerships with Mongolia and Kazakhstan in rare earth exploration 
and mining. Furthermore, within the French tatist context the policy choices seem to be less intensive than those in the corporatist Germany, where interest groups play an active role in policy formulation and implementation. The active policy approaches in Finland and Sweden, the two European countries with important economic deposits of rare earths, are reflected in the strong focus on their domestic mineral sectors. Yet, mineral strategies of other countries are still in their infancy, what is ultimately reflected in the weakly developed European policies related to the domestic supply diversification. All in all, the European policy style can be considered as fragmented and diverse. While the need for launching common initiatives was spelled out already in the late 1970s, this has only been brought back to the political agenda three decades later, based on the request by supranational institutions. This approach is largely in line with Europe's pragmatic yet reactive style without preference for radical solutions. It has nonetheless resulted in the Raw Materials Initiative, the formulation of which has been influenced by Europe's consensual style which created a platform for wide public consultation. Also the formulation and the implementation of mineral policies remain a collaborative effort across various Directorate Generals of the European Commission and often take place within public-private partnerships, stakeholder platforms and multi-stakeholder initiatives, where the process is guided jointly by industry, public services, academia and NGOs. Furthermore, Europe's historical dependence on foreign imports of metallic minerals explains the importance of resource diplomacy focus within its critical mineral strategy. The path dependence in using its external relations to ensure stable supply of resources through liaising with developing countries dates back to the 1970s when the First Lom Convention was established. Over time, external policy dialogues took various forms, and are to-date firmly established under the first pillar of the European Raw Material Initiative. Moreover, resource diplomacy has also been extended to cooperation with resource-poor countries. Similarly, the importance of rare earth recycling is embedded within the European tradition for waste management. This gave rise to various directives which also relate to the recovery of rare earths from batteries and electronic and electrical equipment, and served as a basis for establishing new initiatives in form of rare earth recycling networks and knowledge platforms. Last but not least, currently there exist no research projects for finding rare earth substitutes financed on the European level. This might be a result of the fact that the downstream side of rare earth supply chain has been historically underdeveloped across Europe.

As opposed to the countries previously discussed, Japan's urge for diversifying domestic and foreign supply has been largely influenced by the geopolitical developments in East Asia. Industry associations, business federations as well 
as single large manufacturers affected by the diplomatic dispute between China and Japan which disrupted the rare earth trade, have raised their concerns to the Government and demanded restoring international trade discipline under WTO agreements. As a response, the Japanese Government has allocated supplementary budget for securing rare earth supplies and filed a complaint against China at WTO. These developments clearly reflect the liberal-pluralist, consensual and pragmatic regulatory style of Japan. Furthermore, Japan's preference for active style can be identified in its radical and innovative policies targeting new sources of rare earths, through strategic utilisation of ODA, long term supply agreements with rare earth producing countries, overseas resource development and domestic seabed exploration. These were facilitated by well-functioning institutions and public-private partnerships. In the meantime, supply diversification has become one of the main pillars of Japan's comprehensive Strategy for Ensuring Stable Supplies of Rare Metals. Another prominent pillar of the Japanese strategy is recycling. Similar to the European case, this resulted from Japan's long history of legislation on reducing waste and promoting recycling. But as opposed to the European directives which tend to be more legalistic, Japanese recycling guidelines established in the early 1990s were promoting voluntary initiatives by businesses. This characteristic is in line with the findings by Kagan (2000) that Japan has a strong preference for more informal and less legalistic regulation, which tends to be implemented through informal administrative guidance and voluntary plans by companies. Additionally, its more recent legislation focusing on collection and recycling of home appliances, along with the active role of the State providing financial assistance for developing recycling processes and technologies, contributed to establishing urban mining in Japan. Similarly, the basic and applied research initiatives have emerged from the long history of rare earth permanent magnet research and production in Japan. Analogous with the US experience, Japan's active style of policy making, in terms of coordination and financing, has been the main driver behind establishing extensive R\&D programs and industry-universitygovernment linkages collaborating on lowering the usage of rare earths in permanent magnets. Finally, the current policies targeting stockpiling of "rare metals" are rooted in Japan's historical experience with managing import dependence. The economic warfare in the early 1940s motivated the establishment of stockpiles in Japan and also set stability of supply of imported resources at the centre of its energy policy.

Last but not least, the weakly established policies on critical minerals in Australia can be largely explained by the fact that rather than being a consumer, Australia is an exporter of minerals. In line with this, the downstream side of 
the supply chain remained underdeveloped, what explains the complete absence of policies on diversification of foreign supply, stockpiling, recycling and R\&D in Australia. Yet, Australia has a large potential for rare earth mining, thus most of its mineral related strategies focus on the upstream part of the supply chain, namely on mining and production. In fact, various policies are devised to increase the international competitiveness and the sustainability of the resource sector, both in terms of financial and non-financial incentives, by establishing Industry Growth Centers to foster innovation, and through bilateral mineral consultations with main trading partners. What is more, similar to China, also Australia has established some resource protectionist policies. These reflect concerns of the wider public about losing the grip over country's resources. Overall, the stability of the mining sector is reflected in the comprehensive and active policy style of the Government, which is at the same time pragmatic, in that it provides information on sustainable mining practices in an informal fashion. Also, unlike in Europe, the US and Japan where mineral policy making is decentralised, in Australia this is concentrated in the hands of the Department of Industry and Science. One can conclude that the Australian style of policy making is corporatist, where industrial associations and the government have a rather balanced relationship. This is largely in line with the findings by O'Neill (2000) who concludes that hazardous waste trading policies are characterised by high levels of government control in Australia. Similarly, her findings on the open system of regulation, accommodating the involvement by electorate and environmental groups, are also reflected in the case of mineral policies. Yet, as illustrated by the example of the large opposition against the mining taxation overhaul, which was supposed to redistribute the proceeds from super profit tax to minimise the gap within Australia's two speed economy, the involvement of industry in policy making can also fundamentally alter the policy design. In fact, due to the large controversy among the explorer companies, the original tax proposal was replaced by a new tax which was designed based on the compromise between the industrial lobby and the Government, and was later completely repealed further to the federal opposition. Such findings are also in line with the results of previous empirical literature on Australia's environmental regulation.

\subsection{Conclusions}

This chapter has attempted to map out how the issue of mineral criticality, in particular that of rare earths, has been taken up within various world regions overtime. Due to their special properties of ferromagnetism, superconductivity 
and luminescence, rare earths are key technology components in many high-tech and low-carbon technologies. Yet at the same time their supply is adversely affected by small and concentrated markets and by increased resource protection by producing countries. Within the framework of comparative political economy analysis, the chapter seeks to explain why different world regions adopted different strategies to the common problem of securing stable of rare earth supply. The main conclusion of this chapter is that despite their similar objectives, the foci of country strategies differ. This is caused by the policy making being a path dependent process influenced by countries' national interests and resource abundance, by their historical experience in dealing with supply risk, but also by their respective regulatory styles and the influence of transnational organisations on national policy making. Clearly, resource abundant countries are more prone to devise policies with a strong focus on development of the domestic mineral sectors and on resource protection, than are resource-poor countries. The extent to which they do so depends on whether they are consumers of these resources, such as China, or only exporters, such as Australia. Yet, the Chinese strongly established industrial and mineral policies with long term targets for rare earth industry development are also rooted in its tatist, activist and comprehensive style of regulation. In contrast, the European mineral policies are rather weak, what results from the regulatory styles of European countries having had different development trajectories. Yet, the recent European Raw Material Initiative evolved from the consensual style of European policy making, facilitating the multi-stakeholder involvement and guidance, what has been missing in China's mineral policy making. Instead, the strength of the European policy on resource diplomacy and recycling are rooted in the European path dependence liaising with developing countries to ensure stable supply of resources, as well as in its long tradition of waste management, respectively. The more hands-on approach by Japan evolved from its active, liberal-pluralist, consensual and pragmatic regulatory style, as well as from its national interests in maintaining its international competitiveness in automotive and electronic industries. In this respect, Japan successfully established extensive R\&D programs for lowering rare earth contents in permanent magnets. Concerning recycling, while both European and Japanese rare earth recycling policies emerged from their respective historical tradition for waste management, the activist and informal administrative guidance by the Japanese Government seemed to have resulted in better established policies on urban mining, compared to those which emerged under the legalist reactive European regulatory approach. Finally, in the United States the prominence of R\&D programs lies within its long tradition of national laboratories engaging in research on different aspects of metals and within 
its activist regulatory style. In contrast to China, the American policy making is characterised by highly formalised inter-agency collaboration as well as by participation of the general public. Yet, its adversarial and fragmented policy style was also one of the main drivers behind the disruption of the American rare earth industry in the late 1990s.

To conclude with, the regulatory styles to critical mineral policy making discovered in this chapter broadly correspond with those identified for environmental regulation within earlier empirical literature. Another interesting finding of this chapter is that both Japan and China have been able to build up strong policies, whilst having diametrically opposed regulatory styles. This points to the fact that policy styles alone do not explain the differences in policy making. Events (rooted in economic and political circumstances) as well as persistent traditions of policy making and implementation captured in the notion of policy style, were all found to play an important role in the development of countries' mineral strategies to secure a stable supply of rare earths. In fact, policy choices are heavily shaped by the cyclical mining industries, as well as by the path dependent processes embedded in countries' national interests, resource endowment and their historical experience in tackling supply risk. These should therefore not be disregarded in comparative political analysis of regulation. Moreover, because regulatory styles are rooted in individual countries' legal systems, openness of administrative and political systems and role of consultation and interest mediation, it is not possible to conclude on a one-size-fits-all critical mineral strategy. Nonetheless, based on the above discussion it is possible to generalise that countries with active, comprehensive and radical policy styles tend to devise stronger strategies than countries with preference for reactive, fragmented and less radical solutions. 


\section{Bibliography}

Achzet, B. and Helbig, C. (2013). How to evaluate raw material supply risks - An overview. Resources Policy, 38(4):435-447.

Adachi, G.-y., Imanaka, N., and Tamura, S. (2010). Research trends in rare earths: A preliminary analysis. Journal of Rare Earths, 28(6):843-846.

Advisory Committee on Energy and Natural Resources (2009). Strategy to secure rare metals (Draft). Technical report, Ministry of Economy, Trade and Industry. Available in Japanese only from http://www.meti.go.jp/committee/materials2/downloadfiles/g90603a07j.pdf.

Alonso, E., Sherman, A., Wallington, T., Everson, M., Field, F., Roth, R., and Kirchain, R. (2012). Evaluating rare earth element availability: A case with revolutionary demand from clean technologies. Environmental Science \& Technology, 46(6):3406-3414.

Ames Laboratory (2015). About Ames Lab. Available from https://www.ameslab.gov/about. Accessed: 07-07-2015.

Amodei, M. (2015). H.R. 1937: National Strategic and Critical Minerals Production Act of 2015. Available from https://www.govtrack.us/congress/bills/114/hr1937. Accessed: 09-09-2015.

ANSTO (2015). Rare earth processing. Available from http://www.ansto.gov.au/ BusinessServices/ANSTOMinerals/Capabilities/RareEarthProcessing/. Accessed: 26-082015.

Argy, F., Borland, J., Cobb-Clark, D., Coelli, T., Denniss, R., Fels, A., Freebairn, J., Grafton, Q., Gruen, N., Guest, R., Hamilton, C., Keating, M., Langmore, J., Mangan, J., Menezes, F., O'Donnell, C., Pannell, D., Quiggin, J., Rao, P., Rolfe, J., Smith, B., and Throsby, D. (2010). Economists statement. Available from http://www.scribd.com/doc/31959942/EconomistsStatement. Accessed: 07-07-2015.

Australian Associated Press (2012). Mining tax faces one more hurdle. Available from http://www.brisbanetimes.com.au//breaking-news-national/mining-tax-faces-onemore-hurdle-20120206-1r1r3.html. Accessed: 26-08-2015.

Australian Government (2010). Stronger, fairer, simpler - A tax plan for our future. Technical report, Australian Government. Available from http://www.taxwatch.org.au/ssl/CMS/files_ cms/Glossy\%20B5_final.pdf.

Australian Government (2014). Industry Innovation and Competitiveness Agenda An action plan for a stronger australia. Technical report, Australian Government. Available from http://www.industry.gov.au/industry/Documents/Industry-Innovation-andCompetitiveness-Agenda.pdf.

Australian Taxation Office (2014). Minerals resource rent tax (MRRT). Available from https: //www.ato.gov.au/Business/Minerals-resource-rent-tax/. Accessed: 09-09-2015.

Australian Taxation Office (2015). Exploration development incentive. Available from https://www.ato.gov.au/General/New-legislation/In-detail/Direct-taxes/Incometax-for-businesses/Exploration-Development-Incentive/. Accessed: 09-09-2015. 
Baotou National Rare Earth Hi-Tech Industrial Development Zone (2015). Rare earth: An introduction. Available from http://www.rev.cn/en/int.htm. Accessed: 05-07-2015.

Barnicoat, A. (2013). Australia's critical commodities: Uncovering the potential. Presented during the Annual Research Workshop 2013. Available from http://www.industry.gov.au/Officeof-the-Chief-Economist/Publications/Documents/presentations/australias-criticalcommodities.pdf.

Bauer, D., Diamond, D., Li, J., McKittrick, M., Sandalow, D., Telleen, P., and Wanner, B. (2011). US Department of Energy Critical Materials Strategy. Technical report, U.S. Department of Energy. Available from http://energy.gov/sites/prod/files/DOE_CMS2011_FINAL_Full.pdf.

Bauer, D., Diamond, D., Li, J., Sandalow, D., Telleen, P., and Wanner, B. (2010). US Department of Energy Critical Materials Strategy. Technical report, U.S. Department of Energy. Available from http://energy.gov/sites/prod/files/edg/news/documents/criticalmaterialsstrategy.pdf.

Berry, C. (2015). China, minor metals, and supply chains over the next five years. Available from http://www.discoveryinvesting.com/blog/2015/6/24/china-minormetals-and-supply-chains-over-the-next-five-years. Accessed: 09-09-2015.

Bradsher, K. (2010). Amid tension, China blocks vital exports to Japan. Available from http: //www.nytimes.com/2010/09/23/business/global/23rare.html?pagewanted=all\&_r=1\&. Accessed: 16-11-2013.

Bradsher, K. (2011). Taking a risk for rare earths. Available from http://www.nytimes.com/ 2011/03/09/business/energy-environment/09rare.html?pagewanted=2\&_r=0. Accessed: 2608-2015.

BRIRE (2015). Baotou Research Institute of Rare Earths - About us. Available from http: //www.brire.com/english/english.htm. Accessed: 04-07-2015.

Bromby, R. (2015a). China's rare earth situation: Rampant illegal production, inadequate quotas, imperfect tax system (but great market expansion!). Available from http://investorintel.com/cleantech-intel/chinas-rare-earth-record-rampant-illegalproduction-inadequate-quotas-imperfect-tax-system-but-great-market-expansion/. Accessed: 20-08-2015.

Bromby, R. (2015b). Critical metals: The West is sleepwalking to its economic decline. Available from http://investorintel.com/technology-metals-intel/critical-metals-the-west-issleepwalking-to-its-economic-decline/. Accessed: 26-08-2015.

CAS (2015). CAS Key Laboratory of Rare Earth Chemistry and Physics. Available from http: //english.ciac.cas.cn/rh/rd/200907/t20090710_22709.html. Accessed: 04-07-2015.

Chinese Society of Rare Earths (2015). Introduction of the Chinese Society of Rare Earths (CSRE). Available from http://www.cs-re.org.cn/rareearth/english/aboutcsre/. Accessed: 04-07-2015.

Chovanec, P. (2010). The politics of rare earth. Available from http://www.forbes.com/sites/ china/2010/10/04/the-politics-of-rare-earth/. Accessed: 09-09-2015. 
CNN Wire Staff (2012). Obama announces WTO case against China over rare earths. Available from http://edition.cnn.com/2012/03/13/world/asia/china-rare-earths-case/. Accessed: 0504-2015.

Congressional Budget Office (1983). Strategic and critical nonfuel minerals: Problems and policy alternatives. Technical report, Congress of the United States. Available from https://www. cbo.gov/sites/default/files/doc15-entire.pdf.

Council of the European Union (2007). Competitiveness (Internal Market, Industry and Research). Press Release 9671/07 (Presse 108), Council of the European Union. Available from https://www.consilium.europa.eu/uedocs/cms_data/docs/pressdata/en/intm/94184.pdf.

Council on International Economic Policy (1974). Critical imported commodities. Available from http://www.nixonlibrary.gov/virtuallibrary/documents/nationalsecuritystudymemoranda. php. Accessed: 06-07-2015.

CR3 (2015). Center for Resource Recovery and Recycling - About. Available from http://wp. wpi.edu/cr3/about/. Accessed: 30-07-2015.

CRM_InnoNet (2015). CRM_InnoNet - Substitution of critical raw materials. Available from http://www.criticalrawmaterials.eu/project-summary/. Accessed: 30-07-2015.

CSIRO (2013). Program 1: National Research Flagships. Available from http://www. csiro.au/en/About/Reports/Annual-reports/13-14-annual-report/Part2/Performanceportfolio/Flagships. Accessed: 09-09-2015.

Davis, M. (2011). A snip at $\$ 22 \mathrm{~m}$ to get rid of PM. Available from http://www.smh.com.au/ business/a-snip-at-22m-to-get-rid-of-pm-20110201-1acgj.html. Accessed: 26-08-2015.

Deep Ocean Resources Development (2015). About DORD. Available from http://www.dord. co.jp/english/corporate/index.html. Accessed: 22-08-2015.

DEFRA (2012). A review of national resource strategies and research. Technical report, United Kingdom Government. Available from https://www.gov.uk/government/uploads/system/ uploads/attachment_data/file/69526/pb13722-national-resource-strategies-review.pdf.

Department of Industry and Science (2011). Bilateral minerals and energy cooperation with Japan. Available from http://www.industry.gov.au/resource/Enhancing/bmec/Pages/ bmecJapan.aspx. Accessed: 27-08-2015.

Department of Industry and Science (2014). Industry Growth Centres Initiative. Technical report, Australian Government. Available from http://www.business.gov.au/advice-andsupport/IndustryGrowthCentres/Documents/IndustryGrowthCentresInitiative.pdf.

Department of Industry and Science (2015a). 2015 Energy White Paper. Technical report, Australian Government. Available from http://ewp.industry.gov.au/sites/prod.ewp/files/ EnergyWhitePaper.pdf.

Department of Industry and Science (2015b). Extractive Industries Transparency Initiative - Multi-stakeholder group report to the Government. Technical report, Australian Government. Available from http://www.industry.gov.au/resource/Programs/ ExtractiveIndustriesTransparencyInitiative/Documents/EITI_MSG_ReportToGovt.pdf. 
Department of Industry and Science (2015c). Leading Practice Sustainable Development Program for the Mining Industry. Available from http://www.industry.gov.au/resource/Programs/ LPSD/Pages/default.aspx. Accessed: 26-08-2015.

Department of Industry and Science (2015d). National Mine Safety Framework. Available from http://www.industry.gov.au/resource/Mining/NationalMineSafetyFramework/Pages/ default.aspx. Accessed: 26-08-2015.

Department of Industry and Science (2015e). Resources. Available from http://www.industry. gov.au/resource/Pages/default.aspx. Accessed: 26-08-2015.

Department of Industry and Science (2015f). Working in Partnership. Available from http://www.industry.gov.au/resource/Programs/WorkinginPartnershipinitiative/ Pages/default.aspx. Accessed: 26-08-2015.

Duchesne, L. (2015). MSX technology to break the cost barrier of rare earth industry. Available from http://investorintel.com/technology-metals-intel/membrane-assisted-solventextraction-technology-to-break-the-cost-barrier-of-rare-earth-industry/. Accessed: 21-082015 .

Edwards, J. (2015). R\&D Tax Incentive - R\&D in the mining industry. Available from http://www.kpmg.com/au/en/issuesandinsights/articlespublications/tax-insights/ pages/r-d-tax-incentive-mining-industry-24-june-2013.aspx. Accessed: 09-09-2015.

ERAMIN (2015). ERA-MIN Objectives. Available from http://www.era-min-eu.org/about/ objectives. Accessed: 09-09-2015.

ERAWATCH (2015a). National Basic Research Development Programme (973 Programme). Available from http://erawatch.jrc.ec.europa.eu/erawatch/opencms/information/ country_pages/cn/supportmeasure/support_mig_0004. Accessed: 04-07-2015.

ERAWATCH (2015b). National High Technology R\&D Programme (863 Programme). Available from http://erawatch.jrc.ec.europa.eu/erawatch/opencms/information/country_pages/ cn/supportmeasure/support_mig_0009. Accessed: 04-07-2015.

Erdmann, L. and Graedel, T. E. (2011). Criticality of non-fuel minerals: A review of major approaches and analyses. Environmental Science \& Technology, 45(18):7620-7630.

EREAN (2015). European rare earth (magnet) recycling network. Available from http://erean. eu/project.php. Accessed: 04-07-2015.

ERECON (2015). Strengthening the European rare earths supply-chain: Challenges and policy options. Technical report, European Rare Earths Competency Network. Available from http://ec.europa.eu/DocsRoom/documents/10882/attachments/1/translations/en/ renditions/native.

ETP SMR (2015). European Technology Platform on Sustainable Mineral Resources - About us. Available from http://www.etpsmr.org/?page_id=6. Accessed: 30-07-2015.

EURARE (2015). About EURARE. Available from http://www.eurare.eu/about.html. Accessed: 30-07-2015. 
EUROMINES (2016). Update on national implementation of RMI. Available from http://www.euromines.org/what-we-do/raw-materials-initiative/update-nationalimplementation-rmi. Accessed: 30-03-2016.

European Commission (1975). The Community's supplies of raw materials. Communication from the Commission to the Council COM(75) 50 final, European Commission. Available from http://aei.pitt.edu/1481/1/raw_materials_COM_75_50.pdf.

European Commission (2007a). The Africa-EU Strategic Partnership - A Joint Africa-EU Strategy. Technical report, European Commission. Available from http://www.africa-eupartnership.org/sites/default/files/documents/eas2007_joint_strategy_en.pdf.

European Commission (2007b). Contributing to an integrated approach on competitiveness, energy and the environment policies. Fourth Report of the High Level Group on Competitiveness, Energy and the Environment, European Commission. Available from http://ec.europa.eu/enterprise/policies/sustainable-business/files/environment/ hlg/june_07/fourth_report_11_06_2007_en.pdf.

European Commission (2007c). Public consultation on Commission Raw Materials Initiative Background paper. Technical report, European Commission. Available from http://ec.europa. eu/enterprise/newsroom/cf/_getdocument.cfm?doc_id=633.

European Commission (2007d). VP Verheugen: Securing raw material supply for EU industries. Available from http://europa.eu/rapid/press-release_IP-07-767_en.htm?locale=en. Accessed: 30-07-2015.

European Commission (2008). The Raw Materials Initiative - Meeting our critical needs for growth and jobs in Europe. Available from http://eur-lex.europa.eu/LexUriServ/LexUriServ. do?uri=COM:2008:0699:FIN:en:PDF. Accessed: 09-11-2013.

European Commission (2010a). Being wise with waste: The EU's approach to waste management. Technical report, European Commission. Available from http://ec.europa.eu/environment/ waste/pdf/WASTE\%20BROCHURE.pdf.

European Commission (2010b). Critical raw materials for the EU. Report of the Ad-hoc Working Group on Defining Critical Raw Materials, European Commission. Available from http://ec. europa.eu/enterprise/policies/raw-materials/files/docs/report-b_en.pdf.

European Commission (2010c). Thematic strategy on the prevention and recycling of waste. Commission Staff Working Document Accompanying the Communication from the Commission to the European Parliament, the Council, the European Economic and Social Committee and the Committee of the Regions $\operatorname{COM}(2010)$ yyy final, European Commission. Available from http://ec.europa.eu/environment/waste/pdf/Commission\%20Working\%20Doc.pdf.

European Commission (2011). Tackling the challenges in commodity markets and on raw materials. Communication from the Commission to the European Parliament, the Council, the European Economic and Social Committee and the Committee of the Regions COM(2011) 25 final, European Commission. Available from http://eur-lex.europa.eu/LexUriServ/LexUriServ. do?uri=COM:2011:0025:FIN:en:PDF.

European Commission (2012). EU challenges China's rare earth export restrictions. Available from http://europa.eu/rapid/press-release_IP-12-239_en.htm. Accessed: 09-09-2015. 
European Commission (2013). Third EU-Japan-U.S. Trilateral Conference on Critical Materials - Towards new models in efficient management of critical materials. Available from http: //ec.europa.eu/research/industrial_technologies/event-13_en.html. Accessed: 12-11-2013.

European Commission (2014). Report on critical raw materials for the EU. Report of the Ad-hoc Working Group on Defining Critical Raw Materials, European Commission. Available from http://www.amg-nv.com/files/Report-on-Critical-Raw-Materials-for-the-EU-2014.pdf.

European Commission (2015a). ACP - The Cotonou Agreement. Available from https://ec.europa.eu/europeaid/regions/african-caribbean-and-pacific-acp-region/cotonouagreement_en. Accessed: 30-07-2015.

European Commission (2015b). Ecodesign. Available from http://ec.europa.eu/growth/ industry/sustainability/ecodesign/index_en.htm. Accessed: 07-07-2015.

European Commission (2015c). The European Innovation Partnership (EIP) on Raw Materials. Available from http://ec.europa.eu/eip/raw-materials/en. Accessed: 30-07-2015.

European Commission (2015d). European Rare Earths Competency Network. Available from http://ec.europa.eu/enterprise/policies/raw-materials/erecon/faqs/index_en.htm. Accessed: 30-07-2015.

European Commission (2015e). Minerals Intelligence Network for Europe. Available from http: //www.minerals4eu.eu/index.php/about. Accessed: 07-07-2015.

European Institute of Innovation and Technology (2015). EIT Raw Materials. Available from http://eitrawmaterials.eu/strategy.php. Accessed: 30-07-2015.

Evans-Pritchard, A. (2013). Japan breaks China's stranglehold on rare metals with sea-mud bonanza. Available from http://www.telegraph.co.uk/finance/comment/ ambroseevans_pritchard/9951299/Japan-breaks-Chinas-stranglehold-on-rare-metals-withsea-mud-bonanza.html. Accessed: 17-08-2015.

Extractive Industries Transparency Initiative (2015). What is the EITI? Available from http: //eiti.org/eiti. Accessed: 30-07-2015.

Federation of European Mineral Programs (2015). Federation of European Mineral Programs Home. Available from http://www.femp.org/. Accessed: 30-07-2015.

Feick, J. (1992). Comparing comparative policy studies - A path towards integration? Journal of Public Policy, 12(03):257-285.

Geoscience Australia (2010). Australia's identified mineral resources. Technical report, Geoscience Australia. Available from http://www.ga.gov.au/corporate_data/71584/71584.pdf.

Geoscience Australia (2015). Geoscience Australia - Our partners. Available from http://www. ga.gov.au/about/who-we-are/partners. Accessed: 25-08-2015.

Graedel, T. E., Barr, R., Chandler, C., Chase, T., Choi, J., Christoffersen, L., Friedlander, E., Henly, C., Jun, C., Nassar, N. T., et al. (2012). Methodology of metal criticality determination. Environmental Science \& Technology, 46(2):1063-1070. 
GRINM (2015). General Research Institute for Nonferrous Metals - Brief introduction. Available from http://www.grinm.com/Page/1112/language/zh-CN/default.aspx. Accessed: 0407-2015.

Gschneidner Jr, K. (2010). The rare earth crisis - The lack of an intellectual infrastructure. Available from https://www.ameslab.gov/files/RE_Crisis_Intell_Infrastruc_12.9.10.pdf. Accessed: 22-03-2014.

Hanauer, L. and Morris, L. J. (2014). Chinese engagement in Africa: Drivers, reactions, and implications for U.S. policy. Technical report, Rand National Security Research Division. Available from http://www.rand.org/content/dam/rand/pubs/research_reports/ RR500/RR521/RAND_RR521.pdf.

Haxel, G. B., Hedrick, J. B., and Orris, G. J. (2002). Rare earth elements - Critical resources for high technology. Available from http://pubs.usgs.gov/fs/2002/fs087-02/fs087-02.pdf. Accessed: 30-03-2014.

Hilpert, H. G. and Mildner, S.-A. (2013). Fragmentation or cooperation in global resource governance? A comparative analysis of the raw material strategies of the G20. SWP Research Paper RP 1, Stiftung Wissenschaft und Politik, and Bundesanstalt für Geowissenschaften und Rohstoffe.

Hitachi (2015). NEOMAX neodymium rare earth permanent magnet. Available from http: //www.hitachi.com/environment/showcase/solution/materials/neomax.html. Accessed: 1708-2015.

Hitachi Ltd (2010). Hitachi develops recycling technologies for rare earth metals. Available from http://www.hitachi.com/New/cnews/101206.html. Accessed: 01-03-2014.

Hitachi Ltd (2012). Highly efficient industrial 11kW permanent magnet synchronous motor without rare-earth metals. Available from http://www.hitachi.com/New/cnews/120411.html. Accessed: 13-03-2014.

Hitachi Metals (2013). Sintered Nd-Fe-B magnets. Available from http://www.hitachi-metals. co.jp/pdf/pi20131202ec.pdf. Accessed: 22-08-2015.

Hoatson, D. M., Jaireth, S., and Miezitis, Y. (2011). The major rare-earth-element deposits of Australia: Geological setting, exploration, and resources. Technical report, Geoscience Australia. Available from http://www.ga.gov.au/corporate_data/71820/Complete_Report.pdf.

Honda Motor (2013). Honda established world's first process to reuse rare earth metals extracted from nickel-metal hydride batteries for hybrid vehicles. Available from http://www. hondanews.info/news/en/corporate/c130303eng. Accessed: 04-03-2014.

Hosaka, T. A. (2010). Nations wary of dependence on China's rare earths. Available from http://www.washingtontimes.com/news/2010/oct/4/nations-wary-of-dependenceon-chinas-rare-earths/?page=all. Accessed: 10-08-2015.

Hui, L. (2015). Made in China 2025: How Beijing is revamping its manufacturing sector. Available from http://www.scmp.com/tech/innovation/article/1818381/made-china-2025-how-beijingrevamping-its-manufacturing-sector. Accessed: 09-09-2015. 
Humphries, M. (2013). Rare earth elements: The global supply chain. Technical report, Congressional Research Service. Available from https://fas.org/sgp/crs/natsec/R41347.pdf.

Humphries, M. (2015). China's mineral industry and U.S. access to strategic and critical minerals: Issues for Congress. Technical report, Congressional Research Service. Available from http: //www.fas.org/sgp/crs/row/R43864.pdf.

Humprheys, D. (1995). Whatever happened to security of supply? Minerals policy in the postCold War world. Resources Policy, 21(2):91-97.

Hung Lo, C. W., To Yip, P. K., and Cheung, K. C. (2000). The regulatory style of environmental governance in China: The case of EIA regulation in Shanghai. Public Administration and Development, 20(4):305-318.

Hurst, C. (2010). China's rare earth elements industry: What can the West learn? Technical report, Institute for the Analysis of Global Security. Available from http://fmso.leavenworth. army.mil/documents/rareearth.pdf.

Information Office of the State Council (2003). China's policy on mineral resources. Available from http://news.xinhuanet.com/zhengfu/2003-12/23/content_1244900.htm. Accessed: 3003-2016.

Information Office of the State Council (2012). Situation and policies of China's rare earth industry. Available from http://english.gov.cn/archive/white_paper/2014/08/23/content_ 281474983043156.htm. Accessed: 25-11-2013.

International Raw Materials Observatory (2016). Contextual analysis of the reference countries. Available from http://intraw.eu/publications/. Accessed: 30-03-2016.

InvestorIntel (2015). China is looking everywhere for rare earths outside of China? Available from http://investorintel.com/technology-metals-intel/china-is-looking-everywhere-forrare-earths-outside-of-china/. Accessed: 30-07-2015.

Japan for Sustainability (2011). Japanese agency and university co-develop rare earth-free motor for HEVs. Available from http://www.japanfs.org/en/news/archives/news_id030546.html. Accessed: 09-09-2015.

Japan Metal Bulletin (2010). METI launches new metal resource policy. Available from http: //www.japanmetalbulletin.com/?p=5575. Accessed: 17-08-2015.

Japan Metal Bulletin (2012). METI to support rare earth, rare metal saving projects. Available from http://www.japanmetalbulletin.com/?p=19728. Accessed: 17-08-2015.

JOGMEC (2015a). Japan Oil, Gas and Metals National Corporation - About Us - History. Available from http://www.jogmec.go.jp/english/about/about003.html. Accessed: 17-08-2015.

JOGMEC (2015b). Metal recycling project from Ni-H batteries for hybrid electric vehicles and slag. Available from http://www.jogmec.go.jp/english/metal/technology_016.html. Accessed: 17-08-2015.

JOGMEC (2015c). Rare metals stockpiling program. Available from http://www.jogmec.go.jp/ english/stockpiling/stockpiling_015.html. Accessed: 17-08-2015. 
Kagan, R. (2000). Introduction: Comparing national styles of regulation in Japan and the United States. Law \& Policy, 22(3-4):225-244.

Kaneko, K. (2012). Japan aims for half of rare earth supplies from outside China. Available from http://www.reuters.com/article/2012/11/12/japan-india-idUSL3E8MC1QL20121112. Accessed: $17-08-2015$.

Katholieke Universiteit Leuven (2015). The Rare3 Platform. Available from http://www. kuleuven.rare3.eu/about/. Accessed: 04-07-2015.

Kawamoto, H. (2008). Japan's policies to be adopted on rare metal resources. Quarterly Review, $27: 57-76$.

Kimberly Process Certification Scheme (2015). About. Available from http://www. kimberleyprocess.com/en/about. Accessed: 30-07-2015.

Kosich, D. (2013). Patent fight could impact half of global rare earth metal supply. Available from http://www.mineweb.com/mineweb/content/en/mineweb-industrial-metalsminerals-old?oid=200793\&sn=Detail. Accessed: 28-03-2014.

Lifton, J. (2015). Investing in rare earth supply security, now or never? Available from http://investorintel.com/technology-metals-intel/investing-in-rare-earth-supplysecurity-now-or-never/. Accessed: 09-09-2015.

Löfstedt, R. E., Vogel, D., Renn, O., Slater, D., and Rogers, M. D. (2001). The changing character of regulation: A comparison of Europe and the United States. Risk Analysis, 21(3):399-416.

Lynas Corporation (2010). What are rare earths? Available from http://www.lynascorp.com/ Pages/What-Are-Rare-Earths.aspx. Accessed: 06-11-2013.

Lynas Corporation (2015). Foundations for the future. Available from https://www.lynascorp. com/Pages/about-lynas.aspx. Accessed: 26-08-2015.

Macalister, T. (2009). Rio's deal with Chinalco collapses. Available from http://www. theguardian.com/business/2009/jun/04/rio-tinto-chinalco-investment. Accessed: 26-08-2015.

Mancheri, N., Sundaresan, L., and Chandrashekar, S. (2013). Dominating the world: China and the rare earth industry. Technical report, National Institute of Advanced Studies. Available from http://threeconsulting.com/pdfs/China-rare-earth-strategyin-wHighlights-.pdf.

MarketWatch (2010). Japan considers moves to secure rare earths. Available from http://www. marketwatch.com/story/japan-considers-moves-to-secure-rare-earths-2010-10-01. Accessed: 10-08-2015.

Mason, E. S. (1952). An american view of raw materials problems: The report of the President's Materials Policy Commission. The Journal of Industrial Economics, 1(1):1-20.

Mercer, P. (2011). Can Australia's new mining tax achieve its objective? Available from http://www.bbc.com/news/business-15850019. Accessed: 26-08-2015.

METI (2004). Toward a Sustainable Asia Based on the 3Rs. Technical report, Working Group on Enhancing International Recycling, Waste Prevention and Recycling Sub-committee, Industrial Structure Council. Available from http://www.meti.go.jp/policy/recycle/main/english/ council/reports/report_sutainableasia_en.pdf. 
METI (2006). New National Energy Strategy. Technical report, Ministry of Economy, Trade and Industry. Available from http://www.meti.go.jp/english/information/downloadfiles/ PressRelease/NewEnergyStrategy.pdf.

METI (2008). Guidelines for Securing Natural Resources (provisional translation). Technical report, Ministry of Economy, Trade and Industry. Available from http://www.meti.go.jp/ english/newtopics/data/pdf/080328Guidelines.pdf.

METI (2010a). 100 Actions to Launch Japan's New Growth Strategy. Technical report, Ministry of Economy, Trade and Industry. Available from http://www.meti.go.jp/english/aboutmeti/ policy/2011policies.pdf.

METI (2010b). 3R Policies (Reduce Reuse Recycle). Available from http://www.meti.go.jp/ policy/recycle/main/english/3r_policy/overview.html. Accessed: 17-08-2015.

METI (2014). Strategic Energy Plan. Technical report, Ministry of Economy, Trade and Industry. Available from http://www.enecho.meti.go.jp/en/category/others/basic_plan/pdf/ 4th_strategic_energy_plan.pdf.

Milward, A. S. (1977). War, Economy, and Society, 1939-1945, volume 5. Allen Lane.

Minerals Council of Australia (2008). Henry Tax Review. Technical report, Australian Government. Available from http://taxreview.treasury.gov.au/content/submissions/pre_14_ november_2008/Minerals_Council_Australia.pdf.

Minerals Council of Australia (2013). Submission to Treasury: Minerals Resource Rent Tax Repeal and Other Measures Bill 2013. Available from http://www.minerals.org.au/news/ submission_to_treasury_minerals_resource_rent_tax_repeal_and_other_measures. Accessed: 0909-2015.

Ministry of Employment and the Economy (2010). Finland's minerals strategy. Technical report, United Kingdom Government. Available from http://projects.gtk.fi/export/sites/projects/ minerals_strategy/documents/FinlandsMineralsStrategy_2.pdf.

Ministry of Enterprise Energy and Communications (2013). Sweden's minerals strategy - For sustainable use of Sweden's mineral resources that creates growth throughout the country. Technical report, Government Offices of Sweden. Available from http://www.government.se/contentassets/78bb6c6324bf43158d7c153ebf2a4611/swedensminerals-strategy.-for-sustainable-use-of-swedens-mineral-resources- that-creates-growththroughout-the-country-complete-version.

Mitsubishi Electric (2012). Newly developed automatic dismantling equipment removes and recovers rare earth magnets in just 30 seconds. Available from http://www.mitsubishielectric. com/company/environment/ecotopics/rareearth/how/index.html. Accessed: 17-08-2015.

MLR (2013). Land and Resources issued the notice on the 2013 annual total rare earth tungsten ore, antimony ore mining control targets. Available from http://www.mlr.gov.cn/zwgk/zytz/ 201309/t20130906_1267679.htm. Accessed: 24-11-2013.

MOF (2010). The supplementary budget for FY2010. Technical report, Ministry of Finance Japan. Available from http://www.mof.go.jp/english/budget/budget/fy2010/10sb01.pdf. 
MOFCOM (2012a). Catalogue for the guidance of foreign investment industries (amended in 2011). Available from http://english.mofcom.gov.cn/article/policyrelease/domesticpolicy/ 201203/20120308027837.shtml. Accessed: 24-11-2013.

MOFCOM (2012b). China "building up rare earth reserves". Available from http://english. mofcom.gov.cn/article/counselorsreport/asiareport/201207/20120708233202.shtml. Accessed: 24-11-2013.

MOFCOM (2012c). China launches rare earth trading platform. Available from http://english. mofcom.gov.cn/article/counselorsreport/asiareport/201208/20120808275052.shtml. Accessed: 24-11-2013.

MOFCOM (2012d). China to continue rare earth protection: Official. Available from http://english.mofcom.gov.cn/article/counselorsreport/europereport/201207/ 20120708251407.shtml. Accessed: 24-11-2013.

MOFCOM (2012e). China to tighten standard for rare-earth mining, cut number of license. Available from http://english.mofcom.gov.cn/article/counselorsreport/asiareport/ 201207/20120708235128.shtml. Accessed: 24-11-2013.

MOFCOM (2012f). China's rare earths giant continues production halt. Available from http: //english.mofcom.gov.cn/article/newsrelease/counselorsoffice/westernasiaandafricareport/ 201212/20121208505487.shtml. Accessed: 24-11-2013.

MOFCOM (2012g). Ministry of Commerce notice no. 86 of 2012 on the 2013 rare earth export quota reporting conditions and reporting procedures of the announcement. Available from http://wms.mofcom.gov.cn/article/zt_gypck/ysjsh/201211/20121108458854.shtml. Accessed: 23-11-2013.

MOFCOM (2012h). System to price rare earths. Available from http://english.mofcom.gov. cn/article/newsrelease/counselorsoffice/westernasiaandafricareport/201208/20120808277446. shtml. Accessed: 24-11-2013.

MOFCOM (2014). Announcement no. 97 of 2014 announced the "2015 classification of goods export license management certification directory". Available from http://www.mofcom.gov. cn/article/b/e/201412/20141200854927.shtml. Accessed: 11-01-2015.

Molycorp Inc (2014). Annual report / Year in review: 2013. Technical report, Molycorp Inc. Available from http://www.molycorp.com/wp-content/uploads/Molycorp_AR2013_ WEB.pdf.

Molycorp Inc (2015a). Molycorp chosen to supply rare earths for use in high-efficiency Siemens wind turbine generators. Available from http://www.molycorp.com/molycorp-chosento-supply-rare-earths-for-use-in-high-efficiency-siemens-wind-turbine-generators/. Accessed: 07-07-2015.

Molycorp Inc (2015b). Molycorp Magnequench timeline. Available from http://www.molycorp. com/about-us/our-facilities/molycorp-magnequench/history/. Accessed: 05-07-2015.

Molycorp Inc (2015c). Molycorp Mountain Pass. Available from http://www.molycorp.com/ about-us/our-facilities/molycorp-mountain-pass/. Accessed: 05-07-2015. 
MOST (2015a). National Basic Research Program of China (973 Program). Available from http://www.973.gov.cn/English/Index.aspx. Accessed: 04-07-2015.

MOST (2015b). National High-tech R\&D Program (863 Program). Available from http://www. most.gov.cn/eng/programmes1/200610/t20061009_36225.htm. Accessed: 04-07-2015.

Murkowski, L. (2013). Critical Minerals Policy Act of 2013. Available from https://www. congress.gov/113/bills/s1600/BILLS-113s1600is.xml. Accessed: 06-07-2015.

NANOPYME (2015). Nanocrystalline permanent magnets based on hybrid metal-ferrites - Goals of the project. Available from http://nanopyme-project.eu/background.php?fNumSecc $=4$. Accessed: 09-09-2015.

National Commission of Supplies and Shortages (1976). The commodity shortages of 19731974 - Case studies. Technical report, Department of Defense. Available from http://babel. hathitrust.org/cgi/pt?id=mdp.39015035071110;view=1up;seq $=13$.

National Research Council (2008a). Managing Materials for a Twenty-First Century Military. National Academies Press.

National Research Council (2008b). Minerals, Critical Minerals, and the US Economy. National Academies Press.

NEDO (2012). The Second Trilateral EU-Japan-U.S. Conference on Critical Materials - Seminar on the strategic implications of global shortages in critical materials. Available from http: //www.nedo.go.jp/content/100483482.pdf. Accessed: 12-11-2013.

NIMS (2011). Research trends on rare earth and critical elements in Japan. Available from http://energy.gov/sites/prod/files/Session_A7_Hono_NIMS.pdf. Accessed: 13-03-2014.

NIMS (2015). Our history from NRIM and NIRIM to NIMS. Available from http://www.nims. go.jp/eng/nims/history.html. Accessed: 17-08-2015.

Nippon Keidanren (2011). Proposals for Japan's trade strategy. Available from http://www. keidanren.or.jp/en/policy/2011/030proposal.html. Accessed: 27-08-2015.

Nystrom, E. C. (2003). From neglected space to protected place: An administrative history of Mojave National Preserve. Available from http://www.nps.gov/history/history/online_books/ moja/adhi/adhi8a.htm. Accessed: 01-03-2014.

O'Neill, K. (2000). Waste Trading Among Rich Nations: Building a New Theory of Environmental Regulation. MIT Press Cambridge, MA.

Paxton, R. (2012). Kazakh nuclear firm and Japan's Sumitomo launch rare earth plant. Available from http://www.reuters.com/article/2012/11/02/rareearths-kazakhstanjapan-idUSL5E8M25UR20121102. Accessed: 17-08-2015.

Pierson, P. (2000). Increasing returns, path dependence, and the study of politics. The American Political Science Review, 94(02):251-267.

Productivity Commission (2013). Mineral and energy resource exploration. Productivity Commission Inquiry Report No. 65, Australian Government. Available from http://www.pc.gov. $\mathrm{au} /$ inquiries/completed/resource-exploration/report/resource-exploration.pdf. 
RARE (2012). Coalition letter in support of the "Law of the Sea Treaty". Available from http: //www.rareearthassociation.org/120613_Coalition_LOSTRatification_Kerry_Lugar.pdf. Accessed: 30-06-2015.

RELAB (2015). State Key Laboratory of Rare Earth Materials Chemistry and Applications General survey. Available from http://relab.pku.edu.cn/index-en.php/about. Accessed: 0407-2015.

Retriev Technologies (2014). Recycling technology - NiCad \& NiMH. Available from http: //www.retrievtech.com/recycling/nicad-and-nimh. Accessed: 04-03-2014.

Richardson, J., Gustafsson, G., and Jordan, G. (1982). The concept of policy style. In Richardson, J., editor, Policy Styles in Western Europe, pages 1-16. Allen \& Unwin.

Risk \& Policy Analysis (2012). Stockpiling of non-energy raw materials. Technical report, European Commission. Available from http://ec.europa.eu/enterprise/policies/raw-materials/ files/docs/stockpiling-report_en.pdf.

Robinson, A. L. (1987). Powerful new magnet material found. In Gschneidner, K. A. and Capellen, J., editors, Two Hundred Years of Rare Earths, pages 119-149. Rare-Earth Information Center, Iowa State University, Ames, Iowa, USA.

Robison, P. and Ratnam, G. (2010). Pentagon losing control of bombs to China's monopoly. Available from http://www.bloomberg.com/news/articles/2010-09-29/pentagonlosing-control-of-afghanistan-bombs-to-china-s-neodymium-monopoly. Accessed: 20-082015 .

Schearf, D. (2014). North Korea's rare earths could be game changer. Available from http:// www.voanews.com/content/north-korea-rare-earths-game-changer/1832018.html. Accessed: 21-05-2014.

Scott, J. (2009). China Non-Ferrous barred from taking control of Lynas (update3). Available from http://www.bloomberg.com/apps/news?pid=newsarchive\&sid=aqHyQn1kkeOo. Accessed: $26-08-2015$.

Shah, R. (2014). Japan to import rare earth from India - Nikkei. Available from http:// investorintel.com/technology-metals-press/japan-import-rare-earth-india-nikkei/. Accessed: 17-08-2015.

Shah, R. (2015). Molycorp, Inc. signs restructuring support agreement with key creditors; agreement covers more than $70 \%$ of $10 \%$ secured noteholders. Available from http://investorintel.com/technology-metals-news/molycorp-inc-signs-restructuring-supportagreement-with-key-creditors-agreement-covers-more-than-70-of-10-secured-noteholders/. Accessed: 30-07-2015.

Shen, H. (2014). China to close a total of 103,710 tons of rare earth (oxide) capacities. Available from http://investorintel.com/technology-metals-intel/china-orders-shutter100000-tons-rare-earth-capacities-year/. Accessed: 31-07-2015.

Shen, H. (2015a). China increasing pressure on illegal rare earth activities. Available from http://investorintel.com/technology-metals-intel/china-increasing-pressure-illegal-rareearth-activities/. Accessed: 31-07-2015. 
Shen, H. (2015b). China to levy new resource tax on rare earths May 1st. Available from http://investorintel.com/technology-metals-intel/china-to-levy-new-resource-taxon-rare-earths-on-may-1st/. Accessed: 31-07-2015.

Shen, H. (2015c). China's most buzzworthy exports for July - Dysprosium and terbium. Available from http://investorintel.com/technology-metals-intel/chinas-most-buzzworthy-exportsfor-july-dysprosium-and-terbium/. Accessed: 09-09-2015.

Shen, H. (2015d). China's new rare earth policies are all about control of pricing, supply and competitive R\&D. Available from http://investorintel.com/technology-metals-intel/chinasnew-rare-earth-policies-control-pricing-supply/. Accessed: 31-07-2015.

Shen, H. (2015e). A turning of Japan's heavy dependence on Chinese rare earths. Available from http://investorintel.com/technology-metals-intel/a-turning-of-japans-heavydependence-on-chinese-rare-earths/. Accessed: 17-08-2015.

Skirrow, R. G., Huston, D. L., Mernagh, T. P., Thorne, J. P., Dulfer, H., and Senior, A. (2013). Critical commodities for a high-tech world: Australia's potential to supply global demand. Technical report, Geoscience Australia. Available from http://www.ga.gov.au/ corporate_data/76526/76526.pdf.

Sojitz (2013). Rare earth development \& production in Australia \& Malaysia. Available from http://www.sojitz.com/en/special/project/post-9.php. Accessed: 17-08-2015.

Solvay (2012). Solvay launches its rare earth recycling activity in France. Available from http:// www.solvay.com/en/media/press_releases/20120927-coleopterre.html. Accessed: 05-07-2015.

Sta Maria, S. (2012). Australia says it again: No to Lynas waste. Available from http://www.freemalaysiatoday.com/category/nation/2012/02/21/australia-says-itagain-no-to-lynas-waste/. Accessed: 26-08-2015.

Standing Committee of the National People's Congress (2008). Circular Economy Promotion Law of the People's Republic of China. Available from http://www.lawinfochina.com/display. aspx?id=7025\&lib=law. Accessed: 06-10-2015.

State Council (2013). Circular Economy Development Strategies and Action Plan. Available from http://chinawaterrisk.org/resources/analysis-reviews/8-game-changing-policy-paths/. Accessed: 09-11-2015.

Stop Lynas (2015). Opposition in Malaysia. Available from http://stoplynas.org/opposition-inmalaysia/. Accessed: 26-08-2015.

Strategic Materials Advisory Council (2013). US lobby group warns against rare earth stockpile plan. Available from http://www.strategicmaterials.org/2013/03/28/us-lobby-group-warnsagainst-rare-earth-stockpile-plan/. Accessed: 30-06-2015.

Tanquintic-Misa, E. (2015). Japan gets access to Mongolia rare earths in FTA. Available from http://www.ibtimes.com.au/japan-gets-access-mongolia-rare-earths-fta-1420723. Accessed: 17-08-2015.

Tasman Metals (2010). Principal uses of rare elements. Available from http://www. tasmanmetals.com/s/PrincipalUses.asp. Accessed: 06-11-2013. 
Technology Metals Research (2010). What are technology metals? Available from http://www. techmetalsresearch.com/what-are-technology-metals/. Accessed: 09-11-2013.

Terashima, H. (2009). Ocean Governance and the Japanese Basic Act on Ocean Policy. Presented during The United Nations - Nippon Foundation Fellowship Programme Inaugural Asia - Pacific Alumni Meeting. Available from http://www.un.org/Depts/los/nippon/ unnff_programme_home/alumni/tokyo_alumni_presents_files/alum_tokyo_terashima.pdf.

The Australian Business Journal (2010). Is the RSPT the breaking point for Australian tax reform? Available from http://www.australianbusinessjournal.com.au/is-the-rspt-thebreaking-point-for-australian-tax-reform/. Accessed: 26-08-2015.

The Economist (2012). Australia's new mining tax - Laying 22 economists end to end. Available from http://www.brisbanetimes.com.au//breaking-news-national/mining-tax-faces-onemore-hurdle-20120206-1r1r3.html. Accessed: 26-08-2015.

The Economist (2013). China, Japan and America - Face-off. Available from http://www.economist.com/news/leaders/21590930-chinas-new-air-defence-zone-suggestsworrying-new-approach-region-face. Accessed: 17-08-2015.

The Sydney Morning Herald (2009). Concerns raised over China's 'rare earth' dominance. Available from http://www.smh.com.au/business/concerns-raised-over-chinas-rareearth-dominance-20090901-f6xw.html. Accessed: 26-08-2015.

Tiess, G. (2010). Minerals policy in Europe: Some recent developments. Resources Policy, 35(3):190-198.

Treadgold, T. (2015). The rare earth challenge. Available from http://www.csiro.au/en/ Research/MRF/Areas/Resourceful-magazine/Issue-07/Rare-earth-challenge. Accessed: 2608-2015.

Ucore Rare Metals (2013). Ucore comments on House Armed Services Committee dysprosium stockpile. Available from http://ucore.com/ucore-comments-on-house-armed-servicescommittee-dysprosium-stockpile-initiative. Accessed: 09-09-2015.

Umicore (2014). Umicore battery recycling. Available from http://www.batteryrecycling. umicore.com/UBR/. Accessed: 04-03-2014.

United States Public Laws (1980). National Materials and Minerals Policy, Research and Development Act of 1980. Text from http://legcounsel.house.gov/comps/nmmprd90.pdf. Accessed: 06-07-2015.

United States Public Laws (1984). Public Law 98-373: National Critical Materials Act of 1984. Text from http://uscode.house.gov/statutes/pl/98/373.pdf. Accessed: 06-07-2015.

United Steelworkers (2010). United Steelworkers' Section 301 Petition demonstrates China's green technology practices violate WTO rules. Available from http://www.usw.org/news/ pdfs/Sect301_Summary-of-Submission_USW_09-09-10PDF.pdf. Accessed: 09-09-2015.

U.S. Department of Defense (2013). Strategic and critical materials 2013 report on stockpile requirements. Technical report, U.S. Department of Defense - Office of the Under Secretary of Defense for Acquisition, Technology and Logistics. Available from http://mineralsmakelife.org/assets/images/content/resources/Strategic_and_ Critical_Materials_2013_Report_on_Stockpile_Requirements.pdf. 
U.S. Department of Defense (2015). Strategic and critical materials 2015 report on stockpile requirements. Technical report, U.S. Department of Defense - Office of the Under Secretary of Defense for Acquisition, Technology and Logistics. Available from https://www.hsdl. org $/$ ?view\&did=764766.

U.S. Department of Energy (2011). Trilateral EU-Japan-U.S. Conference on Critical Materials for a Clean Energy Future. Available from http://energy.gov/sites/prod/files/2013/05/f0/ TRILATERAL_CRITICAL_MATERIALS_WORKSHOP_SummaryReportfinal\%2020111129. pdf. Accessed: 12-11-2013.

U.S. Department of Energy (2015). The Department of Energy's critical materials strategy. Available from http://energy.gov/epsa/initiatives/department-energy-s-criticalmaterials-strategy. Accessed: 07-07-2015.

U.S. Geological Survey (2014). Mineral Commodity Summaries - Rare earths: 1988-2014. Available from http://minerals.usgs.gov/minerals/pubs/commodity/rare_earths/\#pubs. Accessed: 23-11-2013.

U.S. Geological Survey (2015a). Mineral commodity summaries - Rare earths, 2015. Available from http://minerals.usgs.gov/minerals/pubs/commodity/rare_earths/mcs-2015-raree. pdf. Accessed: 04-07-2015.

U.S. Geological Survey (2015b). Publications and data products. Available from http://minerals. usgs.gov/minerals/pubs/index.html. Accessed: 06-07-2015.

U.S. House Rare Earth Caucus (2012). Letter to President Obama from the Rare Earth Caucus. Available from http://www.rareearthassociation.org/2-2-12toPOTUSonREandWTO. pdf. Accessed: 30-06-2015.

USMMA (2012). United States Magnetic Materials Association urges U.S. House of Representatives to vote "Yes" on H.R. 4402. Available from http://www.usmagneticmaterials.com/ news/071212.htm. Accessed: 30-06-2015.

Van Waarden, F. (1995). Persistence of national policy styles: A study of their institutional foundations. In Unger, B. and Van Waarden, F., editors, Convergence or Diversity: Internationalization and Economic Policy Response, pages 333-372. Avebury.

Vinacomin (2012). Vinacomin \& Japanese firm to exploit and process rare earth in Lai Chau. Available from http://www.vinacomin.vn/en/news/News-of-Vinacomin/VinacominJapanese-firm-to-exploit-and-process-rare-earth-in-Lai-Chau-278.html. Accessed: 17-082015 .

Vogel, D. (1986). National Styles of Regulation: Environmental Policy in Great Britain and the United States. Cornell University Press Ithaca, NY.

Wagner, H., Tiess, G., Nielsen, K., Solar, S., Hamor, T., Ike, P., Vervoort, A., Espi, J. A., Agioutantis, Z., Koziol, W., and Bauer, V. (2004). Minerals planning policies and supply practices in Europe. Technical report, European Commission. Available from http://ec. europa.eu/eip/raw-materials/en/system/files/ged/14\%20leoben_2004_en.pdf.

WTO (2014). China - Measures related to the exportation of rare earths, tungsten, and molybdenum. Technical report, World Trade Organization. Available from https://www.wto.org/ english/tratop_e/dispu_e/431_432_433r_e.pdf. 



\section{Concluding remarks}

\subsection{Main findings}

The economic textbook solution to climate change mitigation is to use environmental policies towards all GHG point sources and to direct support for innovation in low-carbon technologies. Yet, in the absence of a single global carbon price, climate policy relies on unilateral efforts by national governments and on low-carbon technology innovation strategies by individual businesses. This dissertation examines the need to deal with newly observed problems: how higher electricity price differentials across countries contribute to eroding the net FDI inflows, in spite of individual government's policy choices to correct for distortions on national levels; how the stovepiped approach to climate change policy increases reliance on low-carbon technologies in energy mix without considering the implications for $\mathrm{m}$ used for their production; and how heterogeneous national mineral strategies, often pursuing competing priorities, adversely affect global supply chains. In this respect, the applied analyses within this dissertation allow identifying: the need for energy-efficiency policies as well as for policies at higher levels of government; the need for coordination between low-carbon policies and mineral policies, along with the need to supplement these by innovation policies, to deal with supply risks; and the need for coordination across multiple scales within countries, in order to accommodate national interests and domestic circumstances in face of global market distortions. The issue of climate change mitigation is thus investigated in an broader context than usual, what helps to uncover the need for coordination within the recently adopted climate change framework and to identify useful policies.

This dissertation focuses on coordination from the bottom-up rather than from the top-down. The motivation for this approach is driven by the fact that coordination from the top has proven a difficult process in a world of nation states, which are competing with each other economically and which have developed specific policy approaches reflecting their national priorities, ideologies, interests and legal and cultural traditions. In this regard, the dissertation attempts to answer the following research question: What type of climate change policy architecture is suited for assuring a sustainable and equitable transition to low-carbon energy systems in a world with interconnected systems, heterogeneous national policies and priorities, and distorted markets? This is done within a collection of empirical 
studies, each of which sheds light on the coordination challenges from a different perspective. Their overarching theme is thus the coordination of national and local actions within energy and industrial processes related to climate change mitigation. The need for the latter is inherent to the fact that stabilisation of GHG concentrations in the atmosphere at sustainable levels is a global public good and a collective action problem. In this dissertation however, climate change mitigation is interpreted within a wider socio-economic, technological and geopolitical context, as opposed to the narrow view of emission reduction targets. Such approach is well-suited to examine the interconnections between climate change mitigation, energy and minerals, and to provide evidence on the coordination challenges in a world with interconnected systems, heterogeneous national policies and priorities, and distorted markets. The scope of the dissertation being multidisciplinary, each of the three empirical studies makes a scholarly contribution to its respective field, i.e. energy economics and trade, technological change and innovation, and resource economics and political economy analysis of regulation, respectively. The main contributions of each study are summarised below. Besides these, the results also allow to draw more general conclusions which contribute to understanding how coordination of bottom-up climate change processes should be managed, in order to assure a sustainable and equitable transition to a renewable future. These are discussed in the Section 5.2, where also policy recommendations are sketched.

Chapter 2 examines the economic costs of uncoordinated implementation of environmental policies across countries. In fact, environmental policies, in addition to political events, factor costs and market structure, lead to significant industrial electricity price differentials across countries. Increases in the latter might in turn alter firms locational choices of investment. Relocation of polluting industries from countries with more stringent environmental policies to countries with laxer policies has been explained by carbon leakage and pollution haven hypothesis. Analogous to this, countries with lower electricity prices might attract industries to relocate from countries with higher energy costs. Yet empirical evidence for a panel of countries has been missing in the scientific literature so far. We therefore address this gap by investigating on to what extent electricity prices for industrial consumers lead to a loss of international competitiveness on country level in terms of attracting FDI. The results of the quantitative analysis for EU countries confirm that besides tax rates, unit labour costs and competitive disadvantage in secondary education, also electricity prices contribute to eroding net FDI inflows of the EU countries. While this is true for both sub-regions, south-western countries tend to be more adversely affected than north-eastern both in the short and the long run. Higher electricity prices in south-western countries are mainly driven by non- 
market electricity price components reflecting additional costs of primary fossil fuels due to emission trading schemes, as well as costs incurred by diversification of energy sources towards low-carbon technologies. In order to avoid losing international attractiveness for foreign direct investment, individual countries strive to address such distortions on national level. However, granting tax exemptions and reductions for industries ultimately burdens households and does not provide a long term solution to relocation of industries to countries where environmental policies are less stringent. Instead, this chapter argues that policies should aim at fostering energy efficiency improvements on the one hand, and reducing European price differences on the other. These results have implications on a larger scale too. In fact, should electricity price differentials continue to persist internationally, they might lead to alteration of the global pattern of investment, production and trade. Therefore, a future endeavour might focus on extending our model to a global context, including the United States, Japan and other major industrialised countries. Yet, the feasibility of such analysis depends on availability of sufficiently long time series and its comparability across countries. In fact, the limitation of our study stems from the limitations of the data used: electricity prices are not perfectly comparable across countries due to various tax exemptions which were not reflected in the data. In this regard, there is a need for improved data availability and comparability at country, industry and large industrial consumers levels.

Chapter 3 analyses the implications of inadequate coordination of policies beyond sectoral stovepipes on global supply chains. This is done by investigating the interconnections between low-carbon technologies and mineral resources. In particular, the chapter investigates the far reaching consequences of rare earth demand-supply imbalances on the deployment and innovation of offshore wind turbines and advanced technology vehicles. Bringing together seemingly disconnected strands of academic literature, the multidisciplinary approach allows to provide an overarching overview of economics of rare earths. On the supply side, the chapter confirms the existence of rare earth supply risk which arises from institutional inefficiency within the market. As opposed to the common belief, concentration of production per se is not the main driver of supply risk. Instead, it is China's resource nationalist industrial policies favouring its own industrial upgrading which distort the market. These proved difficult to be overcome by industrial users in the absence of policy support from their respective governments. On the demand side, the chapter provides an account of the rare earth dependence of low-carbon technologies. The results disprove the widespread allegation that supply risk of rare earths impedes the deployment of offshore wind turbines per 
se. Yet, it recognises that deployment of permanent magnet topologies, which are the superior technology on open sea in terms of reliability and efficiency, might become adversely affected depending on their future market share and hybridisation adopted. The automotive industry and its electrification instead, are substantially dependent on availability of rare earths. A potential supply shortage would thus largely disrupt the further development of the market altogether. Taken together, the results provide an accurate and unique assessment of the current technological landscape of offshore wind turbines and advanced technology vehicles. They are also well suited for extrapolation of future penetration of embedded technologies and for construction of more accurate rare earth demand forecasts. Yet, because of the lack of public information, this chapter did not account for varying compositions of permanent magnets across generators and electric motors of various sizes. Therefore, improving the availability of information on rare earth intensities in these technologies would further contribute to the reliability of future scenario development. Finally, the chapter offers insights into innovation strategies by manufacturers of these technologies. The uncertainty about volatile prices and the threat of supply shortages induce manufacturers to optimise designs of their products by innovating in less rare earth-intensive topologies, which are often inferior in terms of their performance. However, it might also follow that manufacturers, and thus all their innovation activities, relocate to China with a view to sourcing cheaper inputs at stable supply. In this regard, an agenda for future research might focus on analysing the extent to which relocation of production facilities by Western manufacturers to China occurs in reality. From a methodological perspective, it is not in the scope of this dissertation to address innovation strategies within a formal theoretical framework. Rather the aim is to offer a first overview of manufacturers' strategies and their potential implications in terms of inefficient uses of materials and technologies. More work needs to be done in terms of developing theoretical frameworks for assessing innovation induced by mineral supply risk. To conclude with, in order to avoid getting the world 'trapped' in rare earth dependence, more concerted action in R\&D directed towards material substitution, increasing efficiency in use of critical minerals, setting up recycling and developing sustainable mining and processing techniques is required. The latter would ultimately enable establishing supply in countries with more stringent environmental policies, for example in Scandinavia and Greenland.

Chapter 4 investigates on the importance of coordinating collective actions at multiple scales within countries, in order to accommodate national interests and domestic circumstances in face of global market distortions. Besides the innovation strategies by manufacturers discussed in Chapter 3, national governments of the 
largest stakeholders in the rare earth supply chain started to develop strategies, in order to tackle the rising imbalances between increased demand for minerals and their tighter supply. The chapter therefore maps out how the issue of mineral criticality has been taken up within various countries and to what extent did national contexts shape the policy choices by individual countries. It first provides an indepth overview of development trajectories of critical mineral strategies through a historical case study analysis of China, the United States, Europe, Japan and Australia. Subsequently it attempts to explain why these countries adopted different approaches in securing stable supply of rare earths. In particular, it examines within a comparative political economy framework how national interest considerations, resource endowment circumstances, countries' historical experience in tackling supply risk and their respective policy styles influenced the development of policy choices. This analysis is the first endeavour in academic literature to explain the development trajectories of mineral strategies in such detail. The overall findings show that despite their similar objectives, the foci of strategies differ across regions. While Europe's efforts target policy dialogue with resource-rich countries, Japan and the United States have a more hands-on approach in R\&D initiatives in substitution, minimisation and improvement of performance of rare earth-free functionalities. Australia's and China's policies instead, focus on development of domestic mining activities and on resource protection. Clearly, resource abundant countries are more prone to devise policies with strong focus on development of domestic mineral sectors and on resource protection. Yet the strength of the policies also depends on countries' regulatory styles (comprehensive tatist in China compared to fragmented and diverse in Europe), their national interests (long tradition of waste management in Japan and resource diplomacy in Europe), as well as historical experience in tackling supply risk (stockpiling in Japan and well-established regulatory environment on critical minerals in the United States rooted in its historical legalist tradition). The results presented in this chapter are not based on rigorous analysis of regulatory policy styles. Rather the conclusions are grounded in history and specific events rooted in economic and political circumstances. Yet, the regulatory styles to critical mineral policy making discovered in this chapter broadly correspond with those identified for environmental regulation. Moreover, this chapter has found policy choices to be shaped by the cyclical mining industries, as well as by the path dependent processes embedded in countries' national interests, resource endowment and their historical experience in tackling supply risk. These should therefore not be disregarded in comparative political analysis of regulation. Policy styles alone do not explain the differences in traditions of policy making. 


\subsection{Findings and recommendations for the coordination challenges}

The ultimate scholarly contribution of this dissertation is to shed light on how the bottom-up coordination of national and local actions related to climate change mitigation should be managed within the recently adopted Paris Agreement. The framework for analysing this overarching question has been informed by theories of public goods and collective action, as well as by the nexus approach to resource governance and by the national system of innovation considerations. This framework allows evaluating the interconnections between climate change, energy and mineral resources. This is done within three empirical studies, each of which analyses different aspects of low-carbon energy transition using different methodological approaches. Taken together, they convey the message that uncoordinated transition to new energy systems might create bottlenecks to socio-economic, technological and geopolitical systems globally. In particular, it can be concluded from Chapter 2 that in a globalised world with capital movements, market imperfections and heterogeneous national policies and priorities, prices alone are a poor coordination mechanism. Despite the efforts by individual governments to correct for electricity price differentials at national level, relocation of investment flows takes place. In fact, in absence of coordinated national environmental policies, the resulting industrial consumer prices alone cause competitive disadvantage for (energy-intensive) producers in countries with more ambitious GHG reduction targets compared to countries where national climate change plans are less demanding. This confirms the proposition made at the beginning of this dissertation, that lack of coordination across national policies leads to reducing the environmental benefits and to increasing the economic costs of emission mitigation strategies by countries with more stringent environmental policies. Furthermore, the general conclusions from Chapter 3 point out that devising sectoral policies without taking into consideration the wider context of the global nexus, adversely affects other parts of the system. In particular, a stovepiped approach to policy making (e.g. increasing reliance on low-carbon technologies in energy mix without considering the implications for related sectors), leads to bottlenecks in other parts of the supply chain (e.g. minerals extraction upstream). This conclusion translates into the need to coordinate environmental policies beyond their sectoral reach within and across countries. Finally, the insights into innovation strategies by manufacturers presented in the second part of Chapter 3, together with the conclusions on policy choices by individual countries from Chapter 4, indicate that coordination of collective actions at multiple scales is also essential within countries. Should 
sourcing of minerals from the distorted global market be left solely to market forces, prices as coordination mechanism might pose barriers to an equitable and stable access to rare earths by manufacturers of low-carbon technologies. Government intervention at multiple levels is thus required to prevent myopic producers from getting locked into investment decisions which might lead to inefficient uses of materials and technologies. Through financing of R\&D initiatives, encouraging industry-university-government linkages and public private partnerships, such intervention might trigger innovations along the whole rare earth-to-low-carbon technology supply chain, ideally resulting in resource efficient uses in processes and materials, establishing recycling, and lowering environmental and social costs of mining and processing. More importantly though, such intervention needs to be coordinated internally, between various actors at multiple scales, due to their distinct and often competing interests (e.g. environmental concerns by civil societies versus profit oriented mining industry). This points to the need to develop country-specific and within-EU multilevel systems of governance, involving civil societies, industries and various government departments, in order to accommodate their respective interests. The interests of these actors, along with countries' legal traditions, political structures and cultural attitudes have been demonstrated to influence the distinct strategies undertaken by individual countries.

In summary, this dissertation argues for a three-dimensional coordination within a bottom-up climate change policy architecture: within national policies, across national policies and beyond sectoral policies. In fact, in order for climate change policies to be beneficial at country level both environmentally and economically, coordination across countries is required to prevent leakage from countries with more stringent to those with less stringent policies. This calls for a more regional approach to coordination, in order to better manage the complexity of transition to low-carbon energy systems in terms of speed and ambition. Therefore, besides the traditional role of energy markets and national policies, both formal and informal cooperation could be established on the EU level, or perhaps even on the level of regional policy clubs gathering countries with similar national interests. On top of this, each country should also develop its own multilevel and possibly polycentric system of governance by involving stakeholders at all levels, in order to accommodate the particular domestic contexts and national interests. This could be facilitated by developing roadmap processes, which would match short term goals with long term objectives and bring different actors at multiple scales together. Finally, besides coordination within sectoral policies, this also needs to occur beyond the sector in order to reflect the interconnections between climate change mitigation, energy and minerals, and potentially other resources. Such an inte- 
grated view could be advanced through technology boards or interdisciplinary fora. In this sense, the dissertation argues for a multilevel and polycentric governance mechanism, advocating an integrated approach to low-carbon energy transition rather than focusing on energy-related GHG emissions in isolation. While the former two are the main pillars of the general argumentation on collective action for common resources, nexus considerations tend to be largely disregarded in the climate change policy architecture debate. Therefore, from the policy perspective the main contribution of this dissertation is to provide evidence of the need for devising sustainable and equitable climate change mitigation policies, by taking into consideration the distinct and often competing sub-national, national and sectoral collective action mechanisms.

In terms of methodological contributions, this dissertation examines the coordination challenges using a variety of methodologies. These range from quantitative analysis of dynamic panel data model, through market analysis and technological landscape assessment, to comparative political economy analysis of policies and policy styles. Such mixed method approach enables examining the energy and industrial processes related to climate change mitigation from a more holistic perspective. In fact, each of the methodological approaches contributes to understanding a different perspective of the coordination challenge. For example, the rigorous econometric analysis allows concluding on the magnitude of the effect of electricity prices on the net FDI inflows within the EU countries, and comparing this across the two sub-regions. Furthermore, the market analysis of rare earths enables uncovering the existence and the origins of the supply-demand imbalances within the rare earth market, and in combination with the technological landscape assessment enables concluding on the former's wide ranging implications for the innovation in low-carbon technologies. Finally, the qualitative analysis of national rare earth strategies in different world regions demonstrates how critical mineral strategies developed as a result of path dependent processes, rather than being driven by short term interests. Taken together, these different approaches allow to examine low-carbon energy transition from a more holistic perspective, to identify some of the new problems which arise from the decentralised climate change policy framework, to uncover causality within specific bottom-up processes, and to offer policy suggestions to tackle these. Moreover, the broad perspective adopted for discussing climate change mitigation within a wider-socio economic, technological and geopolitical context, allows to offer new perspectives on the interconnectedness of climate change mitigation with renewable energy technology deployment and mineral resource supply. In fact, the environmental implications from mining technology metals, the potential supply shortages of mineral resources used for 
manufacturing of low-carbon technologies, as well as the economic implications from unilateral efforts by national governments to devise more stringent environmental policies, have been identified to significantly influence the sustainable and equitable transition to low-carbon energy systems. Therefore, these factors should also be given consideration in future modelling work on climate change mitigation and energy related issues. This would in turn help drawing policy implications within a more integrated perspective and devising more balanced policies within the interconnected global system.

To conclude with, one aspect of coordination which has not been addressed within this dissertation is the role of top-down coordination of climate change policies. Yet, it needs to be acknowledged that the sourcing of minerals being a global issue, absence of a top-down coordination on international level might fail to secure stable access to minerals at fair prices within distorted global markets. For example, the evidence on ruling by WTO against the rare earth export quotas in Chapter 3, indirectly points to the need for a top-down intervention, in order to mitigate China's resource nationalist policies. Global governance could therefore be considered as a vital part of the coordination conundrum, with the overall aim of regulating the equitable access to supply chains and overseeing sustainability issues related to this, as well as reducing barriers to diffusion of technologies and moving into better coordinated innovation and market development processes on both ends of the supply chain. However, rather than creating another formal transnational institution with a limited sectoral reach, we should aim at establishing a more informal multi-stakeholder forum or board, which would examine the pressing nexus issues and would facilitate the international discourse and the strategic short and medium term decision making for a smooth transition to low-carbon energy systems globally. What is more, in order to promote an inclusive low-carbon growth, governments, industry associations and civil societies from both developed and developing countries should be involved. Such considerations might serve as an outlet for future research on the design of a global institutional mechanism, which could facilitate further the coordination in a world with interconnected systems, heterogeneous national policies and priorities, and distorted markets. 



\section{Valorisation addendum}

In accordance with article 23 of the "Regulation governing the attainment of doctoral degrees at Maastricht University" decreed by resolution of the Board of Deans dated 3 July 2013, this addendum discusses the valorisation opportunities presented within the doctoral dissertation.

\section{Relevance}

This dissertation examines the coordination challenges arising from the new climate change mitigation framework adopted in Paris in 2015 (Paris Agreement). The latter is the first-ever universal legally binding global climate change deal, it's societal relevance can thus not be overstated. Yet, it also brings about new challenges which need to be discussed. As opposed to its predecessor, the Kyoto protocol which advocated a top-down approach to emissions abatement, the Paris Agreement advocates a decentralised bottom-up mechanism which guarantees for a broader participation by countries, and leaves it to their responsibility to determine their respective contributions to carbon emissions. Such approach however, leads to significant differences in the level of ambition of countries' national targets, owing to the heterogeneity of their national priorities, economic and political interests as well as legal and cultural traditions. Therefore, a lack of coordination of local and national actions might ultimately not only inhibit reaching the global pledge to limit the temperature increase to well below $2^{\circ} \mathrm{C}$, it might also create bottlenecks to socio-economic, technological and geopolitical systems.

To illustrate this, one such bottleneck arises from increasing non-market electricity price components and from industrial electricity price differentials across countries and over time. These owe to heterogeneous strategies adopted by governments worldwide, such as the development of shale gas production through hydraulic fracturing in the United States, or maintaining strong absolute growth of coal consumption in India on the one hand, and closing down nuclear power plants and subsidising renewable energy in Germany, as well as the introduction of the EU Emission Trading Scheme on the other. The bottom line is that electricity price differentials resulting from the absence of coordinated policies might put producers in some countries to a competitive disadvantage and thus alter firms' locational choices of investment. From a more broad perspective, this might ultimately lead to economic challenges by shifting the global pattern of investment, 
production and trade in favour of countries where environmental policies are less stringent.

Another often disregarded bottleneck in the climate change policy debate relates to the fact that low-carbon energy technologies are heavily dependent on the use of minerals, in particular technology metals such as rare earths. While there exists no threat of their immediate scarcity, the large increase in their demand, driven primarily by the deployment of electric vehicles and offshore wind turbines, in combination with the inability of markets to deliver new supply in short time frames, are affecting the stability of supply and pricing of these metals. The ultimate consequence might be that manufacturers shift to designing less rare earth-intensive technologies which, however are often inferior in terms of their performance and energy efficiencies. Generally speaking, such technological challenges arise from increasing the reliance on low-carbon technologies within energy mix without considering the implications in terms of availability of minerals upstream in the global supply chain.

The overarching objective of the dissertation is thus to discuss these newly observed coordination challenges which arise within the decentralised climate change policy architecture of the Paris Agreement, in a world with interconnected systems, heterogeneous national policies and priorities, and distorted markets. Hence, this dissertation has high social relevance in terms of providing policy advice for assuring a sustainable and equitable transition to low-carbon energy systems.

\section{Target groups}

Besides the academic community, the results of this dissertation are of relevance for all actors who are involved in the climate change mitigation processes. Since this dissertation interprets climate change mitigation within a wider socio-economic, technological and geopolitical context, also its social relevance extends to a broader group of actors: various local, regional and national government departments, as well as industries and civil societies.

In particular, Chapter 2 discusses the impact of electricity prices on countries' competitiveness in terms of foreign direct investment inflows. Hence its implications are mainly intended for policy makers at national level. Chapter 3 offers important insights for both policy makers and for manufacturers of low-carbon technologies. On the one hand, by discussing the wide ranging implications of supply-demand imbalances of rare earths, the chapter demonstrates the need for policy makers to devise climate change policies beyond their sectoral reach. On the other hand, the manufacturers of low-carbon technologies are urged to hedge against supply risk, by incorporating potential mineral supply risk considerations 
into their product designs, monitoring the developments on the upstream side of the supply chain, diversifying their sources of supply, as well as engaging with policy makers and other industries in search for alternatives for increasing supply, resource efficiency and use of alternative technologies. The discussion in Chapter 4 is the most extensive in scope and concerns the coordination of collective actions at multiple scales. Therefore, besides targeting policy makers and industries, also civil societies and other interest groups might be interested to engage within the debate.

\section{Activities}

Besides making contribution to the respective fields covered in each chapter, the dissertation also adds to the broader analytical frame on how the bottom-up coordination of national and local actions should be managed within the recently adopted Paris Agreement. From the policy perspective, the dissertation argues for a three-dimensional coordination: within national policies, across national policies and beyond sectoral policies. In practice this translates into three proposed actions. First, a better management of the complex transition to low-carbon energy systems calls for a more regional approach to coordination. Therefore, besides the traditional role of energy markets and national policies, both formal and informal cooperation could be established on the EU level, or perhaps even on the level of regional policy clubs, gathering countries with similar national interests. Second, in order to accommodate the particular domestic contexts and national interests, each country should also develop its own multilevel and possibly polycentric system of governance by involving stakeholders at all levels. This could be facilitated by developing roadmap processes, which would match short term goals with long term objectives and bring different actors at multiple scales together. Third, besides coordination within sectoral policies, this also needs to occur beyond the sector in order to reflect the interconnections between climate change mitigation, energy and minerals, and potentially other resources. Such an integrated view could be advanced through technology boards or interdisciplinary fora.

\section{Innovation}

The innovative aspect of the analysis presented within this dissertation comes from the holistic perspective offered on the challenges to decentralised climate change framework. In fact, the present research is the first of its type and sets thus a new agenda for future research on coordination challenges within the bottom-up climate change mitigation processes. More specifically, interpreting climate change 
within a wider socio-economic, technological and geopolitical context, as opposed to the narrow view of emission reduction targets adopted in the literature so far, allows to examine newly observed problems and to draw important implications for policy makers and other actors involved within the process. In practical terms, such integrated approach to low-carbon energy transition concludes on the need for a multilevel and polycentric governance mechanism.

\section{Schedule and implementation}

As of 20 May 2016, there are 177 signatories to the Paris Agreement. The Agreement should enter into force once at least 55 Parties to the Convention accounting for at least $55 \%$ of total global greenhouse gas emissions have deposited their instruments for ratification. It is therefore advisable that the debate on policy recommendations and proposed actions put forward within this dissertation is launched soon. The more so, since the global stocktaking exercise, the purpose of which is to regularly review countries' progress in emissions reduction towards the global pledge, is scheduled to take place in 2018 for the first time. It is therefore important to ensure that by the time the new targets need to be set, they will have emerged as an outcome of multilevel and polycentric governance processes and reflect thus the distinct and often competing sub-national, national and sectoral collective action mechanisms. 


\section{About the author}

Eva Barteková was born in Komárno (Slovakia), in 1983. She obtained a bachelor's degree in International Economics and Management at Università Commerciale Luigi Bocconi (Italy) in 2005 and a master's degree in Finance with major in Economic Policy at University of London (UK) in 2011. Additionally, she spent part of her undergraduate studies at Institut d'Etudes Politiques de Paris (France), completed an internship at the Union of Italian Chambers of Commerce in Brussels (Belgium) and held a postgraduate visitor position at the European Commission - DG Competition. During 2006-2012 she acquired extensive professional experience in international finance at both analyst and managerial levels, having been employed at the world's two major index houses - Dow Jones Indexes and STOXX Ltd in Zürich (Switzerland).

Eva joined the UNU-MERIT and the School of Business and Economics of Maastricht University in 2012. As a PhD fellow, she developed new interests in areas of economics of innovation and technology, and resource and energy economics. Her primary research interests revolve around the interconnections between climate change mitigation, renewable energy technologies innovation and sustainable resource use. In the course of her PhD studies, Eva has lectured in the master's programme Public Policy and Human Development at UNU-MERIT and has acted as second reader for masters' theses on topics of finance and energy economics at both Maastricht Graduate School of Governance and School of Business and Economics. Eva has also assisted the coordination of the Design and Evaluation of Innovation Policy (DEIP) training programme for policymakers in science, technology and innovation in developing countries. Furthermore, she has been involved in project work within the Social Challenges of Interdependencies between Energy Transition, Demand for Resources and Climate Change in a Global Perspective (GlobEn) project, as well as within the Sino-European Circular Economy and Resource Efficiency (SINCERE) project. 



\section{UNITED NATIONS UNIVERSITY}

\section{UNU-MERIT}

\section{6}

\section{Eva Barteková}

Multi-Problem Challenges for a Renewable Future: Empirical Studies on Competitive Disadvantages from Electricity Price Differentials and Mineral Supply Risk in an Open Economy World

\section{Jocelyn Olivari}

Entrepreneurial Traits and Innovation:

Evidence from Chile

\section{Muhammad Shafique}

Essays on the role of knowledge, R\&D, and technology-based firms in the evolution of sociotechno-economic system

\section{Serdar Türkeli}

Governance of Innovation Policy: Empirical Studeis on Applied Political Economy by Multi-Methos Analysis

\section{5}

\section{Hibret Belete Maemir}

Dissecting Aggregate Productivity:

International Integration and Growth with

Heterogeneous Firms

\section{Giorgio Triulz}

Looking for the Right Path: Technology Dynamics, Inventive Strategies and Catching-up in the Semiconductor Industry

\section{Abdul Baseer Qazi}

Knowledge flows and networks in the ICT sector: The case of Pakistan

\section{Ajay Thutupalli}

Technology Paradigm Shifts in Agriculture: Drivers of Sustainability and Catch up

\section{Eduardo Urias}

Improving access to HIV/AIDS treatment in Brazil: When are compulsory licenses effective in price negotiations?

\section{Francesca Guadagno}

Why have so few countries industrialised?

\section{Daniel Opolot}

The evolution of beliefs and strategic behavior

\section{Alejandro Lavopa}

Structural Transformation and Economic Development: Can Development Traps be Avoided?

\section{Jinjin Zhao}

Urban water management reform: The case of China

\section{4}

\section{Dirk Crass}

The Impact of Brands on Innovation and Firm Performance: Empirical Evidence from Germany

\section{Samyukta Bhupatiraju}

The Geographic Dimensions of Growth and Development

\section{François Lafond}

The evolution of knowledge systems

\section{Annalisa Primi}

Promoting Innovation in Latin America: What Countries Have Learned (and What They Have Not) in Designing and Implementing Innovation and Intellectual Property Policies

\section{Fatoumata Lamarana Diallo}

Evaluation of Meal and Deworming Programs for Primary Schools in Rural Senegal

\section{3}

\section{Anant Kamath}

Information Sharing through Informal Interaction in Low-Tech Clusters

\section{Flavia Pereira de Carvalho}

What we talk about when we talk about Brazilian Mulitantionals: an investigation on Brazilian FDI, economic structure, innovation and the relationship between them 
80. Jun Hou

Complementarity in Innovation and Development: A

Cross-country Comparison

\section{Rufin Baghana}

Impacts of Government Incentives to R\&D,

Innovation and Productivity:

A Microeconometric Analysis of the Québec Case

\section{Lilia I. Stubrin}

High-Tech Activities in Emerging Countries: A Network perspective on the Argentinean biotech activity

\section{2}

\section{Abdul Waheed}

Innovation Determinants

and Innovation as a Determinant:

Evidence from Developing Countries

\section{Bilal Mirza}

Energy Poverty and Rural Energy Markets in Pakistan

\section{Benjamin Engelstätter}

Enterprise Software and Video Games: An Empirical Analysis

\section{Fulvia Farinelli}

Natural Resources, Innovation and Export Growth: The Wine Industry in Chili and Argentina

\section{Rodolfo Lauterbach}

Innovation in Manufacturing: From Product Variety and Labor Productivity Growth to Economic Development in Chile

\section{Kirsten Wiebe}

Quantitative Assessment of Sustainable

Development and Growth in Sub-Saharan Africa.

\section{Julio Miguel Rosa}

Organizational Strategies, Firms' Performance and Spatial Spillovers. The Canadian Case in Research and Development.

\section{Johannes Wilhelmus Marie Boels}

Joseph Schumpeter, honderd jaar economische ontwikkeling. Een historisch-theoretische beschouwing.

\section{1}

\section{Daniel Vertesy}

Interrupted Innovation: Emerging economies in the structure of the global aerospace industry.

\section{Tina Saebi}

Successfully managing alliance portfolios: an alliance capability view.

\section{Nora Engel}

Tuberculosis in India - A case of innovation and control.

\section{Evans Mupela}

Connectivity and growth in Sub-Saharan Africa: The role of communication satellites

\section{Nantawan Kwanjai}

Cross cultural intelligence amid intricate cultural webs: A tale of the UnDutchables in the land of 1002 smiles

\section{Lina Sonne}

Innovation in Finance to Finance Innovation: Supporting pro-poor entrepreneur-based innovation

\section{0}

\section{Fernando Santiago}

Human Resources Management Practices and Learning for Innovation in Developing Countries: Pharmaceutical Firms in Mexico

\section{Zakaria Babutsidze}

Essays on Economies with Heterogenous Interacting Consumers

\section{Bertha Vallejo} Learning and Innovation Under Changing Market Conditions: The Auto Parts Industry in Mexico

\section{Donatus Ayitey}

Technical Change, Competitiveness and Poverty Reduction: A Study of the Ghanaian Apparel Industry

\section{Sergey Fillipov}

Multinational Subsidiary Evolution: Corporate Change in New EU Member States 


\section{Asel Doranova}

Technology Transfer and Learning under the Kyoto regime; Exploring the Technological Impact of CDM projects in developing countries

\section{9}

\section{Alexis Habiyaremye}

From Primary Commodity Dependence to Diversification and Growth". "Absorptive Capacity and Technological Catch Up in Botswana and Mauritius".

\section{Yoseph Getachew}

The Role of Public Capital in Economic Development

\section{Sandra Leitner}

Embodied Technological Change and Patterns of Investment in Austrian Manufacturing

\section{Semih Akçomak}

The Impact of Social Capital on Economic and Social Outcomes

\section{Abraham Garcia}

The Role of Demand in Technical Change

\section{Saurabh Arora}

Coherence in socio-technical systems: a network perspective on the innovation process

\section{8}

\section{Rutger Daems}

Medicines for the developing world

\section{Johannes Hanel}

Assessing Induced Technology: Sombart's

Understanding of Technical Change in the History of Economics

\section{Rifka Weehuizen}

Mental Capital: the economic significance of mental health

\section{Danielle Cloodt}

The relationship between R\&D partnership formation, social embeddedness and innovative performance

\section{Sabine Fuss}

Sustainable Energy Development under Uncertainty

\section{7}

\section{Tobias Kronenberg}

Reconciling Environmental Conservation with Economic Prosperity: The Feasibility of Double Dividends in the Short and Long Run

\section{Viktoria Kravtsova}

Assessing the Impact of Foreign Direct Investment in Transition Economies

\section{Suhail Sultan}

The Competitive Advantage of Small and Medium Sized Enterprises: The Case of Jordan's Natural Stone Industry

\section{6}

46. Bulat Sanditov

Essays on Social Learning and Imitation

\section{Mamata Parhi}

Dynamics of New Technology Diffusion: A Study of the Indian Automotive Industry

\section{Andreas Reinstaller}

Social structures and the innovation process: Their role in the demand of firms and consumers

\section{Rose Kiggundu}

Innovation systems and development: the journey of a Beleaguered Nile Perch Fishery in Uganda

\section{Thomas Pogue}

The Evolution of Research Collaboration in South African Gold Mining: 1886-1933

\section{Geoffrey Gachino}

Foreign Direct Investment, Spillovers and Innovation: The Case of Kenyan Manufacturing Industry

\section{0. Önder Nomaler}

Technological Change, International Trade and Growth: An Evolutionary, Multi-Agents-Based Modeling Approach

\section{5}

\section{Samia Satti Osman Mohamed-Nour} Change and Skill Development in the Arab Gulf Countries 


\section{Elad Harison}

Intellectual Property Rights: Economics and Policy Analysis

\section{Daniel Dalohoun}

The relationship between R\&D partnership formation, social embeddedness and innovative performance: a multi-level approach of social embeddedness

\section{Müge Ozman}

Networks, Organizations and Knowledge

\section{Bas Straathof}

Product variety and economic growth: The counteracting effects of scale and idiosyncrasy

\section{Wilfred Schoenmakers}

Knowledge Flows between Multinational

Companies: A Patent Data Analysis

\section{Myriam Cloodt}

Mergers and Acquisitions (M\&As) in High-Tech Industries: Measuring the Post-M\&A Innovative Performance of Companies

\section{4}

\section{Paola Criscuolo}

R\&D Internationalisation and Knowledge Transfer. Impact on MNEs and their Home Countries

\section{Maarten Verkerk}

Trust and Power on the Shop Floor

\section{Gottfried Leibbrandt}

Adoption, harmonization and succession of network technologies across countries

\section{Mark Sanders}

Skill Biased Technical change - Its Origins, the Interaction with the Labour Market and Policy Implications

\section{3}

\section{Nadine Roijakkers}

Inter-firm cooperation in high-tech industries: a study of R\&D partnerships in pharmaceutical biotechnology

\section{Viki Sonntag}

Speed, Scale and Sustainability
26. Masaru Yarime

From End-of-Pipe Technology to Clean Technology

\section{Stéphane Malo}

The combinatorial Chemistry Revolution -

Sustaining a Superior Performance Position through Technological Learning

\section{2}

\section{Annelies Hogenbirk}

Determinants of Inward Foreign Direct Investment: the Case of the Netherlands

\section{Bastiaan Johan ter Weel}

The Computerization of the Labour Market

\section{1}

\section{John Adeoti}

Technology Investment in Pollution Control in SubSaharan Africa: The Case of the Nigerian

Manufacturing Industry

\section{Edward Huizenga}

Innovation Management: How Frontrunners Stay Ahead. An Empirical Study on Key Success Factors in the ICT sector

\section{0}

\section{Machiel van Dijk}

Technological Change and the Dynamics of Industries. Theoretical Issues and Empirical evidence from Dutch Manufacturing

\section{9}

\section{Jan Cobbenhagen}

Managing Innovation at the Company Level: A Study on Non-Sector-Specific Success Factors

\section{Marjolein Caniëls}

Regional Growth Differentials: The Impact of Locally Bounded Knowledge Spillovers

\section{8}

\section{Aldo Geuna}

Resource allocation and knowledge production: Studies in the economics of university research 


\section{Reinoud Joosten}

Dynamics, Equilibria, and Values

\section{Hugo Kruiniger}

Investment, R\&D, and the Financing Decisions of the Firm

\section{5}

\section{Hans van Meijl}

Endogenous Technological Change: The Case of Information Technology. Theoretical Considerations and Empirical Results

\section{René Kemp}

Environmental Policy and Technical Change. A Comparison of the Technological Impact of Policy Instruments

\section{Rohini Acharya}

The Impact of New Technologies on Economic Growth and Trade. A Case Study of Biotechnology

\section{Geert Duysters}

The Evolution of Complex Industrial Systems. The Dynamics of Major IT Sectors

\section{Marjan Groen}

Technology, Work and Organisation, A Study of the Nursing Process in Intensive Care Units

\section{4}

\section{Huub Meijers}

On the Diffusion of Technologies in a Vintage Framework; Theoretical Considerations and Empirical Results

\section{Theon van Dijk}

The Limits of Patent Protection. Essays on the Economics of Intellectual Property Rights

\section{Hans Voordijk}

Naar Integrale Logistiek in Bedrijfsketens, Ontwikkelingen in de Bouw

\section{Paul Diederen}

Technological Progress in Enterprises and Diffusion of Innovations. Theoretical Reflections and Empirical Evidence.

\section{Ben Dankbaar}

Economic Crisis and Institutional Change. The crisis of Fordism from the perspective of the automobile industry

\section{Hanno Roberts}

Accountability and Responsibility: The Influence of Organisation Design on Management Accounting

\section{2}

\section{Bart Verspagen}

Uneven Growth Between Interdependent Economies. An Evolutionary View on Technology Gaps, Trade and Growth

\section{Sjoerd Romme}

A Self-organization Perspective on Strategy Formation

\section{9}

\section{John Spangenberg}

Economies of Scale, and Atmosphere in Research Organisations

\section{8}

\section{John Hagedoorn}

Evolutionary and heterodox innovation analysis: a study of industrial and technological development in process control and information technology 
